\title{
E-GOVERNMENT: TRANSFORMATION OF PUBLIC GOVERNANCE IN NEW ZEALAND?
}

\author{
By
}

Rose Regina O’Neill

\author{
A thesis \\ Submitted to the Victoria University of Wellington \\ In fulfilment of the requirements for the degree of \\ Doctor of Philosophy \\ in Public Management
}

Victoria University of Wellington

2009 


\section{Thesis abstract}

New information and communication technologies (ICTs) have been introduced in the government sector throughout the world in the past 10 - 20 years in an attempt to achieve greater operational efficiency and effectiveness. The benefits of ICTs include faster, streamlined administrative processing; lower transaction costs; better use of information resources; greater public access to government information and services; and more opportunities for public participation in democratic processes.

These changes are often heralded by e-government commentators as 'transformative'. This implies that technical innovation will deliver business benefits and produce radical change in the way that government agencies are organised to service parliament and the public. That is, a change in state sector governance arrangements. This thesis examines the concept of 'transformation' in the New Zealand state sector context with a view to determining the form and nature of governance changes that may occur as a consequence of e-government implementation.

Two streams of empirical data gathering have been completed. These provide data on how e-government initiatives are currently being implemented in New Zealand, and the impact senior public officials and public management experts consider e-government will have in the future. A Weberian analytical framework is used to identify the nature of changes that occur as a consequence of e-government initiatives, and where changes may occur in the current public sector governance model.

The empirical evidence suggests that e-government will have two transformational effects in New Zealand: instrumental and systemic. These effects will occur as public officials use ICTs to increase operational efficiency and effectiveness; develop broadbased collaboration and co-production working arrangements; and expand the resources available to government to address policy issues and delivery services. Adjustments to current governance arrangements are required to position public officials to use communication technologies effectively in the future. Initial reform efforts need to be made in the areas of accountability structures and leadership. 


\section{Acknowledgements}

The work in compiling this research has been an effort supported by the expertise, wisdom, good will, patience and kindness of a large number of people. I wish in particular to record my gratitude to my supervisors Professor Miriam Lips and Associate Professor Bill Ryan whose guidance has been invaluable.

As with all life endeavours I owe a debt of gratitude to those people who have taught me the value of critical thinking and have over the years provided me with inspiration, mentoring and a haven to safely express ideas, think through issues, and gain new skills. In particular I would like to acknowledge Sister Eleanor Capper (Christchurch), Professor David Bettison (retired), John Martin (retired) and Associate Professor Maria Humphries (School of Management, Waikato University) each of whom has contributed significantly in different ways to this research endeavour.

I would also like to thank the School of Government, Victoria University of Wellington staff and my fellow $\mathrm{PhD}$ candidates for their continuous encouragement and collegiality. Alongside them, I owe particular thanks to a large number of public officials who gave generously of their time and ideas to support this research (all contributors are listed in Appendix 1). I extend thanks to the senior officials from the State Services Commission, Justice, Police, Land Transport New Zealand, Corrections, and Land Information New Zealand who agreed to be interviewed as part of the research. I would also like to thank the academics, government officials and independent consultants who participated in the focus groups. These conversations have made significant contributions to the thinking embodied here, and I trust I have represented them accurately.

An enormous vote of thanks also goes to my friends, colleagues and family who have provided me with unstinting encouragement throughout this work. Without their words of love and support, and their practical and logistical assistance this research may never have been completed. In particular, my thanks go to Jeanette Schollum whose text review and advice is deeply appreciated. I offer special thanks to Margaret Irwin, Julie Crisford and Robyn Crisford whom I have relied on heavily in all sorts of ways, and whom have been my compass and my anchor. 
Table of Contents

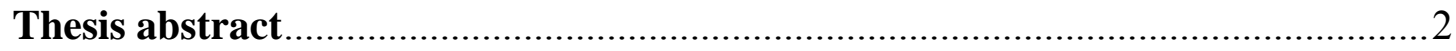

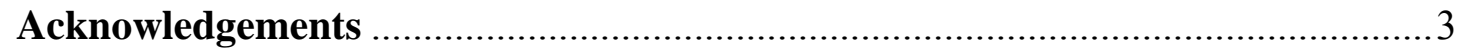

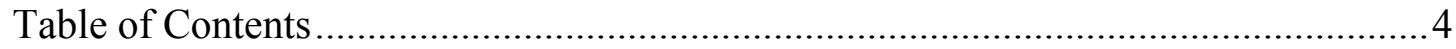

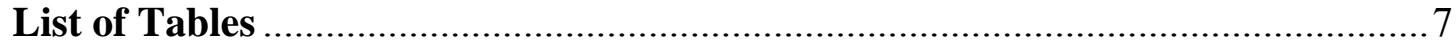

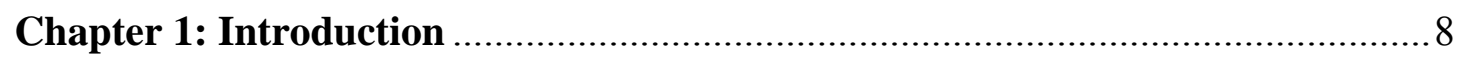

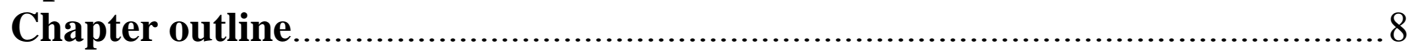

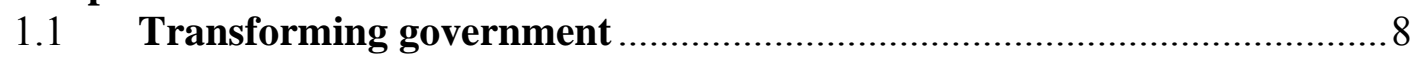

1.1.1 Research genesis: Personal statement .............................................

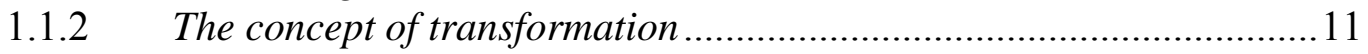

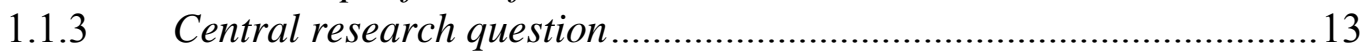

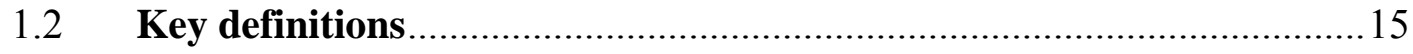

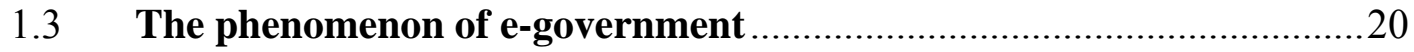

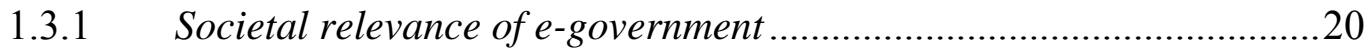

1.3.2 Academic relevance of e-government ...............................................24

$1.4 \quad$ E-government in the New Zealand context ...........................................26

1.4.1 The public governance context of New Zealand .................................2. 27

1.4.2 New Zealand's e-government programme .........................................28

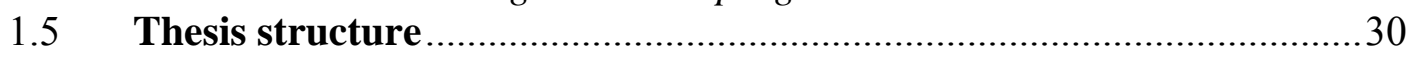

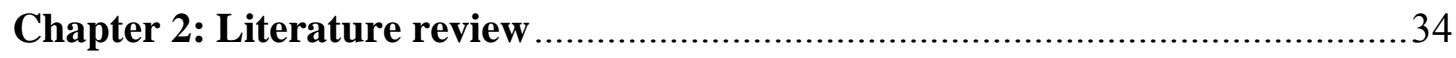

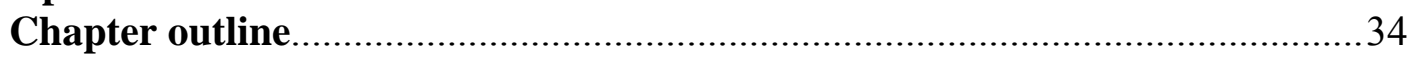

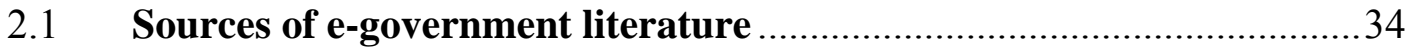

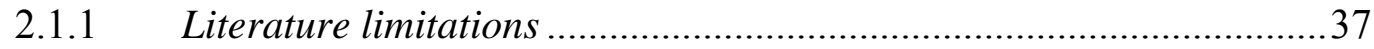

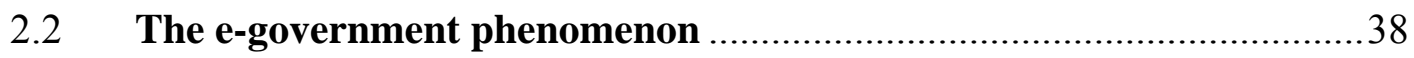

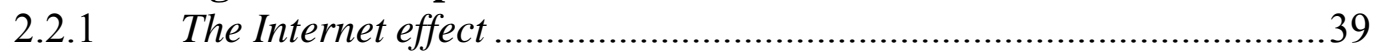

2.2.2 Stages of growth in e-government........................................................ 41

2.3. The public management reform context...............................................4

2.3.1 Understanding public management reforms.......................................46

2.3.2 Theoretical issues in public management .............................................49

2.3.3 The use and deployment of technology in public management.............54

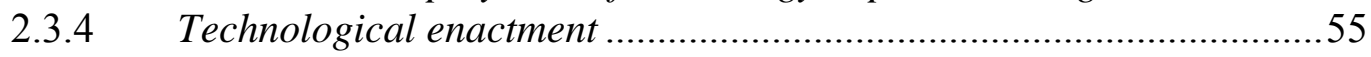

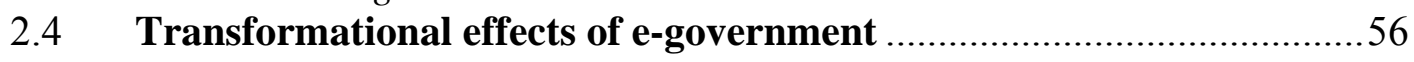

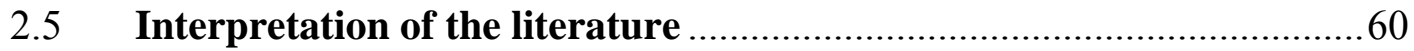

2.5.1 Clarifying the nature of transformation.................................................6 61

2.5.2 Understanding the depth of e-government transformation....................64

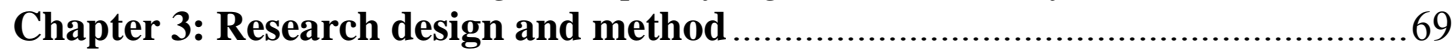

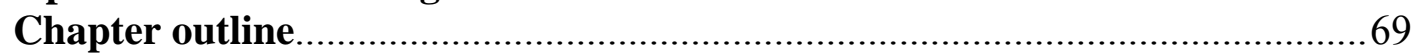

3.1 Ontology: Public management as 'institution' ...................................69

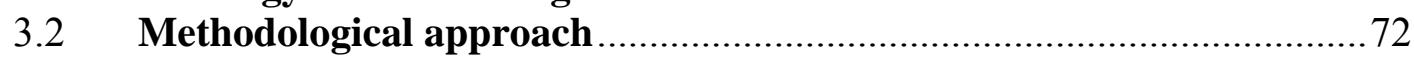

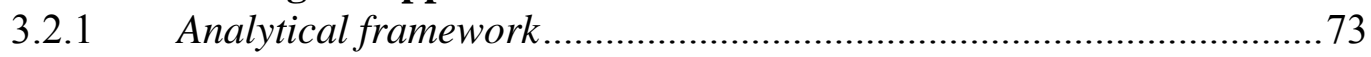

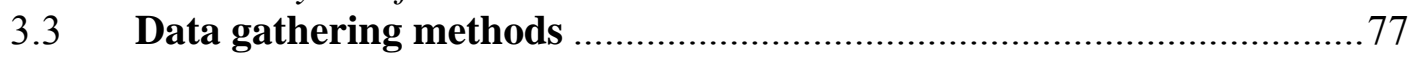

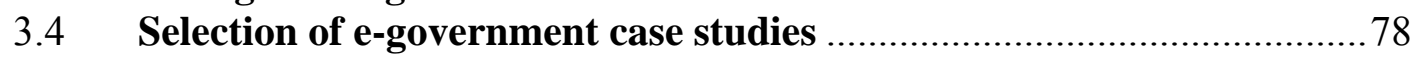

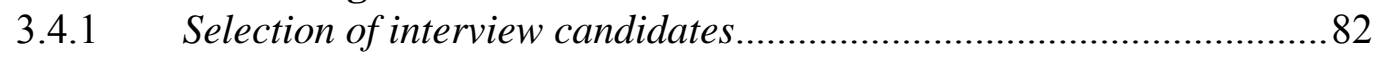

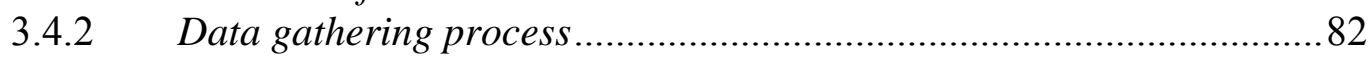

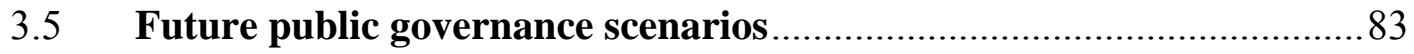

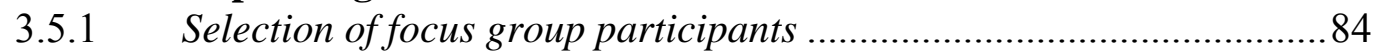

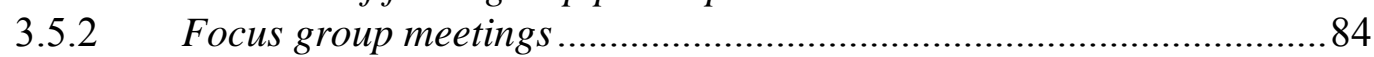

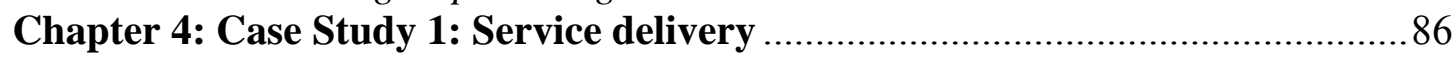

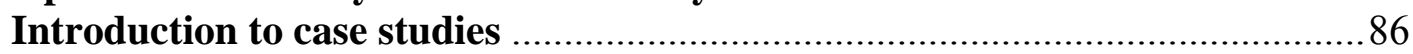


4.1 Land Information New Zealand: Agency context..............................8 86

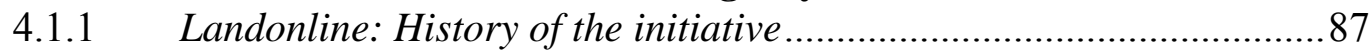

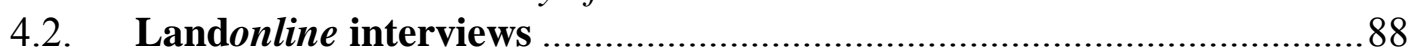

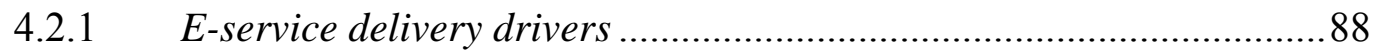

4.2.2 Expected benefits of e-service delivery ............................................. 90

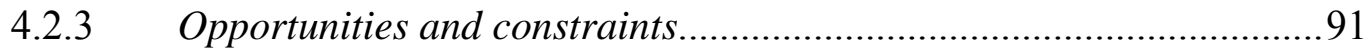

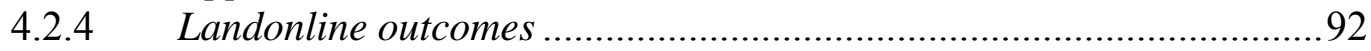

4.2.5 Transformation ......................................................................... 93

4.3 Identifying where Landonline transformational effects occur ..............95

4.4 The nature of Landonline transformational effects.............................99

Chapter 5: Case Study 2: Information management (cross-sector)....................101

5.1 Justice Sector Information Strategy (JSIS): History of the initiative.101

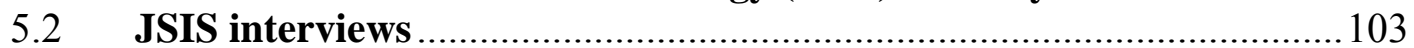

5.2.1 Electronic information management drivers ...................................103

5.2.2 Expected benefits of electronic information management ...................103

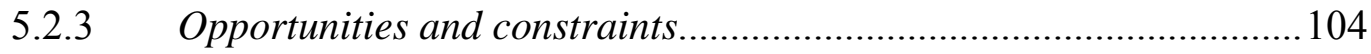

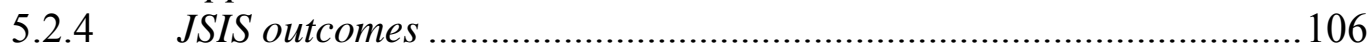

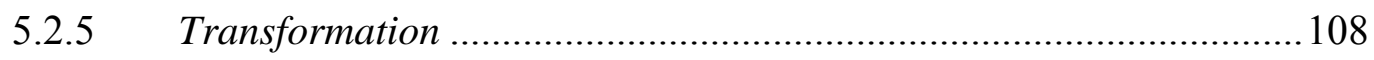

5.3 Identifying where JSIS transformational effects occur......................109

5.4 The nature of JSIS transformational effects ...................................113

Chapter 6: Case Study 3: Knowledge management (State sector wide) ............. 114

6.1 Public Sector Intranet (PSI): History of the initiative......................... 114

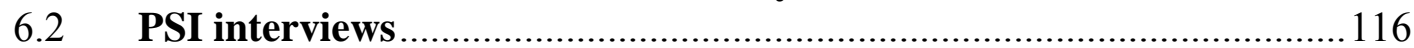

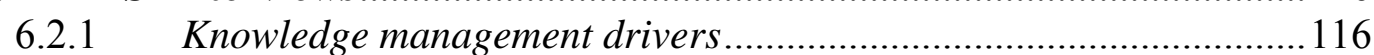

6.2.2 Expected benefits ......................................................................... 117

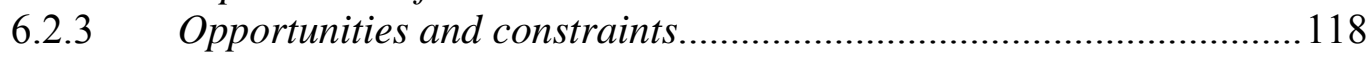

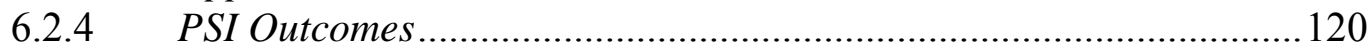

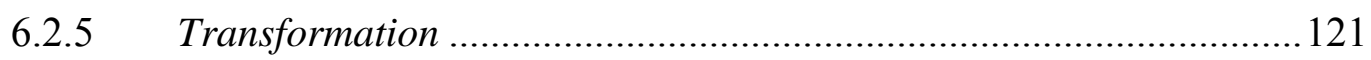

6.3 Identifying where PSI transformational effects occur .......................122

6.4 The nature of PSI transformational effects .................................... 124

6.5 Reviewing transformation in e-government case studies .................... 125

Chapter 7: Future scenarios of public management ..........................................129

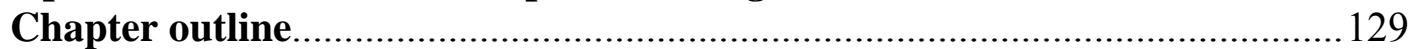

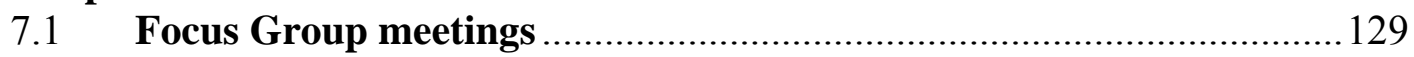

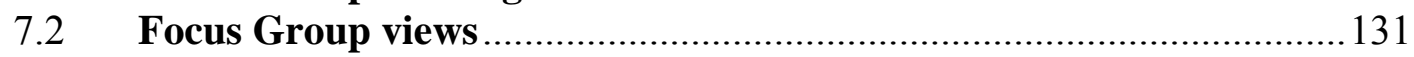

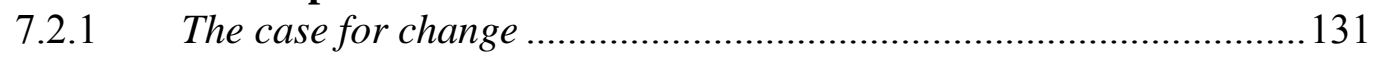

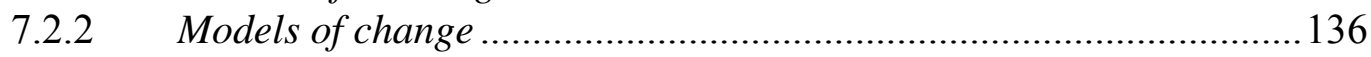

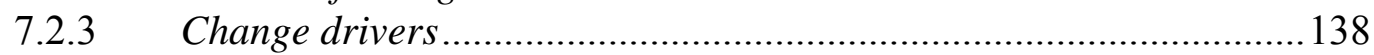

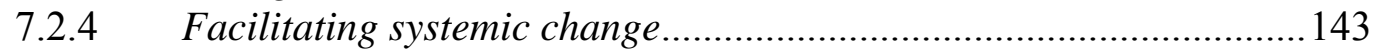

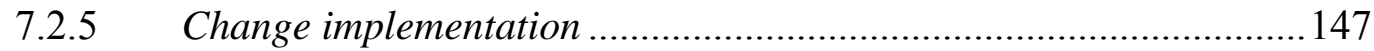

7.3 Identifying where future transformational effects occur ..................... 148

$7.4 \quad$ The nature of future transformational effects..................................150

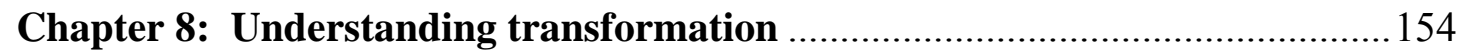

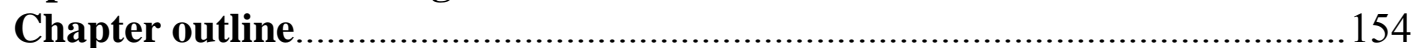

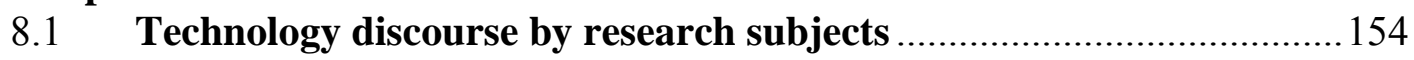

8.2 Public governance discourse by research subjects .............................157

8.3 Future transformational effects of e-government ..............................159

8.4 A new model of public governance in New Zealand ........................... 163

8.5 Future public governance in New Zealand .......................................169

Chapter 9: Implications for New Zealand governance arrangements............... 172 


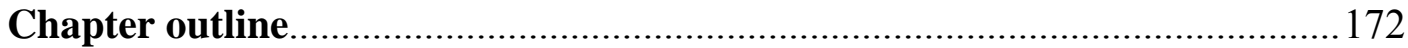

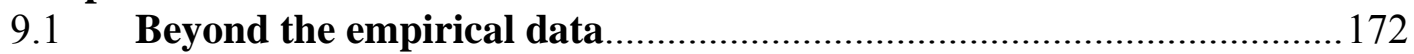

9.2 Future New Zealand public governance: NPM -Connected ................ 173

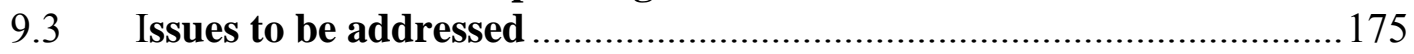

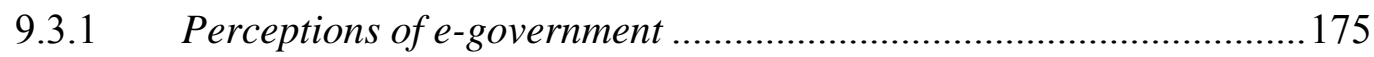

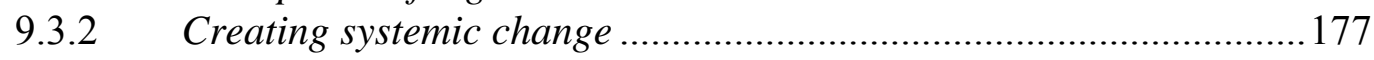

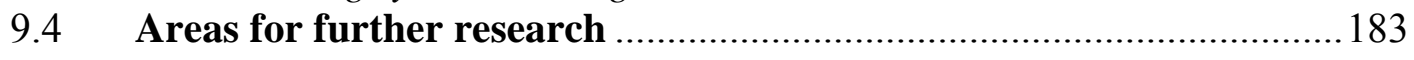

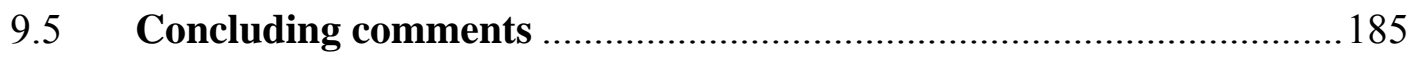

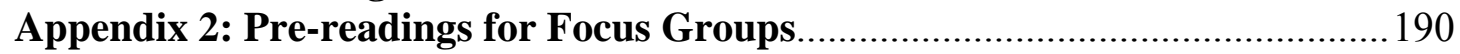

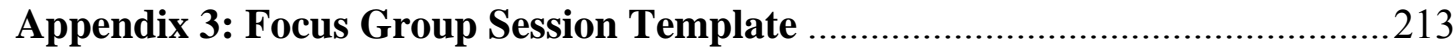

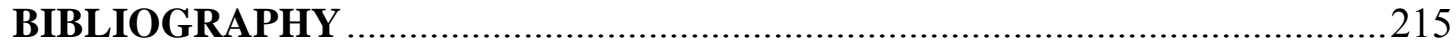




\section{List of Tables}

Fig 1: E-Government Maturity Model Compilation .................... 39

Fig 2: Weber's 'bureaucratic' model .............................. 62

Fig 3: NPM in New Zealand: 'Managerialism' $1989-2008$............. 72

Fig 4: Potential Changes to NPM in New Zealand .......................163 


\section{Chapter 1: Introduction}

\section{Chapter outline}

This chapter sets the background context of the research (s1.1). The genesis of the research is explained (s1.1.1); the concept of transformation is discussed (s1.1.2); and the central research question is posed (1.1.3). Definitions of key research terms are supplied (s1.2). Further explanation is provided on the subject of e-government and its social and academic relevance (s1.3). The New Zealand context in which this research is carried out is outlined (s1.4) and an explanation of how the research is organised is given (s1.5). An outline of the organisation of this thesis by chapter is then set out (s1.6).

\subsection{Transforming government}

Over the past 10 - 20 years many jurisdictions throughout the world have introduced information and communication technologies (ICTs) in the government sector in an attempt to gain benefits of improved efficiency and effectiveness (Danziger: 1998; Margetts: 1998; Wassink \& Kordelaar: 1998; Finger \& Pecoud: 2003; Martin \& Bryne: 2003; Ellis: 2004; Kaczorowski: 2004; Centeno et al: 2005; OECD: 2005; Andersen: 2006; Chadwick: 2006; Jeong: 2006; Thompson: 2008). Efficiency is sought by streamlining administrative processing, increasing the speed of processing transactions at lower costs, and gaining the ability to manage large volumes of data. Effectiveness is sought through more flexible options for delivering services and a greater ability to engage the public in democratic processes (Accenture: 2004; OECD: 2005; United Nations: 2008).

These changes are often heralded by government officials and technical industry-based consultants as 'transformative' (refer Chapter 2). This implies that e-government innovation can not only achieve greater efficiency and effectiveness but will also result in radical systemic change in the way that government agencies are organised to deliver information, policy and services to the public. That is, a radical change in the form and nature of public governance arrangements. This research seeks to deconstruct the concept of 'transformation' as it is used in relation to e-government in New Zealand, to examine whether such claims can be validated. 


\subsubsection{Research genesis: Personal statement}

On 1 July 2000 the E-government Unit was established by Cabinet mandate ${ }^{1}$ within the State Services Commission (SSC) ${ }^{2}$, New Zealand's public administration body. The Unit had responsibility for leading New Zealand's e-government endeavours. In addition to traditional strategy, policy and monitoring roles the Unit had a mandate to "identify opportunities for beneficial collaboration across government, leverage better returns from existing information management and technology investment, and provide coordination for multi-agency e-government projects” (www.e.govt.nz).

I held a role in the E-Government Unit from October 2000 and in July 2001 became the Unit's inaugural Policy \& Strategy Manager. At that early stage the emphasis was on the establishment of a common technical infrastructure across the state sector, and developing policy to facilitate e-government innovations in New Zealand. The policy programme included work on technical interoperability, application standards, metadata, security, authentication and collaborative workspace.

There were two aspects of the E-Government Unit establishment phase that I found particularly striking. One was the Cabinet-directed mandate for cross-agency collaboration and coordination to achieve business, service delivery and participation outcomes. This was relatively rare in New Zealand government at that time as it cut across traditional lines of chief executive independence. While inter-agency working groups that collaborated in relation to various policy areas of interest existed, it was rare to have structural bodies set up with a state sector-wide mandate that covered both policy and infrastructure. Previous examples had been restricted to specific policy initiatives (e.g. the Crime Prevention Unit established in the Department of the Prime Minister and Cabinet in 1993). The mandate of the E-government Unit was broad ranging and unique in scope and thereby in its ability to influence the way that government bodies organised and deployed their resources. In this respect, this initiative had the potential to affect some of the systemic arrangements of public

\footnotetext{
${ }^{1}$ Cabinet reference: [Cab (00) M14/1F (1)]. A more accessible summary of the Cabinet paper can be found at www.e.govt.nz/resources/research/public-sector-2004

${ }^{2} \mathrm{SSC}$ has responsibility for employing departmental heads, and monitoring departmental performance. The Commission also provides central guidance to the State sector on issues of constitutional protocols, machinery of government, performance and State sector service standards.
} 
governance in New Zealand by over-riding the managerial independence of chief executives with respect to purchasing and ownership responsibilities; funding arrangements; and the development and management of core government infrastructure (see also s2.3.1).

The other striking aspect of the e-government initiative was the enormous enthusiasm with which the programme seemed to be embraced by public officials across government, especially those with a technical and/or communications interest. Egovernment was widely acknowledged by officials interacting with the E-Government Unit both informally and formally to have the potential to 'transform' public management in New Zealand. This enthusiasm was undoubtedly in recognition of both the unique mandate of the Unit and the understanding that the advent of the Internet would have far-reaching effects. These expectations were encapsulated in the first strategy document which claimed that:

The Internet, and its associated technologies and business models, is profoundly affecting the way government, business and people interact. Government is adapting to this new environment in a way that will eventually transform how it operates (SSC: 2001; www.e.govt.nz).

In my observation those transformational aspirations were taken for granted by the public officials involved with the initiative at that time, including myself, even though the transformational effects were never specified formally, or informally.

Following my tenure with the E-Government Unit I moved to an operational and policy management role in the Ministry of Justice in 2002. I was surprised, and somewhat shocked to find that at that point in time the enthusiasm and optimism that surrounded the e-government initiative within SSC did not appear to have permeated the mainstream of one of New Zealand's largest public organisations. While the technology branch of the department was engaged with the e-government programme my policy and operations colleagues remained unaware of the initiative; did not register its significance; and had no knowledge of its transformative intentions. At that time many of my colleagues and peers did not make use of basic technical work organisation aids such as electronic calendars. They appeared to be oblivious to any 
need to consider available technologies to enable the improvement of business processes and service delivery. In almost every respect the e-government programme was simply irrelevant to them in terms of the business they were conducting and the policy debates in which they were engaged.

The cognitive disjuncture I experienced between my personal expectations based on my exposure to the e-government agenda and the reality of practice in an operational agency at that time led me to think more carefully about what the concept of transformation meant in the public management environment, and how change takes place. In particular I became interested in examining the strength of the transformative potential of e-government. My questions centred on what the scope and nature of transformation would be as a result of technical innovation. I wanted to understand not only the impact of any one specific technical initiative on an agency and its stakeholders, but the cumulative impact of conducting business online on the arrangements of public governance.

\subsubsection{The concept of transformation}

The concept of transformation has been an enduring one in relation to the egovernment agenda in New Zealand. In early versions of the e-government strategy transformation was described as a process whereby:

The delivery of government services and potentially the operation of government itself is redefined. Information, service delivery and government processes are integrated across traditional boundary lines. Information and services are increasingly customised to the particular needs of individuals and businesses. The identity of individual agencies matters less to people as information and services are accessed through a single point of contact on the web. E-government reshapes the relationships between government, individuals, and business.

The long-term goal of New Zealand's e-government strategy, in conjunction with other programmes, is to change the design, operation and culture of the public sector to better respond to the needs of New Zealanders. 
Increasingly, agencies will take a whole-of-government perspective when designing and implementing services. This will involve collaboration with other agencies, and meeting whole-of-government requirements (SSC: 2003).

The current strategy, released in December 2006, includes goals of transforming the operation of government (by 2010) and people's engagement with government (by 2020) (www.e.govt.nz; refer s1.4.2).

In both cases, the descriptions indicate a limited range of specific outcomes expected (e.g. integration and customisation) in the context of a stated goal to achieve changes of a significant systemic nature (i.e. to the "design, operation and culture of the public sector"). There is however no explanation offered in the strategy documentation of why relationships between government, individuals, and business need to change from those that are currently in place, or what mandate exists to create such change. Nor does the documentation indicate how the implementation of e-government specifically will result in changes to those relationships, and if they do what the new relationships will look like (Gauld: 2006). It is also difficult to ascertain from this discourse what the magnitude of change will be. That is, whether it will be necessary for the existing structures, systems or processes of the state sector to be changed to accommodate these new relationships, and if so how. The lack of clarity in this discussion begs the question of what is meant by transformation: what it will look like; where it will occur; and how it will be manifested through the implementation of e-government (Gauld: 2006). Furthermore, what aspects of public governance are encompassed by the concept of 'transformation'?

The term 'transformation' is not unique to the New Zealand context. It is used frequently in the e-government literature internationally (Silverstone: 1996; Williams \& Edge: 1996; Bellamy: 1998; Frissen: 1998; Taylor: 1998; Zuurmond: 1998; Ellis: 2004; Kaczorowski: 2004; Eggers: 2005; OECD: 2005; Chadwick: 2006; Tapscott: 2007) but regardless of the source, it is universally without any accompanying definition. As the term is critical to this research endeavour I referred to the English dictionary. The word has two quite different definitions depending on its context: a substantive alteration in form, shape, appearance and/or function $(v b)$ or a qualitative change that extends to a change in the spatial or temporal relationships of parts of the universe (n) (Collins Dictionary, 1993). 
The two meanings draw a differentiation between changes in 'form' and changes in 'relationship'. In applying this to the public management context, a change in form indicates that public officials may carry out the same range of activities, within the existing model of public management, but do so in different ways. For example, electronic channels may be used for the delivery of core services in addition to the more traditional manual channels currently on offer (e.g. postal mail, phone, face-toface meetings), and those services may be organised in a way that best meets the needs of the user. A change in relationships however, indicates that there may be a change in the order and/or nature of relations between parliament, the public and the state sector with respect to the fundamental rights and responsibilities between parties. This implies that the basic principles and tenets underpinning the public governance model currently in use in New Zealand may be substantively altered (refer s1.4.1). In this respect, while both meanings of the word involve substantial change, only the latter implies substantive change at the systemic level of governance.

From the dictionary explanation of the term therefore, it is possible to postulate that the transformational effects of e-government may be any one of three different types: changes in form, changes in relationship, or both. This provides a basis upon which to examine the empirical data (Chapters $4-7$ ) to see how transformation is manifested.

\subsubsection{Central research question}

This research seeks to address the question of whether there is any evidence to support the premise that e-government innovation will result in transformational change in the New Zealand state sector; and if so, what the scope and nature of such transformation will be.

The question of the transformative effect of e-government is comprehensive and extensive. Therefore, it is necessary to establish some reasonable boundaries within which it can be addressed in a manageable, but nevertheless meaningful way. Confining the research to the New Zealand context has been a deliberate choice to avoid the complexities of international comparison of e-government initiatives which can produce variable results because of methodological, cultural and 
interpretive difficulties, ${ }^{3}$ and to render the data more amenable to meaningful analysis.

Similarly, choosing to focus the research on the systemic arrangements of public institutions has also been deliberate. It has been argued that the transformational effects of e-government are likely to occur in the interface between government agencies and the public in such areas as service delivery or increased opportunities for participation in decision-making processes (Margetts: 1998; Chadwick: 2006; Kumar et al: 2007) therefore this would seem to be the logical choice for examining transformation. However, it is my contention that in order to understand both the limitations and the opportunities for change in the interface between government agencies and the public it is important to first understand the governance ${ }^{4}$ arrangements of public institutions in order to assess the scope public officials have to participate in change processes, and what ability they have to alter existing processes and systems. By focusing on the point of instigation of the phenomenon of e-government as a starting point from which to begin to understand the notion of transformation, rather than focusing on the point at which its interactional effects are more apparent, a better understanding of the contextual influences of e-government is possible.

The framework of public governance within which public officials operate includes, but is not restricted to, accountability and responsibility regimes, constitutional protocols, policy and operational functions, systems and processes. Some of these are encased in legislation and documented regulations and others in informal procedures (Boston et al: 1996). These governance arrangements influence decision-making by public officials and either restrict, or enable, the responses they make to external pressure for change. Because of this, it is my contention that public governance arrangements are critical to shaping the way that public officials respond to the challenges of the information age through e-government. In gaining a greater understanding of the parameters within which public officials make decisions a clearer view can be obtained of what changes may be possible in the interface between government agencies and the public in the future.

\footnotetext{
${ }^{3}$ Dunleavy et al: 2006 pp $64-66$ provides a useful discussion on methodological complexities of cross-country comparisons.

${ }^{4}$ A detailed discussion of how the term 'governance' is used in this thesis is provided in s1.2.
} 
In seeking to understand the concept of transformation as it pertains to public governance I have limited the scope of this study. However, I am also seeking to bring greater clarity to the discussion on e-government in New Zealand as a basis from which broader issues might then be discussed (e.g. the potential for increased public participation in democratic processes, and the potential for the relationship between public officials and elected members of parliament to be altered through the employment of ICTs). It is my belief that in understanding the institutional context more clearly outcomes that may be possible will also become clearer, as will the opportunities that may be available and the constraints that will need to be addressed.

\subsection{Key definitions}

By locating the research in the New Zealand context it is important that key terms used in the thesis are specified as they may differ to that used in academic literature (refer Chapter 2) depending on the scholarly perspective and geographical location of the originating author. Set out below is an explanation of how some of the main concepts are used. Wherever possible throughout the thesis the way terms are applied is explained at the point at which they are first introduced.

\section{E-government}

In New Zealand, the term 'e-government' is used to encompass a broad range of government activities that involve the use of ICTs as a means to improve operational performance. Although not providing a definitive definition, the New Zealand egovernment website describes e-government as follows:

E-government is a way for governments to use the new technologies to provide people with more convenient access to government information and services, to improve the quality of the services and to provide greater opportunities to participate in our democratic institutions and processes (www.e.govt.nz/about-egovt/vision.html).

This description specifies three desired outcomes: access, participation and service quality. The technologies that contribute to achieving the outcomes required are not specified, therefore it can be assumed that all ICTs utilised for these purposes are 
included. Activities that contribute to these outcomes include, but are not necessarily restricted to information management, service delivery, and public participation in policy and decision-making processes. The description above also implies the inclusion of administrative processes and internal procedures that contribute to achieving improvement in the quality of operational performance for government agencies. This encompasses knowledge management, shared work practices, and shared services.

The application of the term 'e-government' in the New Zealand context differs slightly in its depth and range, but is congruous with that made by other jurisdictions. The World Bank (2006) for example defines e-government in the context of national digital strategies as "... the use of the Internet for the provision of government information and services" (Adamali et al: 2006). That definition is shared by other commentators writing on e-government although it is sometimes qualified to include "any other digital means" in addition to the Internet (West: 2000; Centeno et al: 2005; Chadwick: 2006; Gauld \& Goldfinch: 2006). It is the extensive scope and nature of modern ICTs that provide advantages of managing large volumes of data; speed of transactions; international reach; and reduced processing and transactional costs that is uniquely associated with the opportunities provided by e-government (Ellis: 2004; OECD: 2005; Andersen: 2006; Chadwick: 2006; Dunleavy et al: 2006; Jeong: 2006).

\section{Information and communication technologies (ICT)}

The use of the term ICT in this research encompasses the range of technologies that provide the ability to make information available through a broad range of devices (e.g. televisions, computers, cell-phones) and enable two way communication between people (e.g. telephones, radio, websites, email). It is my contention that the combination of these capabilities gives rise to the potential for technology to be used to achieve the outcomes specified in the New Zealand e-government agenda: improving public access and opportunities for participation in "democratic institutions and processes", and improving the quality of government performance (www.e.govt.nz).

Commentators on the developments in technology over the past twenty years are clear that ICT innovations will continue providing opportunities that cannot yet even be anticipated (Castells: 1996; Fountain: 2001; Eggers: 2005; Dunleavy et al: 2006; 
Jeong: 2006; Tapscott: 2007). Dutton (1996) for example, describes ICTs as having "... far-reaching developments in science and technology in the late twentieth century" (Preface). He goes on to say that:

Personal computers, the Internet, video games, cellular phones, electronic banking, and satellite television are just a few of the ICT innovations that have become an intrinsic part of modern life. The rapid pace of ICT innovation and diffusion will be maintained well into the twenty-first century as computing, telecommunications, and broadcast and print media continue to converge on common digital-based techniques (Dutton: 1996: Preface).

The term ICT is used in this research because of its extensive range and encompassing implications that take account of the present and the future uses of technology for both information and communication purposes.

\section{Public governance}

The term 'governance' is also important to define, as it sets the context and identifies an important boundary within which the research has been conducted. Understanding the way the term is being applied is critical to the key analytical premises.

In examining the transformational effects of e-government (s1.1.3) the object of study is the systemic institutional arrangements of the New Zealand state sector. The institutions of state are organised so that public officials can carry out duties as part of the New Zealand executive to service both parliament and the New Zealand public. The terms most commonly used in the academic literature to describe the range of activities public officials undertake are 'public administration' and 'public management'. Both are problematic in that they "... are sometimes used as if they were virtually interchangeable, sometimes held to be conceptually distinct" (Lynn Jr: 2006: pg 4). The former focuses narrowly on the range of "... work involved in the actual conduct of government affairs" (Ibid: pg 6), while the latter is a term that has been applied to the government sector from its original concept of “... those activities associated with providing direction to the large-scale corporate organisations associated with industrial capitalism" (Ibid: pg 6). The term 'public management' is also often used by scholars to describe the particular form of public sector reform that 
has occurred in many jurisdictions in the latter part of the twentieth century (e.g. Hood: 1989; Pollitt: 1993).

Alternatively, 'governance' is a term which is emerging from both European and American scholars "... to characterise the domain within which both "traditional” public administration and New Public Management, or managerialism, are to be found" (Lynn Jr: 2006: pg 10). In his review of the use of the term governance in the literature Lynn Jr (2006) makes it clear that the terms 'public administration', 'public management' and 'governance' are all used in subtly different ways by scholars depending on their professional and cultural backgrounds (Lynn Jr: 2006: pp 4 -12).

However, the literature emerging around the concept 'governance' (e.g. Peters: 1992, 2000; Rhodes: 1997, 2007; Kettl: 2000; Pierre \& Peters: 2000; Kjaer: 2004; Olsen: 2006) takes account not only of the activities of public officials, but incorporates a broader consideration of the systemic arrangements of public institutions that act to constrain and shape the scope and nature of public administrative duties. There are active academic debates on the significance and importance of different aspects of public governance. For example, the durability of Weberian bureaucracy remains contentious (see Chapter 2 for an in-depth discussion of this point). Scholars also argue that traditional hierarchical power distribution has given way to more diffuse networked governance arrangements as communities of interest organise themselves around addressing specific policy issues (Rhodes: 1997, 2007). There are also debates about the impact and influence of market models (Hood: 1998; Pierre \& Peters: 2000) and the rise of managerialism as new models of governance (Pollitt \& Bouckaert: 2000; Scott: 2001; Lynn Jr: 2006). Some of these aspects of governance will be discussed further in the literature review (Chapter 2).

In the context of this research I have chosen to use the term 'governance', as opposed to the more traditional use of the term 'government' (Shaw \& Eichbaum: 2005) to specifically refer to the way that the full composite of agencies of the New Zealand state sector are organised to carry out the broad range of activities required to service the Government of the day. I see the concept of governance as encompassing the broad range of institutional arrangements where transformational effects might take place. That is, the term includes the full range of activities and duties of public officials, the 
structure and managerial organisation of state agencies, as well as the formal constitutional responsibilities and accountabilities, fiscal management arrangements, legislation, regulations and decision-making rights over public resources. In this respect, the term 'governance' allows for a consideration of the relationships within the New Zealand public management system rather than focusing on the activities and organisation of any one agency within that system.

\section{The New Zealand state sector}

New Zealand operates under a unitary system of central government. As a small country with a population of just over 4 million people there are no state, provincial or federal levels of government. A local government level (Territorial Local Authorities) exists but has no responsibility for the delivery of national public services or for servicing the Government of the day. Rather, Territorial Local Authorities operate in geographically defined districts and regions to "promote the social, economic, environmental and cultural well-being of communities" (Local Government Act, 2002). All of the core public services such as education, justice (including courts and prisons) health, environment, transport, economic and welfare services are administered by agencies of the central government.

The State Sector Act (1988) defines 'State services' as:

All instruments of the Crown in respect of the Government of New Zealand, whether Departments, corporations, agencies, or other instruments (State Sector Act: s2 Interpretation).

The definition under the Act includes Crown entities, Crown Research Institutes and Education services. The 'Public Services' set out in Schedule 1 of the Act list 35 agencies, Ministries and Departments. A further list of Crown agents including statutory entities and autonomous and independent Crown entities are listed in the Crown Entities Act, 2004. Collectively, the Public Service, Crown agencies, tertiary education institutions, Offices of Parliament and some non-State Services such as the New Zealand Police and the New Zealand Defence Force, for example, make up the state sector. 
Throughout this research, the term 'state sector' is used to refer to those Crown bodies encompassed by the State Sector Act, 1988 and the Crown Entities Act, 2004. It is these bodies that carry responsibility for delivering government services to the public and servicing the Government of the day. The local government is excluded from the research analysis for purposes of clarity and containment.

\subsection{The phenomenon of e-government}

\subsubsection{Societal relevance of e-government}

The phenomenon of e-government needs to be looked at in the context of the significance of other technological developments in society. The technical capabilities of ICTs have developed rapidly over the past 10 - 20 years (Castells: 1996), and particularly since the Internet has become available in the public domain.

Sophisticated technologies that are easily accessible and affordable provide individuals with a wide range of convenient, often portable communication facilities (Centeno et al: 2005). The broad range of features available through the Internet and other interactive technologies has radically changed the communication landscape for individuals, businesses and government (Castells: 1996; Silverstone: 1996; Williams \& Edge: 1996; Seely Brown \& Duguid: 2000; Chadwick: 2006).

Consequentially, forms of social behaviour have changed to encompass a wide range of activities facilitated by online capability. For example, individual commercial trading patterns have changed with both buying and selling online; social interactions are conducted online locally, nationally and globally through such mediums as facebook, blogs, chat rooms and other interactive mediums; and people participate in a broad range of online entertainment forums whereby they are both consumers and producers (music; photography) (Lee \& Zhu: 2002; Dutton \& Helsper: 2007; Bell et al: 2008; Ewing et al: 2008; Helsper: 2008) ${ }^{5}$. In line with these behavioural changes and the experience of what can be accessed online, people's general expectations have changed in respect to how and when they can be serviced and what services they can receive (Centeno et al: 2005; Jeong: 2006).

\footnotetext{
${ }^{5}$ The World Internet Project site contains a range of country reports setting out Internet usage trends in 28 member countries (www.worldinternetproject.net).
} 
Members of the public are also experiencing a significant change in service standards and performance from the private sector made possible by ICTs (Centeno et al: 2005; Jeong: 2006). In addition to information services, business services such as banking, shopping and trading are now available at all hours, every day of the week (24/7) from many places in the world. Users are increasingly experiencing accessibility, speed, and convenience of service from the private sector (e.g. online supermarket shopping that is delivered where and when you nominate) as well as technical support when and if required (Centeno et al: 2005; Jeong: 2006; Bell at al 2008).

The experience of such service standards sets a precedent for the standard that people might come to expect from their interactions with government agencies (Centeno et al: 2005). For example, in New Zealand a postal survey of 6,500 New Zealanders was recently completed on public satisfaction with government service quality. This survey organised by the SSC (Kiwis Count survey: SSC: 2008 ) indicated that $68 \%$ of respondents expected public services to be of a higher quality than those of the private sector. This demonstrates a public expectation in the New Zealand context that government service standards (including convenience, cost, timeliness and accuracy) should be high. This would seem to imply that government agencies should use all of the resources available to them, including ICTs, to ensure such standards can be met (Jeong: 2006). It is this expectation of high service standards and performance in the public sector that both drives and is driven by the notion of 'transformation' (Accenture: 2007b).

These changes in behaviours and service expectations can also be seen in the public arena. Technological developments have enabled government organisations to provide a range of services and processes online. For example, downloadable information and a limited range of online services are provided on government websites (West: 2007a). Worldwide, government administrations are moving to take advantage of the potential cost savings, administrative efficiencies and procedural effectiveness that internetbased communication technologies appear to offer (Danziger: 1998; Margetts: 1998; Wassink \& Kordelaar: 1998; Finger \& Pecoud: 2003; Martin \& Bryne: 2003; Ellis: 2004; Kaczorowski: 2004). Centeno et al (2005) for example, place e-government at the centre of public management modernisation and reform, arguing that in the European context technology is being used to modernise public administration 
activities, provide better government, and increase public value. From this perspective, Centeno and her colleagues argue that technology enables government agencies to be “more knowledge-based, user-centric, distributed and networked” (2005: p 59). Similarly, the OECD (2005) publication on using e-government to provide better government suggests that government organisations throughout the world have moved since the 1960s from automating administrative processes to producing and disseminating government information over the Internet. Now, with better technical functionality available, ICTs are being seen by public officials as a means of "developing good and responsive government that provides better value and lower cost” (OECD: 2005, pg 11). Some scholars see these developments as being so profound that they will significantly alter the basis for the delivery of public services (Andersen: 2006; Chadwick: 2006; Jeong: 2006; Thompson: 2008). However, in the public arena there is a lack of empirical data about the social, political, democratic and even organisational effects of these changes (Gronlund: 2005; Norris \& Lloyd: 2006).

Some government jurisdictions restrict and/or block access to the Internet. For example, Myanmar, Cuba, China, Iran, Syria, Saudi Arabia, Thailand, North Korea and Tunisia all impose restrictions on access to some Internet sites that are considered by their governments as politically undesirable (www.it.gen.nz). In jurisdictions with unrestricted Internet access, government agency websites provide the public with a broad range of information on public agencies and their activities. They also provide a range of interactions (i.e. those that do not require user authentication) that can be performed independently of time or space. These are business interactions which in the past were delivered by means of slow manual processes including postal delivery and/or face-to-face meetings during core business hours (e.g. applying for a student loan).

Such services provide a level of user convenience and appear to save both government and members of the public time and cost, and reduce the processing resources required. For example, in New Zealand a tax payment can be made online directly to the Inland Revenue Department's account thus saving both the payer and the agency processing time and administrative resources. While the case for customer convenience and a reduction in front office resources appear obvious (Ellis: 2004; OECD: 2005; United Nations: 2008) it is difficult to quantify how cost shifting to back office processes 
(such as the design, codification and maintenance of the digital system) affects the cost efficiency equation.

Public access to a higher volume of detailed information makes the activities of government in some jurisdictions more transparent than in the past. That is, more information is available in the public arena and can be accessed locally, nationally and internationally. For example, in New Zealand all government agencies have websites containing a wide range of information on policies and services including the annual Statement of Intent that sets out the policy directions and funding resources of the organisation. In his review of 198 countries government websites West (2007a) reported that $96 \%$ of sites provided publications, $80 \%$ had links to government databases and $28 \%$ provided services that were fully executable online.

In theory, such availability of information should increase the access members of the public have to information on political decision-making processes, thereby opening more opportunities to directly, or indirectly, participate in the democratic process. Opportunities for participation may be created by public officials (e.g. by seeking contributions to policy or law-making issues through online consultation processes) or by members of the public themselves demanding access to policy agendas by lobbying politicians and public officials in decision-making roles (Dutton: 1996; Raab et al: 1996; Bellamy \& Taylor: 1998; Margetts: 1998).

In a similar vein, Eggers (2005) argues that in an age where sophisticated technologies enable long-range military precision, the frustration of the average citizen in "navigating an obstacle course of multiple bureaucracies at multiple levels of government, each of which forces citizens to provide the same information over and over again” ( $\mathrm{p} 3$ ) will force public officials to develop new ways of thinking about processes for engaging and servicing the public. Grimsley \& Meehan (2008) see the expectations of e-government by the public as extending beyond customer satisfaction to include much broader social outcomes such as social inclusion, community development, well-being and sustainability. The achievement of these outcomes, they posit, depends on "high levels of citizen engagement with electronically-mediated access to government and public services” (2008: pg 31). 
However, other commentators are more cautious and point out that in different countries different approaches are adopted as to what constitutes better government and how, where, and when it should be implemented (OECD: 2005). Therefore, democratic reform may not be a short-term effect. Chadwick (2006) also notes that to date e-government in the United States and the United Kingdom has been narrowly defined as a programme of managerial administrative reform rather than " $a$ means of revitalising democracy and citizenship” (2006: pg 185).

Some academics argue that technologies do not themselves change public contribution to the democratic process (Snellen \& van de Donk: 1998; Margetts: 1998), but increase the likelihood that online avenues might be used by the public by making the process quicker, easier, cheaper, more timely (e.g. emailing submissions, or texting elected representatives with information or views) than manual processes (Ellis: 2004; United Nations: 2008). Logically, this should mean that there will be a significant increase in the number of people who avail themselves of such opportunities. The uptake of ICTs however, cannot be assumed based on its availability as research has found that more complex social and economic factors underpin technology adoption (Grimmer: 1998; Seely Brown \& Duguid: 2000; Fountain: 2001). In Hong Kong for example, researchers have shown that in spite of vigorous marketing and conducive technical and financial circumstances people have been very slow to adopt cable TV ( $25 \%$ of the population) and interactive TV ( $2 \%$ of the population) as they were fully satisfied by the existing TV technology (Zhu \& He: 2002). In a similar vein, researchers in both Australia and New Zealand have found that politicians have been slow to adopt interactive and Internet based communication mediums because they are fully engaged with existing modes of interaction with constituents (Hume: 2006; Ward et al: 2007).

\subsubsection{Academic relevance of e-government}

From an academic perspective, the changes in information exchange and communication processes that have emerged with the development and deployment of ICTs (Castells: 1996; Dutton: 1996; Frissen: 1998; Snellen \& van de Donk: 1998; Taylor: 1998) over the past half century, and more particularly since the advent of the Internet (Finger \& Pecoud: 2003; Centeno et al: 2005; Andersen: 2006; Tapscott: 2007; Thompson: 2008), raise a broad range of interesting questions in relation to the possible impacts on the administration and management of public affairs (Giddens: 
1984; Kraemer \& King: 1986; Bellamy \& Taylor: 1994, 1998; Castells: 1996; Dutton: 1996; Hood: 1998; Snellen \& van de Donk: 1998; Fountain: 2001; Kamarck \& Nye: 2002; Eggers: 2005; Dunleavy et al: 2006; Chadwick 2006; Christensen \& Laegreid: 2007; Thompson: 2008).

The e-government and public management literature (refer Chapter 2) describe a change process in the public management arena internationally that appears to be linked to advances in technical capability. This change is broad-based and challenges some of the basic precepts of the New Public Management (NPM) mode of governance currently operating to some extent in many western jurisdictions such as New Zealand, United Kingdom (UK), Canada, Australia and the United States of America (USA) (Bellamy \& Taylor: 1994, 1998; Castells: 1996; Zuurmond: 1998; Fountain: 2001; Dunleavy et al: 2006; Christensen \& Laegreid: 2007; Thompson: 2008).

There has been considerable academic debate about the philosophical, theoretical, and empirical significance of ICTs across disciplines. Fundamental to the discussion is the notion that the rapid rate of change that is expected from new technical capabilities will be matched by an equally rapid rate of change in social relationships between those who adopt and use the technology. The academic debate has resulted in significant disagreement amongst academic scholars across what Miles (1996) describes as both the 'control' and 'change' dimensions of the information society. That is, the social, political, and organisational effects of the adoption of ICTs (pg 39). This research is concerned with the change dimension which Miles defines as “... issues surrounding the speed and extent of change" (pg 38). He argues that the change debate is characterised by two polarised positions. At one extreme is a view that he categorises as 'continuism' which holds that:

Claims about the information society, ICTs, and the predicted rate of diffusion of the technology are regarded as overstated. Main features of society and basic power structures are thought unlikely to alter, although social and political initiatives may lead to change. Forecasting mainly for short and medium term, based on extrapolating past experiences (Miles: 1996: pg 39). 
At the other extreme is a view that Miles categorises as 'transformism' which holds that:

Information society is viewed as representing a major historical shift, changing the bases of political power and social classes with a growing role for information workers and knowledge class. ICT seen as revolutionary technology with practical benefits which will promote rapid diffusion. Long-term forecasting based typically on generalisations of leading edge experiences (Miles: 1996: pg 39).

These descriptions continue to hold true of the academic debate today which will be discussed in greater detail in the literature review (Chapter 2). Twelve years after Miles articulated the extremities of the debate there is still a clear gap in empirical evidence (Gronlund: 2005; Andersen \& Hendriksen: 2005; Norris \& Lloyd: 2006) that leaves the various interpretations of the impact of e-government initiatives in the public arena bereft of any substantial support (Bellamy \& Taylor: 1994; Hood: 1998; Andersen \& Henriksen: 2005; Gronlund: 2005; Kraemer \& King: 2006; Norris \& Lloyd: 2006). A raft of questions remain relating to how changes in information exchange and communications should be interpreted in the public sphere; how technical innovations are being managed by public officials to effect operational change; and to what extent these changes are having, or are likely to have, a consequential impact on the governance arrangements of state agencies.

\section{$1.4 \quad$ E-government in the New Zealand context}

The rationale for confining this research to the New Zealand context has been set out in s1.1.3. In addition, this choice has provided some practical benefits. As a researcher with recent experience in public management positions in the New Zealand state sector including one in the original E-Government Unit, I have access to key personnel and resources in the state sector and in the area of e-government that I could not replicate outside of New Zealand. These contacts meant the research could be carried out by gaining the co-operation and participation of a number of key resources that in other government environments may not have been so easily accessible. For example, SSC staff arranged for me to have access to e-government applications which are usually not available to people outside the state sector including the Public Sector Intranet (see 
Chapter 6). My experience as a manager in e-government also gives me an understanding of the cultural context in which e-government in this country is both conceptualised and implemented.

\subsubsection{The public governance context of New Zealand}

New Zealand is widely regarded by many public management academics (e.g. Schick: 1996; Hood: 1998; Scott: 2001; Pollitt \& Bouckaert: 2004; Christensen et al: 2007; Halligan: 2007; Brandsen \& Kim: 2008; Steane: 2008) as one of the early architects and adopters of the current NPM model of public management used in a number of Western jurisdictions. While other countries have partially implemented NPM to suit their own circumstances (Brandsen \& Kim: 2008) the model implemented in New Zealand is unique in its scope and range (Schick: 2001; Christensen, Lie \& Laegreid: 2007). It was implemented through a process of radical organisational and societal reform in the late 1980s, the ramifications of which have been a defining part of the New Zealand economic and social environment for the past 20 years. As such, it has been the subject of close academic scrutiny and its features are clearly articulated (Schick: 1996; Boston et al: 1996; Scott: 2001; Norman: 2003; Walters: 2008). These are set out and discussed in greater detail in s 2.3.1.

The reforms have been the subject of much academic debate since they were instigated as they represent a significant change from a traditional bureaucratic mode of management to a market-driven form of managerialism, whereby chief executives enter into purchase agreements with Minister of the Crown relating to specific departmental outputs (Boston et al: 1996; Scott: 2001; Boston \& Eichbaum: 2005; Shaw \& Eichbaum: 2005). This new form of management has been regarded by some scholars as representing important changes in the social contract between the public and the Crown (Christensen et al: 2007; Gregory: 2007; Halligan: 2007). These issues of governance will be discussed more fully in the literature review (Chapter 2). The implementation of the reforms will be used in this thesis as a useful reference point for analysing changes to governance arrangements (s2.3.1) that may be discernible from the empirical data. 


\subsubsection{New Zealand's e-government programme}

Since its inception, the e-government programme in New Zealand has moved from a conceptual notion (refer 'Strategy: 2003': www.e.govt.nz) to an operational mode involving all state sector agencies. The e-government website contains comprehensive information on the genesis, formation and development of the E-Government Unit within the SSC. It has evolved over time from a small unit with responsibility for developing an initial e-government programme to its current larger form as the ICT Branch of the Commission.

The e-government programme covers a broad range of aspects from technical infrastructure, security and standards to strategy and e-participation initiatives. The outcomes of the e-government programme are being monitored by the SSC. Information on the current strategy and reports on the progress of the programme, as well as information on e-government standards and guidelines and operating projects can be found on the official website for the e-government programme in New Zealand (www.e.govt.nz). The stage of development of the e-government programme means there are a range of mature initiatives available from which empirical data can be collected and analysed.

As with other national e-government programmes (Kaczorowski: 2004) the New Zealand based effort is a mixture of practical, pragmatic infrastructure development (e.g. web guidelines, metadata, interoperability standards and service delivery architecture), co-ordinated operational projects (e.g. security, syndicated procurement, authentication and shared workspace) and aspirational visions for the future. The latter include the claims of transformation not only of government processes and management procedures but also of governance arrangements.

The current e-government strategy goals established in 2006 are that by:

- 2007, information and communication technologies will be integral to the delivery of government information, services and processes. 
- 2010, the operation of government will be transformed as government agencies and their partners use technology to provide user-centred information and services and achieve joint outcomes.

- 2020, people's engagement with the government will have been transformed, as increasing and innovative use is made of the opportunities offered by network technologies (www.e.govt.nz).

This most recent version of the New Zealand E-Government Strategy is heavily based on notions of transformation but to date there is no empirical evidence in New Zealand to indicate how this will be manifested. The early supporting material on the egovernment programme includes comment on the evolutionary nature of the impact of the initiative. This implies that officials have been aware that the e-government programme will go beyond producing operational change to have a systemic impact on the public sector in New Zealand. For example, in his 2004 article on the future of egovernment in New Zealand the current programme Director wrote:

New Zealand has some distinct advantages in having a relatively compact, single tiered central government, a solid foundation of e-government standards developed over the last four or five years, a collaborative management ethos across the Public Services, and a populace who are both Internet savvy and early adopters of new technologies. But delivering on the e-government mission for 2007 will require a sea-change in the way government departments view service delivery: from a supply-based model to a demand-based model centred on the customer. To facilitate this transformation, effective organizational, governance and funding models for shared infrastructures will need to be developed and implemented. This is the next phase of e-government in New Zealand (Millar: 2004 [My emphasis]).

This view seems to take for granted the need for changes in managerial practices in the New Zealand state sector through such instruments as "effective organizational, governance and funding models for shared infrastructures". As the e-government 
programme in New Zealand moves into an era of revising its vision for the future ${ }^{6}$, it may be timely to question all underlying assumptions behind the 'transformation' agenda (refer Chapter 2; Kraemer \& King: 2006). There is an a priori question to address, which is fundamental to this thesis, as to whether change in the public governance arrangements (i.e. systemic change) in New Zealand is either necessary or desirable (and in whose interests, and for what purpose). If change in public management is necessary to ensure that in the future officials are able to effectively service the government of the day, then questions arise as to what order of change is required: organisational, management, or systemic?

\subsection{Thesis structure}

The material in this thesis will be organised as follows:

\section{Chapter 2: Literature review}

In this chapter the current thinking on e-government as an emerging phenomenon is placed in the context of academic analysis of the technological and information 'revolutions' in the 1980/90s as well as the public management reforms of that era. This provides a context for thinking about the purpose of e-government and to clarify the nature of the transformational effects that are expected as a result of e-government implementation. This review highlights the key debates in e-government and indicates the way that technology is conceptualised. Some distinctions are drawn with respect to the notion of 'transformation', and in particular the nature of systemic transformation. These are used in the thesis as the basis upon which the analysis of the empirical data is made.

\section{Chapter 3: Research design and method}

This chapter establishes both the ontological premises that inform the research process and the epistemological basis for the methodological choices made in conducting the research.

\footnotetext{
${ }^{6}$ From 01 July 2009 the operational functions of e-government will be incorporated into the Department of Internal Affairs. SSC officials, under the auspices of the recently created 'Office of the Government Chief Information Officer' are developing new strategies for moving the egovernment programme forward.
} 
Public management is conceived as a social institution (s3.1) that is a specific example of social order experienced by both public officials and members of the public as an objective reality. It is nevertheless an objective reality that can be changed by the actions of public officials in decision-making positions with the requisite authority to materially alter the form and nature of the institution. A qualitative research has been deployed to gather empirical evidence on the transformative effects of e-government, with the intention of gaining an understanding of how e-government is interpreted by those with responsibility for implementing it. A framework for analysing the empirical evidence is developed using features of Weber's typology of bureaucracy (1922) to identify the salient features of public governance that might be expected to change as a consequence of the introduction and use of ICTs (s3.2).

The transformation effect is one which conceptually and practically has a futuristic aspect to it therefore a choice was made to use case studies to examine e-government initiatives that are currently being implemented, and to also run focus groups to consider the impact of e-government implementation in New Zealand over the next 20 years (s3.3). These separate streams of data gathering were chosen with a view to providing a rich picture of the operational effects of e-government implementation in the state sector, and its transformational potential. The methods used for selecting the case studies and gathering data are set out in s3.4. The selection of focus group participants and the organisation of the meetings are set out in s3.5.

\section{Chapter 4: Case Study 1: Landonline}

In this chapter the case study is presented on the Landonline application developed by Land Information New Zealand (LINZ) for the digitisation of land title and land survey records. Interviews were carried out with senior managers involved in the development, implementation and management of the initiative. The interview data is analysed using the Weberian framework developed in Chapter 3 to identify where changes have occurred as a consequence of the implementation of Landonline and what the transformational effect of the initiative has been.

\section{Chapter 5: Case Study 2: Justice Sector Information Strategy}

In this chapter the case study is presented on the implementation of the Justice Sector Information Strategy (JSIS). This is an inter-agency initiative designed to raise the 
quality and integrity of the information base of the Justice sector and improve the management and exchange of information amongst sector agencies. Interviews were carried out with senior managers involved in the development, implementation and management of the initiative. The interview data is analysed using the Weberian framework to identify where changes have occurred as a consequence of the implementation of JSIS and what the transformational effect of the initiative has been.

\section{Chapter 6: Case Study 3: Public Sector Intranet}

In this chapter the case study on the Public Sector Intranet (PSI) application that was developed and implemented by officials in the ICT Branch of the State Services Commission is presented. The PSI has been deployed across the state sector as a knowledge management and central information repository. Interviews were carried out with senior managers involved in the development, implementation and management of the initiative. The interview data is analysed using the Weberian framework to identify where changes have occurred as a consequence of the implementation of the PSI and what the transformational effect of the initiative has been.

\section{Chapter 7: Future scenarios of public management}

Four focus groups were convened to explore the concept of transformation further by identifying the current drivers of public management change in New Zealand and to deduce what changes (if any) are therefore most likely to occur over the next 20 years. Data from the focus group meetings is presented using the Weberian framework to identify what changes in the core features of public management are seen by focus group participants that are most likely to occur and how this will affect the current public management model deployed in New Zealand.

\section{Chapter 8: Understanding transformation}

The empirical data provided in Chapters 4 to 7 is further distilled to clarify how the case study and focus group subjects differed in their interpretation of e-government and public management. These discourses are examined to further understand the concept of transformation and to ascertain how ICTs will be used by public officials in New Zealand in the future. Potential changes to the NPM model of public management in 
New Zealand are identified. A future model of public management in New Zealand entitled 'NPM-Connected' is posited.

Chapter 9: Implications for New Zealand public governance arrangements In this chapter I look beyond the empirical data to draw out the implications of the 'NPM Connected' model of public governance for the future. Issues needing further resolution in the New Zealand state sector to enable the new model of governance to operate are identified and work in the areas of the accountability framework; leadership; creating a positive investment environment; and management of the workforce capability is discussed. Further consideration is given to the implications on public governance in each of these areas. Areas for further research are identified. Concluding comments on the research are made.

\section{Appendices}

Supporting information for the thesis is provided including a list of research contributors (1), reading material distributed to focus group participants (2), and the format of the focus group meetings (3).

\section{$\underline{\text { Bibliography }}$}

A full list of all references cited in the thesis is provided as well as other relevant readings. 


\section{Chapter 2: Literature review}

\section{Chapter outline}

In this chapter, literature on e-government is examined to see how it is conceptualised and explained by scholars, government officials and industry specialists. Of particular interest is the way the notion of 'transformation' is used in relation to the implementation and use of ICTs in government organisations. The exposition of egovernment in the literature demonstrates the scope and nature of the phenomenon; how it is conceptualised theoretically; and the types of transformational impacts associated with ICTs.

In section 2.1 the dominant academic perspectives on e-government from scholarly work on information systems, and public management are explored. Each discipline emphasises and debates different aspects of the e-government phenomenon thereby

highlighting its complexity. The emergence of e-government as an academic subject is traced in s2.2, with a particular emphasis on the impact of internet-based technologies (s2.1.1). I then look at the public management context in which e-government is embedded (s2.3) highlighting the reform agenda of the past 30 years (s2.3.1). Theoretical understandings of public management (2.3.2) and the contribution of technology $(2.3 .3-2.3 .4)$ are explored to clarify some of the core issues involved in the notion of 'transformation' of government (2.4).

At the end of the chapter, the use of the term 'transformation' as used in the literature in reference to e-government is clarified (refer 2.5). The bureaucratic typology (Max Weber: 1922) is used to map the current features of the New Zealand public governance model. This provides a means of clarifying the types of transformation effects that may be identified in the empirical data.

\subsection{Sources of e-government literature}

This research is informed by bodies of work from academics writers who provide a scholarly context for examining the phenomenon of e-government and its significance in the public management domain today and in the future. One scholarly perspective on e-government comes primarily from the discipline of 'information systems' or 
'information management'. These scholars tend to apply a micro-analytical approach focusing on the technical details of e-government and in particular the ways in which new technologies alter information flows in business processes. For example, Moon (2002) and West (2000 - 2007) examine the website development of municipal and state government organisations to assess perceptual effectiveness and identify the number and types of government-held information made available to the public online. Jutla et al (2004) focused their research on the building of knowledge management infrastructure, while Millard \& Iversen (2004) looked at the reorganisation of government back offices. Other research using the micro-analytical approach includes Heeks (2005), who developed structure and process 'checklists' for managers undertaking the technical design and build of e-government initiatives. Reddick (2005) provides an examination of the attributes of citizen online interactions with government. Similarly, Gil-Garcia \& Martinez-Moyano (2007) posited that changes in the performance and accountability regimes of government organisations were resulting in changes to the rules governing the design, implementation and use of egovernment initiatives. Such instrumental changes are then examined by scholars for their transformative effects on management practices in government organisations (Hernon et al: 2006).

By contrast, public management academics tend to apply a macro-analysis approach that treats the phenomenon of e-government in two ways: one as a tool to enable managers to implement policy changes driven by socio-political and economic factors (Hood: 1998; Kraemer \& King: 2006), and the other as a phenomenon that is likely to have far-reaching and possibly transformative effects on public governance (e.g. Bellamy \& Taylor: 1998; Frissen: 1998; Fountain: 2001; Dunleavy: 2006). Those scholars who conceptualise e-government as an enabling mechanism tend to regard it as a secondary feature of the public management context that is instrumental in its implementation and effect. However, other academic writers see e-government as a phenomenon that is having social, political and organisational impacts that go beyond instrumentality to have a substantive effect on the relationships between parties in the democratic process (Bellamy \& Taylor: 1994; Raab et al: 1996; Margetts: 1998; Snellen \& van de Donk: 1998). Attempts have been made to explain and describe the longer-term impacts of such changes. The different academic perspectives will be discussed in detail in this review as a means of clarifying the core issues relating to e- 
government and highlighting the expectations relating to its transformative effects (s2.2).

The scholarly work noted above is supplemented by a body of work that has emerged from public service officials throughout the world recognising e-government as a distinct public management phenomenon. These writers are often closely involved with either the design and development of e-government policies or the implementation of e-government programmes and discrete initiatives. This work includes policyoriented discussion papers primarily appearing on government websites (see for example, www.e.govt.nz; www.finance.gov.au; www.cabinetoffice.gov.uk; www.canada.gc.ca; www.whitehouse.gov; www.irlgov.ie; www.ec.europa.eu; www.premier-ministre.gouv.fr). They cover topics as broad as infrastructure, security, channels, metadata, interoperability, open source systems, shared workspace, procurement and enterprise architecture to mention but a few. Most government websites also contain the nation's e-government strategy but only a small number provide information on progress being made towards implementation goals. It is within this body of work that claims of the transformative effect of e-government initiatives are often to be found, and will be highlighted in this review as a means of identifying the type of expectations that are associated with the implementation of egovernment initiatives.

In addition, a number of industry-based consultants have also developed a significant body of work on diverse aspects of e-government (in particular, but not exclusively Accenture, Cisco, IBM, Gartner, and Gen-i). The work of these writers must be recognised as having a commercial interest, and as such they also have a propensity to make broad claims about the transformational effects of e-government. Nevertheless, they have developed over time a detailed, internationally applicable discourse on developing e-government strategy and vision, as well as a wide variety of material on the opportunities for, and barriers to, e-government implementation. They also provide papers discussing technical aspects of e-government and specific project implementation processes. The work of such industry-based consultancy groups often complement the work of international bodies such as the Organisation for Economic Co-operation and Development (OECD), the World Bank, and the United Nations in providing information on the progress of e-government implementation, and 
assessments of the economic and political environment of countries as a precursor to successful e-government implementation. This body of work, while not enjoying the categorisation of academic scholarship, has been enormously influential and to some extent has shaped and influenced the way that e-government has been implemented by public officials throughout the world (see for example the discussion in 2.2.2).

\subsubsection{Literature limitations}

As a public management phenomenon e-government is a relatively recent concept having emerged from a broader discussion on the 'technical revolution' in the literature roughly around the turn of the century (Gronlund: 2005). In this respect, it is somewhat undeveloped as an academic concept. Much of the literature reflects this in that theoretical frameworks explaining the relevance and implications of e-government are not yet common, and the empirical research base remains limited. Surveys of egovernment literature in peer-reviewed academic journals carried out by Andersen \& Hendriksen (2005) and Norris \& Lloyd (2006) show that articles on e-government appearing in academic journals between 1998 and 2004 focused almost entirely on technical capabilities and interactions and their effects on e-services largely ignoring policy issues, theoretical implications or value distributions.

Norris \& Lloyd (2006) also found that only 57\% of the articles appearing in journals up to the end of 2004 had any empirical content, prompting them to conclude that current e-government research “... lacks rigor and sophistication and is not adequately connected to prior relevant scholarship” (pg 52). Similarly, Gronlund (2005) who surveyed 170 papers at three major e-government conferences found that theory generation and testing was not frequent and that “... Dubious claims (beyond what is reasonable, given the method used) are frequent, appearing in 29\% of the papers" (pg 21).

In spite of these limitations, the academic research on e-government alongside " $a$ burgeoning gray literature of white papers, consultation documents, consultants reports, corporate documents, and league tables ..." (Chadwick: 2006 pg 185) which, as noted above, have been enormously influential, provide a useful base for describing the scope of the phenomenon and identifying its associated transformational effects. 


\subsection{The e-government phenomenon}

In the 1980s and 1990s academic interest in technology tended to focus initially on the impact of the 'technical revolution' on society (Kranzberg: 1985; Silverstone: 1996; Williams \& Edge: 1996; Castells: 1996; Seely Brown \& Duguid: 2000), and its associated 'information revolution' (Beniger: 1986; Carnoy: 1989; Dutton: 1996; Marshall: 1998). Academics recognised technological advances as 'revolutionary' with respect to the consequential impact on almost every facet of modern life and a broad range of social and economic endeavours such as (but not restricted to) medicine, science, manufacturing technologies, media, and transportation (Castells: 1996, pg 30).

Associated changes to the structure of modern societies were regarded by academic scholars as historically significant. For example, Castells (1996) postulated that a new form of 'networked society' would emerge as a consequence of the use of new technologies (see also Bellamy: 1998). He described the 'IT paradigm' as having distinct characteristics of being based on information as a raw material; having all pervasive effects on human interactions; operating according to a network logic; being flexible; and increasingly moving towards convergence of specific technologies (pp 61 -62). All of these factors come together to form a phenomenon that is both powerful in its materiality and compelling in its social effects.

Some academics recognised the possible impacts of technological innovation on public management and began to explore how these might be manifested (Taylor et al: 1996; Bellamy: 1998; Frissen: 1998; Taylor: 1998). For example, Bellamy \& Taylor (1994) described the emergence of an 'information polity' recognising that the use of a variety of electronic capabilities would become a central feature of societal interactions and have a commensurate impact on the relationship between members of parliament and the public. ${ }^{7}$ Bellamy \& Taylor (1994) also posited that there would be a distinct change in the ways that politicians accessed and used information, and as a consequence there would be more direct engagement by the public in democratic processes. Margetts (1998) argued that using ICTs in government organisations would change the way policy tools are used by re-engineering existing tasks, and opening up

\footnotetext{
${ }^{7}$ See also Rabb et al: 1996; Margetts: 1998; Snellen \& van de Donk: 1998; OECD: 2001 for discussions on the impacts of technology on democratic processes.
} 
policy opportunities not previously possible. Danziger (1998) and Margetts (1998) both also postulated that ICTs would generate significant changes in human resource management particularly with the emergence of what Margetts described as "... new armies of technical specialists” (pg 458) in government organisations.

To date, these early propositions have not yet been strongly supported by empirical evidence (Andersen \& Hendriksen: 2005; Gronlund: 2005; Chadwick: 2006; Norris \& Lloyd: 2006). Early work by Lips (1998) indicated that progress in the area of government e-services may not be as rapid as originally anticipated, and Wassink \& Kordelaar (1998) demonstrated that there may be some unintended consequences of ICT adoption created by rigidity of software applications. Work completed by the OECD (2003b) also indicates that significant challenges exist for efforts to successfully establish e-government and gain the anticipated benefits such as increased take-up of services, improved access to government processes for citizens, and more cost efficient service provision.

\subsubsection{The Internet effect}

The advent of the Internet being made available in the public domain in the mid to late 1990s had a profound effect on the rapid development of ICT capabilities (Chadwick: 2006) and also affected the way technology is conceived of in government, commercial and academic realms. Businesses and governments throughout the world began to invest heavily in the development and implementation of a wide range of internetbased information, service, and transactional innovations.

The emergence of e-government as a distinct public management phenomenon emerged in the USA as early as 1993 and in other countries around the turn of the century (Gronlund: 2005) in recognition by public officials of the importance of technological investment to an information society. It was characterised by the establishment of national e-government bodies (e.g. the Australian National Office for the Information Economy was established in 1998; the Office of the E-Envoy was set up in the UK in 1999; and New Zealand established an E-Government Unit in 2000).

In recognition of the importance of social and economic opportunities associated with internet-based capabilities most countries also now have a digital strategy of some 
form (OECD: 2003a; Accenture: 2007c). In 2006, the World Bank sponsored a review of national 'e-strategies' across 40 countries (Adamali et al: 2006) which showed that $85 \%$ included all of the following features:

- e-government - providing information and services via the Internet

- infrastructure - constructing physical components

- e-education - improving teaching and school administration and basic e-literacy, and

- legal/regulatory - creating and modifying legal and regulatory mechanisms to enable and support ICT adoption in business and government and to safeguard users of ICTs (Adamali et al: 2006: pg 96).

The convergence of these four features across national e-strategies prompted the authors to postulate that each one of them is fundamental to the creation of an ‘information society' (pg 96).

The advent of this machinery of government and policy response by public officials to technological advancements was complemented by the emergence of a large body of academic work focused specifically on e-government from scholars with an interest in information management, and to a more limited extent to those interested in public management. From the information systems/management discipline a wide range of egovernment literature is available concerned with varying aspects of technical architecture and infrastructure (Layne \& Lee: 2001) such as portals, security and authentication, web standards (Moon: 2002), interoperability (Millard \& Iversen: 2004), metadata, open source software, domain policy, connectivity (Reddick: 2005), procurement practices, project design (Gil-Garcia \& Martinez-Moyano: 2007) and build issues (Gouscos et al: 2001; Heeks: 2005; Jutla et al: 2004). In addition, there is some focus on the challenge to managers in developing and successfully deploying technical capabilities in the public sector (Aldrich: 2002; Heeks: 2005; Gauld \& Goldfinch: 2006; Hernon et al: 2006). Gauld \& Goldfinch (2006) for example, identify a number of government technology investments in New Zealand that have resulted in both time and cost over-runs, and have failed to deliver the functionality they were originally established for. 
Considerable research effort has also gone into website analysis. For example, Brown University has surveyed up to 1,813 state and federal government websites in the USA on an annual basis to assess the range and quality of features available online (West: 2000 - 2007). In recent years, this research has been extended to incorporate an assessment of government websites internationally.

Research has also been carried out on identifying Internet usage trends (e.g. Zhu \& He: 2002; Canadian Internet Project: 2005; Bell et al: 2008). Universities and research institutes throughout the world have collaborated on the World Internet Project since 1999. Twenty-eight countries have provided data on Internet usage in their jurisdictions including breakdowns by gender, age and occupation as well as the types of sites that people access and for what purposes (www.worldinternetproject.net). Complementing the Internet research, industry-based analysts run annual surveys of multiple countries e-readiness and e-government implementation and provide an international ranking of performance. The rationale for this is business driven. Ranking “... provides companies that wish to invest in online operations with an overview of the world's most promising investment locations" (Accenture: 2007c).

\subsubsection{Stages of growth in e-government}

One of the common concepts used in the e-government literature from all sources, is a 'maturity model'. This is an important indicator of both the purpose and intent of public officials in investing in electronic technologies in the public domain. Primarily though it is used by public officials and technology industry personnel as "... a method for judging the maturity of the processes of an organisation and for identifying the key practices that are required to increase the maturity of these processes" (Windley: 2002, pg 1). The maturity model is usually described as 'stages of growth' for egovernment development and like many evolutionary models each stage is progressive in nature and moves from the basic interactions to more complex transactions.

The details of the stages of growth vary slightly according to the purpose for which particular writers are working (e.g. policy and technical writers emphasise different aspects of the stages), but in a broad sense there is some consensus that the stages move from information dissemination through transaction-based service delivery to 
'transformation' of government systems and processes (Layne \& Lee: 2001; Windley:

2002; Reddick: 2005; Hernon et al: 2006; Gil-Garcia \& Martinez-Moyano: 2007).

Fig 1: E-Government Maturity Model Compilation ${ }^{8}$

\begin{tabular}{|c|c|}
\hline Level 1 & Information Dissemination \\
\hline & $\begin{array}{l}\text { Lists of departments and contact information } \\
\text { Links to other government sites } \\
\text { Policy statements } \\
\text { Organisational structure charts } \\
\text { Downloadable forms } \\
\text { Access to papers and documents. } \\
\text { No change to the nature of public user or business interaction with government. }\end{array}$ \\
\hline \multirow[t]{2}{*}{ Level 2} & Online Government: Basic Transactions \\
\hline & $\begin{array}{l}\text { Online forms for applications and registrations } \\
\text { Online payments (usually from client to agency) } \\
\text { Request for services or information via email } \\
\text { Online surveys } \\
\text { Online assistance via FAQ, resolution services } \\
\text { Basic account enquiries. } \\
\text { The focus remains on the government organisation, but transactional services are } \\
\text { added in an attempt to add value to the public users and/ or businesses. }\end{array}$ \\
\hline \multirow[t]{2}{*}{ Level 3} & Integrated Government: Interactive Transactions \\
\hline & $\begin{array}{l}\text { End-to-end electronic transactions } \\
\text { Automated RFP processes } \\
\text { Automated procurement } \\
\text { Information sharing between departments } \\
\text { Shared workspaces } \\
\text { Shared business processes } \\
\text { Web-based training } \\
\text { Automated advice and resolution data } \\
\text { Limited configuration capabilities. } \\
\text { Requires integration of back-end processes. Moves away from individual agency } \\
\text { transactions and allows for a single, integrated face for the public users and/or } \\
\text { businesses. Multiple processes from different organisations are brought together in a } \\
\text { meaningful way for the users. }\end{array}$ \\
\hline \multirow[t]{2}{*}{ Level 4} & Transformed Government \\
\hline & $\begin{array}{l}\text { Citizen-centric, integrated, inter-departmental processes (across all levels of } \\
\text { government (federal, state and municipal/ local) } \\
\text { Common technical architecture for enabling content through any channel } \\
\text { Internal/ external business process integration. } \\
\text { Online services are built from the public user's viewpoint meeting individual } \\
\text { requirements and needs. Is dependent on a fully integrated architecture and is } \\
\text { delivered independently of back-end structure and organisation. }\end{array}$ \\
\hline
\end{tabular}

${ }^{8}$ This table is a compilation of the material provided by the authors listed. 
It can be seen from this model that the levels of progression imply a movement from passive to interactive transactions between government agencies and the public. This movement is not necessarily linear, however, as several levels can overlap and be operating at the same time. The greatest level of maturity depends on the successful integration of both business processes and technical capabilities across organisations, and indeed across different jurisdictional levels of government. Nevertheless, the concept of government transformation as the ultimate goal of e-government implementation is explicit. This assumes that change to business systems and processes in government as well as to governance structures is both desirable and inevitable.

The maturity model described above is commonly used as a reference point for public officials and industry-based consultants in particular in assessing progress of egovernment implementation (Accenture: 2003-2007; OECD 2002 - 2008) and it is on this basis that some commentators conclude that e-government initiatives to date have 'failed' to reach their expected potential for organisational cost-savings and downsizing, and that governments are not yet making full use of the available technologies (West 2000; Moon: 2002; OECD: 2008). The sentiment expressed by the OECD that "... there is a significant gap between what is possible with information and communication technologies and what has actually been accomplished ... thus far" (OECD: 2008) is not an uncommon one. Other writers assert that most e-government projects fail claiming that even when they are successfully implemented they "...do not often deliver the financial and other benefits they promise" (Gauld \& Goldfinch: 2006: pg 10). Heeks (2005) argues that e-government often fails in one of four ways: the technical system is never implemented; the technology is abandoned after implementation; major goals are not attained (relating to cost, implementation timeframes, and capability) and/or they result in significant unexpected undesirable outcomes.

This type of critique of e-government implementation after such a short period of time (in that internet-based capabilities only became widely available in the public domain over the past 10 years) raises a number of questions relating to how e-government performance is being measured, what criteria are being used to judge its success 
(Bannister: 2007), and what expectations of organisational change are being linked to technical capabilities. The empirical evidence of technical implementation shortfalls (Heeks: 2005; Gauld \& Goldfinch: 2006; Dunleavy et al: 2006) indicates that egovernment innovation is often large, complex and extremely difficult. The sheer logistical complexity of large IT projects stands in stark contrast to the relatively short timeframes that are often proposed for implementation, and the expected outcomes of future cost savings, process efficiency and organisational transformation.

\subsection{The public management reform context}

The literature on e-government as outlined in the section above implies that at the micro-analytical level public officials, industry consultants and some academic scholars assume transformative effects described in terms of integrated technical infrastructures and business processes to be an outcome of the implementation of egovernment initiatives. The emphasis on technical implementation of e-government, and its progression towards some form of organisational transformation (as demonstrated in Fig 1) masks the complexity of the public management environment and the policy, constitutional and structural barriers to providing interactive online services for government sector organisations.

For example, issues of equity, access, interoperability and authentication are complex and intransigent and act as significant barriers to the provision of online services in the government context (Lips 1998; Andersen: 2006; Kumar et al: 2007). Andersen (2006) also highlights specific management challenges in the public sector with respect to egovernment. These include the high cost of investment in IT systems with longer timeframes for recovering costs through lower transaction costs; demand for online services; the high labour intensity of public service provision; and the need to develop and maintain IT competency in the public sector (2006: pp 1 -6).

There is little consensus amongst scholars on the contribution ICTs make to state institutional arrangements and the prima facie case for the likelihood of transformational systemic change remains contentious (refer: s1.3.2; Miles: 1996). In contrast to those scholars who assume that transformation of government is a characteristic of the maturity of e-government (refer Fig 1) some public management scholars argue that there is no empirical link between ICTs and changes in the power 
structures of governance (Hood: 1998; Kraemer \& King: 2006). For example, Hood (1998) suggests that claims of transformation are unsubstantiated and overblown noting that:

Some of the informatization [sic] gurus see developments in information technology as heralding a quite new era of public management, taking us into the 'information polity' and even more drastically, the 'virtualization' of public management' (pg 198).

Kraemer \& King (2006) also argue persuasively that empirical evidence demonstrates that ICTs have not to date contributed to public administration reform in the USA. Furthermore, they argue that the claim of transformational change is fundamentally flawed in that it is based on two questionable assumptions:

(i) that reform is required in government, and

(ii) that IT can be used to carry out such reforms (pg 9).

With respect to the first of these assumptions Kraemer \& King argue that the bureaucratic form of public administration is already highly refined and comprehensive in carrying out the tasks of government and there is no compelling case for this to be changed. With respect to the second, they claim that in the American context egovernment is one part of a broader government reform agenda focused on improving customer service and a greater responsiveness to citizens. In this agenda they argue that technology is inconsequential:

... claims that e-government will fundamentally alter governmental structure, performance, citizen engagement, and so on ... are likely to be dashed, given that IT in and of itself consistently has proven to have little bearing on those kinds of government reforms. IT is a general-purpose engine that can enable reform efforts, but unless the other factors for reform are in place, the role of IT is immaterial (2006: pg 13).

Kraemer \& King's position demonstrates the perspective of a number of public management academics who question both the efficacy and likely outcome of e- 
government initiatives, and who argue that process and management change, however pervasive, will not result in systemic changes in public management (Hood: 1998; Pollitt \& Bouckaert: 2004). To more fully understand the impact of technological changes in the public sector context it is useful to look more closely at recent public management reforms.

\subsubsection{Understanding public management reforms}

Radical public sector reforms took place internationally in the late 1980s in an attempt to reduce costs and improve operational effectiveness (Hood: 1989, 1991; Pollitt: 1993, 2002; Boston et al: 1996; Scott: 2001; Pollitt \& Bouckaert: 2004). Bouckaert (2008) noted that economic problems faced many OECD countries at that time. He suggests that at the macro-economic level the government sector in many countries was too high a proportion of Gross Domestic Product (GDP), and suffered from significant skill and efficiency deficits resulting in a lack of performance and productivity.

The OECD report on public management reforms (2000) identified three main drivers of public sector reforms in OECD countries during the 1980/90s. Firstly there was the need for governments to be responsive to increasing demand by the public for better, faster and a wider range of services. Secondly, there was a wide perception that the public had lost confidence and trust in public institutions, and lastly there was a significant change in the role of governments as competition from the business and non-government sector increased, and societies were increasingly being opened up to international influences (OECD:2000).

The public management model that emerged as a result of reform programmes in that era is referred to as New Public Management (NPM) or 'managerialism'. The key features of the NPM model of public management are consistent with the theory of 'economic institutionalism' and represent an attempt to introduce the management philosophies of private industry and the marketplace into the public sector to create greater fiscal efficiencies and produce higher productivity. Institutional economics has a particular emphasis on the 'principal/agent' relationship and therefore is characterised by the specification of outputs in a clearly defined contractual relationship which provides the means to measure performance and maintain fiscal efficiency (Scott: 2001; Walters: 2008). In effect, monetary criteria were introduced to measure 
efficiency, and this became the predominant driver of performance (Pierre \& Peters: 2000).

While each country customised versions of the model according to their own cultural and political idiosyncrasies (Brandsen \& Kim: 2008) New Zealand is widely credited with having introduced the model in its most radical form (Schick: 2001; Christensen, Lie \& Laegreid: 2007; Halligan: 2007). For example, Halligan (2007) notes that "The New Zealand model won international admiration as a unique case of public sector reform because its framework was innovative, sophisticated and coherent” (pg 48). Similarly, in his second review of the reforms Schick (2001) noted that "... in New Zealand, the reforms are the system. There is no other managerial system” (pg 2). At the time the reforms were first introduced, New Zealand was facing an economic crisis and radical reform of the public sector was seen by politicians and senior public officials as essential to create fiscal and performance efficiencies (Boston et al: 1996; Schick: 1996; Scott: 2001; Norman: 2003; Walters: 2008).

Through the enactment of legislation in 1988 (the State Sector Act), agencies of the state in New Zealand have been organised in a manner which reflects the following principles:

- separation of purchase and ownership responsibilities

- separation of policy and operational functions

- separation of funders, purchasers and providers

- encouragement of competition between service providers (Walters: 2008).

Other features of the model include vertical accountability lines, and chief executive managerial independence. The latter involves a decentralisation of core administration functions with chief executives assuming responsibility for such things as the employment of staff, setting pay and employment conditions and financial management. In practice, not all of these characteristics remain or were ever fully implemented in New Zealand, but they are generally accepted as the underpinning characteristics of the model implemented during the 1980's reforms (Schick: 1996; Boston et al: 1996; Scott: 2001; Norman; 2003; Walters: 2008). 
The introduction of a 'market' ethos into the public management arena had profound impacts on the way some areas of government in New Zealand carried out service delivery functions (e.g. health, housing and transport). A greater customer-focus permeated service delivery agencies and greater emphasis was placed on competition in service provision as a means to drive up quality and increase the range of services available to the public (Boston et al: 1996; Scott: 2001; Norman: 2003). The Public Finance Act was enacted in 1989 to provide the accountability framework for fiscal policy for the state sector to support the organisational and management reforms (Walters: 2008).

In 2001 a review of the operation and practice of public management in New Zealand ${ }^{9}$ was carried out (SSC: 2002). The reviewers endorsed the general principles of public governance underpinning the New Zealand state sector. Some amendments were suggested primarily around achieving better co-ordination of resources in managing complex policy problems. This resulted in some legislative changes (e.g. Crown Entities Act, 2004) and the introduction of three state sector-wide initiatives: the establishment of 'circuit breaker' teams to solve complex problems at the operational level (e.g. family violence); HR reforms to improve leadership across the state sector; and the adoption of a 'managing for outcomes' management ethos. These initiatives were supported by the enactment of the Public Finance Amendment Act, 2004 that removed statutory restrictions on cross agency collaboration and emphasised a focus on policy outcomes as opposed to financial outputs (Walters: 2008).

These subtle adjustments to the management ethos in the public sector in New Zealand towards collaborative endeavours to achieve collective outcomes are not easily aligned to the statutory principle of chief executive independence endorsed by the 'Review of the Centre' review team or to the emulation of self-regulating market models to achieve fiscal efficiencies (Norman: 2003; Boston \& Eichbaum: 2005; Gregory: 2006). As a result, a systemic tension exists in New Zealand that public officials negotiate with respect to policy development and operational management.

\footnotetext{
${ }^{9}$ This review was called the 'Review of the Centre' and was commissioned by the Minister of Finance and the Minister of State Services. The report of the review team was published in 2002 and has been a catalyst for ongoing public sector policy reform in New Zealand.
} 
Managing for outcomes requires collaboration and cooperation at the policy level, integration of business processes across agencies, and a sector (or cross sector) perspective with respect to funding and managerial oversight. This implies that for an outcome orientation to be successful there will need to be adjustments to the current principles and arrangements of public governance in New Zealand. These high level issues are currently part of the debates taking place in New Zealand.

\subsubsection{Theoretical issues in public management}

Since the first wave of public management reforms of the 1980s much of the international academic literature on public management has focused on the social, managerial and organisational impact of NPM and in particular the impact of 'market' dynamics in the public arena (Kettl: 2000; McLaughlin et al: 2002; Boston \& Eichbaum: 2005).

In addition, scholars have looked at how the NPM model has been modified over the past twenty years (Gregory: 2006, 2007; Lynn Jr: 2006; Christensen et al: 2007). Roness (2007) for example, explores changes in regulatory functions and degrees of specialisation along both horizontal and vertical axes of organisational management in New Zealand, Australia, Sweden and Norway. He argues that in recent times the devolution or vertical specialisation that took place in the 1980s reforms has been largely reversed in Australia and New Zealand. This is supported by research carried out by Whitcombe (2008), demonstrating that more recent moves in New Zealand towards managing for collectively agreed outcomes has led to a re-coupling of policy and regulatory functions within single agencies.

Scholars see the 1990s as representing a period of consolidation and modification of the reforms, but argue that since the turn of the century the focus on improving efficiency and effectiveness by the application of market principles has given way to some extent to a new emphasis on organising the management of public affairs to achieve politically determined social and economic outcomes (McLaughlin et al: 2002; Boston \& Eichbaum: 2005). Perri 6 et al (2002) argue that the organising principle of NPM has remained that of functionality and this sets up internal incentives that prevent public officials from effectively working together towards cross-sectoral social, 
economic and political outcomes. Ryan (2004, 2008), however, argues that at the operational 'front-line' public officials are developing horizontal work practices that allow them to achieve practical outcomes for the clients regardless of the structural constraints of the vertical public management accountability structures. This conclusion is also borne out by research on joined up government carried out by Eppel et al (2008) in New Zealand.

For some scholars these changes indicate that NPM as a public management model will be replaced in the future by new forms of public governance. For example, Rhodes posits that networked systems (Rhodes: 1997, 2007), where communities of interest determine key policy developments, will replace traditional hierarchical processes, and (Dunleavy et al: 2006) envisage a form of 'digital era governance' whereby technology significantly modifies existing public administrative processes thereby forcing systemic changes (see 2.4 below). Scholars also anticipate that changes in ICTs will see new forms of participatory democracy arising (Eggers: 2005; Chadwick 2006; Tapscott: 2007; Grimsley \& Meehan: 2008).

The debate on the efficacy of NPM in achieving public sector reform is interwoven with an associated theoretical debate about the extent to which NPM represents a complete break from Max Weber's (1922) typology of 'bureaucratic' public management, or is only a current manifestation of managerial practices within a more enduring framework of institutional bureaucracy. The bureaucratic typology is characterised primarily by hierarchical control, a highly articulated division of labour, and uniform control over personnel. Impersonal rules govern recruitment, promotion and dismissal as well as the nature of the work itself. The defining theme of the system is legal-rationalism. The bureaucratic system has proven to be the most efficient means of organising public administration over time (Peters: 1992; Fountain: 2001; Hopfl: 2006; Lynn Jr: 2006). Lynn Jr (2006) notes that Weber himself viewed “... a system of bureaucratic rule in the modern state as inescapable; he could discover no known example of a bureaucracy being destroyed" (pg 174).

Nevertheless, some scholars refer to NPM as though the adoption of managerial, and more particularly 'market', principles and practices are of such significance that they constitute a new era of 'post-bureaucratic' public management (Hedlund: 1994; 
Heckscher: 1998; Zuurmond: 1998; Child \& McGrath: 2001; Kamarck: 2002, 2003; Josserand: 2004). This position is strongly debated by academics who argue persuasively that the bureaucratic model is constant and that historical changes including the introduction of market principles only represent changes in form, rather than substance (Hopfl: 2006; McSweeney 2006; Gregory: 2007). Hopfl (2006) and McSweeney (2006) for example argue that periodisation is not verifiable and that the move to managerialism is not a post-bureaucratic form of public management, but merely a refinement of the base model whereby different features of the Weberian model have been de-emphasised and some minor aspects of specific features have even been discarded completely. Some of these changes are significant and give rise to completely different administrative systems and processes for engaging with parliament and the public (e.g. aspects of provider competition and service delivery), but they nevertheless rely for their stability on the basic tenets of the bureaucratic typology (Gregory: 2007) by which public officials are organised to carry out their duties.

Hopfl's proposition (2006) is supported by other academics applying a more historic analysis to modern public management (Fountain: 2001; Clegg \& Courpasson: 2004; McSweeney: 2006). For example, Fountain (2001) posits that “... bureaucracy that formed the foundation of the modern state is now outmoded in many ways. But although modified ... each of its elements remains central" (pg 62). It is this process of modification and re-modification of the basic features of the bureaucratic model that gives rise to new forms of public management such as NPM.

To provide an understanding of how modification of the bureaucratic model takes place it is useful to examine existing theoretical frameworks that explain the operation of the institution of public management. Institutional theory in particular has specific application to public management and the organisation and management of government agencies (Selznick: 1948; DiMaggio \& Powell: 1983, 1991; Scott: 1987, 2001; March \& Olsen: 1989; Roness: 2007). This framework holds that the behaviour of public officials is deeply rooted in, and reflective of, multiple contexts including organisational culture, constitutional protocols, legal frameworks, regulations, and agency interests. 
In 2004 Richard Scott collated the works of a variety of institutional theorists (Scott: 2004). He surmised that organisational institutions are variously comprised of three common elements - cultural cognitive, normative and regulative - each of which is emphasised by different institutional scholars depending on their various interests (e.g. sociologists tend to focus on the normative elements, whereas economists emphasise the regulatory elements). The common theme that Scott identifies amongst the institutional scholars is that "... social behaviour and associated resources are anchored in rule systems and cultural schema" (Scott: 2004: pg 9). Cultural cognitive elements refer to those elements of an institution which are so common that they are 'taken for granted' by the actors. Normative elements are those which derive from social obligation or moral imperatives (i.e. perceived as the 'right' thing to do), and regulative elements are those that are usually formally encapsulated in legislation, regulation or rules. Each of these elements act as strong influences in shaping the behaviour of organisational actors and constraining change processes within an organisation.

In general, institutional theory can be applied to a consideration of the public sector by recognising that the management of public resources is a socially constructed arena within which diverse, interdependent organisations carry out specified functions (Bourdieu: 1977; DiMaggio \& Powell: 1983; Scott \& Meyer: 1983). Scott (2004) points out that it is important for scholars to recognise that institutional environments are not monolithic but often varied and conflicted with non-alignment between the cultural cognitive, normative and regulative elements of the organisation; weak boundaries that enable a mixture of logics to permeate thereby supporting divergent behaviours; and a variety of structures and repertories of acting promoted by minority interests (Scott: pg 11).

Within such diverse and complex environments public officials engage in a range of actions that affect decision-making processes. These include such things as interpretation, sense-making, translation and negotiation (Edelman: 1992; Dobbin et al: 1993; Weick: 1995). Both DiMaggio \& Powell (1991) and Scott (2004) emphasise the importance of understanding the ability of public officials to have both micro and macro influence on their institutional environment. DiMaggio refers to this as 'agency' defined as the capacity to 'make a difference' in one's situation. Scott notes that it is 
essential to confirm the (varying) potential for institutional actors to reconstruct "... the rules, norms and beliefs that guide - but do not determine - their actions" (Scott: 2004: pg 12). In conceptualising public officials as actors reacting consciously to their environment DiMaggio \& Powell (1991) and Scott (2004) are arguing against determinism. With respect to the development, implementation and management of ICTs this implies that e-government is both the means and ends for sense-making (Weick: 1995) public officials. The interpretation of e-government by public officials in positions to decide how, where, what and when ICTs should be developed and implemented is therefore important in the context of this thesis.

Institutional theorists hold that formalised organisational institutions such as public management are stable and resilient over space and time. In this respect, in spite of the capacity for organisational actors to individually and collectively influence their environment and effect change, the process is a complex and slow-moving one. DiMaggio \& Powell $(1983,1991)$ pay particular attention to the cultural cognitive elements of institutions and invoke the concept of 'organisational isomorphism' (i.e. the tendency to produce and reproduce the same organisational form) to explain the enduring stability of the status quo and the influence of institutional cultural norms on the decision-making of senior officials. They argue that a range of forces competitive, mimetic, normative, and coercive - act to ensure that public officials act in most instances to maintain the existing institutional arrangements.

In this context DiMaggio \& Powell (1991) see the primary concern of senior public officials as the maintenance of resource stability for their particular agency, as this ensures their continuing existence and relevance. In this respect therefore political relationships are of paramount importance, not least because they determine the functional mandate of an organisation and control the funding basis on which state sector agencies operate. To ensure resource stability, senior public officials engage in activities that support the social and political legitimisation of the organisation by becoming embedded in political, organisational and cultural relationships through which legitimacy is conferred. Political relationships underpin public governance arrangements, and their primacy is such that it can be inferred that ICTs will be used by public officials to ensure those relationships are maintained. 
The implication of this conceptualisation is that the primary concern of most organisational actors therefore is to maintain the status quo. DiMaggio \& Powell (1991) posit that the primacy of the motivation for organisational legitimacy is such that when forced to choose, decision makers will select options that preserve and enhance organisational legitimation over organisational efficiency. They maintain that legitimation is more powerful in terms of maintaining resource streams for continued existence, than internal efficiencies. This has particular importance when considering how senior public officials make choices about the design, development and deployment of technologies for the purposes of internal administration and for information management and service delivery.

The point that DiMaggio and Powell (1991) make about securing and maintaining organisational legitimation goes to the heart of where the power of the public management institution lies, and which actors can have most influence and/or determine whether change will take place in public management, for what reasons, and in what way. Although the notion of dialectic relationship implies that all organisational actors can influence change, there is no doubt that for transformational (i.e. radical) change to occur a critical mass of behaviour change must take place with enough impetus to create change in the regulatory elements of the institution. Radical ideas (such as e-government leading to transformation in government operations) therefore, are not enough to create change. For ideas to be translated to actual change requires a commensurate change in the behaviour of organisational actors. This goes some way to explaining the disjuncture between policy and practice noted in the beginning of this thesis (refer s1.1.1).

\subsubsection{The use and deployment of technology in public management}

The contribution of information to organisational culture and decision-making is important in considering the contribution that e-government can make to change in public management. Commentators hold enormously disparate views on what influences emerging ICTs will have on social and organisational relationships. On one hand technological determinists maintain that the force and speed with which changes in technical capability are occurring will result in a world where technical imperatives over-rule human will (Frissen: 1994). In this vein Dunleavy et al (2006) for example, argue that information technology systems are now so costly and complex that they 
impose a serious limitation on the discretionary actions of policy-makers (Dunleavy et al: 2006: pg 26). That is, if a computer software programme does not 'allow' a particular action to be taken then it can't be done, making technology a critical determinant of the limits of human activity and a primary consideration in systemic and organisational level change. Under this scenario, computer systems become a central influence on public management, establishing artificial boundaries and limiting not only administrative processes, but also policy implementation.

At the other end of the spectrum is a school of thought that advocates that technology is socially determined and as such is malleable to human will. The more open it is, and the more people can participate in developing and designing it to suit their own purposes, the greater utility it will have and the greater its potential for shaping and reshaping human behaviour (Castells: 1996; Eggers: 2005; Doczi: 2007; Tapscott: 2007). In this respect, technology enables social policy to be implemented and is a secondary influence in systemic and organisational level change.

While these two perspectives differ considerably on what the world in the future will look like, neither provides a useful explanatory framework for understanding how change occurs in the public management arena which, as argued by institutional theorists (DiMaggio \& Powell, 1991; March \& Olsen: 1989; Scott: 2001; Kraemer \& King: 2006) has a strong propensity to maintain the status quo. Implicitly, the underlying driver for assumed changes in behaviour from both perspectives appears to be the logical force of the technology functionality itself. This does little to account for how change will occur in a historically and culturally evolved public management institution grounded in stable constitutional socio-political relations.

\subsubsection{Technological enactment}

Fountain (2001) provides a specific consideration of how technology is conceived by public officials and thereby how it is generally implemented and used in a public management environment. She introduces the concept of 'technological enactment' (pp 83 - 103) which holds that technology is implemented by officials in ways that reflect the need to obtain and retain institutional legitimation. This inevitably leads to differences in outcomes than might be expected on the basis of technological logic and efficiency alone. 
That is, the potential uses of technical capabilities will not necessarily be realised if public officials do not see them as being consistent with their need for resource stability obtained through legitimation. In this respect, the driving imperative for technology adoption is unrelated to the technology itself. No matter how sophisticated the technological capability is, and how its application might 'transform' the business processes, it is the interpretation by senior officials in decision-making positions of the cultural and organisational 'fit' within their environment that determines whether any particular technology will be adopted.

Fountain (2001: pp $102-103)$ posits that the power of the institutional status quo is extremely strong, and therefore reform efforts focused on customers and technical reforms are more likely to succeed than structural changes. She also maintains that the accountability structures of public management are such that it is actually easier for public-private networks to be established than for cross agency integration to occur. Fountain also proposes that it is the institutional, cultural, and social context within which senior officials interpret their reality that drives the speed and nature of change that may take place in public management governance arguing that "The culture, history, mental models, and standard practices of a policy domain or agency will affect technological enactment...” (Fountain: 2001: pg 103).

The technological enactment concept has considerable explanatory power in understanding which technology innovations will be supported by public officials and when and why they will be resisted, regardless of what new technical functionality is on offer. It provides a rebuttal to technological determinism and exercises a considered restraint on those who advocate a rapid and radical transformation of public management in the near future (Miles: 1996). This perspective takes account of the constraints and limitations of the institution of public management, and therefore will be used in this thesis in considering the empirical evidence available on technological innovations in the public sector.

\section{$2.4 \quad$ Transformational effects of e-government}

The discussion above demonstrates that the context within which the phenomenon of egovernment occurs is complex and multi-faceted. A number of scholars argue strongly 
that the heavy emphasis of academic research on the technical processes and procedural changes in public agencies as a result of ICT implementation, risks missing the longer-term and more fundamental changes occurring as e-government initiatives alter the way that information is used, and indeed how it is thought of as a core element of public resourcing (Bellamy \& Taylor: 1994; Raab et al: 1996). Wassink \& Kordelaar (1998) claim dramatically for example, that "ICT obliterates existing structure and culture, new structure and culture come into being. This goes for society in general as well as for public administration in particular. ICT determines. ICT enables” ( $\mathrm{p} 425)$. Kumar et al (2007) argue that the way that governments manage information is critical to the provision of quality services to citizens, businesses and other members of the public (p 64) while Grimsley \& Meehan (2008) posit that the design and management of e-government technologies directly contributes to the level of trust the public has in public institutions.

Taylor \& Lips (2004) describe the use of information as the "... flows of blood and the nervous system ..." of contemporary public administration, and argue that an understanding of information distribution is essential:

... it is only by addressing the flows of intentionally and unintentionally communicated information afforded by electronic networks that we can as scholars truly understand contemporary public administration, on the one hand, whilst adding value to its practice, on the other (Taylor \& Lips; 2004: pg 2).

Scholars who accept the notion of transformation of government organisations attributable to the adoption of ICTs (e.g. Frissen: 1998; Fountain: 2001; Dunleavy et al: 2006; Tapscott: 2007) have attempted to look specifically at the structural and governance impact of ICTs on public management. For example, Fountain (2001) writing in the American context before the major effects of internet usage became apparent postulated nonetheless that in the public sector a 'virtual state' would emerge with the following features:

- government agency websites making information available worldwide 
- groups of agencies linked by common clients via co-location of information but with no back office integration

- agency intranets integrating internal structural arrangements, and

- groups of agencies integrating some of their activities, requiring operational, political and institutional change (Fountain: 2001: pp $98-103)$.

Dunleavy et al (2006) writing in the UK context argue that the effects of e-government are now so pervasive that they mount a challenge to NPM governance and that over the next few years there will be a move to what they have termed 'digital era governance'. This model is characterised by what Dunleavy et al categorise as:

- Reintegration - putting back together elements separated by NPM through processes of joined-up-government; reabsorbing outsourced activities; re-engineering back office processes to realise productivity offered by modern technology; and shared services.

- Needs based holism - providing more agile, responsive government services that fundamentally change the relationships between agencies and clients through such processes as data warehousing; one-stop service provision; and citizen-centric services.

- Digitisation changes - whereby electronic channels become the central feature of organisational management enabling electronic service delivery; open book government; radical disintermediation; and mandated channel reduction (Dunleavy et al: 2006: pp 224 242).

The notion that ICTs will have a transformational effect on government has its genesis in the earlier academic analysis of the technical and informational 'revolutions' of the 1980/1990s that saw technological developments as all pervasive. For example, Castells (1996) asserted that: 
$\ldots$ at the end of the twentieth century, we are living through one of these rare intervals in history. An interval characterised by the transformation of our "material culture" by the works of a new technological paradigm organised around information technologies (Castells: 1996: pg 29).

The impact of ICTs was seen as being so pervasive that new theories were required to take proper account of them. In the government context, Frissen (1998) argued that:

Cyberspace is a virtual reality which is in itself political and administrative. But its politico-administrative characteristics are dramatically different from the reality public administration theory has until now conceptualized and interpreted (Frissen: 1998: pg 33).

Frissen (1998) further argued that three different types of transformation could be seen to be taking place:

- Horizontalisation - network type horizontal configurations

- Deterritorialisation - time and space are no longer limiting. Information and communication can be organised independently of existing patterns of organisational structure of decision-making, and

- Virtualisation - existing realities can be simulated by integrating technologies and media (Frissen: 1998: pp $36-37$ ).

Tapscott (2007) postulated that four different types of 'revolution' are converging in a technological paradigm to force public sector transformation: technology (through participatory websites); demographics (as 'digital natives' change the expectations of technology available in the workplace); social networking (increasing expectations of responsive and customised public services); and economics (through mass, global collaboration) (pp $1-2)$.

Thus, while some of the expected transformational effects have been articulated by academics, the consequential impacts on government agencies and public management governance is less clear, and several commentators have pointed out that the empirical 
evidence to support the transformational claims is as yet insufficient (Andersen \& Henriksen: 2005; Gronlund: 2005; Norris \& Lloyd: 2006). The empirical evidence in this thesis is focused on public governance. Therefore, it will not provide an examination of the effect of technical deployment necessary to either support or debunk the theoretical propositions posed by the scholars above. However, these concepts will be revisited in the data analysis section (Chapter 8) to ascertain whether they can further explain the transformational effects of e-government in the New Zealand context.

\subsection{Interpretation of the literature}

In reviewing the literature on e-government and the public management context within which it operates, the argument of Castells (1996) that technological advances are creating a phenomenon that is having a very important impact on the fabric of societies globally is compelling:

The prophetic hype and ideological manipulation characterising most discourses on the information technology revolution should not mislead us into underestimating its truly fundamental significance. It is ... at least as major a historical event as was the eighteen century Industrial Revolution, inducing a pattern of discontinuity in the material basis of economy, society, and culture (Castells: 1996: pg 30).

E-government is a specific application of technical advances in the public management arena and there is a body of thinking that supports the view that it will prove to be an important contributing factor to public management reform in the next twenty years (Bellamy \& Taylor: 1994; Frissen: 1998; Fountain: 2001; Cento et al: 2005; Eggers: 2005; Dunleavy: 2006; Tapscott: 2007; Thompson \& Jones: 2008). While this proposition will only be verified over time, the arguments relating to the substantive impact of ICT usage on management and operational practice are convincing enough to suggest the need to build up empirical evidence to demonstrate clearly the impacts of egovernment implementation. Such evidence needs to encompass a number of spectrums including the operational and management practices of individual organisations; interactions between agencies, businesses and the public; and with respect to public management structures and governance. 


\subsubsection{Clarifying the nature of transformation}

There is, however, a lack of precision in the literature regarding the concept of transformation of government. There is a tendency for academics, government officials and industry-based consultants alike to use the term generically (e.g. see government websites; World Bank: 2006; Accenture: 2007a; United Nations: 2008) without specifying the nature and scope of the expected transformational effects. From my reading of the e-government and public management literature I surmise that the term is used by different authors to imply one of two different types of transformation. That is, if a transformational effect can be empirically verified, it is likely to occur in one of two distinct forms:

1. Instrumental transformation - i.e. a radical change in the existing administration, information management and service delivery practices of government agencies that may also have a consequential impact on organisational structures and/or management practices; or

2. Systemic transformation - i.e. a radical change in the existing governance arrangements of public management including constitutional responsibilities and accountabilities; fiscal management; legislation; regulation; and decisionmaking rights over public resources.

The differentiation between these two types of transformation is critically important to the discussion on the concept of transformation in this thesis. Like the dictionary definition (s1.1.2) 'instrumental' transformation is primarily one of form, while 'systemic' implies a change in key relationships. The application to the public sector is important as it goes to the scope and nature of changes that will be distinguishable from e-government implementation. It is not my intention in this thesis to arbitrate on whether one type of transformation is more important than the other, but rather to understand where and how each will occur and what its impact will be.

\section{Instrumental transformation}

Empirical research to date demonstrates that the implementation of e-government initiatives often results in operational changes that deliver benefits to organisations and 
clients of increased speed, greater consistency and quality, and lower transaction costs (Layne \& Lee: 2001; West 2000 - 2007; Moon: 2002; OECD: 2003; Jutla et al: 2004; Heeks: 2005; Hernon et al: 2006; Gil-Garcia \& Martinez-Moyano: 2007; Jacobsen: 2007) . Transformation of this order can be described as 'doing the same things differently'. The speed and efficiency with which a service is delivered has no influence on the intrinsic nature of the service itself. The transformative effect is instrumental in nature; the order of socio-political relationships and the referent frameworks of public management remain unchanged. In this instance, the effect of egovernment can be expected to manifest itself in organisational structure and management practices, and in positive changes to the quality, accessibility, convenience and cost of transactions between government agencies and the public and/or businesses.

The United Nations (2008) summarises the purpose of e-government as follows:

The underlying principle is to improve the internal workings of the public sector by reducing financial costs and transaction time, to better manage the work flows and processes, to improve institutional linkages between different government agencies, ministries and units and enable a better flow of resources and allocation of responsibilities to promote the delivery of public services (Statement by Director).

This would imply that the transformational effects most likely to occur will be instrumental ones, whereby agency structures, organisational systems and processes and management practices are radically altered to accommodate new electronic channels for carrying out administrative tasks, organising information and delivering services to the public. The primary driver of this type of transformation is operational efficiency and effectiveness in keeping with the underlying principles of NPM.

\section{Systemic transformation}

The transformative effect of e-government may also manifest itself in changes to the institution of public management through alterations to governance arrangements. The implication here is that by using ICTs the relationships, and thereby the behaviours, of politicians, the public and public officials will be radically altered. This in turn will 
force new models of governance to emerge that will result in new forms of public management (Frissen: 1994; Bellamy \& Taylor: 1994; Raab et al: 1996; Fountain: 2001; Dunleavy et al: 2006; Tapscott: 2007) that transcend, or at least significantly modify the existing system of NPM. From this perspective, transformation includes both 'doing the same things differently' (e.g. perhaps reorganising fiscal distribution and financial reporting) and 'doing different things' (e.g. possibly using ICTs to create new types of services; identifying new resources; and redistributing decision rights) (Moore \& Hartley: 2008).

Several academic writers (e.g. Finger \& Pecoud: 2003; Centeno et al: 2005; Eggers: 2005; Kumar et al: 2007; Lips: 2007) suggest that conceptualising e-government solely as a management tool for achieving efficiency and effectiveness (i.e. instrumental transformation) is limiting in its effects. Centeno et al (2005) for example, argue that e-government needs to be more knowledge-based, user-centric, distributed and networked (pg 59). This view is supported by writers such as Eggers (2005) who suggests that new ways of thinking are required for information age government and Tapscott (2007) who is establishing research to explore how to exploit “...new models of web-based collaboration to reinvent the way that governments develop policy, partner across institutional boundaries, and engage and serve constituents” (pg 2). These perspectives are more suggestive of systemic transformation in public management.

Critical to this debate is the way that technology is conceptualised as a contributor to public management reform. ICTs are regarded either as unitary in their effect, i.e. as a management tool that acts as an 'enabler' of policy change (Hood: 1998; Kraemer \& King: 2006; United Nations: 2008) or as an influencer of more systemic change (Frissen: 1998; Fountain: 2001; Dunleavy: 2006). This raises the question of whether technology should perhaps be regarded as something that can have dual and/ or multiple effects: that it should be regarded as something that can enable instrumental change and be a factor that will have a profound influence in contributing to systemic change in public management.

The common element of these two distinct forms of 'transformation' is the magnitude and nature of the change that is expected to occur. Whether applied to the 
organisational processes and practices of public sector agencies, or to the model of public management itself, it is anticipated that the introduction of ICTs will result in significant change of a radical nature. It is my contention however, that only systemic transformation can be conceived of as contributing to a paradigm shift in public management that will fundamentally redefine the way governance is organised.

The empirical data collected in this research (set out in Chapters $4-7$ ) will be analysed to determine if transformational effects are occurring in the New Zealand context as a result of e-government implementation, and if so of what nature: instrumental or systemic. This empirical exploration helps in understanding the impact of egovernment on public management in New Zealand.

\subsubsection{Understanding the depth of e-government transformation}

In the context of this research the question of whether NPM is a distinct 'postbureaucratic' structure (Hedlund: 1994; Heckscher: 1998; Zuurmond: 1998; Child \& McGrath: 2001; Kamarck: 2002, 2003; Josserand: 2004) or a unique form of Weber's bureaucratic typology ${ }^{10}$ (Hopfl: 2006; McSweeney 2006; Gregory: 2007) is also important to clarify as it bears on the question of the ability of e-government initiatives to contribute to transformation of governance. The distinction may be subtle, but it is important in understanding where and how the transformational impact of egovernment may manifest itself and what substantive form it may take, if it can in fact be determined to occur at all. That is, as a consequence of e-government are we likely to see transformation of NPM to some other model of public management, or can a claim be made that ICT capabilities may impact on the enduring features (Thompson $\&$ Jones: 2008) of the bureaucratic model itself?

To explore this issue further I created a chart (Refer Fig 2 below) using the fourteen attributes of Weber's bureaucratic typology identified in Hopfl's work (2006) to map out the current characteristics of the NPM model of public management currently in use in New Zealand. These include:

- securing the orderly, routine, day-to-day execution of duties by a staff of administrators

\footnotetext{
${ }^{10}$ Refer to discussion in section 2.3.2.
} 
- strictly hierarchical and highly articulated division of labour and strict and uniform control over personnel

- agencies of government are grouped (departments/ agencies/ ministries etc)

- impersonal rules including those governing recruitment, promotion, dismissal etc.

- professional qualifications and knowledge are essential

- officials are selected, not elected

- promotion on 'next in line' not merit

- salaries relate to status, not performance

- jobs are for life

- monocratic control i.e. one person, not a body

- keeping of records is critical to rationality and the efficiency of bureaucracy as an instrument of power

- remuneration fixed - usually in the form of a salary

- great importance is attached to official secrets

- the defining theme of bureaucracy is that of legal-rationalism (Hopfl: 2006).

In considering the modern form of public management it is a useful reflection to question whether this model still has durability. Glancing through the list above, one can quickly identify aspects of the model that no longer exist, or have been considerably remodified in modern public management in New Zealand. For example, jobs are no longer for life; promotion is based on merit; performance is actively managed; and there is considerable flexibility in remuneration packages. Nevertheless, closer scrutiny of the operation of the modern organisational model may throw up more similarities to the above attributes, than differences.

Set out below is a comparative table that examines each of the features Hopfl (2006) identifies in the Weberian model of bureaucracy and compares it to the current model of public management operating in New Zealand today. 


\section{Comparisons between Weber's model of 'bureaucracy' and the 'New Public Management' model of public management as used in New Zealand.}

\begin{tabular}{|c|c|}
\hline Weber's model of 'bureaucracy' & $\begin{array}{l}\text { Modern Public Management in } \\
\text { New Zealand }\end{array}$ \\
\hline $\begin{array}{l}\text { Routine - orderly, day-to-day execution of } \\
\text { duties by a staff of administrators. }\end{array}$ & $\begin{array}{l}- \text { - Jobs are specified in formal job } \\
\text { descriptions. At the operational level some } \\
\text { jobs continue to be highly regulated. }\end{array}$ \\
\hline $\begin{array}{l}\text { Hierarchy - articulated division of labour; } \\
\text { uniform control over staff. }\end{array}$ & $\begin{array}{l}- \text { - Management structures are flatter than in } \\
\text { the past, but nevertheless are organised } \\
\text { according to a hierarchical division of labour. } \\
\text { Control over staff is managed through job } \\
\text { descriptions, line management, performance } \\
\text { management systems, and employment } \\
\text { contracts. }\end{array}$ \\
\hline $\begin{array}{l}\text { Grouped organisation - specialised } \\
\text { jurisdictions. }\end{array}$ & $\begin{array}{l}\odot-\text { Departments, ministries, Crown owned } \\
\text { agencies are based on specialisation of } \\
\text { purpose. }\end{array}$ \\
\hline $\begin{array}{l}\text { Impersonal rules, particularly those } \\
\text { governing recruitment, promotion, dismissal } \\
\text { etc. }\end{array}$ & $\begin{array}{l}\text { () - HR policies and regulations control } \\
\text { appointment procedures. Legislation applies. }\end{array}$ \\
\hline Professional qualifications and knowledge. & $\begin{array}{l}\text { - - Higher academic qualified personnel are } \\
\text { commonly appointed within the public } \\
\text { service, particularly in ministries and } \\
\text { departmental policy, research, and other } \\
\text { areas of specialisation (e.g. legal, science, } \\
\text { history, technical, and financial expertise) } \\
\text { and at senior management level. } \\
\text { Many officials are now regarded as } \\
\text { 'generalists' and move freely between } \\
\text { government agencies during the course of } \\
\text { their careers applying their skills across } \\
\text { organisational boundaries. }\end{array}$ \\
\hline Officials are selected, not elected. & $\begin{array}{l}\text { - Apolitical public service. State Service } \\
\text { Commissioner appoints Chief Executives, } \\
\text { and appointments below that level are made } \\
\text { by managers within the department. }\end{array}$ \\
\hline Salaries relate to status, not performance. & $\begin{array}{l}\text { - Salaries are managed within 'bands' for } \\
\text { specific job descriptions of comparable } \\
\text { expertise. Performance benefits can be } \\
\text { added on. }\end{array}$ \\
\hline $\begin{array}{l}\text { Monocratic control - i.e. one person, not a } \\
\text { body. }\end{array}$ & $\begin{array}{l}\text { - Each agency has its own head, } \\
\text { contracted to the Responsible Minister for } \\
\text { delivering specified outputs. The state }\end{array}$ \\
\hline
\end{tabular}




\begin{tabular}{|c|c|}
\hline & $\begin{array}{l}\text { sector is headed by the State Services } \\
\text { Commissioner as the 'employer' of core } \\
\text { Public Service department and ministry } \\
\text { heads. }\end{array}$ \\
\hline $\begin{array}{l}\text { Record keeping - creation of 'institutional } \\
\text { knowledge. }\end{array}$ & $\begin{array}{l}\text { - The form of record keeping is likely to be } \\
\text { both electronic and paper-based but } \\
\text { continues to be a basic requirement for } \\
\text { maintaining a history of core decisions and } \\
\text { institutional actions. }\end{array}$ \\
\hline Fixed remuneration - salaried workers. & $\begin{array}{l}\text { (-) Personnel are likely to be a mix of } \\
\text { salaried and contracted workers. Salaries are } \\
\text { related to 'job size' and nature. Flexibility of } \\
\text { working arrangements is possible. }\end{array}$ \\
\hline Official secrecy. & $\begin{array}{l}- \text { - 'Budget Secret' conventions remain. } \\
\text { Information gathering and usage is regulated } \\
\text { under the Privacy Act, } 1993 \text {. } \\
\text { There is a greater degree of transparency of } \\
\text { official information under the Official } \\
\text { Information Act, 1982. Limited provisions } \\
\text { exist for with-holding information for a } \\
\text { variety of reasons, but the precedent is for } \\
\text { making information available whenever } \\
\text { possible. } \\
\text { A large amount of government-held } \\
\text { information is available to the public via the } \\
\text { Internet (government agency websites and } \\
\text { related sites). }\end{array}$ \\
\hline Legal-rational model. & $\begin{array}{l}\text { - The theoretical underpinning of the } \\
\text { current public management model in NZ is } \\
\text { known as 'institutional economics' which is } \\
\text { a legal-rational model of behaviour and } \\
\text { interactions. }\end{array}$ \\
\hline Promotion on 'next in line', not merit & $\begin{array}{l}\mathbf{X}-\text { Appointments are made on merit. } \\
\text { Appointment processes are transparent and } \\
\text { contestable. }\end{array}$ \\
\hline Jobs are for life. & $\begin{array}{l}\mathbf{X}-\text { Permanent appointments continue to be } \\
\text { made at lower levels in the organisation, but } \\
\text { there is a lot of movement within and across } \\
\text { organisations. } \\
\text { The general workforce is made up of a } \\
\text { combination of permanent employees, fixed- } \\
\text { term and short-term contractors. } \\
\text { Senior managers, including chief executives } \\
\text { are appointed for fixed periods of time } \\
\text { (usually only 3-5 years). }\end{array}$ \\
\hline
\end{tabular}


The comparison provided in Fig 2 clearly demonstrates that the general bureaucratic typology continues to underpin the current NPM model of public governance in New Zealand. Only two attributes no longer appear in the New Zealand model of public management: jobs for life, and promotions based on length of tenure rather than merit. All of the other attributes continue to characterise the NPM governance arrangements albeit in a different form to that which existed in New Zealand prior to the 1980's reforms (Schick; 2001; Norman: 2003).

Based on this comparison the perspective of those scholars who argue that NPM is a specific form of Weberian bureaucracy (Peters: 1992; Fountain: 2001; Clegg \& Courpasson: 2004; Hopfl: 2006; Lynn Jr: 2006, McSweeney: 2006; Gregory: 2007) is compelling and will be used to inform the empirical data analysis (Chapters $4-7$ ). That is, I am assuming that any transformational effects that can be ascertained from the implementation of e-government, regardless of whether they are instrumental or systemic in nature, will only have a minimal or nil impact on the bureaucratic typology of public management. Any effects that can be ascertained will affect the NPM model of governance arrangements that is currently in mode in the New Zealand context but will not go deep enough to affect the underpinning principles and tenets of the bureaucratic typology. Therefore, Weber's bureaucratic typology will be used in this research as a base framework against which movements in governance arrangements can be identified. This position will be developed further in the research design (Chapter 3). 


\section{Chapter 3: Research design and method}

\section{Chapter outline}

This chapter discusses the ontological premises that inform the research process, and the epistemological basis for the methodological choices made in conducting the research. The approach of the research is largely derived from a sociological understanding of the world as created and enacted by social actors, applied to the public management context (s3.1). To understand the transformational effects of egovernment on the NPM model of public governance used in New Zealand a qualitative research methodology is applied to the data gathering process to collect information on how senior decision-makers in New Zealand interpret e-government (s3.2). An analytical tool has been developed based on concepts of Weber's bureaucratic typology to identify where and how any transformational effects might occur in New Zealand's public management system (s3.2.1). The research data is collected by using selected case studies of current e-government initiatives (s3.4) and a series of focus group meetings on the future of public management in New Zealand (s3.5). In combination these provide a rich set of information from which to derive an understanding of the scope and nature of any transformational effects of e-government that may occur in New Zealand's public management system over the next twenty years.

\subsection{Ontology: Public management as 'institution'}

In this thesis e-government is being examined as a discrete public management phenomenon. The emphasis is on how public officials understand and use technologies to support public management activities including policy development, legislation and regulation setting, administration, service delivery and information management. This interpretive perspective ${ }^{11}$ highlights how public officials in decision-making positions, as agents of change, interpret and understand the e-government programme in relation to the wider public management context that both shapes and constrains the institutional environment in which they work. In this respect I am treating egovernment as a phenomenon that has been socially created and enacted by public officials and is therefore inherently social, rather than technical, in its manifestation.

\footnotetext{
${ }^{11}$ Based in the tradition of sociological thinkers such as Georg Simmel, 1907; Max Weber, 1922; and Alfred Schutz, 1932.
} 
In their seminal work in 1966, Peter Berger and Thomas Luckman argued persuasively that the genesis of knowledge is in understanding the actions of human beings as social actors who create and re-create their own social reality. They conceptualised social order as a human product, and an ongoing human production (Berger \& Luckman: pg 51). Over time, these creations of social reality are transferred as objective realities to future generations through the processes of habitualisation (i.e. repeated action) and socialisation (i.e. internalisation of the norms and values of society). Berger and Luckman describe this process of repeating social action so that it becomes interpreted by social actors as part of the base construction of their social fabric, as the basis of social institutions such as family and culture. "Any action that is repeated frequently becomes cast into a pattern, which can then be reproduced with an economy of effort and which, ipso facto, is apprehended [sic] by its performer as that pattern" (Berger \& Luckman: 1966: pg 59). Furthermore:

Institutionalisation occurs whenever there is a reciprocal typification of habitualised actions by types of actors ... any such typification is an institution. What must be stressed is the reciprocity of institutional typifications and the typicality of not only the actions but also the actors in institutions. The typifications of habitualised actions that constitute institutions are always shared ones (Berger \& Luckman: 1966: pg 60).

Thus, at the most abstract conceptual level public governance is a 'social institution' that is a specific example of social order experienced by public officials and the public as an objective reality. It is nevertheless an objective reality that acts upon, and is acted upon by human actors with the ability to change the nature of its objectivity by their actions. That is, public officials are engaged in a dialectic relationship whereby their actions are constrained and shaped by the externalities of the tradition within which they work, but at the same time those traditions can be shaped and modified by the ongoing actions of the public officials (Berger \& Luckman: 1966: pg 61). From this perspective, the decisions of senior public officials to implement e-government initiatives is subject to institutional constraints and at the same time contributes to shaping and modifying the public management environment. 
The notion of the dialectic relationship is important in that it presents the theoretical possibility of institutional change over time, and recognises that the behaviour of public officials is not necessarily determined by the institution itself. Rather, although public management is experienced as an external reality to both those working within government agencies and members of the public, it has been socially created and can be re-created by the collective action of all those people. Regarding public officials as social actors engaged in a dialectic process of interpreting and re-interpreting the institution of public management highlights the complexity of the decision-making process. Such complexity negates the adoption of a deterministic view of public officials acting only within the constraints of the institutional structure or its requisite functions. Rather, the structure of public agencies and their legislated functions are regarded as features of the social institution that can be deliberately and/or unintentionally changed by the actions of social actors, particularly those in the most senior decision-making positions.

It is an assumption in this thesis that within the institution of public management a wide range of operational practices take place that vary in their degree of adherence to the formal model of governance (refer Scott: 2004; Eppel et al: 2008). However, to materially alter the form and nature of public governance (i.e. for systemic change to occur) formal change processes must take place that result in substantive alterations to the documented regulatory and legislative frameworks that govern the actions of public officials. In New Zealand changes of this order can only be made through appropriate parliamentary processes, which rely on the actions of those public officials in decisionmaking positions with the requisite power and authority to recommend such changes to Parliament.

It is senior public officials who have the power and authority to influence the referent governance frameworks. In some cases policy and operational decisions made by senior officials (e.g. e-government investment and/or implementation) may only affect the substantive object of that action. However, senior public officials are also likely to have the experience, knowledge and expertise and be in a position to use their authority to have a material influence on the public management model within which they operate. Thus, “...man [sic] (...in his collectivities) and social world interact with each other. The product acts back upon the producer" (Berger \& Luckman: 1966: pg 
61). For this reason, public officials in decision-making positions in the New Zealand state sector have been selected as the research subjects. This selection presumes that the interpretation of e-government by senior public officials (s3.4 and s3.5) will influence (but not necessarily determine) their actions with respect to implementation decisions and thereby the nature and scope of the transformational effects in respect of public governance. This does not necessarily imply a causal relationship, but recognises that for systemic change to occur changes need to take place in either legislation, regulatory arrangements, accountability structures, fiscal controls and/or decision-making rights. Senior public officials are key decision-makers in respect of such changes.

\subsection{Methodological approach}

The methodological choices in this research have been made with a view to gaining an understanding of how e-government is interpreted by those with responsibility for its implementation, and thereby to gain some insight into the likely transformative effects on public governance that may accrue as a consequence. A qualitative approach to data gathering (s3.3) has been adopted that is consistent with the philosophical position of 'social reality' (Berger \& Luckman: 1966). This approach emphasises understanding complex, interrelated, or changing phenomenon and deals with it by taking account of the context within which it occurs (Morgan: 1997; Mittman: 2001; Patton: 2002; Yin: 2003).

The notion of 'transformation' is a complex one. In one respect it implies a mechanistic cause and effect relationship: thus, the New Zealand e-government programme is built on a premise that if state agencies use ICTs today to "...provide user-centred information and services and achieve joint outcomes" (www.e.govt.nz) then in the future (2010) the operation of government and (2020) people's engagement with government will be transformed (Programme goals: www.e.govt.nz). However, the desired outcome of 'transformation' is not defined in any concrete way: from what to what? What is encompassed in the "operation of government" and "people's engagement with government" is unclear therefore it is difficult to quantify or measure changes that take place. 
I have adopted a research epistemology by which I can acknowledge that e-government is implemented according to the interpretation of social actors thereby both constraining and shaping its transformational effects, and at the same time impose a theoretical logic on the research data to understand how the implementation of egovernment affects public management as a social institution. To clarify the transformational effects of e-government and identify where they might occur I am employing heuristic tools that highlight the inter-relationship between public officials' interpretation of public management and the external constraints of the governance model. To analyse the data I have developed an analytical tool based on the Weberian framework described in Chapter 2 (refer Fig 2) that provides a means by which to identify both where any possible transformational effects of e-government are likely to occur and if they do, what nature they are likely to be. From this, I can then assess what the likely systemic impacts on public governance may be (see s3.2.1 below).

It is important to note that in using qualitative methods for gathering data I act both as an external observer/ researcher, and simultaneously as a contributor to the research inquiry (Patton: 2002). In this respect, my choices in the research process influence and shape the data gathered. For example, my choice of questions, the way I word the questions, or the points that I choose to clarify as a researcher may all invoke different responses and trigger new thoughts and ideas from the participants. In this way, the research is in itself a dialectic process whereby I influence the research process, and my thinking and the thinking of the participants is influenced by it. The choice to run focus groups involved working interactively with participants to reach a common understanding about change in New Zealand's public management governance ${ }^{12}$.

\subsubsection{Analytical framework}

Institutional theory and the concept of technological enactment as discussed in the literature review (refer: s2.3.2 and s2.3.4) go some way to explaining the institutional pressures and constraints that act upon public officials to influence decisions taken in relation to implementing ICTs. In both cases, however, the focus is on explaining why

\footnotetext{
${ }^{12}$ In discussion, participants identified the research process as a continuous part of their own thinking. While contributing their own knowledge to the process, they simultaneously used the research questions and the interactive discussion and debate to expand and challenge their own viewpoint.
} 
change does not take place as quickly or as easily as might be expected. To understand changes in public management in New Zealand that can be attributed to the implementation of e-government initiatives an analytical framework is required that demonstrates where and how such change is occurring.

In the absence of an existing framework I have used the original Weberian typology of bureaucracy to create an analytical tool by which to track changes created by egovernment initiatives in the governance arrangements of public management in New Zealand. From the fourteen attributes that are described as the bureaucratic ideal type (Hopfl: 2006; refer Fig 2) I am using the four categories that encapsulate the most salient features of the bureaucratic model to identify where the transformational effects of e-government (if any can be determined) might occur:

- the management model (incorporating aspects of hierarchy and monocratic control of agencies and policy control of information resources)

- workforce characteristics (incorporating aspects of capability and HR regulations)

- record management (where electronic technologies can be expected to have a significant impact on traditional paper-based processes) and

- structure (as an indicator of changes in the systemic order).

To these I have added two further categories: 'leading discourse' and 'relationship management'. The former refers to the tenets and principles of public management in New Zealand. It has been included as a means of highlighting the underpinning rationale of the public management system and examining whether this can be shown to change over time. The 'relationship management' category refers to the way public officials manage a wide range of relationships including those within and across agencies and sectors of government, and those with external stakeholders. It is included as a means of comparing over time the working arrangements entered into by public officials in order to carry out their official functions. 
As a base-line I have used the analytical tool incorporating the six categories to describe the way that NPM is currently operating in New Zealand: ${ }^{13}$

Fig 3: New Public Management in New Zealand: ‘Managerialism’ 1989 - 2008

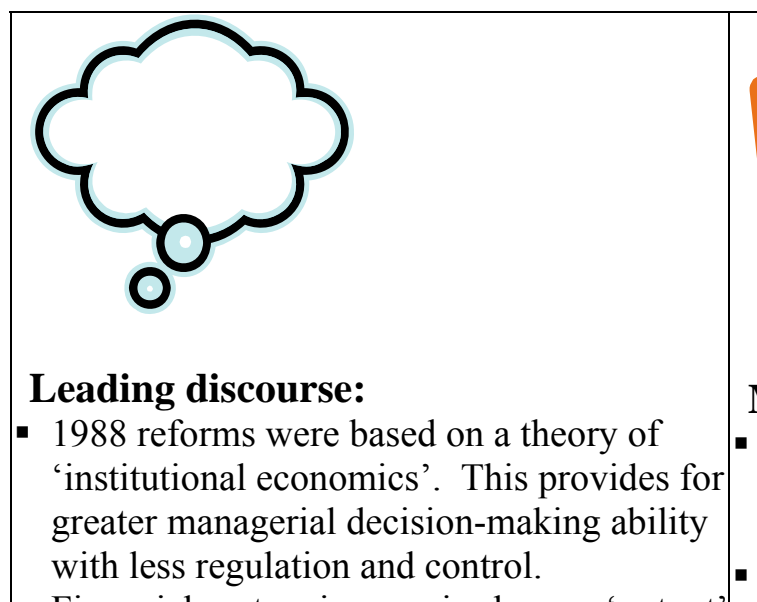

- Financial system is organised on an 'output' basis with accrual accounting practices common. There is an emphasis on government agencies providing fiscally efficient and effective services to clients/customers.

- Apolitical public service whereby officials are selected by impersonal recruitment procedures remains.

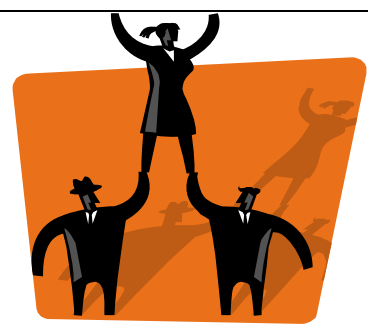

\section{Management model:}

- A clearly established hierarchical system of supervision by higher offices with a clearly articulated division of labour.

- Jobs are 'sized' and appointments made according to an assessment of competence against a scaled range.

- Promotion within specified grades is based on performance.

- Monocratic control both within the organisation (Departmental Head) and the public service (State Services Commissioner).

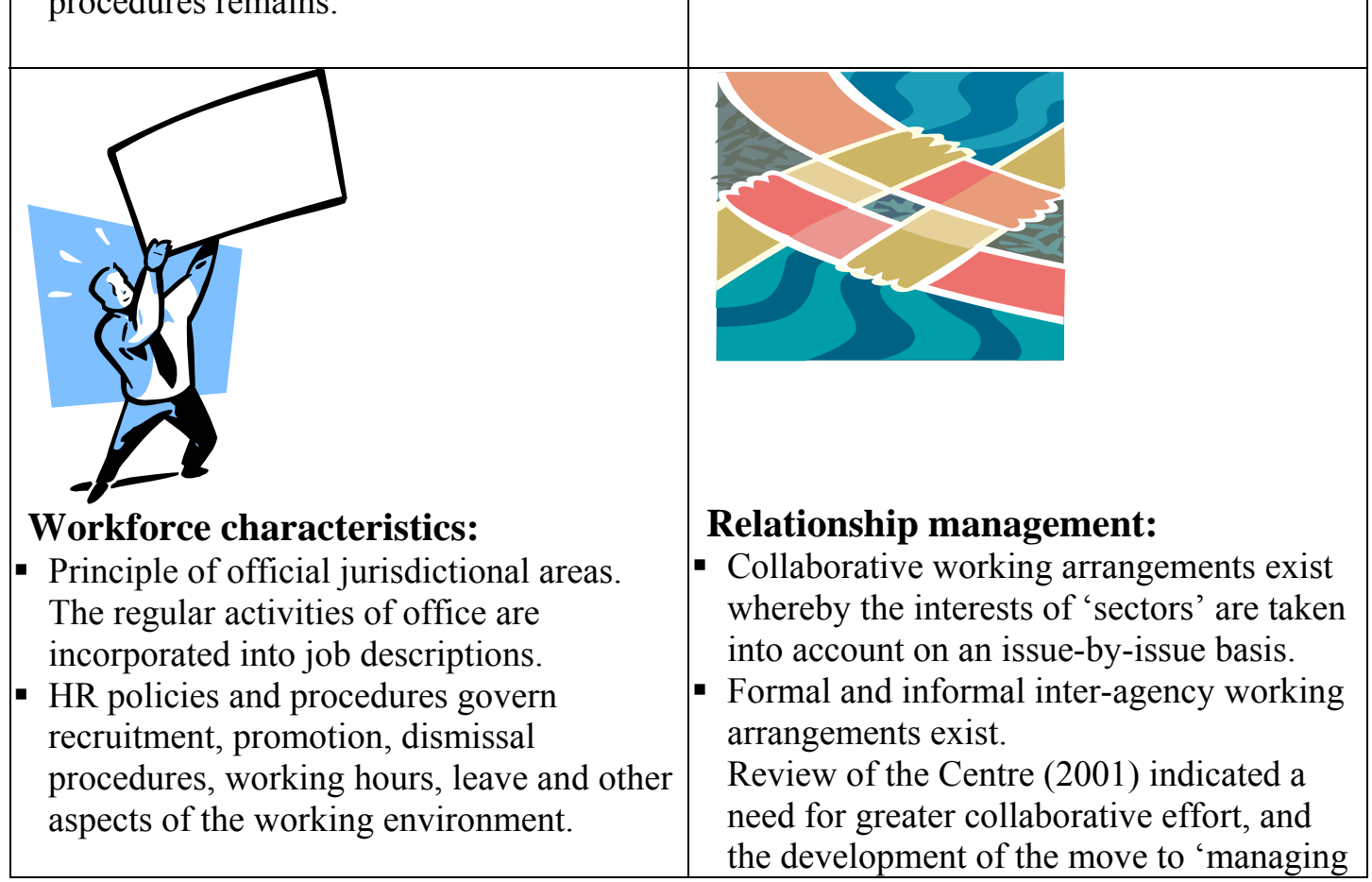

${ }^{13}$ This analytical framework has been informally tested with expert informants on the New Zealand public management system. That is, earlier versions were given to a range of senior public servants, public management academics and commentators to review. The final version was amended in accordance with feedback received. 


\begin{tabular}{l|l|}
\hline $\begin{array}{l}\text { These are developed at the departmental } \\
\text { level and allow for considerable flexibility } \\
\text { in working arrangements. }\end{array}$ & $\begin{array}{l}\text { for outcomes' emerged. This is led at the } \\
\text { most senior level. }\end{array}$ \\
- Recruitment is by open market competition. & \\
- At the most senior level appointments are \\
made on a fixed term contract basis. \\
$\begin{array}{l}\text { Other staff appointments can be made on a } \\
\text { permanent basis or under fixed-term or } \\
\text { other contractual arrangements. }\end{array}$
\end{tabular}

This analytical tool will be used in this research to categorise and compare specific changes identified as a consequence of e-government initiatives in the case studies (Chapters 4-6). It will also be used to categorise the material provided by focus group participants (Chapter 7) regarding their view of how e-government will affect public management in New Zealand in the future. Analysis will be undertaken to identify where and how the baseline (Fig 3) has changed, or may change in the future as a consequence of e-government implementation. If significant change can be seen to have occurred against several of these major features, then a case could be mounted to 
claim that systemic transformation has occurred. Changes to only one feature, or minor changes across several features, would indicate that instrumental transformation has occurred.

\subsection{Data gathering methods}

In order to gain an understanding of how the use of ICTs will contribute to change in the state sector in New Zealand over time, I have chosen to examine e-government initiatives that are taking place currently, and to also look at how things might occur in the future. The latter poses a number of methodological complexities because the future is difficult to predict especially when numerous variables contribute to potential outcomes. However, the notion of transformation conceptually and practically has a futuristic aspect to it and my ontological approach suggests that it is the interpretation of social actors in the here and now of their social reality that influences decisions which then have a consequential impact on the future.

On this basis the research involves two streams of data gathering with a view to gaining two sets of separate, but related, information that will jointly provide a rich picture of the operational effects of e-government implementation in the New Zealand state sector, and its transformative potential. The first stream of work uses current case studies (refer s3.4) designed to gather information about the interpretation of egovernment by public officials in decision-making positions with responsibility for implementing discrete operational technical initiatives. The second stream of work is based on focus group meetings (Patton: 2002; Yin: 2003) held to explore potential future public governance arrangements in New Zealand (refer s3.5). Participants in these meetings included public officials in decision-making positions, as well as public management experts (both academics and consultants) who contribute to thought leadership in New Zealand.

In both work streams a reflective mode of enquiry has been used, albeit in different modes. Data gathering has been formulated around heuristic methods that use open questions as opposed to focusing on more tightly, structured enquiries. In the case studies an open interviewing technique was used that started with a set of questions to be explored (Norman: 2003). It is the responses to these questions by key informants with expertise in their field of knowledge that provide a rich data set from which 
analytic induction is then applied to draw some preliminary conclusions. Norman (2003) refers to this as "a field of questions rather than answers" and posits that the reflective interview technique can be seen as "seeking a snapshot of realities as perceived by a representative group" (pg 48). The focus group discussions were also organised around a set of open questions designed to explore issues relating to changes in public governance (refer s3.5).

\subsection{Selection of e-government case studies}

An examination of the official register of New Zealand e-government initiatives (http://initiatives.e.govt.nz) ${ }^{14}$ was made to identify potential case studies. Over 512 different technology development projects are currently recorded on the register which is updated by officials in different departments on a voluntary basis. As a consequence the data is out of date (while some parts of the register were updated in March 2008, most were 2 years old). Nevertheless, this is the only register that lists e-government initiatives across all agencies in the New Zealand state sector in one place.

The e-government initiatives register indicates that there are 14 streams of work designed to deliver the goals of the e-government strategy (www.e.govt.nz). This demonstrates the scope of the e-government programme in New Zealand. The work streams are:

1. Delivering government services.

2. Enabling variety in delivery.

3. Adding value to information.

4. Providing authoritative data.

5. Delivering value for money.

6. Building standards and interoperability.

7. Building the foundational infrastructure.

8. Addressing collaboration.

9. Providing collaborative tools.

10. Fostering innovation and the use of technology.

\footnotetext{
${ }^{14}$ This site is closed to the public and can only be accessed by State sector officials. Permission to access the site on a one-off basis for the purpose of this $\mathrm{PhD}$ research was granted and organised by the ICT Branch, State Services Commission.
} 
11. Building ICT professionalism.

12. Enhancing public engagement.

13. Strengthening trust and security.

14. Managing the govt.nz space.

The range of initiatives within each of these categories is wide and varied. They include amongst others 110 initiatives listed as 'online services', 72 listed as 'website redevelopment including blogs and wikis', and 26 as 'Web 2.0'. Generically, I have summarised the initiatives as each contributing to one of the following five categorises:

1. Improving government service delivery (work streams $1 \& 2$ ).

2. Improving information management (work streams $3 \& 4$ ).

3. Building appropriate infrastructure to support ICTs (work streams 5 - 7).

4. Improving state sector capability and knowledge management (work streams $8-11)$.

5. Enhancing the interface between government agencies and the New Zealand public (work streams $12-14$ ).

Of these, initiatives in categories 1,2 and 4 fall within the ambit of my research interest. It is the implementation of these categories of e-government that can be expected to demonstrate if the transformational effects as specified in the New Zealand e-government strategy goals occur or not. Building the technical infrastructure (Category 3 ) is a pre-requisite for such initiatives to take place but in itself is limited in scope and nature and therefore in its effect on governance. The initiatives relating to the public interface (Category 5) may also have a transformational effect on public institutions but as argued in s1.1.3 are outside the scope of this research. The focus of this research is on understanding the governance arrangements of public institutions as a foundation on which to build a future understanding of the transformational effects of interactions between members of the public and government agencies.

Because of the likelihood of being able to ascertain a transformational effect, the categories from which to select case studies for the research was restricted to those of service delivery, information management and knowledge management. The criteria for selection from each category included that the initiative be: 
- operationally significant to the initiating state agency and its clients

- implemented in the past 5 years

- of relevance to a broad range of stakeholders such as government to citizens (G2C), government to business, cross sector and state sector

- an example of advanced technical capabilities, and

- able to demonstrate a reasonable degree of technical and business maturity and diversity.

With respect to the service delivery and information management categories a number of initiatives fit these criteria. Four possible service delivery case studies were identified (Land Information NZ, Inland Revenue, Customs and Internal Affairs). Three possible case studies were also identified in the information management category (Justice, National Library and Education). In order to gain as deep an understanding as possible of the interpretation of e-government, I made a choice to select only one example from each category and to concentrate on obtaining in-depth information regarding each case. Therefore, of the options available in each category initiatives in Land Information NZ and Justice were prioritised as they had the added advantage of well documented information on the genesis and implementation of the initiative, and were examples of government initiatives demonstrating how egovernment was deployed with respect to government to business, and on a crosssector basis.

The knowledge management category only had one existing initiative that met the broad stakeholders (state sector wide) and advanced technical capability criteria. The Public Sector Intranet (PSI) is an initiative that is much less technically mature than the other examples selected as it is currently still in an early initiation phase, and subject to ongoing development. The requisite business processes that support the application are similarly immature. However, the scope of the initiative and its potential for having a wide-ranging impact on the collaborative working patterns of public officials over time warranted its inclusion in the research.

The case studies selected cover a range of organisational arrangements: government to business; cross sector and state sector. They also cover a range of aspects of e- 
government that might be expected to contribute to any instrumental and/or systemic transformation of governance. As such, while each initiative is unique in its purpose, design, and implementation, it also makes a contribution to the national e-government strategy with its explicit goal of "... transforming the operation of government by 2010" (www.e.govt.nz). The selection of case studies for this research was:

(i) Service delivery (Government to business): Land Information New Zealand (LINZ) - the online registration of land titles and land survey data

(ii) Information management (Cross sector): Justice Sector Information Strategy (JSIS) - a cross agency initiative for sharing and managing information

(iii) Knowledge management (State sector wide): Public Sector Intranet (PSI) - a state sector wide initiative for sharing information, resources and knowledge.

Detailed descriptions of these initiatives and the organisations in which they are located are provided in the chapters setting out the empirical data gathered (Chapters 4-6).

This research makes no comment on the design, development or implementation of each initiative itself, but rather looks at the effect of the implementation on the organisational relationships with end users to see if transformational effects have occurred. In this respect, the data gathering is designed to generate information on the interpretation of the key decision-makers involved in each initiative as to:

- the positive and negative contributions of the initiative to the host organisation

- the relative contribution to the e-government programme

- its substantive impact on end-users and on the agency/client relationship, and

- any changes (instrumental or systemic) they intended, or observed as a consequence of the initiative implementation. 


\subsubsection{Selection of interview candidates}

In December 2006, email contact was made with the chief executives of Land Information New Zealand, the Ministry of Justice, and the Director of the EGovernment Unit in the SSC to seek permission to contact senior managers involved with the Landonline, JSIS and PSI initiatives. In all cases, agreement was provided by return email and the chief executives and E-Government Director nominated agency contacts to arrange the interview process. The JSIS initiative is a cross-sector initiative and therefore the Chief Executive advised that further permission would be required from the JSIS Governance Group. This was subsequently obtained.

In all three cases, the nominated agency contact within the individual departments identified the relevant senior managers to participate in the research. A total of nineteen interviews were completed with senior managers who were closely involved with the design, implementation and/or maintenance of each initiative. In the case of LINZ and SSC all senior personnel involved with their respective initiatives were approached by the nominated agency contact and agreed to be interviewed (seven LINZ personnel and five from SSC). With the JSIS Governance group, several senior managers from each agency were involved with the initiative. In this case, each agency nominated those senior managers to participate who had roles that were critical to the initiative implementation. This included four representatives from the Ministry of Justice who had made major individual contributions at different stages of JSIS development, and one senior manager from Land Transport New Zealand, Corrections and New Zealand Police, bringing the total JSIS contributors to seven.

\subsubsection{Data gathering process}

Background information and details of development and implementation for each of the three initiatives were gathered from existing case studies (Patton: 2002; Yin: 2003), ${ }^{15}$ agency policy documents and academic papers. These were examined to provide background context and to establish the stated objectives of the initiatives as a basis from which to understand the information provided by the interviewees.

\footnotetext{
${ }^{15}$ Information sources included ANSOG Case Studies; www.e.govt.nz/resources/; and internal case material provided by officials.
} 
Every e-government initiative differs according to the environment in which it is initiated, the resources available to implement it (people, time, funds and expertise), and the purpose for which it is intended. In this respect, the interviews were conducted to elicit information on the interpretation of public officials of the context in which they are implementing technical changes. The interpretive perspective excludes the possibility of generalising any of the information regarding a particular initiative to others of its own type (e.g. a land register initiative cannot be compared to a companies register initiative because although both are service delivery initiatives each one is unique in its purpose, technical complexity, stakeholder involvement, scale and scope).

Each interview was based on a set of discussion points allowing the respondents to share information, ideas and perceptions based on their experience of the initiative they were involved with, and their understanding of the broader state sector context in which it was delivered. The discussion prompts covered the incentives and drivers of government investment in ICT initiatives, the constraints and opportunities of the state sector environment, and the perceived outcome of the initiative under discussion.

Feedback processes were organised with LINZ and JSIS officials where they had an opportunity to provide further input. The feedback session was also used as an opportunity to ensure that the analysis resonated with the respondents at a generic level. Officials interviewed in relation to PSI did not wish to avail themselves of a feedback session.

\subsection{Future public governance scenarios}

The focus group method was selected to explore future public management governance models on the basis that the process of groups interacting together generates ideas and discussions over and above what an individual might contribute through a more passive method of data gathering such as a Delphi Group or computer assisted discussion threads (Morgan: 1996, 1997; Mittman: 2001). I was seeking to gather data that reflected the generalised view of a group of well-informed and knowledgeable participants. In using focus groups, I have contributed to shaping the research process in setting the parameters of the topic for discussion and directing the type of data gathered. In this respect focus groups are “... a research technique that collects data through group interaction on a topic determined by the researcher. In essence, it is the 
researcher's interest that provides the focus, whereas the data themselves come from the group interaction" (Morgan: 1997, pg 6).

\subsubsection{Selection of focus group participants}

Participants in the focus groups were a mixture of senior public officials and thought leaders (academics, consultants and private individuals with significant state sector experience) in New Zealand. Invitations to participate were issued on the basis of professional knowledge or expertise in the area of public management and/or egovernment in New Zealand. All of the participants were actively engaged in a process of thinking about, or dealing with, issues of public management that were pertinent to this research endeavour. A total of thirty-six people participated in the focus groups.

\subsubsection{Focus group meetings}

The focus groups were held in November 2007 on the Victoria University campus, on consecutive days. The meetings were of three and a half hours duration each and were structured to provide participants with information about the research and to elicit structured discussion on a number of key questions (See Appendix 3 for focus group format).

Pre-readings ${ }^{16}$ were prepared for the participants as a way of ensuring that all participants had a core information set and were appraised of the key interests of the research. The first set of papers provided described the changing forms of the public management system in New Zealand over two twenty-year periods: 1968 - 1988 (preNPM: Command \& Control); and 1989 - 2008 (the current NPM system). These periods were chosen based on the enactment of the State Sector Act, 1988. This is seen in the literature (Boston et al: 1996; Schick: 1996; Scott: 2001; Norman: 2003; Walters: 2008) as a defining milestone in the history of New Zealand's public management and therefore was selected as a relevant starting point for discussing New Zealand's current public management arrangements. For each of these periodisations the predominating public management model during that time was described using the Weberian analytical tool described in Fig 3. This demonstrated the substantive changes over time in public management governance in New Zealand.

\footnotetext{
${ }^{16}$ The full set of pre-reading materials, including the details of each of the scenarios is provided in Appendix 2.
} 
The second set of papers focused on the twenty year period from $2009-2028$. This was selected as a future period where potentially a new form(s) of public management could predominate. Possible future scenarios were created from current technological debates, as set out in the literature review (s 2.3.3). Again, each scenario was described using the Weberian analytical tool (Fig 3). A summary of the scenarios is provided in Chapter 7, and details of each model can be found in Appendix 2.

In constructing future scenarios, care was taken to avoid specific predictive elements, especially with respect to the future deployment of particular technologies. The current rate of technical development is so rapid that such speculations were seen to be of limited value, and more likely to distract participants from the focus of the research. Rather, the Weberian framework served to provide both a descriptor of the operational model of public management used in each period, and to highlight the often subtle similarities and differences between the various forms of bureaucracy that might emerge as a direct response to the development and implementation of sophisticated new modes of ICTs.

In addition to the public management scenarios, participants were provided with a table of emerging trends in public management identified from current literature (Dunleavy et al: 2006; Bozzelli: 2007) and recent conferences held in New Zealand on public management ${ }^{17}$ to stimulate discussion on areas of future change. The discussion points used to shape the focus group discussions are set out in Chapter 7 (refer 7.1.1).

A follow-up session was held in April 2008 to provide participants with a summarised version of all of the data gathered from the focus groups. A structured presentation was given by the researcher followed by open discussion. This session was used as an opportunity to test the preliminary analysis of the data and to generate more substantive input.

${ }^{17}$ Government Insights Conference: Wellington, NZ, 2007; Driving Government Performance Conference: Wellington, NZ, 2007. 


\section{Chapter 4: Case Study 1: Service delivery}

\section{Introduction to case studies}

The case study material has been organised into three chapters (4-6) for clarity purposes. Each chapter will start with a brief outline of the e-government initiative and the agency context within which it has been developed (s1). The material from the interviews with senior public officials involved in the design, development and implementation of each respective initiative will be presented (s2). The interviews ${ }^{18}$ provide information on how the senior managers interpret the contribution of egovernment to their organisations and the wider state sector (refer 3.4). For ease of reading the interview material has been arranged around the subject areas of investment drivers, expected benefits, opportunities and constraints, outcomes and transformation. The information set out in s2 will then be drawn upon using the Weberian analytical tool developed in s3.2.1 (Fig 3) to gauge where the transformational effects, if any, can be seen to occur with respect to the public management framework in New Zealand (s3), and what its nature is (s4).

\subsection{Land Information New Zealand: Agency context}

Land Information New Zealand (LINZ) is a government agency with responsibility for providing authoritative land and seabed information including boundary definitions and titles of property dealings (www.linz.govt.nz). The agency manages over 30 million land records (LINZ: 2007/08). This includes information on all private land surveys and ownership, topographic maps and nautical charts as well as information on Crown land interests.

In addition to its informational services LINZ oversees the buying and disposal of more than two million hectares of Crown land (i.e. approximately eight percent of the New Zealand land area). Such land ranges from large pastoral leases to forests held in trust for Treaty of Waitangi ${ }^{19}$ claims and small plots of land (LINZ: 2007/08 pg 12). The

\footnotetext{
${ }^{18}$ Quotes will be used in presenting the interview material but in all cases these are not attributed in accordance with the agreements made with research contributors. A system for identifying subjects by category (e.g. senior manager; client manager etc) has also not been used as all of the senior managers involved with each initiative were interviewed, and the numbers are so small that individuals could be identified.

${ }^{19}$ The Treaty of Waitangi is New Zealand's founding document signed in 1840. It is a legal
} 
agency also ensures that the national land rating valuation system is fair and consistent (www.linz.govt.nz). LINZ provides information and transactional services to businesses and other government agencies, and provides geospatial information to the New Zealand public via the Internet (www.linz.govt.nz).

\subsubsection{Landonline: History of the initiative}

In April 2000 LINZ launched a project (Landonline) to develop and implement a secure, reliable electronic means of disseminating digital land information and processing survey and title transactions. Accurate and reliable land information provides members of the New Zealand public with secure property rights. This contributes to economic growth by providing individuals and businesses with "confidence and incentives to innovate and remain productive" (LINZ: 2007/08: CE's overview). Movement from manual systems to digitisation of New Zealand's land and seabed information is regarded by LINZ officials as part of the process of continuing to gain efficiency and protect New Zealand's information assets (Case study: www.e.govt.nz/resources).

The technical capability of Landonline is complex. It involves interactive databases that bring together geodetic information (i.e. a network of survey marks covering New Zealand) and cadastral survey plans that define the spatial positions of land parcels together with land title records. These databases have been created by converting to a digital form all of the existing paper-based land titles. This involved the conversion of over 7 million physical records, survey plans and records of land titles dating back to 1840. Seventy percent (approximately 1.4 million) of the existing survey plans were also converted into the databases. ${ }^{20}$

The approval processes for survey plans and issuing of land titles are automated within Landonline (ANZSOG Case study: 2006). The new digital system provides a secure, ${ }^{21}$ real time environment enabling surveyors and lawyers to electronically lodge routine

contract between the British Crown and New Zealand Maori setting out agreements regarding sovereignty and specifying rights of ownership of land, forest, fisheries and other possessions. Refer www.nzhistory.net.nz

${ }^{20} 30 \%$ of the survey plans were excluded because they were too old or were unreadable or in a damaged state due to age and poor preservation.

${ }^{21}$ A multi-layered security system is used for Landonline including digital certificates and Public Key Infrastructure (PKI). 
land transfers (e-dealing) and survey transactions (e-survey), and to electronically search all of these records (ANZSOG Case study: 2006). Uptake and implementation of Landonline has been incremental, and all processes related to land survey and titles were planned to be fully automated during 2008 (Jacobsen: 2007).

Using Landonline has reduced title processing time for land buyers from three weeks to real-time. That is, land purchasers can now leave their solicitor's office with a copy of the title in their hand. Theoretically the cost of the transaction has significantly reduced although there is no empirical evidence available to date that demonstrates that solicitors are passing this saving on to their clients.

Title searches can now be done online and consequently some public counters and LINZ offices were closed as Landonline rolled out throughout the country. Local offices were replaced with five regional offices, and by the end of 2008 it is planned to have replaced the regional offices with two national centres dealing with residual customer queries. These office closures represent radical structural change for LINZ as an organisation (112 staff positions will be phased out by 2010). The closures also reduce the cost of operating LINZ as a government agency without losing efficiency and service to the public.

\subsection{Landonline interviews}

\subsubsection{E-service delivery drivers}

There was a high level of consistency amongst the responses from the senior managers interviewed about what they perceived as the key drivers for e-service delivery, and for Landonline in particular. This high level of uniformity was not unexpected given the strong official documentation setting out the business case and justifications for the Landonline initiative which all of the respondents, in their capacity as departmental senior officials, could be expected to be familiar with (www.linz.govt.nz; www.e.govt.nz; LINZ Statement of Intent: 2007/08; unpublished departmental documentation relating to the Landonline initiative). The responses were also reflective of the state sector environment and the relationship between the agency, the professional organisations they service, and the New Zealand public. 
All respondents indicated that the key driver of e-service initiatives within government is decreasing transactional costs. They indicated that LINZ is a zero surplus business: "there is no profit and no loss". Therefore, the emphasis was on driving costs down at all points of the transactional process. Respondents saw this as in keeping with the overall focus by managers in government agencies on improving process efficiency to ensure that there are faster, consistent, and more reliable transaction processes available to a range of users at greater convenience and less cost. In the case of Landonline respondents saw the initiative as being about providing LINZ customers with greater consistency and transparency of process, i.e. clients get the same response each time they interact with LINZ and know what to expect.

Respondents indicated that the efficiency driver for LINZ officials was also about providing certainty of property status:

The gain to government is greater certainty. There is an assumption that on an electronic system the risk of alteration, loss, or damage is less than on a paper-based system.

In this respect having an undisputed, authoritative land record was regarded by respondents as providing value to the New Zealand public and users. Customers receive a higher quality service and issues of fairness and equity are overcome by 24/7 availability of records to the public. Respondents pointed out that in New Zealand land title is guaranteed by the Crown, therefore there is a Crown responsibility to provide the highest quality and most secure land record system possible. Digital records were regarded by respondents as being about the "maintenance of the guarantee of title in perpetuity".

Logistical imperatives were also seen by respondents as a driver for e-service delivery in the LINZ case. Managers faced a practical problem of physically preserving the paper-based national historical record particularly original surveys, hand drawn plans and surveyors' log books. These needed to be preserved. One respondent described the problem as a "paper war". Respondents regarded the physical security of land records as a long-term benefit accruing to the public. 


\subsubsection{Expected benefits of e-service delivery}

Respondents saw a number of generic and agency specific benefits to e-service delivery. In the first instance they identified addressing machinery of government issues as a major benefit. The policy and regulatory functions of LINZ were separated "for the purpose of future outsourcing". That is, operations could be transferred to other organisations within government in the future. In general, digitisation of services was seen by respondents as assisting with the process of removing government from private business space, i.e. minimising the regulatory environment and "asking professional bodies to look after themselves". The regulatory environment was described as needing to be "as much as is necessary and as little as possible". In the case of LINZ this applies to surveyors and conveyancers. LINZ has traditionally had a strong regulatory responsibility in respect of these professions. The digitisation of land title and survey processes enabled a move away from regulation to standards setting.

Respondents also saw e-services as a means of enabling government to work digitally in a digital age. They perceived there to be a pressure on governments internationally to be able to transact business globally in a digital mode. New Zealand is responding to this pressure by digitising its information services. This position was summarised by the view of one of the respondents that "if we hadn't done it already, we would be under pressure to do it now".

Providing disaster recovery options for land records was also identified by respondents as a specific benefit to LINZ of the Landonline initiative, and a general benefit to government from e-services. In the case of LINZ digitisation enables the same land title record to be held in two places (or more) at the same time thereby protecting it from natural disasters (e.g. earthquakes) or technical failure (e.g. electricity disruption).

On a practical level respondents also saw the sharing of knowledge amongst colleagues as a major benefit of the process of developing e-services. In developing Landonline officials examined similar technical initiatives in other countries to learn from them. One example offered of how this benefited the initiative was that the Australian digital land title system demonstrated that the implementation of relational databases provided additional benefits that could not be obtained by mainframes. New Zealand officials used this information to implement relational databases thereby providing a higher 
quality system with greater capability and longevity. These types of information exchanges assisted with the implementation process and reduced the likelihood of errors.

Nevertheless, respondents acknowledged that some decisions were taken that in retrospect had not produced all of the expected benefits. For example, the technicians interviewed were of the view that infrastructure would have been better with a 3-tier survey system, rather than the 2-tier one that was implemented. The 3-tier system is a more integrated and less 'clunky' application. However, respondents indicated that this decision was based on the best information available at the time and upgrading such features would depend on the availability of future funding.

\subsubsection{Opportunities and constraints}

Respondents were asked what they saw as the particular considerations senior managers had to take into account in decision-making (opportunities/ constraints) when developing and implementing service delivery innovations such as Landonline. This part of the interview drew a much broader range of responses amongst respondents.

The substantive management 'issues' mentioned by respondents included managing the project environment well and ensuring that there was effective change management, training, and stakeholder management processes in place. Respondents noted that quality, system reliability and consistency of technical support and service were required in order for customers to have confidence in the new technical application before they agreed to use it for business purposes. A virtuous cycle had to be created. Software releases had to happen on time, and the supporting infrastructure had to work for the trust equation to be built with the communities of professionals who were going to use the system.

Respondents also indicated that there was a constant demand for effective change management as the business processes changed. As Landonline was rolled out public offices were closed and this had a substantive impact on staff. This however, was also seen by respondents as one of the major opportunities resulting from the development of an e-service initiative in that different skill sets were required in the workforce of the organisation as digitisation became the predominant mode for all business processes. 
The human resource prerequisites within the industry were seen as changing: "we need people with higher education ... and people with complex knowledge”.

Extensive training was required for both LINZ staff members and professional users of the system. The professional culture of the users, particularly lawyers and conveyancers was not understood by LINZ officials and this was perceived by all respondents as one of the major contextual issues that had to be carefully managed. This is summarised by one respondent as follows:

The focus was not on the customers, it was on the transaction. It was on the types of documents and processes that could be converted to an interaction basis (how things were done), rather than who the customers were, and what their drivers were. There was a belief that the people who signed the documents were the customers, when in fact they were not.

Because of the private sector/ public sector interface respondents indicated that effective stakeholder management and participation were required. LINZ also had to manage the budget expectations of the potential future users, and it was necessary to anticipate and manage the effects of lobbying groups. The organisation had to strive to develop a culture of understanding in respect of the vendors and the customers. Respondents noted that most of the revenue generated by LINZ came from the conveyancing community and therefore they saw the incentives for the industry to engage with the surveyors as being too low. In their view traditional methods of marketing (influencing uptake via discounting versus increasing the price of one channel over the other) were not effective, and this in part contributed to very low levels of voluntary uptake.

\subsubsection{Landonline outcomes}

Respondents were strongly of the view that while LINZ customers received a number of benefits from Landonline (higher speed, lower costs and greater consistency of service) the initiative was primarily about the needs of the organisation itself. The development and implementation of Landonline was done from the perspective of what suited the organisation, as opposed to the needs of the customers: "LINZ saw it as more important to change the customer than their own business”. Respondents 
indicated that organisational efficiency was assumed by officials to be a general good for all parties to the transaction, but this was not tested and verified. This view was highlighted by one respondent who held the view that:

In Landonline, no-one brought the customer into the vision. In the [public] service the needs of the organisation come first, not the needs of the customer. Driving costs down was the sole driver for government investment in technological innovation. It was not value or 'public good' based. If so, it would have been more holistic.

Landonline was seen by respondents as having been developed as part of a broader policy agenda of maximising operational efficiency and enabling the separation of policy and regulatory functions to position LINZ for future machinery of government modifications (i.e. absorbing the various functions of LINZ into a larger government organisation).

One of the outcomes that respondents highlighted was the collective benefit to other government agencies of the technical developments involved in Landonline.

Respondents noted that LINZ is not the single repository in government of all land information. New Zealand Police, the departments of Conservation, Customs and Internal Affairs as well as the ministries of Research, Science and Technology and Economic Development along with other non-government organisations all hold different sets of information relating to land and the seabed. There are a number of interdepartmental work areas (e.g. geospatial - National Address Register; Oceans 2020) involving geospatial information systems that are able to leverage off the applications developed for Landonline. Respondents saw this as providing cumulative benefits to government across the sector.

\subsubsection{Transformation}

Landonline respondents did not claim transformational outcomes for the initiative. As indicated, they saw Landonline as simply providing an electronic channel for an existing procedure without changing the business process, or the customer relationship. They indicated that in instigating the initiative LINZ and the professional bodies (Law Society and the Survey Association) had the attitude of "build it and they will come 
because the benefits will stare them in the face”. However, the implementation process highlighted the situation as more complex than expected by officials.

Respondents indicated that in designing Landonline LINZ officials failed to understand the supply chain. The benefits to the professional users assumed in the business case were actually proven to be incorrect because all parties in the transactional process had not been properly identified. In many cases title searches were outsourced by conveyancing firms for tax purposes to specialist search companies. These companies were effectively going to be put out of business by the implementation of Landonline, and the conveyancing firms who used them would lose a tax advantage. As a consequence, there were inadequate incentives for voluntary uptake of Landonline by conveyancing firms. LINZ had to move to make online lodgement compulsory in order to recuperate the development costs of the initiative.

The respondents were very conscious of the 'transformation' expectation surrounding the Landonline initiative. Their overall view was that digitisation did not simplify, or even alter, the land registration process. It only made it electronic thereby changing the delivery channel. In this respect:

It is possible to manage the process as always - only lodge electronically. The organisational structure, values and culture have largely remained unchanged.

Respondents described Landonline as a "single-point intervention". That is, it is doing the same thing via a different delivery channel and in that sense respondents did not regard Landonline as having transformational potential either within LINZ or across the state sector:

A customer approach would be transformational, but that requires system thinking rather than single point intervention. Doing the same thing, but doing it differently ... This is not transformation.

While they acknowledged that some structural features of LINZ were altered (e.g. closure of offices; reorganisation of some workforce groups), they saw these changes 
as being accommodated without any impact on the legislative mandate of the agency, or affecting the managerial principles of public management under which they operate. The following comment sums up the general view of respondents in relation to the nature of Landonline: "It is transformation when technology can enable you to do things that you couldn't do before. That is not the case with Landonline".

Respondents thought that transformation for LINZ, and for government agencies across the board, would come when, and if, "they interact with their customers differently". Some respondents suggested that the current managerial emphasis on fiscal efficiency should be replaced with an economic framework that is about 'creating wealth' for New Zealanders. Their view was that if the state sector is to handle public money efficiently and effectively then there is a need to find ways of creating value and longterm wealth for New Zealanders.

In addition, respondents believed that a serious financial commitment by government to the development and deployment of e-government initiatives is necessary if transformation of any nature is to occur. They indicated that they saw a need for a set of priorities to be established within an all-of-government roadmap that was politically supported and sufficiently resourced. Respondents queried where the leadership and stewardship of the 'big picture' was coming from: "Who are the stewards responsible for maintaining the basic government infrastructure?" They suggested that the context for e-government development should be within a broad discussion about the purpose and role of government and the best way is to use public funds to deliver services to the public.

\subsection{Identifying where Landonline transformational effects occur}

The interpretation of the Landonline initiative by LINZ senior managers can be organised using the categories set out in the Weberian analytical tool (refer s3.2.1): leading discourse; management model; workforce characteristics; record management; relationship management; and structure. This organisation of the material will start to build a heuristic model for understanding how Landonline has been enacted by public officials, and therefore what its transformational effect has been, and where this might be seen in the public governance framework. The base-line established in s3.2.1 (Fig 3) will provide a framework for identifying where change is occurring. 


\section{Leading discourse}

The LINZ senior managers interviewed provided three ways of explaining the implementation of Landonline. Firstly, improving economic efficiency by driving organisational transaction costs down was identified as the single, most important driver of the initiative. Respondents saw this as being a responsibility they have as public managers under the Public Finance Act, 1989.

Secondly, Landonline was seen by respondents as necessary to maintain New Zealand's ability to compete in a global economy (i.e. to maintain effectiveness). Respondents argued that the digitisation of the land record system made a critical contribution to New Zealand's ability to participate in the global economic market. There was a common view amongst all respondents that digitisation is part of the modern way of conducting business and that it is imperative that the infrastructure, systems and business processes to operate in this manner are developed and implemented if New Zealand is to keep up with international progress. Respondents thereby perceived the process of making land records available online to businesses and the New Zealand public as inevitable as it is a sound economic proposition.

Stewardship of New Zealand's core economic assets was the third explanation respondents gave for the implementation of Landonline. Respondents saw themselves as stewards of the public record with a responsibility to ensure that the business processes of their organisation kept abreast of the new economic sphere by the utilisation of modern technological capabilities. As one respondent noted, "The commercial equation is not relevant to the 100 year benefit to New Zealanders. It is simply not feasible for the paper-based record to continue in the digital age”.

All three of these explanations are consistent with the current NPM discourse of institutional economics with its emphasis on government agencies providing fiscally efficient and effective services to clients/customers (Fig 3).

\section{Management model}

LINZ officials indicated that Landonline did not alter the management model of the organisation. They saw the initiative as a "single point intervention" designed to 
modernise business process and was well within the bounds of managerial discretion and independence afforded chief executives under the current model of public management operating in New Zealand. Respondents also indicated that the implementation of Landonline better positioned the department to be amalgamated with broader economic interests of government in the future. In this respect, the implementation of Landonline has no substantive impact on this aspect of the public management model (refer Fig 3: s3.2.1).

\section{Workforce characteristics}

A change in the nature of the workforce was one of the outcomes that LINZ senior officials saw as a direct result of the implementation of Landonline. There were not only significantly fewer staff in LINZ as Landonline was rolled out, but the remaining staff were deployed on tasks requiring greater specialisation and different types of expertise. In this respect there has been a change in the core competencies of staff within the organisation. People with higher levels of computer skills are now required in the workforce than under the previous manual regime. The new digital business processes requires less discretionary judgment by staff, and tasks involve a higher level of data quality control.

It should be noted however, that while the range of capabilities that may be required in the LINZ workforce has changed, the HR policies and procedures by which the labour force is recruited and administered has not been affected. In this respect, the base-line model (Fig 3: s3.2.1) remains unchanged.

\section{Relationship management}

Respondents pointed out that while the business transaction processes for survey and land title transactions have been significantly modified with respect to channel, data quality, speed, and cost the legislated regulatory relationship between LINZ and their primary (lawyers and surveyors) and secondary (end-users) customers remains unchanged. LINZ has the statutory power to implement business process change, even where this involves significant cost to their business stakeholders. Although there were demonstrable benefits to end-users (land buyers and owners) in terms of speed and consistency of transaction processing, respondents indicated that there were also considerable costs to customers (in particular, law firms and surveyors) in compliance. 
Officials saw cost-shifting away from government to the private sector as a significant latent outcome of the initiative.

Furthermore, there was a clear indication in the interviews that all of the respondents were aware of the coercive nature of the regulatory relationship with their industry clients and were conscious of the fact that Landonline, although done as co-operatively as possible, was nevertheless a change that was imposed by LINZ as a government agent on conveyancers and surveyors. As indicated in the discussion on Landonline outcomes, respondents were conscious of the organisational-centric nature of the initiative and noted the compliance costs to clients. The long-term plan is to close all other channels over time in order to ensure that the business and financial benefits to government are realised.

On the other hand, the relationship between the government and professional bodies has become less prescriptive. LINZ has used their regulatory powers to set industry standards and the role of professional monitoring is now carried out by the professional bodies. While this movement represents a change in practice, it has no substantive impact on the regulatory positions (e.g. Registrar General; Surveyor General; Valuer General) established by legislative mandate.

\section{Record management}

Landonline has changed the form of record keeping in LINZ, but the same information sets are still being recorded. Respondents described Landonline as a modern, technological solution to a significant problem facing LINZ officials as the stewards of New Zealand land records. The existing paper-based system had an inherent problem that needed to be solved. It did not provide long-term physical protection of land records and was space hungry.

Over time this problem was simply going to get worse. Historical, hand drawn, survey records in particular were becoming fragile and increasingly likely to be damaged beyond repair by repeated handling. The conversion of paper records to an electronic form was seen by respondents as timely and critical to protecting the physical land record, and thereby the long-term interests of New Zealand citizens. At the same time, it provided a practical solution to an organisational dilemma. While record keeping 
practices involve storage of the same data sets, these are now held digitally thus overcoming the space management problem. Multiple copies of records also provide more low cost disaster recovery options. Again, these changes to record management practices within LINZ do not change the base-line model where record-keeping is a core requirement of public organisations (Fig 3: s3.2.1).

\section{Structure}

The physical structure of LINZ has been significantly changed as a consequence of the Landonline initiative. There are fewer physical offices with a much lower level of interaction with the public. As a consequence there is also fewer operational staff carrying out administrative tasks, processing lodgements or dealing face to face with clients. The transaction process has also been structurally altered with the removal of title search companies from the supply chain. Nevertheless, no structural change has occurred at the macro-level. LINZ continues to exist in the same form as that prior to the Landonline implementation, and to maintain the same legislative and functional relationship with its clients.

\subsection{The nature of Landonline transformational effects}

Landonline provides efficiency benefits to LINZ as a government regulatory agency and to the legal and surveying industries. It also provides benefits to the New Zealand public. For example, core paper records including historical hand-drawn survey maps dating back to the mid- $19^{\text {th }}$ century can now be archived as national records and removed from public use, thus ensuring their long-term preservation. There are also intangible benefits that accrue from the initiative. For example, the digitisation of land title records facilitates New Zealand's ongoing participation in an increasingly digital global economy. Landonline is a technically complex electronic imaging and information system that provides faster, more reliable, and cheaper processing of both survey and land title information than was possible with the pre-existing paper-based system. The process by which the survey and land title information is generated remains unchanged, but the form in which the information is processed is digital. Some changes to the composition of the workforce and to the way core business relationships are managed are discernible from the interviews. 
All of these outcomes, while significant, are entirely consistent with the interests of the organisation as the stewards of New Zealand's land interests. Landonline enables the agency to provide core services more efficiently and at a lower cost. As a consequence they are able to maintain institutional legislative functions, retain regulatory and legislative control over the survey and conveyancing industries, and continue to secure resource stability for the ongoing operation of the agency. Apart from convincing Cabinet of the feasibility and long-term positive return on investment (ROI) for New Zealanders, officials have the requisite authority and capability to implement Landonline in a unilateral manner. When voluntary uptake levels did not meet expectations after the first two years of operation and looked to be jeopardising financial recovery targets LINZ officials gained the support of Cabinet to make electronic lodgement compulsory forcing private sector interests to comply (Jacobsen: 2007).

In this sense Landonline is an initiative that is an example of instrumental transformation in that the introduction of digital technology has radically altered the existing administration and service delivery practices between LINZ and those who use the information services. At an organisational level some changes have occurred that relate to structure, the separation of policy and regulatory functions, and the movement to standards setting for the survey and conveyancing industries. Each of these changes occur within the existing management arrangements and the discretionary power of the chief executive to organise the resources of the agency to best deliver the outputs agreed with the Minister, and funded by The Treasury.

Changes to operational management have an impact on LINZ as an organisation, but do not alter the core institutional relationships between LINZ and the public (including businesses), LINZ and other government agencies, or between LINZ and Ministers of the Crown. Furthermore, no changes have been made in respect of the agency's regulatory power in relation to the survey and conveyancing industries. Across the six categories of public management used to locate any transformational effects accruing from the Landonline initiative, there was no evidence of systemic level change. 


\section{Chapter 5: Case Study 2: Information management (cross-sector)}

\subsection{Justice Sector Information Strategy (JSIS): History of the initiative}

The Justice Information Strategy (JSIS) has been developed by seven government agencies: the Ministry of Justice, the New Zealand Police, the Department of Corrections, the Ministry of Social Development, Land Transport New Zealand, the Legal Services Agency and the Crown Law Office. The initiative arose in the mid 1990's when the Government took the decision to close the Wanganui Computer Centre which had been the national repository of criminal justice information since 1976. The Wanganui computer system was built on aging and outdated technology and needed to be replaced. Justice sector officials decided at that point in time to reevaluate the operational needs of the individual Justice sector agencies and to identify what the common information needs were, and what data needed to be held centrally. JSIS was developed by officials in response to the outcomes of that assessment process. The purpose of the strategy is to raise the quality and integrity of the information base of the Justice sector and improve the management and exchange of information amongst sector agencies (Ministry of Justice: 2006).

Official documentation on JSIS indicates that over the past 12 years, since the closure of the Wanganui Computer Centre the implementation of the strategy has enabled:

- interagency collaboration in research, policy development and strategic decision-making

- improvements to data quality and data management

- the establishment of a broad-based, comprehensive data warehouse

- extended provision of justice information services to the community

- protection of the justice network, and

- an extension of justice information services to other relevant agencies (Clayton Cosgrove media release, 2006) ${ }^{22}$.

The current Justice Sector Information Strategy $(2006$ - 2011) is the third version of the strategy that has been developed by the Justice sector agencies since $1996 .{ }^{23}$ Over

${ }^{22}$ Clayton Cosgrove held the position of Associate Minister of Justice in the Labour Government 2005-2008. 
time, the initiative has established a central electronic database to support Justice sector research, established common standards and protocols for sharing data, and provided access for all organisational stakeholders to Justice sector information that they previously did not have. Since the inception of the collaborative effort to improve justice related information, a secure virtual network has been developed consisting of seven different technical operating systems (Ministry of Justice: 2006: pg 10):

1. Case Management System (Justice).

2. Collections System (Justice - for fines and other penalties).

3. Driver Licence Register (Land Transport).

4. Motor Vehicle Register (Land Transport).

5. Police Infringement Processing System (Police).

6. National Intelligence Application (Police).

7. Integrated Offender Management System (Corrections).

Although the physical infrastructure is located in four different agencies, data sharing occurs across the technical systems on a daily basis through multiple data exchange interfaces (approximately 24) enabling an estimated 12 million annual transactions (Ministry of Justice: 2006: pg 9).

These seven technical operating systems have been used across a wide range of information exchange initiatives that have been implemented as part of the strategy including the establishment of an electronic database of over 300,000 palm prints; electronic data exchange (e.g. the filing of infringements issued by non-Police prosecuting authorities into the Courts for enforcement and collection); criminal intelligence analysis tools; development of cell phone blocking systems; collaboration tools; implementation of touch-screen information kiosks within prisons; and the provision of online re-licensing of motor vehicles, change of vehicle ownership and address details for driver licence holders (Ministry of Justice: 2006: pp 14-21).

${ }^{23}$ Previous versions were released in 1996 and 2003. 


\section{$5.2 \quad$ JSIS interviews}

\subsubsection{Electronic information management drivers}

There was a strong level of agreement amongst the respondents that the primary driver for government to invest in electronic information management initiatives is to improve operational efficiency amongst agencies:

There is widespread recognition that the sector has to work together but sometimes it is the level of that interaction that has to be worked out. Ten years of Justice experience has changed the thinking about this. We have an ongoing relationship established - now the emphasis is on how we improve how we work together.

In the case of JSIS this driver relates to those agencies with a responsibility for managing the criminal and civil courts of New Zealand. Respondents described an awareness of the public interface involved in the day to day management of courts and associated with that were strong incentives for each agency in the sector to "get it right" as "the consequences of getting it wrong are very high". There was a general view on the part of respondents that if any one part of the courts operation fails, it is usually very public therefore there are incentives on all agencies involved to manage the operation of courts together, and to manage efficiently. This incentive has driven the investment in JSIS.

\subsubsection{Expected benefits of electronic information management}

Respondents acknowledged that with respect to ensuring the New Zealand courts are managed efficiently, agencies across the sector have similar interests. These include an interest in data quality; operational efficiency; responding to the changes in communication channels by the New Zealand public and with it a change in their expectations regarding channel options, accessibility and immediacy of service; managing the complexity of integrating technology and information; and sharing expertise, knowledge and skilled resources. In the view of respondents JSIS offers positive benefits with respect to each of these interests:

This is about community safety; the long-term management of offenders; and the level of security required to manage offenders 
effectively. Information can be used to improve management and to reduce risk.

Respondents also perceived Justice sector agencies as the "guardians of the criminal justice information records". They indicated that there is a "government mandate to maintain criminal justice records centrally and to aggregate data for research and evaluation purposes". JSIS has been developed in a way that is consistent with this requirement.

\subsubsection{Opportunities and constraints}

There was a considerable amount of consistency in what respondents saw as the particular considerations senior managers had to take into account in decision-making (opportunities/ constraints) when developing and implementing information management innovations such as JSIS. Primarily, respondents saw the operation of courts as dealing with people moving between areas under the jurisdiction of different government agencies (e.g. between prisons (Corrections) and courts (Justice)). As such, they identified an operational need to share data and information on individuals in order to operate the courts in a safe and orderly way. The JSIS initiative was regarded as being about realising the opportunities provided by electronic technology to support the logistics and operational management of a large body of people at any one time.

To make operational processes work effectively on a daily basis in every court in New Zealand, respondents noted that officials from Police, the Department of Corrections, and the Ministry of Justice have to work closely together alongside a number of other private and organisational players such as lawyers. Having data and information provided digitally was seen by respondents as an opportunity to improve efficiency for all stakeholders. It is speedier and large amounts of data can be interrogated at one time. Respondents also regarded it as more cost effective to work in this way. They described a long tradition of sharing data and working together amongst the agencies of the Justice sector. The base philosophy of sharing data is seen as an accepted value by respondents, and they indicated that "no-one needs convincing" to accept the opportunities offered by ICTs to support this way of working: 
It's history - we have been joined up for 50 odd years. There is a long tradition of sharing data and working together. The base philosophy of sharing data just exists ... It is the degree and the sophistication of thinking that is new.

Respondents also saw JSIS in a conceptual sense as an effective means to improve operational management and reduce risk. JSIS was regarded by respondents as " $a$ tool to calculate ongoing risks, i.e. the provision of a mathematical formula that can be used to create a risk profile for an individual", and thereby inform the operational staff about what is required to manage that person safely. Respondents also saw JSIS as an opportunity for officials to continuously iterate and improve the criminal justice system.

Constraints in the system were primarily identified by respondents as being related to the availability of funding for projects, and the tension created by vertical accountability structures when working horizontally. Respondents identified funding as a critical issue for the ongoing success of JSIS and saw joint funding efforts as one of the key outcomes of the initiative. They indicated that for public officials there is always a question of whether specific initiatives can be funded from agency base-lines (if so, which agencies would contribute), or whether they should be jointly funded. Respondents advised that in order to get an IT initiative into the budget cycle it is necessary to put forward a business case two years in advance because discretionary funding is very limited and bids for 'Funded New Initiatives' from The Treasury had to be coordinated across the sector. This was identified by respondents as a point of tension because annual cycles of budget management mean it is difficult to get interagency co-ordination and co-operation for longer-term initiatives that have little process flexibility.

In keeping with the principle of chief executive independence and accountability for resource management, respondents acknowledged that IT investment decisions were made separately by each individual agency. A limited amount of funds are available for the JSIS initiative to coordinate activities and develop data standards across the sector. However, respondents indicated that the bulk of the money for technical innovations comes from individual agency baselines therefore it could not be 
controlled by JSIS managers. Rather, they see their role as exerting collective influence over the expenditure of those funds to achieve the best outcomes for the sector.

There was widespread recognition amongst respondents that the sector had to work together to achieve operational efficiencies but they also indicated that sometimes the appropriate level of interaction had to be worked out by trial and error. Officials had to identify how to balance agency information needs against legal constraints and accountabilities. Respondents identified a constant need to balance external and internal demands, and to get the managerial support that enabled that balance to be maintained. That is, to weigh the needs and values of the organisation against the interests of the sector, and to act in a manner that was beneficial to both sets of interests:

People in the sector realise that their interests are inter-related. There is separate and independent internal agency work still, but common information leads to a common approach.

Respondents saw the common interest in the Justice sector as occurring at the operational interface. They saw barriers occurring around rules, standards and privacy interpretations according to different sets of operational and management interests. Respondents saw it as important that each agency maintained its operational, policy and managerial independence, while at the same time working to promote the best interests of the sector.

\subsubsection{JSIS outcomes}

JSIS was perceived by the respondents to be more than a group of technical data management applications. In addition to the efficiency outcomes for individual Justice sector agencies, it was also perceived to have outcomes relating to agency coordination, knowledge sharing, improved resource management, the leveraging of infrastructure, and relationship management.

Respondents noted that one of the key outcomes of JSIS has been a change in operational governance arrangements across the Justice sector. Managerial oversight 
arrangements have been integrated at a number of different levels to provide appropriate policy, funding and resource support for the initiative. JSIS operates with an oversight committee of chief executives, a JSIS Governance Group made up of agency Chief Information Officers (CIOs), and a third tier inter-agency management group. A number of cross-agency working groups also convene to develop and implement specific pieces of work relating to the strategy. While these arrangements were not seen as compromising the agency accountability of members, or impinging on existing authority structures, they were regarded as being about collective ownership "There is a collective view about where we are going forward in the future and how we can share information and other resources".

The structures set up for managerial oversight were described by respondents as an opportunity for Justice sector agency officials to get together and understand the connections to each other's work. For example, the CIOs used the oversight forum as a way to coordinate resources for mutual benefit. The focus of this group of officials was described by respondents as being on:

- the production of standards, practices, and a strategic overview

- identifying and utilising leverage points for greater sector coordination

- sharing agency information technology strategies

- understanding and agreeing the policies, practices and technical applications needed to facilitate the sharing of information

- reducing barriers to information sharing, and

- ensuring operational and fiscal efficiency by sharing intellectual property and other resources to achieve the best collective outcomes.

Respondents saw it as the responsibility of the CIOs to solve the technical problems that impeded efficient information sharing between agencies; something that they advocated could be achieved with "time and commitment".

The JSIS managerial oversight arrangements were regarded by respondents as a means to develop and support a common view about the strategic direction of the sector, and identifying the shared information needs and other resource requirements to achieve joint outcomes. JSIS was seen by respondents as a way for large operational agencies 
(e.g. Police, Corrections and Courts) to combine with policy agencies (e.g. Ministry of Justice, Land Transport and the Crown Law Office) to ensure that decisions taken on information initiatives worked for both groups. Operational agencies had to put such decisions into operation on a daily basis therefore respondents saw this type of integration as imperative to efficient operation.

Another key outcome respondents identified was that strong relationships have built up amongst officials across the Justice sector based on trust and commitment to the collective interest. Respondents indicated that over time officials have learned to operate on a sector-wide basis in a manner that "is mutually beneficial to the interests of their individual agencies and to the collective sector interest". Examples provided were in respect of officials being able to rely on their colleagues across the sector for support for new technical innovations, and in the sharing of expertise and resources to support initiatives for the benefit of the sector.

One of the practical benefits of the operation of JSIS respondents reported is that all new technological initiatives are now examined for their wider applicability within the sector, rather than only their benefit to an individual agency. For example, a new technology being piloted by the New Zealand Police (e.g. computers in cars) was also tested for its utility to other agencies within the sector, and even to other agencies with related interests such as emergency services (ambulance, fire and civil defence).

JSIS was recognised by respondents as an initiative that had positive outcomes for the wider public in the sense that all New Zealanders benefit from having criminal and civil courts efficiently managed. While acknowledging this, they were also clear that the primary benefits accrued to the Justice sector agencies in the efficient operation of their businesses.

\subsubsection{Transformation}

In the Justice sector the imperative to share information was seen by respondents as being based on real operational problems with a public interface. They recognised that for other agencies the external facing issues can be very different and require different courses of action, therefore it is difficult to generalise the drivers within the Justice sector to that of other government sectors. 
The uniqueness of this type of collaborative network was something that respondents were aware of, but at the same time they clearly indicated that the intrinsic value of the initiative and the reason it has been so strongly supported over such a long period of time is because of the discrete and cumulative benefits to each individual agency in the pursuit of their organisational interests.

Respondents saw a need for an all-of-government perspective on how technical infrastructure is leveraged to deliver what the New Zealander public need (e.g. telecommunication services from a range of companies). They expressed the view that there was a need to identify how to utilise existing infrastructure better, and anticipate future needs. Respondents identified the critical driving factor for any e-government initiative as being its operational and strategic purposes, i.e. the contribution that is being made to the resolution of a clearly identified problem.

With respect to JSIS, respondents saw the transformational effects in terms of the collective benefits that have accrued to the sector of operational efficiency, the utility of the collective perspective, practical sector management of resources (physical, funding and personnel) and the strength of relationships that they perceived as facilitating better business practice:

As a sector we have moved to be more strategic. It is about the longterm health of organisations and how they work together. We have developed a $2-5$ year view of connectivity and interoperability. It is both tactical and operational.

\subsection{Identifying where JSIS transformational effects occur}

As with the LINZ material in the previous chapter (s4.3) the information provided by respondents on the JSIS initiative will be organised according to the categories of leading discourse; management model; workforce characteristics; record management; relationship management; and structure (Fig 3: 3.2.1) for analytical purposes. This will provide a means of identifying any transformational effect that may have accrued from the JSIS initiative and to understand the nature of such transformation and where it can be seen in the public governance framework. 


\section{Leading discourse}

The senior managers who were interviewed about JSIS were unanimous in their view that operational efficiency is the key driver of the initiative. They described the strategy as a practical operational necessity that provides strong business benefits to all of the participating agencies. Respondents indicated that each agency has its own specific interests in accessing and using Justice sector information. Officials both support the collective interest and recognise that doing so provides them with access to the information and data they may require for the activities of their individual agencies. The initiative also provides them with a number of intangible benefits accruing as a result of good relationship management and sector co-operation and co-ordination.

With a wide range of agencies whose interests intersect at the front end (i.e. in the operation and management of New Zealand courts) the sector has to co-operate in order to operate a very complex system efficiently in the public interest. JSIS is one of the ways of supporting this collaborative effort to achieve common outcomes. It is entirely consistent with the principles of institutional economics (Fig 3: s3.2.1) in that it contributes to both the efficiency and the effectiveness of all organisations involved, without compromising existing accountability structures.

\section{Managerial model}

JSIS has no impact on the managerial structures of individual agencies except insofar as managers within those organisations take responsibility for the work programme and management of resources (infrastructure, funding and personnel) that enable their agency to participate in the initiative.

However, respondents noted that one of the major impacts of the initiative has been the establishment and maintenance of cross-agency managerial oversight arrangements at a number of levels. This multi-layered, integrated approach is required to enable crossagency accountability for collective outcomes, and to ensure the efficient operation of the strategy. The existence of these cross-agency structures however, does not shift existing legislated responsibilities within the sector. Rather, the managerial oversight arrangements are accommodated within the existing referent framework of public governance (Fig 3: s3.2.1). 


\section{Workforce characteristics}

Respondents did not indicate that JSIS has any substantive impact on the resource distribution of individual agencies. The design, development and implementation of each of the various databases have been carried out by contracted specialist resources. Skilled staff are required in each agency to maintain and use the available databases. The information from the databases is used by a range of policy and operational staff in the contributing agencies to support their core work processes. The emphasis of the strategy is on working together collaboratively. In this sense, the strategy is an encompassing one that requires input from a wide range of staff resources.

Some respondents noted that it may be possible to organise resource sharing across the sector in the future to complete particular pieces of work related to the strategy. At the current time however, this does not occur.

\section{Relationship management}

JSIS has been operating for over 10 years, and respondents indicated that a strong collaborative ethos has been established amongst officials. Collaboration and cooperation is mission critical both at a strategic level in terms of the maintenance of the strategy, and at the operational level with respect to implementing the strategy. Incumbent senior officials indicated that they transferred this ethos to new participants in the strategy so that there was no loss of continuity in collaborative practice with any change in personnel.

New people don't have the institutional knowledge and may question why; what is the value of this; what do we lose? There is always the risk of loss of institutional knowledge but to some extent this is mitigated by regular meetings and governance on a bi-monthly basis.

Respondents also noted that the support of the strategy with integrated managerial oversight structures reinforced the behaviour of officials acting in ways that benefit the collective interest. Integration is formalised at several levels in the organisation, and reflected in agency's documentation including key planning and reporting papers. A mixture of formal and informal behavioural protocols underpins JSIS and respondents 
reported these relationship management benefits are strongly valued by officials in each of the agencies: "There are stable people in the sector with good working relationships based on trust so that you can ring up and deal with issues as they arise". These relationship management arrangements are consistent with the emphasis on managing for outcomes which has emerged in New Zealand since the 2001 Review of the Centre (Fig 3: s3.2.1).

\section{Record management}

Respondents indicated that JSIS represents not only the information and data sets held by each of the contributing agencies, but has been developed into an information repository that is more than the sum of the parts. The integration of data sets reduces duplication between agencies and enables the establishment of databases that can be accessed and interrogated for multiple uses across the sector. It is greater in scope and range than any information sets that were previously available to individual agencies, and is more useful to each agency because of its integrated data, accessibility and interrogative properties. This represents a degree of innovation within the current public governance framework (Fig 3: s3.2.1) but the nature of the records, and the purpose for which they are held and used is consistent with existing record management practices.

\section{Structure}

To a large extent JSIS has little substantive impact on the structure of individual agencies. A small dedicated work team has been established in the Ministry of Justice specifically to deal with the co-ordination and development of the strategy. In other cases however, the work relating to the strategy is incorporated into base-line activities of existing resources. No separate structural arrangements have been implemented.

There is no change to the status quo (Fig 3: s3.2.1) with respect to the relational distance and function of individual agencies involved in the strategy. Each agency has its own function within the state sector and participation in JSIS does not alter this; it only enables those functions to be carried out more efficiently and effectively. 


\section{$5.4 \quad$ The nature of JSIS transformational effects}

Information sharing and data management innovations in the Justice sector occur because they support and maintain existing institutional structures. Contributing to the collective interest also serves the best interests of each of the individual agencies involved in the process. The Justice sector operates (particularly with respect to courts) within the domain of the coercive power of the state, i.e. holding people to account rather than providing them with social or economic assistance. Officials work within a strong legislative and regulatory framework. This framework drives the behaviour of both staff and members of the public with respect to their own responsibilities/ needs and their interactions with each other. Coordinated information and data management through electronic channels enhances these processes rather than altering them and simultaneously supports the legislative function and resource stability of each agency involved.

In this respect, the e-government initiatives carried out under the auspices of JSIS can also be regarded as delivering instrumental transformation. Primarily the initiative deals with the organisation and management of data sets to improve the operational intersections of independent agencies. In this sense, JSIS is an example of 'back office integration' whereby agencies collaborate, but maintain the same public face. The networked approach hints at the potential for deeper, more fundamental, systemic change but the respondents were very clear that this collaborative structure was useful only insofar as it facilitated the needs and interests of individual agencies and improved their operational effectiveness. No systemic effects are identified across the six categories of the public management model (Fig 3: s3.2.1). 


\section{Chapter 6: Case Study 3: Knowledge management (State sector wide)}

\subsection{Public Sector Intranet (PSI): History of the initiative}

The Public Sector Intranet (PSI) was developed by officials within the Information and Communication Technologies branch of the State Services Commission (SSC).

The PSI site is hosted by SSC and administered by ICT Branch officials alongside other e-government programme initiatives (refer s3.4). It is available to all state sector agencies via the Internet (www.psi.govt.nz) and is operated on a secure network that cannot be accessed by the public, or by any organisation outside the state sector. Essentially the PSI is a knowledge management system that includes professional practice sites (e.g. HR, Policy Managers, Corporate and IT); media services (including podcasts); Cabinet information; best practice case studies; project case studies; and other general information relevant to public officials such as an events calendar and contact/ mail details.

The history of the PSI development has not yet been formally documented. The information in this section has been provided by SSC officials interviewed for this research, all of whom have been closely involved with the initiative over the past eight years. PSI was developed and implemented following a large body of research relating to collaborative working spaces (O'Neill et al: 2000, 2001). The initiative can be described as a solution to a practical problem (the need for inter-agency collaboration) that grew and developed into a new interactive information repository application. Originally, as public officials from various agencies were working together on projects they wanted functionality that was more intuitive and less clumsy than email. There was a demand for a collaborative working space, especially by HR and Policy Managers across the state sector. In providing this capability, the initiative grew to a more elaborate information repository for all public officials, rather than only those working on specific work projects.

The site offers the technical capability for officials to enter into a broad range of collaborative working relationships with colleagues from across the state sector. As a centralised information repository the PSI provides officials with the ability to reduce duplication between agencies thereby increasing overall operational efficiency and 
reducing transaction costs. The collaborative functionality is a means of rationalising core state sector information sets (e.g. HR policy and processes, financial management and performance data).

The original concept of dedicated, secure shared working space for state sector officials (O’Neill et al: 2001) was regarded by SSC officials as theoretically sound, but in-house research carried out in 2002 of existing agency models showed that unless people got technical support with shared workspaces, they did not use them. A HelpDesk and a reliable operating system are essential technical supports. In the context of the state sector, the former requirement was seen as expensive, and the latter as not being able to be guaranteed given the different range of independent systems that exist.

An external contractor from Ernst \& Young working on a long-term project in SSC was familiar with collaborative tools and wished to have them available for his project so he paid for a developer and built one. It was hosted on the SSC home server, unsecured. Slowly other E-Government Unit (the predecessor to the current ICT Branch in SSC) work groups (e.g. e-GIF - Government Interoperability Framework) were given access to the collaborative tools until there were eight groups of varying sizes and with a range of purposes using the applications under the auspices of an internal 'pilot'.

In 2005 a business case was developed and $\$ 1.3 \mathrm{M}$ over three years was added to the SSC baseline to provide collaborative working applications. With this money, the server was upgraded (including security) and new staff were employed to develop the initiative. Initially, the PSI was a low-key initiative that was available to a limited number of agencies on a voluntary basis. SSC senior officials saw no particular reason to market it as the initial uptake was more rapid than they had planned for and they did not have the technical infrastructure or staff resources necessary to support it. The application was officially launched in July 2006 and made available to all state sector agencies. 


\subsection{PSI interviews}

\subsubsection{Knowledge management drivers}

All respondents described the PSI as a demand-driven initiative. The key driver was a requirement by users for streamlined processing and presentation of information across the ssector, and more efficient management of information resources, including knowledge management. Respondents indicated that a push for policy shared workspace was the originating and lead concept that drove the investment in this initiative. The movement to a single state sector-wide information repository from the original shared workspace concept was a consequence of the limitations users experienced in using shared workspace applications. While respondents acknowledged that some officials do have a need for a small protected space, they regarded a large amount of the material officials deal with as being suitable for sharing with their peers and not requiring the higher security level of shared workspaces. Users were requesting easily accessible, flexible and agile applications.

The PSI in its current form evolved initially through the demands of Policy and HR Managers who meet together regularly under the facilitation of the SSC. Policy Managers wanted to "share information with their colleagues in the state sector such as training material, specific policies and job descriptions". Email distribution was regarded by officials as "cumbersome" and involved considerable duplication of resources. A controlled way of accessing a single set of information was required by users. They were also seeking a mechanism for sharing specialist knowledge with colleagues across the state sector - "We had a choice between sending out links and information to a large number of people, or finding out what was available on the PSI”.

At the same time as Policy Managers were looking to find an efficient means of information sharing, respondents indicated that there was a demand from HR Managers arising from the sheer frustration of trying to send out complex attachments via email to a large number of recipients in different agencies (e.g. presentations). They were often hampered by agency firewalls and security systems. Having a single link available on a central repository that could be accessed by a wide range of users seemed conceptually and administratively easier. Participants wanted the electronic functionality that would enable them to share information across agencies in an 
efficient manner. They asked the SSC to act on their behalf to collate and administer the collective interest in this area:

Collaboration tools are a move towards recognition of the collective interest. We are avoiding re-inventing the wheel.

\subsubsection{Expected benefits}

One of the key benefits respondents saw arising from the PSI was the ability for state sector officials to share core information across a broad range of interests in a secure electronic environment unavailable to the public: "The PSI is a repository for sharing information in some sort of structured form. It became more in demand than the shared working space where people were restricted to a small, protected space". Respondents noted that while officials recognised that there are a diverse range of specialist interests across the state sector they were increasingly identifying common interests within particular functions of organisational management such as HR, financial management, IT and policy.

They also recognised that common business processes such as recruitment, training and development, procurement, and performance management for example would benefit from being streamlined across the state sector. The value of the PSI was described by respondents as offering the technical capability to share information sets thus reducing duplication and increasing capability relating to core business practice. It was also seen by respondents as offering an agile, open and secure communication forum for occupational groups and communities of interest to share information, resources and knowledge in their field of interest:

Firstly, it filled a niche that didn't exist before - there was somewhere to put secure documents electronically. They didn't have to go to their own IT shops to request collaborative space.

Other benefits respondents identified were that a single technical platform prevented infrastructure duplication by agencies, and the initiative met government security policies. No vendor relationship was required, because the initiative was developed in 
an evolutionary way within SSC on behalf of other agencies, using existing technical capabilities.

\subsubsection{Opportunities and constraints}

For the first 12 months of its operation SSC officials were primarily concerned with marketing the application to government agencies across the state sector and to individual users. Respondents put forward the view that there were only two barriers to officials using the site. The first was availability (i.e. that the host agency belonged to the PSI membership), and the second was that officials knew it existed. They felt that both of these constraints could be relatively easily addressed with appropriate marketing activities.

Once officials knew the site was available and how to access it, respondents saw the major issue of concern being whether the content was useful enough to ensure ongoing usage by officials, and support by agencies. Respondents identified content management as both an opportunity and a constraint. Although the SSC has a dedicated resource to manage the site content this role is a logistical and administrative one. The responsibility for providing appropriate content for the site resides with member agencies and communities of interest. SSC officials work with agency representatives to identify useful content, and ensure that material provided by agencies is loaded onto the site in the right format and in a timely manner. Respondents saw both the range of information and the quality of that information as critical factors affecting take up and ongoing usage by officials.

Respondents acknowledged that there were also infrastructure and management oversight issues to be resolved. By February 2007, eight months after it was launched, 73 state sector agencies had signed up for the PSI, almost 100\% more than the original business case had stipulated (40). The SSC only had minimal resources to support the site, and limited funding to provide a state-sector wide resource. Senior officials felt that they were in a situation where quality was being compromised: "... we have 80 being supported poorly rather than 40 being supported with quality”. To address this 
issue a business case was put forward by SSC officials for ongoing site development and operational support for the initiative. ${ }^{24}$

The rapid adoption of the site was also seen as an opportunity by respondents who were of the view that as more people used the site regularly the additional capabilities users wanted and/or needed would emerge. Respondents indicated that an organic approach to site development was adopted and the site administrator had a mandate to work with agency representatives to develop content and technical capability in accordance with the emerging needs of the user community. One of the respondents advised that the model of administration officially sanctioned by agency chief executives was a 'social-networking' one whereby "staff contribute with content, and start using the site to break down communication silos across government".

However, respondents also indicated that the future development of the site depended on the resolution of a number of critical issues at a conceptual level. Key to this was the need to clarify the ultimate purpose of the site, and how its capability could best be used to promote the collective interests of the state sector. Tied in with this was a need to resolve issues relating to the managerial oversight arrangements, promotion of the site, maintenance, technical support, funding, and the status of the site as a repository of authoritative official information. As one of the senior officials described the situation, “...There is an ongoing programme of development but we haven’t got 'ownership' at the current time”.

Respondents indicated that they saw the lack of managerial oversight arrangements for the initiative resulting partly from the organic, social-networking approach that they had advocated for the development of the site. Although they had chosen the model as being the most appropriate means to develop the capability in ways that best suited the user group's future needs, they suggested that the model had '... greater fragility to it and one that takes time to get established". Without established ongoing funding, strong management-led support, and promotion of the site respondents recognised that there was an inherent risk that the initiative would not achieve an optimal number of regular users that would enable the information flows across the state sector to be

\footnotetext{
${ }^{24}$ In December 2008 respondents advised the number of agencies signed up to the PSI had risen to 115 .
} 
maximised. They indicated that they believed ongoing development work would be difficult without a clear rationale and guiding objectives.

\subsubsection{PSI Outcomes}

Respondents recognised that the PSI initiative is immature with respect to its technical capabilities and in terms of its operational development, and therefore they were reluctant to claim early outcomes, or to speculate on likely longer term outcomes. The uptake by agencies was higher and faster than expected, but early research commissioned by SSC (SSC: 2006) on users of the site indicated that there was a significant uptake problem by officials within agencies signed up to the initiative. The research data (SSC: 2006) indicated that agency officials in a position to advocate or arrange agency uptake (primarily technicians, Chief Information Officers and communications personnel) saw some benefit to the functionality available, but there was less understanding, interest, or knowledge about the site by policy, management, or advisory officials. Respondents saw this as a marketing problem that needed to be addressed with some urgency.

However, respondents were also conscious of the fact that the initiative depended on regular, accurate and relevant user contributions from a wide range of officials for its ongoing credibility and evolutionary development. They saw long term outcomes relating to the management of information resources across the state sector as entirely dependent on the proven usefulness of the application to a broad range of users. Respondents indicated that one of the problems they faced in terms of getting the site recognised by officials as a definitive source of state sector information was competition from individual agency intranet sites. While some agencies had a link to the PSI on their intranet 'Homepage' many intranet sites duplicated information available on the PSI and in some cases provided more up-to-date information as a result of using dedicated technical and communications staff. Respondents saw this competition as reducing the motivation and incentives for officials to use the PSI. This acted as an inhibitor to achieving the outcomes that respondents saw as possible with the PSI functionality.

Respondents were candid about the fact that establishing the PSI as an organic, selfmodifying application carried high risks. It depended on the user community 
supporting the ongoing development of the site by the provision of relevant, high quality content, and by recognising, promoting, and using the site as the default information repository for all state sector work. Failure on either of these two counts was likely to lead to a loss of relevancy for the site and consequently to the atrophy of the application as a state sector resource. Respondents recognised that such an outcome was also likely to damage the reputation of the state sector e-government programme itself. Nevertheless they also saw the success of the social-networking approach as the best way to realise the full potential of the technical capabilities available through the site.

\subsubsection{Transformation}

The early stage of the PSI implementation means that transformation effects may not yet be realised in full. Respondents indicated that they saw the value of the PSI to be in the facilitation of people working together well at a cross-agency level. The transformation effects that officials expect over time are in the availability of different working models that reduce state sector resource and information duplication and enable specialist work areas (e.g. HR, finance, policy) to leverage core information for greater policy and operational efficiency.

At this early stage the PSI was seen by respondents as lacking the critical number of users to redirect information flows across the state sector. Respondents indicated that issues of content reliability, authority and relevance inhibit officials from using the repository to inform their substantive work. The PSI was not recognised by state sector officials as an authoritative and formally mandated centralised information and knowledge repository. As a consequence it was not embedded in day to day practice within agencies. The exception to this is the availability of Cabinet information on the site. The PSI is the only repository of this information available to all state sector agencies and therefore it is used on a daily basis by policy advisers and staff in Ministers' offices.

Respondents noted that at this time there is a substantial gap between the transformative aspirations of the PSI developers and the operational practice across the state sector. They recognised that in the long-term use of the site by public officials could simplify and reduce the cost of some of the core transactions within the state 
sector, and radically alter working methods amongst officials involved in central administrative duties such as policy development, research and regulation setting (rather than service delivery).

The respondents who were involved with the design of the original PSI concept indicated that their vision is that the PSI in its current form will give way over time to a wider scope of collaborative tools embedded in agency operating systems so that there are a range of collaborative working spaces available to public officials on every desktop.

\subsection{Identifying where PSI transformational effects occur}

The analytical categories of leading discourse; management model; workforce characteristics; record management; relationship management; and structure (Fig 3: s3.2.1) will be used to organise the information provided by respondents on the PSI initiative. This will build on the analysis carried out in the previous two chapters (s4.3; s5.3) to identify where transformation may have occurred in the public management framework of New Zealand as a consequence of PSI and what its nature might be.

\section{Leading discourse}

SSC officials saw the PSI in the context of evolving e-government initiatives. They indicated that it was an application that evolved over time driven by user needs for greater technical sophistication and agility. The leading discourse was nevertheless primarily about achieving business process efficiency across government organisations. Technical capability was seen as the means to providing collaborative working methods to support officials in carrying out their duties.

In this particular case, officials saw the distribution of information and knowledge as a way of effectively managing state sector resources by reducing duplication of information and sharing knowledge. Knowledge and information sharing was also presented as a means of strengthening capability across the state sector. The principles of efficiency and effectiveness are consistent with the NPM model of public governance operating in New Zealand (Fig 3: s3.2.1). 


\section{Management model}

The social networking approach to the development and evolution of the PSI is a model that requires no strong support by chief executives or senior managers.

Respondents saw this as one of the major inhibitors to uptake and usage of the site. In the interviews respondents did not indicate that the PSI had any impact on the management arrangements in the SSC or in any of the agencies using the application. There is no evidence therefore that the PSI has any impact on the current management arrangements of public governance in New Zealand.

\section{Workforce characteristics}

Respondents indicated that no additional staff were required to manage or operate the PSI. One of the ICT Branch staff had responsibility for the provision of content and technical intermediation for the PSI but this fell within existing staffing arrangements for the Branch. Staff within member agencies also dealt with the PSI as part of their core functions or collective interest duties within the organisation. No additional specialist skills are required to produce content by staff within member agencies. No information provided in these interviews suggested there are any impacts on workforce characteristics relating to the PSI initiative.

\section{Relationship management}

Membership of the PSI and contributions to its content are voluntary. The SSC has deployed a marketing approach to sell the benefits of the site to officials across state sector organisations. The design and content management of the site is achieved by relationship management between the SSC and member agencies.

The PSI functionality facilitates relationship management across the state sector by the provision of information sets to communities of interest, and the provision of collaborative working spaces accessible from the site. Respondents indicated that there is no data available on how the PSI has affected these relationships in terms of working practices. No information is available on whether the original needs identified by HR and Policy managers have been met by the development and deployment of the PSI, and there is no indication that any HR systems or processes have been affected. 


\section{Record management}

The PSI operates as a single point information repository for state sector agencies. Content is managed by member agencies. Information which is recorded and held on the site is vetted by agency representatives who have responsibility for ensuring its accuracy and relevance. The site does not over-ride the responsibility of individual agencies for record management but adds an additional repository that is accessible by all member agencies.

\section{Structure}

The PSI is an electronic information repository hosted on a server within SSC. It requires no structural edifices to operate. No structural implications were noted by respondents in this research.

\subsection{The nature of PSI transformational effects}

The technical capability of the PSI provides for changes in the ways that public officials across state sector agencies access and use information to carry out core administrative and executive functions. The small number of initial users, however, makes it difficult to assess if such changes are occurring. It can also be argued that if the PSI is adopted and used by all state sector agencies as a core information repository and knowledge management system, existing managerial authorities may be circumvented in some cases (e.g. open source contributions could potentially bypass existing management content control and sign-off processes). This would challenge the ability of user agencies to control the content and also alter behaviours around how the information is used by officials. Cross agency collaboration and coordination in areas of executive functioning (i.e. policy development; legislation and regulation setting; and advisory functions) can also be increased by utilising the information on the site thereby subtly altering both processes and relationships in these areas of operation.

Centralised information systems provide the ability to achieve greater efficiency in administrative functions through streamlining processes and procedures. Examples include, but are not restricted to, HR; research; financial administration; IT management; and other corporate functions. If officials use the PSI to electronically recentralise core sets of information relating to generic functions that are currently 
customised to every government agency some categories of occupational class (e.g. HR advisors and other corporate officials) could be significantly affected. This would be a fundamental systemic change from the current NPM arrangements as it challenges (but not necessarily negates) the principle of managerial independence that is embedded within the current model of public management in New Zealand. There is no evidence in this case study, however, that this is occurring. Early indications from respondents is that the PSI competes with the more popular departmental intranet sites for utility and unless staff had a particular reason for using its functionality, such as participating in the shared workspaces or accessing Cabinet Office information, it was not widely known about. This indicates that the PSI is not yet recognised by state sector officials as the authoritative repository of government held information and knowledge resources.

At this stage of its development, it is difficult to argue that the PSI has yet delivered either instrumental or systemic change. The implementation of the PSI application is based on a social networking approach and as such is not formally sanctioned or supported by state sector managers and chief executives. It has been provided to state sector organisations at a very low cost (general functionality is free, and a nominal charge is made for the establishment of secured shared workspaces) as a useful technical aide to assist with information dissemination and the promotion of good working practices. It is, however, left to individual organisations to promote its uptake internally, and to provide relevant and authoritative content. The collaborative ethos required to operate the PSI as a state-wide resource appears to be at odds with vertical organisational arrangements and accountabilities of individual government agencies. Without a formalised mandate and commensurate resources (financial, personnel and management governance) to support collaborative working arrangements and centralised information repositories, the benefit realisation possible from the PSI initiative is likely to be impeded.

\subsection{Reviewing transformation in e-government case studies}

The interpretation by senior public officials in New Zealand of e-government as a means by which to improve the efficiency and effectiveness of their organisations $(\mathrm{s} 4.4 ; 5.4 ; 6.4)$ is consistent with Fountain's observation that: 
... whenever possible, decision-makers have used information technology in ways, however innovative, that leave deeper structures and processes - such as authority relations, political relations, and oversight processes undisturbed. (Fountain: 2001: p 19).

The e-government case studies (Chapters $4-6$ ) demonstrate that senior public officials implement technological innovations where they benefit individual agencies and third parties without affecting existing institutional relationships. The empirical data on LINZ and JSIS demonstrate that technology initiatives are implemented where they clearly provide economic and operational benefits. The empirical data on the PSI however, suggests that where technological innovations do not offer clear external benefits or internal efficiencies there is less formal support by senior public officials.

This finding is consistent with the position of institutional theorists (e.g. DiMaggio \& Powell: 1991) that institutional legitimation is more important than process efficiency. All of the case studies also provide some empirical support for Fountain's technological enactment perspective (2001). This holds that technology is implemented by officials in ways that reflect the current legitimation of their organisation within the public management system. In the New Zealand state sector legitimacy is legislatively defined (State Sector Act; Crown Entities Act). Legitimacy is both conferred and maintained by formal public management protocols and constitutional mechanisms (e.g. Output Agreement between the Chief Executive and the Portfolio Minister) relating to the servicing of Parliament and by less formal activities that define and maintain the cultural membership of the state sector (e.g. the 'State Sector Code of Conduct'). Government agencies rely on legislative specification (State Sector Act, 1988) and the allocation of funding according to the exercise of the Public Finance Act, 1989 as their key sources of legitimation.

The service delivery (Landonline) and information management (JSIS) initiatives clearly maintain the institutional legitimacy of the organisation's interests. This is not an unexpected result as in order to implement e-government initiatives of any substantive order and cost public officials first have to put in a business case to The Treasury to obtain the required resources. Public officials do not have unlimited resources or an unfettered ability to develop or deploy technology except where it can 
demonstrably provide benefits to either the organisation, all-of-government, the members of the public over which the organisation has a sphere of responsibility, or all three. Accountability for public services and the expenditure of public monies act as constraints on what is possible.

It is important to note, however, that instrumental transformation can involve substantive change in business operating environments. For example, the LINZ case study demonstrates that the business environment is substantively different as a result of the implementation of Landonline to that which preceded it in the following respects:

- the land title transaction itself is delivered via a new channel

- the unit cost of the transaction is significantly lowered

- the speed of the transaction is dramatically increased (from three weeks to real time)

- fewer public offices exist

- the workforce is reorganised with the loss of 112 staff, and the redistribution of other skills (e.g. more staff carrying out quality control functions)

- historical documents are removed from the public domain and archived as records of national significance

- the supply chain is reorganised. Many conveyancing firms had outsourced the title search function and these have now been reincorporated into core business, and

- there are changes in the way some statutory roles (e.g. Surveyor-General and the Register-General) now carry out their functions with a move to setting industry standards, and mediating on breaches of professional standards.

The changes described above may not individually be radical in their effect, but collectively they substantively alter the way public officials carry out their operational duties. The status quo is significantly altered in terms of business priorities, internal processes, cost management, inter-agency communications, information flows, knowledge management and operational efficiency. 
Similarly, the JSIS case study indicates that Justice sector organisations can demonstrate substantive changes in process and in operating relationships as a direct consequence of the JSIS initiative. Organisations participating in this initiative have benefited from shared infrastructure and shared data sets. They have also implemented joint priorities for information sharing and backed these with joint funding where this is required. One of the change effects demonstrated by the JSIS case study is the sector-based perspective that senior officials bring to bear on their decision-making with respect to information sharing policy and technical innovation. Respondents acknowledged that this is a different mode of working from that which was common prior to the implementation of JSIS. The individual agencies accountabilities are now met within a framework of sector interests.

Instrumental transformation in itself therefore can be a very powerful form of change. Business processes and procedures can be substantially altered. As demonstrated in the LINZ example the customer experience can be significantly different and benefits such as increased speed, greater consistency of service and lower transaction costs can be delivered. For the implementing agency the changes can be equally far-reaching including job losses, alteration to business processes, the development of new skills, and the re-distribution of existing labour. Transactional efficiencies can be achieved and some functions (e.g. regulatory controls) and structures can be altered. In the JSIS case study the difference in information flows and the way information is interrogated and utilised has operational benefits across the sector.

All such changes have distinct value as an end in themselves and in many cases are substantively different to the existing order. Nevertheless, there is no evidence from these case studies that e-government implementation will result in systemic transformation of public governance. This leaves the question open as to whether instrumental transformation, even if powerful in its effects, will be enough to position public officials to be able to address the demands arising from the societal changes taking place through the pervasive use of ICTs (refer discussion s1.3.1). To this end, focus groups were convened to discuss further the transformational effects of egovernment on New Zealand's governance arrangements over the next 20 years (Chapter 7). 


\section{Chapter 7: Future scenarios of public management}

\section{Chapter outline}

The empirical work presented in this chapter looks to examine the concept of 'transformation' further by identifying the current drivers of change in public management in New Zealand and attempting to deduce what changes (if any) are most likely to occur over the next five to twenty years. No attempt is made to discuss what individual sectors of the public management system might look like over the next 20 years, or the types of ICTs that might be deployed to effect change. Rather, more generic issues of change are examined with a particular emphasis on the contribution that the e-government programme in New Zealand will make to arrangements of public governance in the future.

Section 1 of this chapter summarises the future scenarios that were presented to the focus groups as discussion starters (s7.1). These models are designed to emphasise the role of technology in public management. The general topic areas covered by the focus group discussions are also indicated. The summarised views of the focus group participants in each discussion area are then presented (s7.2). The same analytical framework that was used to locate the transformation effects in the case studies is applied (s7.3). The nature of future transformation is discussed in s7.4.

\subsection{Focus Group meetings}

As described in Chapter 3 (s3.5.2) material was prepared to inform the focus group participants on changes to the New Zealand public management system in the past. In addition, a range of potential future scenarios were developed to describe possible changes to the New Zealand public management in the future influenced by egovernment initiatives based on an expansion of the status quo, changes driven by socio-political forces, or by technical change drivers (refer Appendix 2).

In the pre-readings dealing with future scenarios a twenty year period from 2009 2028 was selected as a future period where potentially a new form $/ \mathrm{s}$ of public management could predominate. Three possible future scenarios were created based 
on the major current technological debates (refer s 2.3.3): a continuance of the status quo; socio-political drivers of change; and technical drivers of change:

- Enhanced NPM - extending the status quo through more complex and sophisticated development of technology assisted service delivery, information management and administrative functions. This effectively represents a position where technology initiatives will continue to be used by senior public officials to effect instrumental change within the existing system;

- NPM Connected - socially determined public management whereby any systemic changes that occur are largely influenced by complex political, social and economic pressures. In this scenario technology is not a key driver of change but will be used by senior public officials as an enabler to effect required policy and business process changes. Any systemic changes that occur will be deliberative and put in place to facilitate broader political and policy objectives;

- IT Strikes Back - technologically determined public management whereby the technical systems become so sophisticated and complex that they limit policy-makers and senior decision-makers ability to take discretionary action. In this scenario technology becomes a key determinant of political and policy changes.

Using these hypothetical future scenarios as a discussion point each focus group explored the following questions:

- Is change in the New Zealand public management system necessary? Is there a case for change?

- If change takes place what model/s of change management will predominate?

- What factors are driving changes in public management at this time? How do ICTs and e-government contribute to public management change in New Zealand?

- What are the critical issues to be addressed to facilitate change?

- What type of change will occur, and what will be the process for making it happen? 
The collated view of all four focus groups on each of these questions is set out below.

\subsection{Focus Group views}

\subsubsection{The case for change}

There was unanimous agreement amongst participants that New Zealanders are experiencing a period of societal change that is greatly influenced by the adoption of new ICTs in personal and professional communications. Participants described the current environment as multifaceted, complex and difficult to analyse. At the same time they saw it as exciting, creative and challenging. The predominant view was that change is happening so fast that the future is almost unknowable. Technological changes continue to reshape people's private worlds and put pressure to change on their professional worlds, and the speed at which this is occurring is beyond what participants had previously experienced in their careers. One comment summed up the general position of the participants:

The next ten years will represent 200 years of progress in terms of technology.

Participants indicated that as a direct consequence of the rapid adoption of increasingly sophisticated ICTs in the social arena, there were a number of tensions that public officials find themselves managing in the professional world. These tensions, as described by the participants, fell into two categories:

(i) personal/professional disjuncture, and

(ii) institutional disjuncture.

\section{Personal/professional disjuncture}

Participants noted that new software capabilities available over the Internet now provide people with open access to new areas of interest (e.g. photography/ music/ video). In the past these areas were largely the domain of 'experts' with specific skills and knowledge sets not widely available without training. This is no longer the case. For very little cost people can now produce their own videos for example and post them on the Internet where they are available to an international audience (e.g. YouTube; MySpace; FaceBook; BeBo). Similar facilities are available with music and 
photographs. In addition, people have the ability to write on a wide range of topics and publish to an international audience without mediation. This provides them with the ability to participate in, and sometime lead, topical debates on political and policy issues regardless of whether invited to do so by public officials (e.g. www.kiwiblog.co.nz; www.stuff.co.nz/blogs/politics) ${ }^{25}$.

This expansion of personal skills and knowledge was seen by participants as a stark contrast to their professional working environments where for reasons of commercial and professional security and safety people are experiencing increasing restraints on their usage of the internet. People described situations whereby their organisations were increasingly 'locking down' technological functions because the open aspects of the Internet are seen by management and technical administrators as compromising the professional boundaries of the organisation: "From an IT systems perspective these things are threats". For example, use of laptops and USB memory sticks are in some government organisations severely restricted or prohibited in an attempt to ensure that unauthorised software is not introduced to the organisational operating system. In a small number of government agencies this risk aversion is taken to the point that staff are only permitted restricted access to the Internet.

Similarly, participants described a situation where people are developing technical skills (e.g. production and editing of photographs and videos, publishing, and open source programming skills) that are not valued or cannot be used in the state sector. This was identified as a significant issue for the upcoming generation of public officials who are seen to be learning a wide range of technical skills and with it different modes of communication and social interaction that are not sanctioned in the professional working environment:

Generation $\mathrm{X}$ and $\mathrm{Y}$ are from a different set of values and experiences. ... Ways of working have not caught up with the options available in government.

\footnotetext{
${ }^{25}$ See also www.kiwiblog.co.nz/must_read blogs for a list of blogs on a wide range of topical issues.
} 
In addition, participants saw the Internet as providing faster, cheaper, and more convenient access to a wide range of personal services (e.g. banking, shopping, organising travel and so forth). This was seen as contrasting markedly with restricted access to information and services in the state sector that affects not only the way that individuals operate within their professional environment, but also the ability of organisations to provide online services to the public:

The role of emerging technologies on the personal lives of individuals is leading to changing gender and age roles and also to changing expectations of government services. People are demanding speed, quality and range.

Two examples cited were that public officials are rarely able to organise their own business travel, and agency procurement arrangements are carried out by particular categories of officials with delegated authorities. Participants described these traditional administrative methods as bureaucratic in nature and recognised that they serve the organisation but pointed out that they are not necessarily in keeping with the capabilities available via the Internet, and that officials are slow to move to adopt technologies in order to deliver these types of administrative functions in different ways: "People are not yet even using the small functionality improvements that are available within organisations".

\section{Institutional disjuncture}

Participants indicated that they thought that a similar disjuncture was becoming apparent in the way organisations interact with external stakeholders in the political, economic and social spheres in which they operate. It is this institutional disjuncture which participants saw as building internal pressure for change at the systemic level. They were clearly of the view that the availability and use of a broad range of technologies enables changes in both information management and communication processes. These changes are multifaceted and occurring so rapidly that they are difficult to quantify and categorise.

The tensions participants identified are each complex in themselves. They relate primarily to speed and flexibility of processes; alterations in production modes; 
changes to regulation and control functions; expanding boundaries of operation and spheres of influence for government agencies; and managing risk.

\section{Speed and flexibility of processes}

There is a tension between the rapid speed of communications and interactions by people internationally which is facilitated by the Internet and the operational slowness and lack of flexibility of government agencies. Participants indicated that this was particularly apparent in the lack of ability of public officials to respond rapidly to the informational needs of Ministers compared with the speed at which private and third sector actors could obtain and use information. This created a "crisis of disintermediation. Product delivery is too slow for the need of the public". The inability of organisations to respond rapidly also impacted on their ability to put government policies into operation quickly:

Government policies currently can't be implemented in time because of technical system complexity - there are time and money constraints. Some of the policy changes are not 'doable' changes in a technical sense. Policy implementation can happen but it is more complex than policy makers and politicians expect. There are changed expectations of customers. Back end investments have not moved at the same rate as functional possibilities. New Zealand suffers from scale.

\section{Alterations in production modes}

Participants suggested that co-creation is currently occurring whereby communities of interest are able to mobilise local, national, and even international support for specific issues, often using ICTs to promote the cause and facilitate interaction. This is contrasted with organisational 'ownership' of community-based problems with public officials designated as 'experts' with responsibility for both defining the nature and scope of the issue and designing appropriate solutions. Officials' responsibilities are 'bounded' by institutional constraints and this has priority over a focus on solutions. Communities of interest are able to use ICTs in a far more flexible way to mobilise support and gain information from a broad range of sources. They are also able to pool information and expertise to develop more innovative and multi-dimensional solutions to problems: 
We are seeing the emergence of unprecedented global mobility and information networks. Collaboration across boundaries is occurring. How will this happen, and what will be its impact?

\section{Regulation and control functions}

Internet based capabilities enable independent interactions outside of traditional regulation/ control (e.g. the music industry where the production and distribution of work can no longer be controlled by commercial interests). This is in contrast to notions of ethical probity and challenges facing government of 'protecting' citizens from cyber crime. Participants recognised that the Internet environment defies many of the traditional 'control' mechanisms (e.g. legislation) as it is difficult to monitor individual use. Nevertheless, the privacy and rights of people need to be protected. This issue evoked broadly different responses regarding the role of government in the digital age, as shown in the following two quotes:

Government has a role in protecting people from technology cybercrime/internet trading/IP. Where do the borders lie and how is control maintained?

People will need to protect themselves from government control. People are being liberated. Peer to peer assessment is taking place. Issues of probity/ credibility will be moderated by the online community itself. Self-governing will occur.

\section{Expanding boundaries of operation}

Technology also facilitates permeable international boundaries whereby people address issues of interest at a global level and mobilise international resources to provide created solutions. This challenges traditional notions of unitary government with jurisdiction over geographically defined and bounded territory. Participants indicated that issues of jurisdiction have to be taken into consideration in the international economic environment. As there are increasingly international business opportunities, so too do issues of international regulation need to be resolved. Technologies offer 
increased opportunities for boundary expansion, but also complicate matters of international regulation.

\section{Expanding spheres of influence}

ICTs provide constituents with more direct access to politicians and an ability to have an immediate influence on their thinking regarding specific policy issues. Public discussions on topical issues are held via email and interactive websites (YouTube/ blogs/ wikis) providing immediate information to politicians on public opinion. This highlights the limited ability of agencies to respond to Ministers and other members of parliament at speed given existing governance/ legal and constitutional constraints. Participants indicated that this fluidity in communication would result in a "movement in the apex of power" and suggested that "the fundamental relationship between the citizen and state has changed already". There was a general view that this will require changes in political leadership responses in the future with a flow on effect to state agencies.

\section{Managing risk}

Many ICTs are such that users operate using mechanisms of risk awareness and selfmanagement of online participants in an 'open' system (e.g. TradeMe and FaceBook). Government agencies tend to operate in a risk averse manner which reflects responsibility and accountability for public money and resources. This is particularly obvious in investing in new technologies where the demand for new functionality (to provide online services) is set against the consequences of 'getting it wrong' for public officials. Participants indicated that the accountability regime fostered a culture of risk aversion whereby individual public officials are 'blamed' in public, especially by the media if new technologies did not perform as expected.

\subsubsection{Models of change}

Participants saw a situation whereby the immediate future for New Zealand will involve a hybrid of change models. In the absence of comprehensive systemic change, participants felt that a more disorganised and incremental change process will take place. In this scenario participants think that a number of different models including command and control, NPM, and more modern forms of networked governance will co-exist in different parts of the system depending on what problem they are 
addressing. For example, participants indicated that initiatives relating to joined-up government and 'Managing for Outcomes' could well result in new networked governance arrangements in particular areas and/or relating to particular policy issues (e.g. multiple problem families). These arrangements will not necessarily permeate other parts of the system, at least in the short term.

The majority of focus group participants were of the view that public management change will occur in New Zealand as a result of a mixture of pressures, rather than one in particular. In addition, they were strongly of the view that public officials will at all times remain in control of their organisational environment and any changes that are effected will occur as a consequence of deliberate decision-making on the part of public sector leaders. While people recognised that this may not always be possible, they were of the view that change occurs by and large as a deliberative process. In this respect they took the view that technology will be adopted and used if, and only if, it can be demonstrated to advance the key policy, legal, and regulatory agendas of the day (i.e. improve the ability of public officials to carry out their executive functions to government).

In this respect, changes that occur in public management over the next 20 years may be significantly assisted by technological developments and indeed enabled by them but participants were clear that these will be driven by changes in different priorities in the government and public service agendas such as managing for outcomes, joined up government, and the push to deliver citizen-centric services. Participants were almost unanimously of the view that major systemic change in the constitutional arrangements of public management will not occur as a result of the use of ICTs. They recognised however, that radical changes to organisational systems and processes including service delivery had already taken place as a result of e-government initiatives, and would continue to do so for the foreseeable future.

The future model of public management in New Zealand (refer s7.1) which most resonated with focus group participants was that described as 'NPM Connected' socially determined public management whereby any systemic changes are largely influenced by complex political, social and economic pressures. In this scenario technological advancements occur as a direct result of decisions made by public 
officials. Focus group participants were overwhelmingly of the view that ICTs are enablers of change, but that the change process itself will emerge from socio-political forces.

\subsubsection{Change drivers}

Although focus group participants identified a situation of strong disjuncture between the private and professional worlds of public officials and in the way public organisations worked with external stakeholders, they nevertheless did not see technology issues as the key drivers of change in public management. Rather, participants identified a range of political, economic and environmental issues as the keys to future change. Five major factors were identified by all four of the groups: globalisation; changes to the role of governments; changes to production modes; accountability; and changes in workforce requirements. The key points respondents made in relation to each of these issues are outlined below:

\section{Globalisation}

All four focus groups identified globalisation as one of the most significant drivers of change in public management. Participants indicated that New Zealand is part of a global community and increasingly nations do not operate independently (e.g. the Zimbabwe elections 2008) but are open to international scrutiny. In this environment New Zealand is under pressure (real and perceived) to ensure it has online capabilities and modernised business processes to enable international communication, information sharing, and trade to take place. All parts of government including the trade, diplomatic, economic, social, and environment sectors are affected by this driver.

Participants posited that in the $21^{\text {st }}$ century there are issues that are common across the globe that concern most, if not all governments. These include, but are not restricted to such things as climate change, safety and security of citizens (terrorism/ hackers/ identity fraud), and the spread of deadly diseases such as SARS and bird 'flu where the risk of a pandemic is significantly increased by the mobility of the international community. In addition, cataclysmic events such as tsunami and cyclone that destroy physical and human environments both affect global communities and are responded to globally by way of logistical support, aid, and reconstruction. 
With respect to global economies, participants felt that ICTs (especially internet-based technologies) contribute to both international competition and opportunities across all categories of labour, markets and capital. In this respect technologies are the instruments of support for globalisation and at the same time ICT capabilities enable globalisation across a whole range of areas from entertainment and recreation to market engagement. The existence of internet-based technologies has opened up the global economy and the global social interface and enabled them to flourish in ways that are driving change across a number of frontiers including public management.

\section{Changes to the role of government}

In New Zealand, participants saw the move to adopt a Mixed Member Proportional (MMP) electoral system of government in 1993 as having led to significant changes in the processes of polity and public governance. For example, there is what participants described as "more organic processes of policy negotiation". That is, extensive consultation and negotiation processes are now required with minor parties on particular policies in return for support for the Government of the day on issues of confidence and supply. This has significantly affected the way that public officials operate in carrying out policy and regulatory duties. These changes alter the working processes and the relationships officials have with those of other agencies, and with Ministers and other members of parliament.

There have also been changes in the role of government in New Zealand, and throughout the world, that participants identified on matters of regulation and control. To illustrate this, several participants cited examples of governments being called upon to make decisions and introduce policies that have an impact on the span of human life. That is, due to the development of medical technologies there is an increasing ability for intervention with the human life cycle at either end, and governments have a role in mediating this process. For example, the technical capability now exists for medical staff to identify physical defects in humans before birth; to save babies when there are complications with the birthing process; to either save or prolong life following serious accident or diseases; and to prolong life by altering or ameliorating the effects of the aging process on human beings. At all of these stages governments throughout the world are interceding to regulate and control the access to, and means by which these technical capabilities are deployed. Such decisions inextricably affect the 
demographics of a population, and consequentially the scope and quantity of public services required.

Participants thought that there were complicated issues involved with the changing role of government over time relating to individual interest and public value. Government agencies hold a large amount of data on individuals who interact with them especially where they require public services of any form (i.e. licensing, benefits, health services, education and so forth). There are serious questions to be answered about "what the government obligations are in relation to holding, maintaining and using such information sets".

Participants perceived New Zealanders as "a people who are strongly protective of privacy information". In this respect, public officials have to take account of balancing personal confidentiality with the ability to use interactive databases for collaborative purposes that might enable greater public value (e.g. merging name and address information so that individuals do not have to produce the same data multiple times for different agencies). These issues are linked to those of the compatibility of technical infrastructures and the ability of information to be shared to create greater efficiency, and whether such efficiencies would in fact create public value (and how this is defined and by whom).

\section{Changes to production modes}

Participants identified changes to the production modes as another major driver of public management change. They expressed the view that the individual agency approach inherent in the current NPM public management model operating in New Zealand has led to the duplication of resources (including for example, information; policy frameworks; HR and financial management structures and systems; and in some cases technical infrastructure) thereby creating huge financial waste. Collectivity across some core infrastructures was seen as far more cost effective in a country as small as New Zealand. For example, shared services whereby a number of agencies utilise common technical applications under a single license, and collective procurement and base infrastructure that provide core services for the whole public service were all cited as areas that could provide savings if applied across the state sector. 
Participants were also of the view that as a small country with a relatively insubstantial GDP it is important to look at how shared infrastructure can be "managed more efficiently in the collective interest". There was recognition amongst participants that the current resource allocation method restricts the pool of resources available (including skills, information, knowledge and labour) to apply to creating solutions to particular problems. It was acknowledged that the move to an outcome focus through such initiatives as joined-up government and managing for outcomes has resulted in the development of a number of new models for allocating resources, skills and knowledge both within and across departments, and this may invoke further changes in the future:

Life has moved past outputs. Defining and redefining the mandate of the department is required. We need to get rid of the input/output model and replace it with a funding model whereby the $\mathrm{CE}$ is accountable for outcomes. The current model is not accommodating of 'outcomes'. Fiscal cycles drive behaviour within organisations, and drives decision-making.

Furthermore, participants acknowledged that moves toward achieving outcomes by government organisations was producing different forms of co-production whereby government agencies are working more closely with other government organisations, the private and not-for-profit sector and local communities of interest. The view was that in the past there were occasional pockets of this type of co-production for specific issues. One example cited was the Queen Elizabeth II National Trust ${ }^{26}$ set up under legislation in $1977^{27}$ to preserve landscape of value for New Zealanders. This Trust is jointly funded and operated by private contributors and government officials from the Department of Conservation. Participants felt that the managing for outcomes agenda was increasing the frequency of such initiatives.

Working in a co-productive way requires different behaviours from public officials and redefines the roles they have previously held in taking sole responsibility for defining

\footnotetext{
${ }^{26}$ This is a resource that helps private landowners in New Zealand to "protect significant natural and cultural features on their land through open space covenants in perpetuity" (www.openspaces.org.nz).

${ }^{27}$ The Queen Elizabeth the Second National Trust Act, 1977.
} 
problems and controlling their solutions (Eppel et al: 2008). Participants noted that coproduction activities are often facilitated and made possible by internet-based ICTs which enable input from people living and working in other parts of New Zealand and even overseas. This significantly alters the resource pool and how it can be utilised to apply to a particular issue.

\section{Accountability structures}

The fourth driver of public management change, and one that participants regarded as central to the debate about the model of public management for the future, was that of accountability structures. Participants were strongly of the view that within the current New Zealand model of public management the move to outcomes based management (as set out above) over the past five years is not supported by the existing model of output structures. That is, government agencies are not funded to produce 'outcomes' and their accountability and responsibility structures (as legally specified) are in fact counterintuitive to the behaviours public officials have to display in order to achieve collectively defined outcomes. This tension acts as a significant inhibitor to officials developing and using ICTs for collective purposes. The early failure of the eprocurement programme in New Zealand that was intended to provide government agencies with an online process for purchasing capital assets was cited as an example of this disjuncture.

Participants saw the input/output model as "representing both the strength and the weakness of the 1980s public management reforms in New Zealand". While enabling a number of significant inefficiencies of the pre-1989 model of public management to be addressed, it was generally agreed that the output focus of the model may no longer be as beneficial as it was in the past. There was wide agreement amongst participants that the accountability model has to be modified to meet the challenges of the modern age if officials are to be able to utilise ICTs for collective purposes. The following comment summarises the view of the participants on the public management accountability framework:

This is the 1000 pound gorilla sitting in the middle of the room. 
No suggestions were proffered as to the specific modification that needs to take place with respect to the mechanisms of the accountability structure, but people were clear that the disjuncture it causes in relation to the ability of government organisations to contribute in a sustained way to the managing for outcomes agenda is a significant driver of change in the current NPM model.

\section{Workplace requirements}

There was a strong view amongst participants that New Zealand is increasingly experiencing a shortage of traditional workplace skills required in the state sector. As societal demographics are changing towards an ageing population, and societal changes are increasing the disjuncture between personal and institutional experiences (s7.2.1) the state sector is under pressure with respect to workforce capability and in the future may also face capacity challenges. This was seen as being compounded by the expectations of Generation ' $\mathrm{Y}$ ' workers regarding the availability and usage of internet-based technologies. Some of the recent moves in the state sector to more flexible working arrangements for staff were interpreted by participants as an attempt by public managers to obtain, and retain, core skill bases.

In this context, digitisation of paper-based functions and processes at the back-end (i.e. administrative functions such as procurement and financial processing) was seen as essential to compensate for a shortage of traditional work skills in these areas.

Participants saw this type of modernisation as inevitable and increasing as organisations sought to gain efficiency in administrative processing and concentrate on increasing professional skills and expertise available to them.

\subsubsection{Facilitating systemic change}

Emerging from the five core drivers participants identified (as discussed above), was a general consensus amongst participants as to the critical issues to be addressed to facilitate generic systemic change in the New Zealand public management context. The following factors were those that were identified by all four focus groups, in order of what they saw as priority:

1. The output accountability framework

2. Leadership - shared vision 
3. Risk/investment equation

4. Skills/expertise and knowledge.

\section{Accountability framework}

Accountability was identified by all four focus groups as the most critical issue to address in the New Zealand context if systemic change is to occur. Participants acknowledged the benefit of the current accountability framework in that, unlike the previous input-based model, the output-based form of accountability "allows for greater flexibility in management and reduces administrative bureaucracy". At the same time, focus group participants also acknowledged that the current arrangement of public agencies holding individual specialist jurisdictional authority acts to restrict chief executive accountability and places major constraints on all-of-government responses to issues. In this respect, public officials are restricted in the resources they can contribute and the extent to which they can commit to policy and activities that support the collective interest, if those activities are seen to run counter to the accountabilities of the chief executive. In this context participants thought that public officials are not even considering how the use of ICTs might support the collective ability to achieve commonly agreed outcomes.

Participants also saw the accountability framework as a critical issue for public officials because the boundaries of institutional responsibility are rigidly defined (often in legislation) and the incentives are for public officials to work within them rather than working collectively for common outcomes. The formal accountabilities of chief executives reflect legislated spheres of responsibility. Often in a particular sector two or three different organisations may have a pre-defined role, but there are no defined accountabilities or responsibilities for a collective outcome.

The example given to demonstrate this point was that Police, Courts, Corrections, Work \& Income, Education, and Health (as well as some other agencies) all have specifically defined roles in relation to young people. However, none of those agencies has responsibility for ensuring the general health and well-being of young people. This means that there are no structural, financial, occupational, or policy incentives to ensure that they are organised and carry out their defined functions in ways that support the work of other officials and are designed to improve the overall outcomes 
for young people. This type of fragmentation was seen by participants as one of the critical issues that had to be addressed to effect systemic change in public management. However, as mentioned in the previous section, participants were unclear about how the accountability structures should be changed, or what process should be invoked to effect change.

\section{Leadership}

Participants argued that leadership in managing the technology resources of the state sector currently exists, particularly through the ICT Branch of the State Services Commission and the IT CE's forum. As a consequence of this, new forms of managerial oversight are emerging to manage risks and take advantage of opportunities (e.g. the Justice Sector Information Strategy managerial oversight arrangements described in Chapter 5). They were of the view, however, that the New Zealand egovernment strategy (refer 1.4.3) supports the current institutional order, and chief executives only act within their own tightly defined accountabilities and thereby largely only within the best interests of their own agency. Movement toward establishing a common technical infrastructure in New Zealand's state sector ${ }^{28}$ was seen as successful only because the financial cost equation was positive (that is, cost savings were made) and because it had been mandated by Cabinet. Without the latter incentive participants were of the view that the programme would continue to struggle against the principle and practice of chief executive independence.

Participants indicated that a shared vision is needed from people in power who can design, develop, and implement comprehensive change and who have knowledge and understanding of how ICTs can be used to contribute to this process. Much like the 1980s reform process, participants saw a need for such a leadership group to involve both politicians and senior public officials. Participants were clear that this form of leadership does not currently exist and that ICT and e-government leadership as it currently operates does not provide the necessary leadership to ensure the requisite changes occur. It was suggested that leadership change needs to occur at the executive level first. Participants thought that a useful model might consist of five or six Ministers in charge of sectors and responsible for collective outcomes. At the current

${ }^{28}$ This was an early initiative of the E-Government Unit. 
time there are around 84 specialist jurisdictional portfolios and this was seen by participants as an impediment to achieving consensus on a core set of required outcomes.

An appropriate leadership forum would enable such things as changes to the accountability framework to be seriously addressed. Participants indicated that in the absence of such a forum the current systemic disjuncture arising from the accountability framework would continue. In this case, unless there was a major crisis that forced accountability framework changes, the state sector would remain limited in its ability to produce collective outcomes at the rate required to meet societal demands. There was a general view that Ministers would increasingly be frustrated with the ability of the state sector to meet their informational needs and to adjust services to meet the demands of the public.

\section{Risk/ investment equation}

If New Zealand is to be able to develop the technological expertise it requires to operate in a global economy that demands digital expertise and capability, participants saw it as necessary to create an environment that permits and even fosters technical experimentation. People were undecided if New Zealand could afford to operate such an environment, but were equally unsure that the nation could afford not to if it was to maintain any relevancy in the international economy.

Participants saw this issue as critical because it highlights a paradox in the existing system that acts as a significant barrier to change. That is, public officials are risk averse for reasons relating to their role as guardians and stewards of public money and resources. Participants indicated that there were significant negative consequences for public officials if experimentation failed especially in the IT sphere where development costs are high. For this reason creating a balanced environment that rewards innovation is difficult, especially in the absence of appropriate leadership.

\section{Skills/expertise and knowledge}

There was a general view amongst focus group participants that there exists a serious skills and knowledge deficit in the state sector in respect of using ICT applications. Participants claimed that anecdotal evidence showed that the current generation of 
public officials do not have the skills and ability to use the functionality currently available to them to its full potential (e.g. collaborative workspaces/ PSI/ wikis and other interactive communication tools).

It was widely expected that the next generation of workers will have different skills and knowledge and a different set of expectations regarding the technological capabilities that should be available to them in the workplace, as will the clients that they serve. It was suggested that if government agencies did not provide the environment for Generation Y workers to use the technology they know about, they will use it anyway because it is integral to their way of thinking and behaving. It was generally agreed that if their expectations are not met, a workforce crisis will occur whereby government agencies will not be able to attract or retain younger workers.

\subsubsection{Change implementation}

Participants were reticent when it came to describing what features of the current public management bureaucratic model were actually going to change, and how this process might take place. Although they could see and understand the environment they are experiencing, the path to change appears to be extremely unclear. The consensus on the notion that there will be a period whereby multiple models of governance will co-exist indicated that none of the participants saw system-wide radical change as imminent, but that change of a more modest order would be continuous with a cumulative effect.

The major view was that while there are tensions in the current system the status quo is very strong, and at this point in time no irrefutable case for systemic change exists. Some of the current e-government initiatives are producing changes that are very significant in terms of investment and business process changes for individual agencies (e.g. Landonline). However, participants saw these types of business process changes as perhaps representing the current tolerance level for change by public officials in the immediate future. This position reflected a recognition by participants that whilst tensions clearly exist, as described in s7.2.1, the current accountability system, legislative framework of the state sector, and constitutional protocols (s7.2.3) act to constrain change processes. Certainly in the absence of strong leadership on this issue (particularly political leadership), participants were of the view that the momentum 
does not yet exist to pressure for fundamental systemic change. Nevertheless, participants did argue that systemic change was both necessary (s7.2.3) and inevitable (s7.2.4) in order to respond to external pressures, but they recognised that institutional constraints meant change was likely to be slower than might have been expected given the transformational aspirations documented in the New Zealand e-government strategy (s1.4).

\subsection{Identifying where future transformational effects occur}

The focus groups looked at the future of public management in New Zealand and were therefore working in a predictive mode. However, it will nevertheless be useful to use the analytical categories applied to the case studies (s4.3; s5.3; s6.3) to further explore how the focus group participants described the potential future of New Zealand public management.

\section{Leading discourse}

Focus group participants were cognisant of the current pressure for output related fiscal management with an emphasis on producing organisational efficiency. The main discourse in the groups, however, was predominantly related to moving beyond this model to find ways that organisations can be managed to achieve social, economic and environmental outcomes.

There was a strong theme running through the discussion of how public management resources can be most effectively utilised to enhance organisational collaboration to produce results that are not primarily measured by fiscal outputs. The ethos of collectivity dominated the discussions. In this context ICTs were seen as a means for achieving collective resource management. Participants saw major inhibitors in the current model of public management to building and deploying ICTs effectively for this purpose.

\section{Management model}

Participants did not make comment on the efficacy, or otherwise, of the current hierarchical model of management in the state sector. Rather, they identified three other aspects of the current management model that need to be changed in the future. Firstly, participants saw the principle and practice of chief executive independence as 
working against the collective interest, and inhibiting the ability of public officials to achieve common outcomes. They saw the duplication of infrastructure and resources as contributing to financial inefficiency across the state sector.

Secondly, participants saw the need for new arrangements whereby a range of officials from different agencies work together to provide managerial oversight, funding, infrastructure and deployment of skills and expertise to address particular policy areas. In the absence of systemic change, participants thought that such arrangements would be set up informally and will appear in pockets alongside other more conventional managerial arrangements depending on the policy issue being dealt with.

Participants also saw the need for new leadership requirements at the executive level of parliament and chief executives to lead changes in public management for the future. Knowledge of ICTs and how they can be used to establish new forms of communication and information exchange was seen by participants as necessary for the development of new modes of working in the state sector.

\section{Workforce characteristics}

ICTs are now so pervasive in the workplace and in society that participants felt that their ongoing deployment would result in changes in both the capacity and capability of the state sector workforce in New Zealand in the future. They indicated that if the state sector continues to be risk averse in its management of technical resources agencies will not be able to attract and retain future generations of workers. This will lead to a workforce crisis.

Participants also saw the skills and expertise required to design, develop and maintain ICTs as requiring an increase in workforce personnel with specialist technical skills. In addition, public officials working in more traditional roles of policy advisers, researchers, legal advisers and so forth would also need a higher level of skills and expertise in using ICTs to keep abreast of the new ways technologies are being used in the workplace. 


\section{Relationship management}

The implications of future changes for relationship management processes were inferred by focus group participants rather than openly discussed as a discrete topic. In particular, participants spoke about the need to alter production modes to enable coproduction whereby policy issues are defined by a wide group of participants rather than public officials, and policy and operational solutions are negotiated by the group. ICTs were identified as a critical conduit through which co-production could be facilitated. Co-production implies new forms of relationship management as a wider set of actors are involved in policy development and service delivery processes.

\section{Record management}

Participants did not explicitly discuss the impact of future models of public management on current record management protocols. Some people indicated that the New Zealand state sector is losing institutional knowledge because of poor record management processes. No specific details or examples were provided to support this perception.

\section{Structure}

Participants were not exercised by the notion of changes in the organisational structure of public management in the focus group discussions. Their views on structure reflected more concern with the structures of management and governance as opposed to physical organisation. Some of the discussion covered the potential for different 'back office' arrangements through better resource management processes. In particular, participants saw online technologies as offering the capability to rationalise core functions that are common to all government agencies such as procurement, IT infrastructure, and other forms of corporate operation.

\subsection{The nature of future transformational effects}

While participants were very conscious of the impact ICTs appear to be having on New Zealand as a society they were cautious about predicting the effects on the structural, constitutional and regulatory arrangements of public management. Instrumental changes occurring at the level of business process within and between government agencies and in the client interface were acknowledged by participants but there was greater reticence about regarding such changes as necessarily precursors to systemic 
change in governance. Participants acknowledged that the status quo in public management is difficult to change and does not happen easily, or quickly. There was a general recognition that issues of systemic change are complex and 'common sense' expectations may not necessarily be realised because of the interdependency of preexisting structures, protocols, relationships, and business processes that may act as barriers to change.

Nevertheless, participants were clear that the availability and use of ICTs by the general public were creating a situation of pressure and disjuncture within state sector organisations that will in the longer-term demand a systemic response, rather than a process-based one. Participants indicated an awareness that pressure within the existing public management model is building, acknowledging that some changes are already occurring that they characterised as so complex that they are difficult to define, anticipate and manage. There was a strong view that in the next twenty years public management in New Zealand may well be different in some core areas of systemic arrangement (e.g. accountability structures) from what exists today. The means by which this will be achieved is uncertain, but participants did not consider that it would either be forced, or facilitated by the personal and professional use of ICTs or by the deployment of ICT applications for business purposes.

Rather, participants saw the disjuncture public officials experience between their use of ICTs in their private sphere and the availability and deployment of ICTs in the professional sphere as being only one factor that combines with other political and policy driven pressures to create a set of complex tensions within the public management system. In particular, participants identified issues of globalisation, changes in the role of government, production modes, and workforce requirements along with pressures relating to the public management accountability framework as the primary change drivers. At this point in time the pressures created by these forces were not regarded by participants as being of a serious enough nature to constitute a 'burning platform' from which to launch radical systemic reform. Overall, participants anticipated that in the short-term change will continue to be accommodated within current systemic arrangements. Participants acknowledged that this may pose difficulties given the existing accountability framework, but nevertheless believed that 
significant changes were achievable given the right incentives and some managerial flexibility.

The change process will involve a number of different process arrangements operating simultaneously in different parts of the state sector for different reasons. Participants thought that change will be socially determined in that it will be controlled by senior public officials and driven by political and economic concerns, and it will continue to put pressure on the existing system (accountability/ workforce capabilities). Over time these pressures may force a greater level of change. However, in the absence of an economic or fiscal crisis ${ }^{29}$ that will create an immediate need for a political response, combined with the absence of strategic leadership, systemic change is unlikely to occur in the immediate future.

Of the models of future governance posited to the focus groups (refer s7.1) participants saw the 'NPM Connected' model as having most merit consistent with their interpretation of how change will take place in the New Zealand state sector over the next 20 years. This model holds that technology will be used by officials to implement policy and business process changes. Broad policy and political objectives will be the key drivers of change in the public sector. Any systemic change will need to be deliberatively made by senior public officials and parliament. The implications of this model will be discussed further in Chapter 8 .

The focus group data did not suggest that participants saw the current system as having the types of managerial, communication and financial inefficiencies within it that precipitated the 1980s reforms. However, the policy, resource and infrastructure disjuncture that is apparent in the New Zealand public management system does indicate rising pressure on public officials from ministers, businesses, and the general public). These tensions could potentially create a situation whereby they become significant inhibitors to the realisation of critical goals for the state sector (e.g. being the 'employer of choice') and serious barriers to ministers in realising their policy objectives. It may become increasingly difficult for public officials to continue to

\footnotetext{
${ }^{29}$ It should be noted that the focus groups took place in November 2007 before the full effects of the current international economic crisis were apparent. The impact on public services in New Zealand of the 2008 financial downturn has yet to be ascertained.
} 
effectively service politicians and the public of New Zealand. Unresolved, the existing tensions hold the potential to create workforce and performance crises in the future that may force systemic change to occur more rapidly. 


\section{Chapter 8: Understanding transformation}

\section{Chapter outline}

The e-government case studies (Chapters $4-6$ ) and the focus group discussions (Chapter 7) highlight the differences in scope and nature between instrumental and systemic transformation (refer 2.5.1). In this chapter the empirical data is examined further to identify any substantive differences between the two groups of research subjects (case study respondents and focus group participants) with respect to their interpretation of technology/e-government (s8.1) and how it can be used to create change in public governance (s8.2). These different interpretations are then brought together to gain further insight into the concept of transformation in the New Zealand public governance context (s8.3). From this, a new model of public governance in New Zealand is mooted (s8.4). A summary of the research analysis is provided in s8.5.

\subsection{Technology discourse by research subjects}

To understand how the research subjects interpreted e-government it is useful to refer back to the theory of 'institutional economics' (Boston et al: 1996; Scott: 2001) which underpins the NPM model of public management currently operating in New Zealand (Schick: 1996; Norman: 2003: Walters: 2008). One of the basic tenets of this theory is that information is a scarce (and therefore expensive) commodity (Scott: 2001). However, the advent of internet-based technologies in the public domain has altered this premise. As has been demonstrated in the case studies (Chapters 4-6) information is now not only plentiful, but can be used flexibly to achieve better operational outcomes. The availability of advanced technological capabilities provides public officials with the means by which to alter the way information, as a primary resource, is managed.

In each of the case studies the discourse on technology, manifested in the discussions by senior public officials on e-government initiatives, relates to the way that ICTS provide the means to record and use information resources more efficiently. Public officials interpret e-government as the availability of online capabilities that enable multiple users to utilise a single set of data for a range of different purposes at a lower 
unit cost. For example, land titles and survey data can be digitally created and regardless of the originating source can be held in an electronic data-base and accessed by people in different geographical locations in the world at minimal cost. Under the previous paper-based system such records were physically held in a range of geographically dispersed locations throughout New Zealand and only available to those who were able to visit the relevant offices during office hours. A higher unit cost was necessary to maintain personnel to process the paper-based records, and to operate the physical infrastructure to store and process the records.

Case study respondents noted that digitising data and making it available to a broad range of users for multiple purposes also contributes to improving operational effectiveness. Data creation can be tightly controlled by means of digital certificates and Public Key Infrastructure security to maintain the integrity of the data.

Digitisation enables greater accessibility and use of information data sets and provides greater long-term data preservation and disaster recovery options. Data integration is a means of reducing operational duplication, reducing costs and improving resource efficiency. In this respect, ICTs are regarded by officials as a management tool. The emphasis is on the innovative management and deployment of information resources.

When thinking about the future, the discourse on technology in the focus groups was somewhat different. The emphasis was not on using ICTs to achieve fiscal efficiency or operational effectiveness, but rather to facilitate a range of different working relationships for the purpose of improving the quality of services to the public and achieving better social, economic, and environmental outcomes. Focus group participants regarded the flexibility, speed and volume of data that can be processed by ICT capabilities as providing a range of business benefits relating to the quality of services and of business and administrative processes that were previously unavailable using manual processes for handling information resources. The perspective on technology therefore shifts from one of how to use existing resources better, to one of how to access and use new resources to do things differently, or perhaps even to do different things, to achieve a different set of outcomes.

For example, ICTs also provide public officials with the ability to communicate locally, nationally and globally at rapid speeds for little or no cost thereby enabling 
government business to be conducted in ways that previously were impractical. There was a strong view amongst focus group participants that ICTs could be used more effectively by public officials in the future to widen the resource base available to government in addressing a broad range of policy areas (through co-production); to apply a wider range of information and knowledge to solving policy dilemmas and managing public resources; to provide higher quality services at a lower cost; and to manage a broad range of internal and external stakeholder relationships more effectively. The key challenge for state sector officials therefore, is learning how to use the technical capabilities of ICTs more effectively to create and facilitate new models of resource allocation and management for better service delivery and the development of policy solutions. Focus group participants regarded ICTs as the practical mechanism that enables public officials to manage resources collaboratively in co-operation with multiple stakeholders to achieve collective outcomes.

The technology discourse by focus group participants was less linear in focus to that of the case study respondents. The emphasis subtly shifted from managing information resources to using communication resources more effectively. By widening communication channels public officials have more options in identifying and using resources, delivering services and managing a broad range of relationships. In effect, ICTs are the link between the policy direction public officials wish to take (managing for outcomes) and the ability of government organisations to identify and use a broad range of resources in addressing policy concerns.

Emphasising the communication capabilities of ICTs enables a more sophisticated consideration of the possibilities for altering business processes, stakeholder relationships and communication processes. It also raises the possibility of reconsidering the "instruments government uses to animate and direct the production system for achieving desired goals" (Moore \& Hartley: 2008: pg 18). For example, focus group participants indicated that regulations, legislation, funding policies and procedures, performance agreements, leadership and managerial oversight arrangements would need to be adjusted in the future. This was not seen as a consequential outcome of e-government initiatives but as a prerequisite to enable public officials to take advantage of the benefits of ICTs and enhance collaborative 
working arrangements. Without such infrastructural support, the ability of public officials to fully utilise ICTs would be limited.

\subsection{Public governance discourse by research subjects}

With respect to public governance, a shift in thinking of a similar nature can be discerned between the two groups of research subjects. In each of the case studies the public management discourse is consistent with the current model of NPM with its emphasis on improving operational efficiency and effectiveness. For LINZ managers this is primarily about driving organisational operating costs down. For agencies in the Justice sector it is about managing sector resources to enhance the operational outcomes for each individual agency in the sector. In a similar vein the Policy and HR managers who drove the PSI initiative wanted to improve business processes for greater efficiency and effectiveness in areas of policy development and corporate functioning. Digitisation of information resources and using ICTs to manage those resources more effectively is perceived by respondents as ensuring that operational processes are carried out in a fiscally responsible manner. In the case of LINZ, respondents also see digitisation of information resources as having the added benefit of enhancing New Zealand's economic competitiveness in a global economy and protecting New Zealand's core economic assets.

The current accountability structures of the NPM model allow for chief executive independence and flexibility in the use of resources to deliver outputs agreed with Ministers and The Treasury. Collaboration occurs where it benefits the output arrangements of individual agencies. This is clearly demonstrated in the way formalised structures (including managerial oversight arrangements) are applied where the outcome of the e-government initiative affects the ability of the agency to meet the required outputs (e.g. Landonline and JSIS).

In keeping with the NPM model, the case studies demonstrated how ICTs can enhance and improve existing business processes thereby enabling state sector officials to produce services at lower costs and to make better use of the available financial, physical and human resources. Officials recognised that some things need to be done differently (e.g. collaborative managerial oversight arrangements for JSIS) but these changes are limited to specific policy initiatives and put in place to ensure the benefits 
to each contributing agency are realised. None of the case studies involved changes to the legislated mandate or functions of the initiating organisation. ${ }^{30}$

There is no evidence in the case studies of any cohesive, strategic intention by public officials to use technology to effect changes in the organisation, structures, roles or functions that currently constitute the public management system in New Zealand. Even where technological capability could theoretically enable a range of different working structures and processes (e.g. the PSI), no strategic or systemic incentives exist to make this happen. The case studies demonstrate that senior state sector officials regard the purpose of e-government investment in operational initiatives as being to improve administrative and transactional processes in order to gain procedural and financial efficiencies, improve service delivery, and drive down costs. Current governance arrangements of public management (i.e. at the Executive level) remain unchallenged by the design and implementation of operational e-government initiatives. No attempt has been made by public officials to alter the regulatory or legislative power relationships between government agencies and the sectors of the community that they interact with (business or members of the public) by the implementation of e-government initiatives.

In the discussion on the future of public management in New Zealand the discourse started to move to a focus on how state sector organisations can be managed to achieve social, economic and environmental outcomes. Collaboration and co-ordination of resources across the state sector was seen as a means to enhance collective effectiveness. Participants indicated that in order to achieve collective outcomes the NPM model needs to be altered in several critical aspects to enable greater flexibility in resource deployment and management. Although the ethos of managing for outcomes has emerged from the Review of the Centre (SSC: 2001) ${ }^{31}$ which also endorsed the existing institutional framework, focus group participants saw implementation efforts as being restricted by current systemic arrangements. They saw the need in the future for more flexibility of business process, greater use of a broad range of community and

\footnotetext{
${ }^{30}$ A change was required to the Land Transfer Act, 1952 to enable the required changes to business process to accommodate electronic lodgement procedures (Land Transfer (Computer Registers and Electronic Lodgement) Amendment Act, 2002). This has no impact on the legislated function of LINZ.

${ }^{31}$ Refer to s2.3.1 (FN: 8) for an explanation of the Review of the Centre.
} 
other non-government resources, varied management oversight arrangements, and different forms of performance measurement based on greater variation in funding arrangements, including financial accountabilities.

The existing accountability arrangements based on output funding and the independence of chief executives in managing resources to best deliver those outputs was seen by focus group participants as effective in rationalising resources to achieve cost efficiency, but counterproductive to managing resources to achieve collective outcomes. New models of leadership were posited at the executive level of government to enable public management resources to be utilised in a more responsive manner. Participants recognised that to establish new forms of leadership there would need to be a reconsideration of current performance management procedures.

Changes in relationship management, especially with the New Zealand public, businesses, and non-government organisations, were also highlighted by focus group participants. New models of co-creation and co-production were seen as necessary if outcomes are to be achieved. ICTs were seen as a useful tool to reorganise the 'back office' procedures of government to enable more flexible use of information and as a communication aide at the operational 'front-end' (i.e. the interface with the public and businesses).

\subsection{Future transformational effects of e-government}

What then do the discourses on technology and public management in New Zealand indicate about the concept of transformation and the effects of e-government? The combined view of both groups of research subjects indicates that over the next 20 years in New Zealand ICTs will be used by public officials in ways that may create both instrumental and systemic transformation. Instrumental transformation will occur as an outcome of the implementation of e-government initiatives. Systemic transformation, on the other hand will need to be deliberatively instigated and managed by senior public officials in order to enable the more effective use of ICTs to achieve policy outcomes.

The interpretation by senior public officials of e-government as a means for achieving organisational efficiency gains would imply that any transformational effects of e- 
government are likely to be instrumental. That is, while e-government initiatives may contribute to a range of efficiency benefits to different government and nongovernment stakeholders, the order of socio-political relationships and the referent frameworks of public management remain unchanged. However, the focus group discussions suggest that the situation is more complex. Participants strongly indicated that a case for systemic change does exist (refer s7.2.1) but that the extent of change required, and the process by which it will happen, has yet to be determined (s7.2.4). The caveat on this proposition is that such changes are likely to be the consequence of the convergence of a number of sophisticated inter-related political, social, economic and environmental pressures including technological advances. As such, any public governance changes that do occur cannot necessarily be attributed to the implementation of e-government initiatives alone. Rather, they are more likely to be instigated as a means to achieve socio-political outcomes. However, the effective use of ICTs to achieve the desired outcomes will also be reliant on systemic changes.

That is, the discourse on the future of public governance in New Zealand implies that change may occur in simultaneously counterbalancing ways. That is, political, social, economic and environmental pressures may combine in ways that create systemic change, and at the same time systemic changes may be necessary to enable public officials to take full advantage of ICT capabilities in order to position themselves to respond appropriately to changing policy objectives created by socio-political pressures (s7.2.4). It may be difficult to assess which of these forces is dominant and will have the greater influence on effecting public governance changes.

The contribution made by technologies to changes in public governance relates to the behavioural and communication changes between public officials and stakeholders are made possible by the utilisation of ICT capabilities. The empirical data from both groups of research subjects suggest that there will be three distinct effects discernible from the implementation of e-government initiatives over time, and each will have different influences on operational practices and governance arrangements.

\section{Using ICTs to achieve instrumental transformation}

Firstly, e-government initiatives will continue to be used primarily to achieve efficiency and effectiveness gains in the New Zealand state sector and this will result in 
various forms of instrumental transformation such as those demonstrated in the LINZ and JSIS case studies. As argued in s6.5 the instrumental transformational effects of egovernment can be powerful in terms of the operational impact on individual organisations and the client experience of service delivery. In and of themselves however, they will not effect changes in public management governance arrangements.

\section{(ii) Using ICTs for collaboration and co-production}

The implementation of ICTs will also be used to support public officials' responses to major socio-political drivers of change in public management such as globalisation and changes to the role of government in society, production modes, accountability, and workforce requirements (s7.2.3). Focus group participants indicated that a number of new organisational processes and inter-agency/cross sector working arrangements will start to emerge alongside the more traditional modes of operating (s7.2.1). These will include, but not be restricted to, such features as new inter-agency managerial oversight arrangements (e.g. JSIS initiative: refer s 5.2.4); new forms of public consultation on policy issues using electronic forums (e.g. e-participation forums utilising wikis and/or blogs as well as other interactive capabilities); and new forms of co-creation and coproduction (s7.2.1). The ability that ICTs afford to reach beyond traditional jurisdictional boundaries and access wide information sets, and communicate with people with different spheres of knowledge and expertise, will be increasingly important to public officials as they seek to expand the government and nongovernment resources available to address social, economic and environmental issues (Bellamy: 1998; Moore \& Hartley: 2008).

These new ways of working are likely to be applied on a case-by-case basis. Public officials will make adjustments to their working environment to accommodate the coexistence of different forms of working arrangements (s7.2.1). The existence of multiple working modes will serve to increase the internal disjuncture officials experience (refer 7.2.1) between practice and the premises of organisational independence embodied in the NPM public management model. Focus group respondents were of the view that growing internal disjuncture will increase pressure for systemic change. 
(iii) Using ICTs to expand the resource base of government

The third effect of the implementation of e-government initiatives is that public officials will use ICT capabilities to alter both the information flows within the state sector (Taylor \& Lips: 2004) and the communication modes by which business is conducted. The alterations in information flows are important in creating the instrumental changes that improve operational service delivery and drive down transactional costs. Landonline and JSIS are both examples of how core functions can be done differently by using ICTs. The changes in modes of communication, however, open possibilities of accessing a wider range of resources (people, information and knowledge) and utilising them to address substantive operational and policy issues in the state sector. This effect has the potential to redefine traditional boundaries of time, space, and fields of knowledge within which public sector functions are delivered.

These three effects each signify substantive change in the way public officials organise themselves to carry out their duties. In the latter two cases, systemic alterations (e.g. in accountability arrangements, legislation and/or regulation) may need to occur to enable different working arrangements to be most effective. Aspects of the structural and governance impacts anticipated by scholars (Frissen: 1998; Fountain: 2001; Dunleavy et al: 2006; Tapscott: 2007. See discussion: s2.4) can be seen in the way ICTs will be utilised by public officials.

In particular, the empirical evidence provides support for Fountain's proposition that a 'virtual state' will emerge whereby groups of agencies are linked by common clients via co-location of information, and integration of some activities that will require operational, political and institutional change (Fountain: 2001: pp 98 - 103). Also, Frissen's (1998) concept of ‘deterritorialisation' whereby information and communication can be organised independently of existing patterns of decisionmaking, is central to co-production and using ICTs to expand the resources available to government. The move towards the provision of more agile, responsive government services and the mandated channels reductions anticipated by Dunleavy et al (2006) can also be seen to be emerging in examples such as that provided by the Landonline case study. While the evidence gathered in this research is not extensive enough to support more fully the theoretical propositions of Frissen (1998), Fountain (2001) or 
Dunleavy et al (2006) (refer s2.4) they are consistent with the general theoretical concepts of significant and enduring change that these scholars propose.

The understandings of e-government that have emerged from the focus group discussions, however, more closely fit with Tapscott's (2007) notion that different types of forces are converging to force public sector transformation: technology; demographics; social networking; and economics (Tapscott: 2007: pp 2-3). Each of these factors were identified by focus group participants as contributing to the existing tension public officials experience between the opportunities offered by the use of ICTs and the institutional constraints within which they work. There was a lack of clarity, however, regarding what systemic change is needed to manage or reduce this tension, and how a change process could be put into effect.

Focus group participants were relatively conservative in their consideration of systemic change; proffering no suggestions about when and how changes would take place (refer s7.2.3). This did not appear to stem from a lack of awareness of the requirement for change in the New Zealand governance model (s7.2.1), but rather from recognition of the complexities involved (s7.2.3) and an awareness that the solution in some critical respects such as leadership lies in the political arena (s7.2.4) over which they had little influence, and less control. Nevertheless, participants saw the change process as inevitable, but the speed at which it would occur is likely to be constrained by the nature of the public governance institution itself.

\subsection{A new model of public governance in New Zealand}

While the case studies demonstrate reasonably clearly how e-government implementation may create instrumental transformational effects, it is less clear is what forms of systemic transformation will be required to enable public officials to use ICTs for collaboration and co-production purposes and to expand the resource base of government (s8.3). Focus group participants described the process of systemic change in the public sector as multifaceted and indicated that although the current model of public management is under pressure from a range of different aspects there is not currently enough disruption to invoke radical systemic change of the order that took place in New Zealand in the late 1980s (refer s1.4.2; s7.2.5) including a reorganisation 
of chief executives accountabilities, alterations to management ethos and business processes, legislation and regulation changes, and broad-based structural changes.

Rather, the focus group participants took a position that the status quo is resilient enough to tolerate quite high levels of disjuncture and pressure (s7.2.5; Fountain: 2001). This is consistent with the concept of organisational isomorphism (DiMaggio \& Powell: 1983; s 2.3.1) which asserts the tendency for the same organisational form to be created, and re-created over time. Thus institutions are very stable and systemic change is not achieved easily. Scott asserts that “...institutions by definition connote stability but are subject to change processes, both incremental and discontinuous" (2001: pg 48). This implies that a great deal of change can occur within the institution itself without challenging systemic stability.

From this perspective it can be assumed that any systemic change in the New Zealand public sector over the next 20 years is likely to be gradual and incremental. That is, that NPM in its current form and the political relationships that underpin it will largely remain intact, and what systemic changes do occur are likely to be adjustments to existing features of the model. Focus group respondents were predominantly of the view that change will be deliberatively controlled by public officials as they respond to a wide range of socio-political variables. That is, in the New Zealand context governance changes to the state sector are most likely to be implemented consciously by senior officials in collaboration with ministers to create the environment necessary to respond to complex pressures, rather than emerge as latent effects of other phenomenon (such as e-government initiatives).

The table below (Fig 4) sets out the potential changes to the existing NPM model of public governance in New Zealand over the next 20 years. The model is based on the 'NPM Connected' scenario provided to focus group members as a discussion starter (Appendix 2) and has been adjusted to take account of the views that have emerged from the public officials interviewed for the case studies and the focus group discussions. The changes identified may emerge as public officials take advantage of the communication capabilities that advanced technologies offer. The changes are mapped against the base-line model established in Chapter 3 (refer Fig 3: s3.2.1) to highlight the where change may occur, and what the nature of that change might be. 
Many of the predicted changes are subtle and will come into effect over time.

Nevertheless, they highlight those features of the NPM model where change is most likely to occur (italicised in the right hand column) based on the availability of new resources and the development of new modes of working. These are facilitated by ICTs and occur as a response to generic drivers of public management change (refer s7.2.3).

Fig 4: Potential Changes to NPM in New Zealand

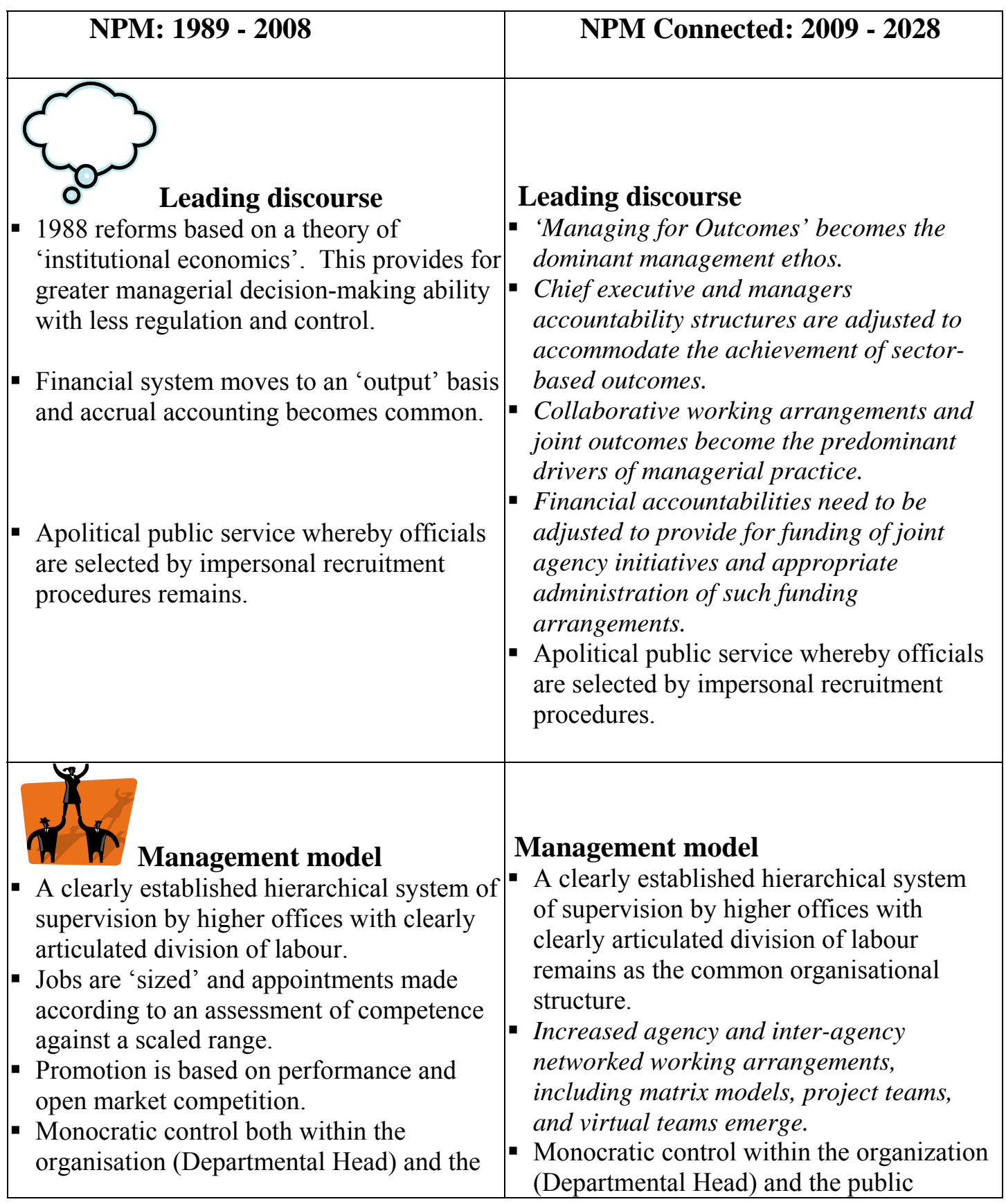




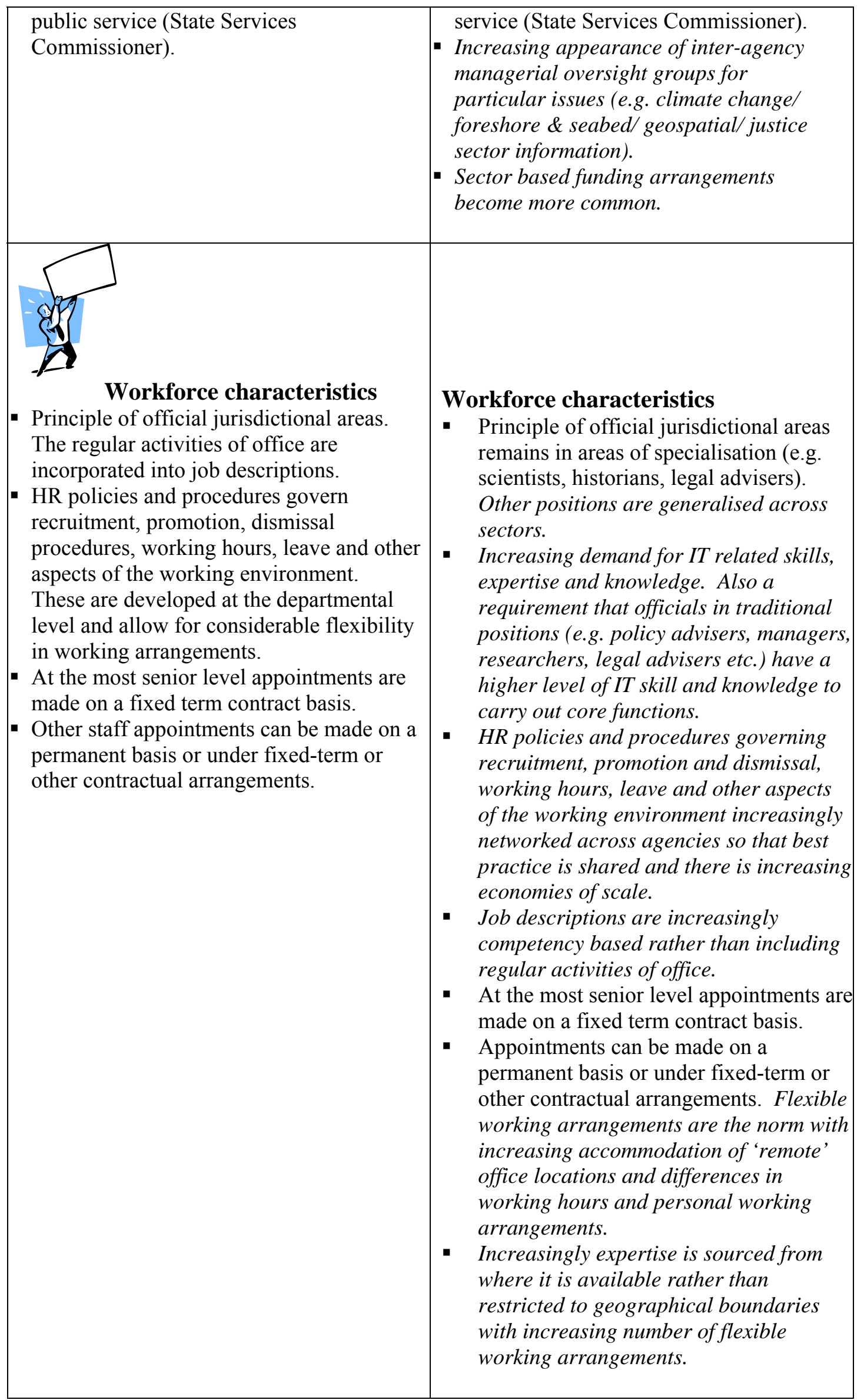




\section{Relationship management}

- Move to collaborative working arrangements whereby the interests of 'sectors' are taken into account on an issue-by-issue basis.

- More inter-agency working arrangements at a formal and informal level.

- Review of the Centre (2001) indicated a need for greater collaborative effort, and the development of the move to 'managing for outcomes' emerged. This is led at the most senior level.

\section{Relationship management}

- Collaborative working arrangements based on the interests of 'sectors' increase with the aim of achieving common outcomes for the public for which agencies will be held accountable.

- More inter-agency working arrangements at a formal and informal level facilitated by Internet based collaborative working tools networked across the public/ state service.

- Policy development processes will increasingly engage with a wider range of resources from outside the public sector to define issues and design and implement solutions.

\section{Record management}

- Electronic document (and record) management systems are introduced. These usually operate in conjunction with paper-based systems.

- Wide range of government held information is available on agency and related government websites.

- Disaster Recovery Backups are commonly held off-site (often in other geographical areas) so that the critical infrastructure of government can be maintained in a national emergency.

- Other official records such and administrative functions are starting to become electronic (e.g. payroll systems; financial management systems; HR/personnel records etc.). Each department is building its own system according to its own needs.

\section{Record management}

- Official records are held in electronic document (and record) management systems.

- Government held information is increasingly available on agency and related government websites. Access can be obtained through 'citizencentric' portals organised around the needs and interests of users.

- Disaster Recovery Backups are commonly held off-site (often in other geographical areas) so that the critical infrastructure of government can be maintained in a national emergency.

- Other official records such and administrative functions are increasingly digitized (e.g. payroll systems; financial management systems; HR/personnel records etc.) and these are becoming standardised across the state sector to reduce transaction costs.

- Those records pertaining to individuals become networked and transportable across the state sector. 


\section{Structure}

- The principle of single jurisdictional responsibility remains but is configured differently. In some cases policy and operational functions are split.

- Development of policy 'ministries' (e.g. health, education, justice, transport, labour)

- Establishment of single focus operational departments (e.g. Corrections, Courts, NZ Income Support, Child, Youth \& Family). In the past 5-6 years some of these have been regrouped (e.g. parts of the Department of Labour were merged with NZ Income Support to form Work \& Income NZ which was later re-linked with its policy arm under the umbrella of Ministry of Social Development).

\section{Structure}

- The principle of single jurisdictional responsibility remains but is configured in clusters of sector based organisations.

- Policy and operational functions remains split in those cases where this maximises efficiencies.

The 'NPM Connected' model above demonstrates that the most likely ICT-facilitated systemic changes in public management in New Zealand over the next twenty years will be:

- an adjustment in managerial accountability structures to facilitate collaborative working arrangements to achieve joint outcomes

- standardisation of common administration functions

- sector-based managerial oversight arrangements

- collaborative working practices

- increased IT skills and knowledge

- co-production using resources available in geographically dispersed areas

- flexible working arrangements, and

- flexible funding arrangements to support collaborative resource allocation and management dedicated to achieving agreed policy driven outcomes.

Some of the changes indicated in the NPM-Connected model can already be seen in the way New Zealand public officials currently carry out their functions. Both the JSIS case study and the focus groups indicate for example, that sector-based managerial oversight arrangements are currently in place in New Zealand for specific initiatives. 
Similarly, LINZ officials noted a movement towards a requirement for greater IT skills and knowledge in their organisation, and reported that more flexible working arrangements were being instigated by using ICT capabilities. However, the research subjects also indicated that these examples were linked to specific policy areas and were not necessarily part of mainstream practice in the New Zealand state sector.

Not all of the changes identified in the NPM-Connected model will require legislative or regulatory change. However, it is likely that changes to the accountability structures of chief executives and managers will be pivotal in enabling other changes to take place. Formal processes of review and legislated mandate will be required to enable accountability structures to be altered. Most of the other changes identified are likely to emerge over time. They will be facilitated by shifting the emphasis on managing information as a primary resource to gain efficiency, to one of utilising communication capabilities. Changes in communication modes enable the harnessing of new resources, skills, and expertise and facilitate new modes of service delivery and resource management.

\subsection{Future public governance in New Zealand}

The analysis of the case studies and focus groups suggests that in the next 20 years in New Zealand the transformational effects of e-government are likely to have two distinct forms. The implementation of e-government initiatives in public organisations may result in instrumental transformation whereby substantive changes may occur in the form, shape, appearance and/or function of the existing administration, information management and/or service delivery practices. These changes may have a consequential impact on organisational structures and/or management practices (s2.5.1). Secondly, it is also likely that public officials will introduce some adjustments to the current NPM model of public governance thereby producing systemic transformation. As a consequence, public officials will be able to more effectively utilise ICTs for the purpose of establishing collaborative and co-productive working arrangements, and to expand the resource base available to apply to the resolution of policy issues.

The empirical data from this research provides no evidence that any alteration in the fundamental principles and practices of governance as exemplified in the current NPM 
model will occur in the immediate future in New Zealand as a direct result of the design, development, and implementation of e-government initiatives. E-government is currently implemented by public officials to manage and interrogate information and data sets more effectively to improve service delivery to businesses and the public, and to drive down transaction costs. However, the data from the focus group discussions does suggest that the use of ICTs will result in some changes in public management governance arrangements in the future. As yet, where these changes will be and when they will take place remains unclear. At the current time there is no strong case for immediate radical and disruptive systemic change in the view of the focus group participants. Whilst public officials experience some level of personal and professional disjuncture, particularly as a result of using ICTs, research participants did not regard this as enough in itself to justify systemic change of a broad and encompassing nature.

Focus group discussions indicated that there is internal pressure building around the inability of public officials to utilise the capabilities of ICTs to service Ministers at the speed and to the quality standard of private individuals and businesses. It is this performance deficit, combined with future workforce capability deficits created by a disjuncture between the skills and expertise of younger workers and the inability of government agencies to provide an environment in which those skill sets can be used (s7.1) that are most likely to create the level of pressure necessary to produce future systemic change. In addition, the 'managing for outcomes' policy orientation emerging from the 2001 Review of the Centre requires collaborative working practices at the operational level in order to be successful, and the existing accountability structures are not consistent with this requirement.

Traditional modes of relationship management are resource intensive, time consuming and carry high transaction costs (e.g. face-to-face meetings of interagency officials). The use of technical capabilities for collaboration with respect to information and data sets have been demonstrated to reduce costs and improve operational efficiencies across sectors (refer JSIS, Chapter 5). Interactive ICTs also offer collaborative communication capabilities that could be used more effectively in the future to improve relationship management processes and harness new resources (e.g. by using case management systems utilising shared workspace capabilities). Similar cost savings and efficiency gains to that achieved by data-sharing could be made. 
The data gathered in this research provides no support for the notion that technology will be a primary driver of public management change over the next twenty years. The major change drivers identified by focus group participants were globalisation, changes in the role of government, production modes, accountability and workforce composition. The effects of e-government are seen by the research participants as more subtle, and related to changes in behaviour and communication by public officials that occur through the utilisation of available ICT capabilities.

E-government is therefore integrally related to change processes as an enabler for managing administrative, policy, and service delivery requirements and as a mediator of change processes. The transformative effect of ICTs is instrumental in its impact on organisational processes and procedures, and can be directly experienced by businesses and members of the public accessing government information and services. Benefits include increased transaction speeds, improvements in service quality and consistency, and reductions in purchase price for consumers.

The need for collaborative working relationships to achieve collective outcomes will increase the pressure to alter governance arrangements (e.g. accountability frameworks and funding arrangements) to create the required infrastructure and management environment whereby these operational practices can flourish. Some changes to the legislative, regulatory and funding arrangements may be necessary. It can be postulated that as a consequence of such changes, information and communication flows will be redistributed creating possibilities for new and different levels of interaction by public officials across the state sector and between government agencies and businesses and the public. These changes will manifest themselves in ways that can not easily be anticipated at this time. 


\section{Chapter 9: Implications for New Zealand governance arrangements}

\section{Chapter outline}

In this chapter I will look beyond the empirical data provided by the case studies and focus group meetings (s9.1) to further explore the implications of the 'NPM:

Connected' model of public governance (s9.2). Issues that arise will be discussed and possible steps to be taken towards resolving these will be mooted (s9.3). Areas of further research will be identified (s9.4) and the chapter will conclude with some closing comments on the relevance of the research completed (s9.5).

\subsection{Beyond the empirical data}

As a phenomenon that has largely gained traction in the international public management arena over the past $10-20$ years, e-government may yet be developed in ways that cannot be anticipated at this point in time. It is difficult to make any definitive statements about how e-government as a cohesive programme of work might manifest itself in New Zealand over the next 20 years, as it will be influenced by a broad range of factors including advances in technical sciences and political proclivities. However, the case studies and the focus group discussions have provided a rich set of information that assists in understanding more fully the concept of 'transformation'.

Using the Weberian analytical framework has been useful in identifying where transformational effects are most likely to be seen in the New Zealand institutions of state, and what the nature of that transformation might be. The case studies have demonstrated examples of what instrumental transformation can enable (s6.5). Similarly, the 'NPM Connected' model (s8. 4; Fig 4) provides an indication of where systemic transformation may occur in the future, and what its longer term effects may be. It will now be useful to discuss the 'NPM: Connected' model in further depth to explore some of the possible implications for public governance in New Zealand.

At the beginning of this thesis I noted that the academic debates on ICTs have been characterised by what Miles (1996) depicts as two polar positions relating to the speed and extent of change that will occur as a consequence of ICT deployment. On one 
hand is the view of 'continuism' which holds that the main features of society and the basic power structures are unlikely to change. On the other hand is a view of 'transformism' that regards the information society as a major historical shift characterised by changes in the bases of political power and social classes. ICTs are seen in the latter view as revolutionary technologies (Miles: 1996: p39).

The empirical evidence from the case studies in this research would appear to provide some support for the 'continuism' perspective. The data suggests that at the current time ICT initiatives implemented in the New Zealand state sector are being used by senior decision-makers primarily for the purpose of improving organisational performance through efficiency and effectiveness gains. In this respect, the implementation of e-government initiatives is organisation-centric in orientation. Although some of the transformational effects are significant (s6.5) for individual agencies and their stakeholders, they have no systemic effect on the governance arrangements of public agencies in New Zealand.

The focus group data, however, suggests that public management changes are driven by socio-political factors rather than technology advances. Focus group participants indicated that ICT capabilities can be used to change some fundamental features of public management such as how resources are accessed and used to address policy and operational matters. Conversely, some systemic change will also occur in response to socio-political pressures that will enable public officials to utilise ICTs more effectively to create innovative working arrangements and alter stakeholder relationships. While this does not necessarily lend support for the 'transformism' perspective, it implies that ICTs will be more important in public management change processes than is immediately apparent from the way e-government is currently being implemented by public officials in the New Zealand context.

\subsection{Future New Zealand public governance: NPM -Connected}

The 'NPM Connected' model of public management depicted in Chapter 8 (Fig 4) suggests that in New Zealand a number of longer term changes are likely to occur across several aspects of the current NPM model including management arrangements, workforce, relationship management, and record management. Some of these are already happening in isolated pockets on a case-by-case basis. Changes to the structure 
of organisations may also occur in the future. Modifications to these features of the NPM model have largely been driven by the change in policy direction from output management to managing for outcomes, but they are either enabled or mediated by the use of ICTs. The shift towards managing for outcomes is a significant development in that managerial efforts in some parts of the New Zealand state sector have moved from a focus on efforts to deliver services efficiently to one of achieving greater effectiveness by providing citizen-centric services. Where efficiency has traditionally been measured by public officials as delivering higher volume of services with better quality at lower costs, ${ }^{32}$ the measurement of effectiveness is about demonstrating improved outcomes for service users (Eppel et al: 2008).

While the need to make organisational efficiency gains is likely to remain important for the New Zealand state sector to ensure that fiscal deficits such as those that preceded the 1980's reform do not reoccur, the redirection of policy priorities to economic and social outcomes opens the way for a reconsideration of the use of ICTs. If public officials wish to engage with stakeholders differently, to expand the available pool of resources and to access different realms of knowledge and expertise, serious analysis of the opportunities afforded by reshaping traditional communication modes through the use of ICTs may be necessary. This may require reconceptualising how ICTs are currently deployed as business tools. This will be discussed further in s9.3 below.

The focus group discussions also imply that in the New Zealand context there is a view that a case exists for further systemic adjustment to the NPM model to take place (refer Kraemer \& King: 2006; s2.3). The purpose of such adjustments is to enable New Zealand public officials to more effectively respond to national and international sociopolitical pressures and to ensure that the infrastructure support is properly aligned to ensure that social and economic outcomes can be achieved. The precise systemic changes necessary have yet to be clearly identified but the focus groups indicated areas where initial work will be required (s7.2.4). These will also be discussed further in s9.3 below.

\footnotetext{
${ }^{32}$ Indicators of volume, quality and cost are used in departmental annual financial reports in New Zealand.
} 


\subsection{Issues to be addressed}

\subsubsection{Perceptions of e-government}

The case-studies examined (Chapters $4-6$ ) show that ICTs are being used by public officials as enablers of business reform. Effectively, ICTs are conceived of as a means to put into effect modifications to existing systems and processes to achieve business improvements. In this respect, they are secondary to the change process. That is, managers decide the business modification required and then look to find, or create, a technology that will enable them to achieve the new capability or efficiency gains they desire. In this case, ICTs provide the solution to business 'problems'.

The LINZ case used in this research (refer Chapter 4) is a useful example of this. The business problem was one of a space hungry paper-based process with inadequate disaster recovery and record preservation options. This was compounded by high processing costs and inconsistency of service quality in different geographical locations. Digitising the land title records and land survey information overcame these difficulties. All of the requisite technology did not exist at that time, and therefore some of it had to be developed. While the e-government initiative provided a range of benefits to public users, it was an organisation-centric initiative in conception and implementation. The other operational examples used in this research demonstrated similar organisation-centric characteristics.

If public officials were to conceive ICTs as an integral part of policy and business design, it may be possible to take advantage of the opportunities networked technical capabilities offer to design more flexible and open solutions to policy and operational problems. For example, focus group participants pointed out that collaborative working arrangements often involve officials from different agencies working together to produce citizen-centric services. That is, common clients are 'handed on' seamlessly to each part of government that deals with separate pieces of an individual's service needs. This means that communication is high between public officials, but as in the example of youth services cited by focus group participants (refer s7.2.4) such endeavours remain organisation-centric as boundaries of responsibility for each agency are clearly differentiated, usually by legislation. From an infrastructure perspective such endeavours require multiple technical systems, albeit interoperable ones, to 
service each agency's information and communication requirements. Email is often used as the connecting communication technology.

However, alternative more agile means of entering into collaborative working arrangements are possible using ICT capabilities, but to be effective they require not so much a 'citizen-centric' approach as an 'outcomes-centric' approach whereby the outcome of the agency/client interaction is the point around which business processes are designed such as that posited by focus group participants in relation to young people (refer s7.2.4). For example, currently, data integration technologies (e.g. JSIS) can make information resources available to public officials in a range of agencies to assist them to deal with the public more effectively. This is an organisation-centric approach where the point of focus is on enabling public officials to do their jobs more effectively. However, interactive communications technologies (e.g. teleconferences, videos, cell-phones, secure workspaces, podcasts) can alter traditional methods of case management. Using such technologies public officials working in operational areas can engage with families and non-government stakeholders (e.g. training providers, health professionals) in different ways, and access information and support resources that traditional means might overlook (e.g. family members in other geographical locations).

Similarly, a different range of resources can be engaged to define and address policy issues. Discrete examples of this are already emerging in the state sector where wikis and blogs are being used to seek a wide range of stakeholder input (locally, nationally, and internationally) on major areas of policy and legislation reform (e.g. families policy; Police legislation review; setting priorities for road safety). ${ }^{33}$ In all cases, officials have reported that the policy and regulatory solutions that emerged were quite different to those that they originally envisaged (E-participation seminar series: 2008; personal communication with officials) and this has had positive effects on the quality of the policy and operational products developed.

\footnotetext{
${ }^{33}$ The New Zealand Families Commission (www.nzfamilies.org.nz) runs an online panel whereby the public can participate in polls and questionnaires and contribute views about issues relating to family life (www.thecouch.org.nz); the New Zealand Police used a wiki to elicit public views about proposed legislation reforms of the Police Act; and New Zealand Land Transport Authority used a blog to develop priorities for road safety policy.
} 
By considering ICTs as part of the business proposition and/or solution design, different possibilities for engagement with a broad range of stakeholders to apply collective knowledge to the development of problem resolution are possible. These differences are important as they have implications for the way that policy and service delivery as core functions of government are carried out, but also on the costs of these activities. ICTs provide the means to access a greater range of resources to apply to a particular activity, with lower transaction costs and with the likelihood of a higher quality product that has a higher level of stakeholder buy-in. The 'outcomes-centric' approach requires a re-consideration of the traditional responsibilities of officials to define policy 'problems' and design their solution. This goes beyond the scope of the empirical evidence provided by this research, but in thinking through the implications of the focus group discussion it is possible to speculate that by widening the resource base that can be applied to policy problems (e.g. by broader engagement of the public and/or field experts) and allowing solutions to be designed more organically by the stakeholders the role of public officials shifts from one of control to facilitators of coproduction. That is not to say that the responsibility public officials have to service Ministers in areas of policy and regulation setting will be removed or negated, but that the process of achieving those things can be modified through the effective use of ICTs to produce better results.

\subsubsection{Creating systemic change}

Changing the way that ICTs are used by public officials may be something that can be addressed by policy adjustments to the e-government programme in New Zealand. However, the issue of governance changes that will provide the infrastructure support for using ICTs in different ways still needs to be addressed. The empirical evidence in this research demonstrates that it is unlikely that systemic change to the NPM model of governance is likely to occur as a direct consequence of e-government implementation. Nor is it likely to arise by unintentional default. The case studies have demonstrated that the underpinning governance structures in the public arena are extremely robust, and while instrumental change may occur that is not overtly anticipated by the introduction and use of ICTs, systemic change is unlikely to be incidental. Rather, systemic change needs to be deliberatively instigated by senior public officials as a means to addressing a range of complex issues. A proactive management approach to 
designing and implementing systemic change would position the New Zealand state sector to meet the challenges of information age governance.

Four areas of initial focus were identified by the focus group participants as a starting point for action if systemic change in governance arrangements is to occur: the accountability framework; leadership; investment management; and workforce skills and knowledge (s7.2.4).

\section{Accountability}

Focus group participants identified the current accountability framework as being one area which is inconsistent with the collaborative working arrangements and joint responsibilities required for public officials to achieve politically determined outcomes (refer 7.2.4). They noted that this inconsistency creates operational difficulties in allocating resources including funding for the resolution of policy problems that affect a number of different government interests. It also severely constrains the contribution that front-line staff can make to collaborative efforts to achieve joint outcomes.

Similarly, inconsistency between formal accountability requirements and the demand for collaboratively produced outcomes restricts the policy effort, and constrains managerial support for collaboration and inter-agency co-operation where the collective outcome is not compatible, or extends beyond, the mandate of individual agencies (refer 7.2.4). There was, however, a considerable degree of uncertainty amongst participants about what changes should be made to the accountability framework or how any such changes could be effected. This uncertainty leaves a number of serious questions open for further consideration many of which are beyond the scope of this thesis, but nevertheless are worthy of noting in the context of this discussion on the future of public management in New Zealand.

The primary issue is whether the current accountability framework that embodies the principle of chief executive independence remains fit for purpose in the twenty-first century public management environment and whether it is in form, or merely in application, incompatible with the current policy emphasis on managing for outcomes. Further exploration may be required to ascertain what flexibility exists to apply the accountability framework differently without compromising its integrity or losing the 
efficiencies gained by the diffusion of managerial responsibilities, such as fiscal accountability. That is, clarification is required as to the order of change (minor/ major) necessary to the existing accountability framework in order to support the use of collective resources (human, information, technical, knowledge, and financial) to achieve agreed outcomes. Some secondary issues are also of relevance to this discussion, such as whether re-centralising some corporate functions in order to produce efficiency and productivity gains across the state sector (financial, resource and process) is possible without compromising the managerial independence of chief executives and re-introducing unnecessary bureaucratic processing. In his review of the New Zealand public management model in 2001, Schick agued that the architecture of the current model was so integrated that change would be difficult, but not impossible (Schick: 2001). It may be timely for New Zealand public officials to carefully test Schick's proposition.

ICTs can be used by public officials to address some of the issues relating to the way the accountability framework in New Zealand is applied. For example, technical capabilities exist that could be used to integrate some corporate functions across the state sector for cost-saving purposes such as HR administration (Danziger: 1998). This could be done without affecting the ability of individual agencies to negotiate and customise staffing levels, remuneration rates, and core skill requirements. It is unlikely that any legislative or regulatory changes would be necessary to enable this to happen.

Rather, chief executives could agree to such a form of rationalisation and contract an existing provider or build a customised system to replace existing infrastructure. Incremental migration at the point of technical fatigue in legacy systems could reduce the risk of losses on current infrastructure investments. Technical capabilities also exist to integrate data and manage information to enable collaborative working practices. Where this involves public officials sharing personal information across current agency boundaries (e.g. health, education, work and income, and housing) to meet the needs of high service users a more careful consideration may be required of the efficacy of existing systemic instruments (e.g. privacy legislation) to enable the necessary technical capabilities to be implemented. 
The main point here is that ICTs can be used by public officials to both explore the boundaries of the current accountability and governance arrangements, and to identify where change is required. The extent to which the current accountability framework can be used more flexibly to accommodate an outcomes-based policy orientation I would suggest needs to be tested further. The technical capabilities of ICTs can be utilised more to rationalise the choices available to chief executives in pursuit of the efficient and effective management of their agencies, without removing the right of choice from them.

\section{Leadership}

The need for new forms of leadership in public management in New Zealand came through strongly in the focus group meetings (refer s7.2.4). The focus group participants regarded the current oversight arrangements for the e-government programme as good, but saw them as insufficient to achieve the diffusion of vision and commitment required to implement systemic change to provide the environment where the advantages of ICTs can be fully exploited by the state sector (refer 7.2.4). To achieve such commitment, there was a general view by participants that people with the power to create systemic change (i.e. members of Parliament and senior public officials especially those from central agencies) need to share a vision of public management in New Zealand in the future and understand how ICTs can be used to contribute to that vision (refer 7.2.4).

This implies that systemic change will be most effective if it is done in the context of a vision of public management in New Zealand over the next 20 years that takes account of the possibilities for business process and stakeholder relationship changes that may be facilitated by the use of ICTs. Such a vision needs to be understood and endorsed by Parliament and senior state sector officials in order to be properly supported and implemented effectively. Systemic changes that support the vision need to be identified and priorities set for implementation. In addition, multi-level leadership forums need to be established to manage the implementation of systemic reform to create the appropriate legislative and regulatory frameworks required to implement the vision. 
To take account of the actual and potential impact of ICTs officials need to ensure that any public management vision developed includes a clear conception of not only how business processes can be modernised, but also of how communication technologies can be utilised to harness resources not currently available and use them to achieve greater productivity and effectiveness in government policy and service delivery. New forms of state sector leadership may be required from all of the central agencies in a combined effort with members of Parliament to harness the collective resources of the state sector and use them to greater effect to achieve better outcomes for New Zealanders. Ensuring that issues relating to ICTs are fully understood by Parliament and state sector officials may be necessary.

\section{The risk versus investment environment}

One of the tensions that focus group participants identified in the state sector is the need to invest in ICT capability that will produce strong efficiency gains if successful (e.g. Landonline) and the negative professional and reputation consequences where success does not occur (refer 7.2.4). ICTs have to be trialled to discover which capabilities produce the greatest efficiencies and effectiveness. This at times sits uncomfortably alongside the need to manage risk so that Government is not unduly politically exposed and public resources are not needlessly wasted.

The implication of this tension is that officials need to consciously make a choice about which ethos will dominate the public management environment: risk aversion or calculated investment. The data from the focus group meetings provides evidence that at the current time a risk averse culture predominates the New Zealand state sector with examples being provided of government agencies 'locking down' their operating systems and restricting staff use of the internet and auxiliary technologies such as laptops, memory sticks, wireless connectivity and so forth (refer 7.2.1). As pointed out by focus group participants one of the adverse effects of managing ICT related risks in this manner is that younger workers who are used to operating with more open ICT spheres in their personal lives may not be so attracted to working in such a closed professional environment (refer 7.2.4).

The calculated investment approach implies a more open policy relating to the use and deployment of ICTs for business purposes in government agencies. This approach 
carries a presumption of openness, as opposed to control, of information and policy processes and a relaxation of internal controls except where they are necessary for the operation of a technical application or the security of particular sets of information. In addition, there would be a need to operate such an environment in a way that guaranteed that under properly controlled conditions where the expected outcomes were not able to be achieved, that appropriate adjustments could be made without negative professional and reputation consequences for officials. It is likely that such an environment can only be created with the support of parliament, leadership from central agencies, and organisational cultural change that is endorsed by and actively managed by chief executives.

\section{Workforce capability management}

A deficit in future workforce capability and capacity was seen by focus group participants as a key driver of public management change in New Zealand (refer 7.2.3). Participants noted a disparity in skills and knowledge between current public officials and younger people coming into the workforce. This difference in skills brings with it a difference in expectations of the availability of ICT capability and the ability of workers to use ICTs to greater effect. There was a general view expressed by participants that the inter-generational knowledge gap will only be addressed as current workers retire from the state sector (refer 7.2.3).

Given the immediacy and pervasiveness of changes that are occurring in public management facilitated by the use of ICTs (refer 2.3) it would seem unlikely that New Zealand will be afforded such a slow-moving adaptation period under the pressure of international information-age government. ${ }^{34}$ The NPM-Connected model of public management as developed in Chapter 8 implies that a more aggressive approach to managing the risk of a capability deficit is needed if a workforce crisis is to be avoided in the New Zealand state sector in the future. A push for more technical skills in the current workforce may be necessary including the requirement for advanced skill

\footnotetext{
${ }^{34}$ If one assumes that most senior management positions in the New Zealand State sector are held by people over the age of 40 years, and that they can be expected to retire at 65 (although there is no legal retirement age in New Zealand, so this is only a rough estimate), there is a 25 year period before the 'digital natives' generation will be in decision-making positions to effect changes to the governance model.
} 
training for existing staff to enable the introduction of technology assisted working practices across all levels.

There appears to be a need for cultural adaptation with respect to the use and understanding of ICTs by public officials (s7.2.1) although it has been outside of the scope of this research to provide empirical evidence of this point. To improve the uptake and adaptation to new technologies there may be a case for engaging staff in development and training earlier in the technology development life-cycle so that they understand its business purpose and take responsibility for benefit realisation. This implies the need for change to take place on two fronts: the current conceptualisation of ICTs, and practices relating to the way ICTs are developed and deployed in government agencies.

In the first instance ICTs need be to recast as part of the business environment rather than as a 'technical' issue. Such a re-conceptualisation will shift the responsibility for the re-engineering of business processes from 'technology staff' to business managers thus breaking down the isolation and perceived 'expertise' of technical resources. Secondly, the current practice of designating e-government initiatives as the domain of technical experts isolated from core operational and policy business needs to be rethought. The effect of this is that business and policy officials fail to understand the contribution ICTs can make to operational practice. Such an understanding is required if ICTs are to be used by officials to access and use a broader range of resources for operational and policy matters.

\subsection{Areas for further research}

The boundaries within which this research has been conducted impose constraints on the range of data that could be collected. While this has been necessary to manage the scope of the research, it leaves a number of areas where further research may be helpful to add the weight of empirical evidence to some of the implications I have drawn above.

For example, the empirical evidence available from this research does not assist in elucidating the impact of systemic changes in the public arena on various stakeholders, 
i.e. parliament, the Public Service, the judiciary and the public. Similarly, this research does not provide for an examination of the impact of new ICT facilitated working arrangements by public officials. How either or both of these changes affect democratic relationships and issues of power over information and knowledge creation and management are new research questions that are raised by implication in this research, but are not able to be resolved within the limits of the data gathered.

Further work could also be done to explore some of the questions raised in relation to the relevancy and application of the accountability framework in New Zealand (refer s9.3.1). Empirical evidence to support, or recant, the notion that the accountability framework constrains resource allocation in interagency efforts to achieve collective outcomes would be useful in identifying if changes are required to the framework, and what outcomes such changes might achieve. Similarly, research into the costs, benefits and outcomes of rationalising some of the core administrative functions of government agencies could also provide valuable information on the efficacy of such a course of action.

Other areas where further research could be helpful include looking at effective forms of leadership in the New Zealand state sector and how information can most effectively be diffused to best effect. There are examples in both data streams of this research that indicate that in spite of considerable marketing efforts on the part of people responsible for ICT implementation uptake is not always as is expected, and the purpose of egovernment and its potential effects are poorly understood by many public officials and other stakeholders. Landonline and the PSI both experienced poor initial uptake (refer Chapters 4 and 6). The focus group data indicates that understanding of e-government appears to be uneven amongst state sector senior managers as a factor of its propensity to be regarded as something of relevance to the technical domain. How the conception of ICTs can be changed amongst business managers and the most effective forms of leadership required to support systemic transformation, need further exploration.

In a similar vein, empirical evidence would also be useful on the effects of engaging staff early in the technology development life-cycle to see if this technique does provide better outcomes in the uptake of new ICT capability and greater likelihood of successful benefit realisation. More work could also be done in the area of how a 
calculated investment environment can be established in the state sector so as to protect government and public interests and at the same time allow innovation and experimentation to occur.

Also closely related to the work produced in this thesis, is the effect of e-government initiatives on the four interfaces of government: that is, between the state sector and parliament, the judiciary and parliament; the public and the state sector, and between the public and elected members of parliament. There is a need for empirical evidence to understand how ICTs are being used to facilitate these relationships both now and in the future, and what the impact of that usage will be on issues of polity and democracy. Research that provides empirical evidence to elucidate these issues would be helpful in informing the both the public management and the political science discourses.

\subsection{Concluding comments}

This journey to understand more clearly the concept of 'transformation' has been useful as a means of understanding the importance of e-government as an emerging public management phenomenon. As argued by Castells (1996; refer 2.5) technological advances are becoming pervasive in societies throughout the world. The focus group participants commented on the speed at which change is occurring across a broad range of social and economic spectrums (s7.2.1). It would seem prudent therefore not to underestimate the significance of technology advances, and to anticipate as far as possible the scope and nature of change necessary in public governance to accommodate the information age. This research suggests that the longterm effects of e-government may be important in shaping the nature and form of public governance in New Zealand. The consequence of re-shaping governance arrangements may also have a range of other downstream impacts in New Zealand that cannot yet be envisaged.

'Transformation' is an encompassing term. By deconstructing its meaning it has been possible to more clearly identify the form and nature of the transformational effects of e-government in the New Zealand state sector context. In concluding this work I wish to highlight three key findings. 


\section{Public governance}

In the first instance, the clarification at the macro-level between the underlying principles of bureaucracy as established by Max Weber (1922) and subsequent models of public management whereby those principles are arranged in varied ways to service the needs of individual administrations is useful in clarifying the extent of transformation that can be expected. The NPM model of public governance as it is applied in New Zealand represents a radical departure from management practices prior to the 1980 s reforms, but nevertheless remains a modern form of the 'bureaucratic' ideal type.

By basing the analytical framework used in this research on Weber's ideal type, I have been able to demonstrate that change effects are likely to be seen in the New Zealand context in alterations to the NPM model of governance, but not in the underlying principles of bureaucracy. This is important in setting the parameters of expectation around the concept of 'transformation'. This clarification also enabled an examination of the NPM model of governance to ascertain where transformational effects could be identified and what their nature might be.

\section{Forms of transformation}

Claims of 'transformation' in e-government literature (see Chapter 2) tend to be made in ways which are undifferentiated, but this research demonstrates that the term can be verified to a certain extent depending on how the term is applied. The concept of transformation was deconstructed to show that it can take different forms. The case studies (Chapters $4-6$ ) clearly demonstrate that instrumental transformation that can be linked to e-government is likely to occur in the New Zealand context over the next 20 years primarily as a result of investment in technical applications to manage information resources more efficiency and effectively. The transformational effects will include changes in management practices; improvements in business processes and systems; better services to clients; and changing workforce environments (see 6.5).

Systemic transformation in the NPM model of governance may also be both necessary and desirable in the New Zealand context over the next 20 years. It is unlikely to occur as a direct consequence of the implementation of individual e-government initiatives, but will need to be deliberately created by public officials through the moderation of 
legislative and regulatory instruments. ICTs can be used to both mediate and enable change to behaviours and communication practices by public officials leading to new collaborative and co-productive forms of working arrangements, and a reshaping of relationships amongst internal stakeholders and between government officials and external stakeholders. It is most likely that in the New Zealand context senior public officials will move to actively manage a process of systemic change to respond to the pressures from a range of socio-political pressures, and to position the state sector to take advantage of opportunities made available by advanced ICTs to do things differently, and to do different things.

\section{The transformational effects of communication technologies}

Finally, I would like to highlight the differences that are indicated in this research between information technologies and communication technologies. The case studies demonstrate that instrumental transformation can and does occur when ICTs are used to reorganise, modify and manipulate information sets. However, the focus group discussion indicates that public officials need to think carefully about the impact of advanced, internet-based communication technologies (e.g. Web 2.0) and how they will affect future working relationships to create extensive collaborative and coproductive working arrangements and to expand the resource base of government (Chapter 8). These new working arrangements in turn may enable new approaches to be taken to traditional processes of policy making and decision-making that cannot yet be envisaged.

The case studies examined in this research demonstrate the breadth and complexity of e-government as well as the wide range of possible effects that will emerge as a result of deploying internet-based technologies to modern business practices. The focus groups discussion highlights the complexity of the current political and social environment in which public officials operate, and the uncertainty officials face in knowing how to most effectively respond to the challenges of the information age. This research makes a contribution to greater empirical understanding of the phenomenon of e-government, and the contribution it makes to public governance in New Zealand. Examining e-government as an intrinsic part of public management, rather than from a restrictive technical perspective, also makes an important contribution to the body of knowledge on public governance. 


\section{Appendix 1: Research contributors}

This research was completed thanks to the contribution of information, knowledge and ideas from the following public officials, academics and consultants ${ }^{35}$.

Carol Abernethy

David Bakker

Sara Barham

Sandi Beatie

Tom Berthold

Alastair Bisley

Sue Boland

Edwin Bruce

Brendan Boyle

Ros Cootes

Len Cook

Adam Cooper

Jeffrey Cornwell

Sharon Cottrell

Maria Crooks

Marguerite Delbet

Marianne Doczi

Andrew Ecclestone

Elizabeth Eppel

Martin Garcia

Derek Gill

Shenagh Gleisner

Christine Goodman

Bob Gregory

Richard Hatfield

Carol Hewitt

Lewis Holden

Maria Humphries

David Jackman

Colin Jackson

Katrina Jacobsen

Brendan Kelly

Tony Lester

Miriam Lips

Derek Lyons

Colin MacDonald

John Martin

Hugh McPhail

Lindsay Meehan

Laurence Millar
GM: Technology \& Services, Justice

Senior Analyst, Land Transport

Senior Analyst, SSC

Deputy Secretary: Justice

Principal Analyst, MSD

Associate, IPS, VUW

Strategic Development Manager, DIA

Web Standards Manager, SSC

Chief Executive, LINZ

Senior Analyst, SSC

Senior Associate, IPS, VUW

Senior Adviser, LINZ

Architecture \& Standards Manager, ACC

GM: Customer Services, LINZ

GM: Sector Strategy, Justice

Manager: Strategy \& Results, SSC

Senior Analyst, DoL

Investigating Officer, Office of the Ombudsmen

PhD Candidate, School of Government, VUW

Manager, Regulatory \& Competition Policy, MED

Researcher, IPS, VUW [MSD]

Chief Executive, Ministry of Women's Affairs

Senior Advisor, SSC

Professor, School of Government, VUW

Landonline Programme Manager, LINZ

Manager: Justice Sector Information Strategy, Justice

Deputy Secretary, Economic Strategy, MED

Associate Professor, School of Management, Waikato

Director: Information Technology, MSD

Independent Technology Consultant

Marketing Manager, LINZ

Chief Advisor, Health Information Strategy \& Policy

Chief Information Officer, LINZ

Professor, Chair in E-government, VUW

Chief Information Officer, Corrections

Deputy Commissioner, Business Development \& Systems, IRD

Maarama Consulting

Manager: Strategy \& Policy, ICT Branch, SSC

Manager: National Office Processing Centre, LINZ

Deputy Commissioner: ICT Branch, SSC

${ }^{35}$ Some contributors have changed their employment status since this research was completed. All positions listed were those held at the time the interviews and focus groups were held. 
Uma Mukherjee

Lyn Provost

Robyn Rendall

Peter Rosewarne

Bill Ryan

Jeanette Schollum,

Laura Sommer

Ian Trotman

Stuart White

Paul de Wijse

Simon Wright

John Yeabsley
Acting Strategy Manager, IRD

Deputy Commissioner: Resource Management, NZ Police Manager: HR Policy, SSC

Acting Group Manager: Information Systems, Customs Associate Professor, School of Government, VUW

National Manager: Organisational Assurance, NZ Police

Manager: Participation Project, ICT Branch, SSC

Retired/ SSC

GM: Special Jurisdictions Courts, Justice

Manager: All-of-government Operations, SSC

Senior Adviser, Bioethics Council of NZ, MfE

Senior Fellow, NZIER. 


\section{Appendix 2: Pre-readings for Focus Groups}

\section{Focus Group Background Papers: Set 1 - Context: Past and Present Models of Public Management in New Zealand}

\section{Introduction}

The papers included in this set are:

[1] Attributes of Max Weber's model of bureaucracy (1922)

[2] Bureaucratic governance: 'Command and Control' 1968 - 1988

[3] New Public Management: 'Managerialism' 1989 - 2008

Collectively, these three papers provide a brief overview of the Weberian 'ideal type' model of bureaucracy, and a review of how public management has been organised in New Zealand over the past forty years. The two papers on the NZ model have been set out in periods of twenty years for the purpose of organising the material into manageable pieces ${ }^{36}$, and in keeping with the dictum of Mao Tse Tung that ' $a$ revolution is needed in any system every 20 years'.

While New Zealand has not seen a 'revolution' in the traditional military sense, it could be argued that the public management reforms in the late 1980's represented a revolution in thinking. I would contend that the development of e-government policies and strategies by public officials in more recent years heralds another era of revolutionary thinking that may lead to radical systemic change in the future.

The models are set out in diagrammatic form, and are based on some of the basic premises of Weberian bureaucracy for comparative purposes. These include the management model; workforce characteristics; record management and structure. To these I have added the categories of 'leading discourse' and 'relationship management' to demonstrate features of each model that characterise the defining themes of public management and the predominant behaviours of officials.

These models are put forward as think pieces only and are not definitive or necessarily comprehensive. Following each table I have set out some of the characteristics of each era that relate to the way that public officials, politicians and members of the public relate to each other within this model.

\footnotetext{
${ }^{36}$ This periodisation is similar to that used in the Review of the Centre, 2001 thereby enabling a useful application of resource materials.
} 


\section{[1] Attributes of Max Weber's ${ }^{37}$ model of 'bureaucracy' (1922)}

The attributes of the original typology of public management, as set out by Max Weber in 1922, are commonly referred to as 'bureaucracy' and have been described in a variety of ways in academic literature. One of the most comprehensive expositions of the model is provided by Harro Hopfl. ${ }^{38} \mathrm{He}$ includes the following list of attributes as making up the bureaucratic model:

- Securing the orderly, routine, day-to-day execution of duties by a staff of administrators.

- Strictly hierarchical and highly articulated division of labour and strict and uniform control over personnel.

- Grouped (departments/ agencies/ ministries etc).

- Impersonal rules including those governing recruitment, promotion and dismissal.

- Professional qualification and knowledge essential.

- Officials selected, not elected.

- Promotion based on 'next in line'; not merit.

- Salaries relate to status, not performance.

- Jobs are for life.

- Monocratic control i.e. one person, not a body.

- Keeping of records critical to rationality and efficiency of bureaucracy as an instrument of power.

- Remuneration fixed - usually in the form of a salary.

- Great importance attached to official secrets.

- Defining theme $=$ rationality

In considering the modern form of public management it is a useful reflection to question whether this model still has durability. Glancing through the list above, one can quickly identify aspects of the model that no longer exist, or have been considerably modified in modern public management. For example, jobs are no longer for life; promotion is based on merit; performance is actively managed; and there is considerable flexibility in remuneration packages. Nevertheless, closer scrutiny of the operation of the modern organisational model may throw up more similarities to the above attributes, than differences.

Harro Hopfl, in his article in the Journal of Change Management (2006) questions the presentation by some public management commentators of a linear progression away from the Weberian model of bureaucracy. In particular, authors discussing the 'new public management' model adopted in many Western jurisdictions including New Zealand in the late 1980s often refer to a move from bureaucracy to 'managerialism'. This is sometimes also referred to as 'post-bureaucracy'. Hopfl argues that this periodisation is not verifiable, and if we look closely at Weber's model many of its features still exist under current systems of public management.

\footnotetext{
${ }^{37}$ Weber, Max An Outline of Interpretive Sociology: Economy and Society (2 vols) ed Guenther Roth and Claus Wittich, University of California Press, 1922.

${ }^{38}$ Hopfl, Harro M. 'Post-bureaucracy and Weber's “Modern” Bureaucracy' in Journal of Organisational Change Management, Vol 19, No. 1, 2006, pp 8 - 21.
} 
Hopfl's proposition is supported by other academics applying a more historic analysis to modern public management. For example, Jane Fountain posits in her 2001 articulation of the Virtual State ${ }^{39}$ that "... bureaucracy that formed the foundation of the modern state is now outmoded in many ways. But although modified ... each of its elements remains central" (pg 62). In this respect the 'new public management' model can be regarded as a variation of the original Weberian ideal typology of bureaucracy. While some of the more limiting features of the model have been revamped, there is no question that the public management model operating in New Zealand and other parts of the Western world remains one that is hierarchically organised, and follows a rational-legal philosophy. Any serious consideration of the Weberian ideal type can demonstrate that the large majority of its categorisations still apply in the modern order.

Set out below is a comparative table that examines each of the features Hopfl identifies in the Weberian model of bureaucracy and compares it to the current model of public management operating in New Zealand today.

\section{Comparisons between Weber's model of 'bureaucracy' and NZ ‘New Public Management'}

\begin{tabular}{|c|c|}
\hline Weber's model of 'bureaucracy' & $\begin{array}{l}\text { Modern Public Management in } \\
\text { New Zealand }\end{array}$ \\
\hline $\begin{array}{l}\text { Routine - orderly, day-to-day execution of } \\
\text { duties by a staff of administrators. }\end{array}$ & $\begin{array}{l}\text { - Jobs are specified in formal job } \\
\text { descriptions. At the operational level some } \\
\text { jobs continue to be highly regulated. }\end{array}$ \\
\hline $\begin{array}{l}\text { Hierarchy - articulated division of labour }+ \\
\text { uniform control over staff. }\end{array}$ & $\begin{array}{l}\text { - Management structures are flatter } \\
\text { than in the past, but nevertheless are } \\
\text { organised in a hierarchical order and division } \\
\text { of labour. } \\
\text { Control over staff is managed through job } \\
\text { descriptions, line management, performance } \\
\text { management systems, and employment } \\
\text { contracts. }\end{array}$ \\
\hline $\begin{array}{l}\text { Grouped organisation - specialised } \\
\text { jurisdictions. }\end{array}$ & $\begin{array}{l}- \text { - Departments, ministries, Crown owned } \\
\text { agencies based on specialization of purpose. }\end{array}$ \\
\hline $\begin{array}{l}\text { Impersonal rules, particularly those } \\
\text { governing recruitment, promotion, dismissal } \\
\text { etc. }\end{array}$ & $\begin{array}{l}\odot-\text { - HR policies and regulations control } \\
\text { appointment procedures. Legislation applies. }\end{array}$ \\
\hline Professional qualifications and knowledge. & $\begin{array}{l}\text { - - Higher academic qualified personnel are } \\
\text { commonly appointed within the public } \\
\text { service, particularly in ministries and } \\
\text { departmental policy, research, and other } \\
\text { areas of specialization } \\
\text { (e.g. legal, science, history, technical, and }\end{array}$ \\
\hline
\end{tabular}

\footnotetext{
${ }^{39}$ Fountain, J Building the Virtual State: Information Technology and Institutional Change, Brookings Institution Press, 2001.
} 


\begin{tabular}{|c|c|}
\hline & $\begin{array}{l}\text { financial expertise) and at senior } \\
\text { management level. } \\
\text { Many officials are now regarded as } \\
\text { 'generalists' and move freely between } \\
\text { government agencies during the course of } \\
\text { their careers applying their skills across } \\
\text { organisational boundaries. }\end{array}$ \\
\hline Officials are selected, not elected. & $\begin{array}{l}- \text { - Apolitical public service. State Service } \\
\text { Commissioner appoints Chief Executives, } \\
\text { and appointments below that level are made } \\
\text { by managers within the department. }\end{array}$ \\
\hline Salaries relate to status, not performance. & $\begin{array}{l}\text {-) - Salaries managed within 'bands' for } \\
\text { areas of comparable expertise. Performance } \\
\text { benefits can be added on. }\end{array}$ \\
\hline $\begin{array}{l}\text { Monocratic control - i.e. one person, not a } \\
\text { body. }\end{array}$ & $\begin{array}{l}- \text { - Each agency has its own head. The state } \\
\text { sector is headed by the State Services } \\
\text { Commissioner as the 'employer'. }\end{array}$ \\
\hline $\begin{array}{l}\text { Record keeping - creation of 'institutional } \\
\text { knowledge. }\end{array}$ & $\begin{array}{l}- \text { - The form of record keeping is likely to be } \\
\text { both electronic and paper-based but } \\
\text { continues to be a basic requirement for } \\
\text { maintaining a history of core decisions and } \\
\text { institutional actions. }\end{array}$ \\
\hline Fixed remuneration - salaried workers. & $\begin{array}{l}\text { - - Personnel are likely to be a mix of } \\
\text { salaried and contracted workers. Salaries are } \\
\text { related to 'job size' and nature. Flexibility is } \\
\text { possible. }\end{array}$ \\
\hline Official secrecy. & $\begin{array}{l}\text { - 'Budget Secret' conventions remain. } \\
\text { Information gathering and usage is regulated } \\
\text { under the Privacy Act, } 1993 \text {. } \\
\text { There is a greater degree of transparency of } \\
\text { official information under the Official } \\
\text { Information Act, 1982. Provisions exist for } \\
\text { with-holding information for a variety of } \\
\text { reasons. } \\
\text { A large amount of government-held } \\
\text { information is available to the public via the } \\
\text { Internet (government agency websites and } \\
\text { related sites). }\end{array}$ \\
\hline Legal-rational model. & $\begin{array}{l}\text { - The theoretical underpinning of the } \\
\text { current public management model in NZ is } \\
\text { known as 'institutional economics' which is } \\
\text { a legal-rational model of behaviour and } \\
\text { interactions. }\end{array}$ \\
\hline Promotion on 'next in line', not merit & $\begin{array}{l}\mathbf{X}-\text { Appointments are made on merit. } \\
\text { Appointment processes are transparent and }\end{array}$ \\
\hline
\end{tabular}




\begin{tabular}{|l|l|}
\hline & contestable. \\
\hline Jobs are for life. & $\begin{array}{l}\mathbf{X} \text { - Permanent appointments continue to be } \\
\text { made at lower levels in the organisation, but } \\
\text { there is a lot of movement within and across } \\
\text { organisations. } \\
\text { The general workforce is made up of a } \\
\text { combination of permanent employees, fixed- } \\
\text { term and short-term contractors. } \\
\text { Senior managers (CEs) are appointed for } \\
\text { fixed periods of time. }\end{array}$ \\
\hline
\end{tabular}




\section{[2] Bureaucratic governance: ‘Command \& Control’ 1968 - 1988}

The pre-1988 reform period has been characterised by Allen Schick ${ }^{40}$ as a 'command and control' model of public management. Set out in the table below are the main characteristics of the model at that time across six categories of defining features: leading discourse; management model; workforce characteristics; relationship management; record management; and structure.

\begin{tabular}{|l|l|}
\hline $\begin{array}{l}\text { - Command and control' characterised by } \\
\text { administrative regulation and bureaucratic } \\
\text { processes. }\end{array}$ & $\begin{array}{l}\text { Management Model: } \\
\text { management. }\end{array}$ \\
$\begin{array}{l}\text { Apolitical public service whereby officials established hierarchical } \\
\text { are selected by impersonal recruitment } \\
\text { procedures. }\end{array}$ & $\begin{array}{l}\text { with clearly articulated division of } \\
\text { labour. } \\
\text { This is supported by an HR 'grading } \\
\text { system' for remuneration. } \\
\text { Promotion is based on 'next in line' and } \\
\text { regulated by progression within the } \\
\text { graded system, rather than by } \\
\text { performance and open competition. } \\
\text { Monocratic control both within the } \\
\text { organisation (Departmental Head) and } \\
\text { the Public Service (State Services } \\
\text { Commissioner). }\end{array}$ \\
\hline
\end{tabular}

${ }^{40}$ Schick, Allen The Spirit of Reform: Managing the New Zealand State sector in a Time of Change, 1996.

Other academic contributors to this model, and the following one $(1989-2008)$ include: Boston, J., Martin, J., Pallot, J., and Walsh, P. Public Management: The New Zealand Model Oxford University Press, 1996; Norman, Richard Obedient Servants? Management Freedoms and Accountabilities in the New Zealand Public Sector Victoria University Press, 2003; and Scott, Graham Public Sector Management in New Zealand: Lessons and Challenges Centre for Law \& Economics, ANU, 2001 


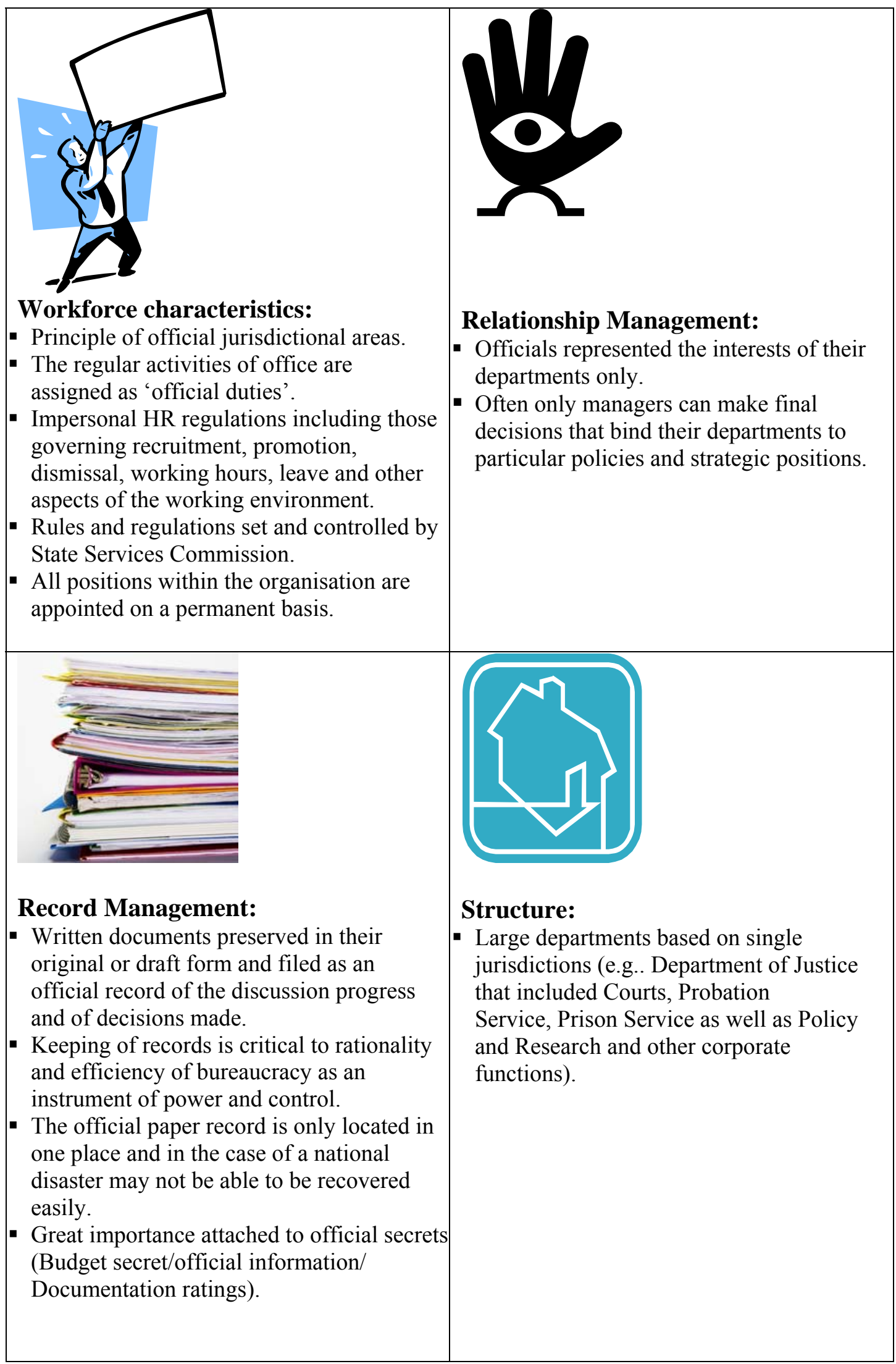




\section{Public Service Relationships}

\section{Politicians}

Relationship with officials is formal, and usually only brokered at very senior positions.

Access by public to politicians is difficult to achieve and usually brokered by staff in constituency office.

Elected representatives meet with the public in formal meetings within their own electorate on specific issues.

Advocacy by the public is made known via written mail and submissions to Select Committees by constituents.

\section{Public}

Relationship is remote.

Services are delivered to the public under strict regulation and control. Officials service their own organisation over the needs of the public (e.g. hours and locations of services are not necessarily convenient or accessible to users). 


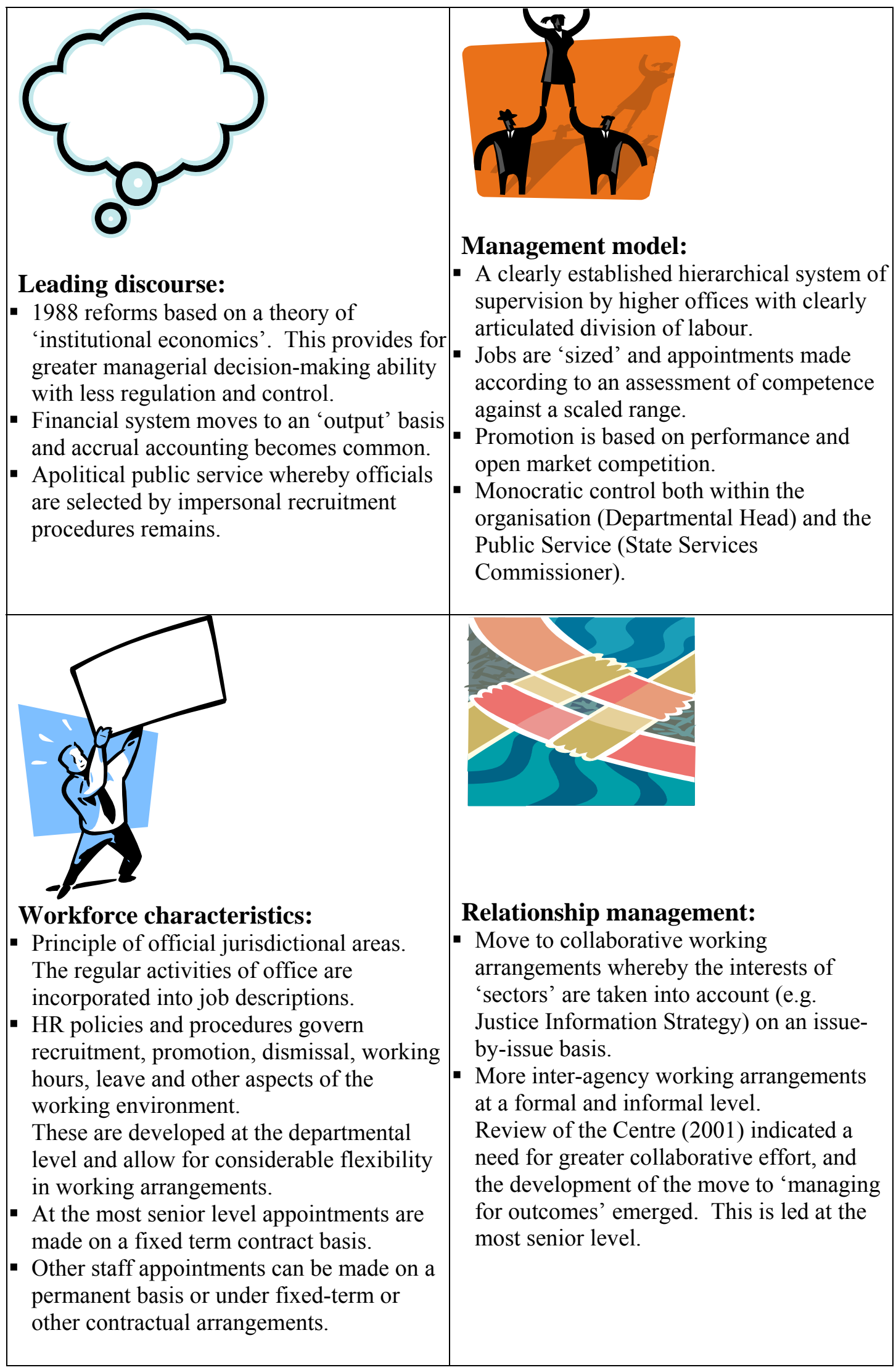




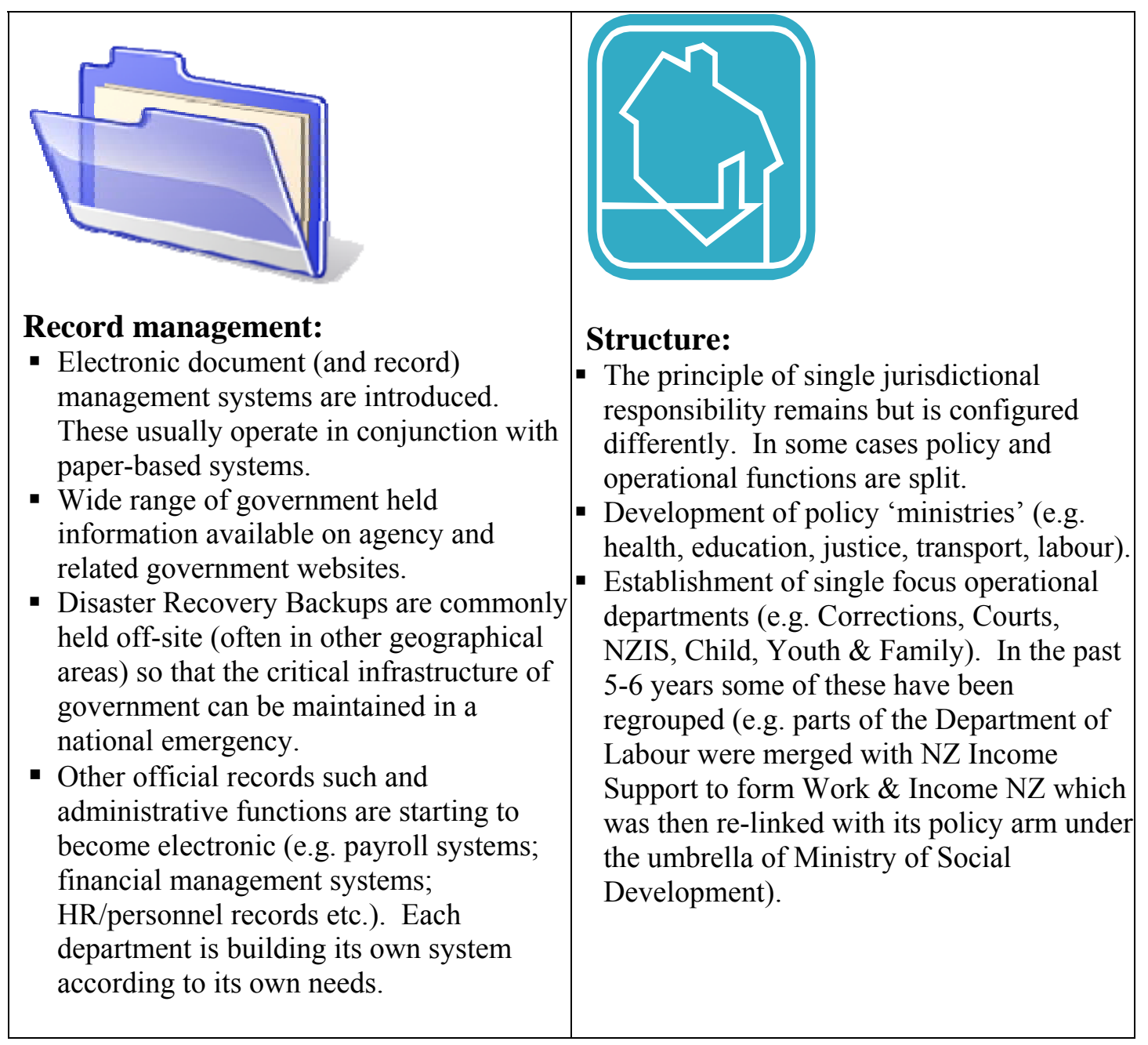

\section{Public Service Relationships}

\section{Politicians}

Relationship with officials is formal.

More junior staff are able to give Minister's advice directly when they are involved in developing policy in specialist areas (in some Ministries and departments).

Ministers are increasingly employing independent advisers to give competitive advice to that proffered by government officials.

Relationships between politicians and constituents are less formal. Members of the public can contact elected representatives directly by email.

MPs can communicate directly with their constituents and other members of the NZ public via web-pages; blogs' wikis and other online tools. Research (Hume, 2007) indicates that although this functionality is available, its use is not widely established.

\section{Public}

Relationships between the public and government officials are less remote. Information is more readily available to the public via online channels.

Members of the public can increasingly participate in some aspects of government via online channels.

Services are increasingly delivered to the public online on a $24 / 7$ basis.

Not all transactional interactions can be done electronically as authentication remains an issue. 
Through the e-participation work government agencies have a framework and protocols for online engagement with citizens on key policy areas. 


\section{Focus Group Background Papers: Set 2 - Future Scenarios of Public Management in New Zealand}

\section{Introduction}

The papers provided in this set include:

[4] Emerging Trends in Public Management

[5] The Future is Now - A Linear Progression: 2009 - 2028

[6] Other Possible Future Scenarios: 2009 - 2028

The papers explore possible future scenarios for public management in New Zealand. The first (\#4) is a paper that briefly identifies emerging trends in public management in New Zealand, and internationally. This provides a background from which to consider how these trends might start to affect the way public management is delivered. The following two papers (\#5/\#6) set out possible future scenarios for public management in New Zealand. The first, labelled The Future is Now uses the same categories as those provided for the pre-NPM and NPM models in Set 1. It represents a model where the current mode of public management (NPM) remains intact, but there are aspects of the model that are enhanced by IT innovation. In particular the enhancements involve:

1. Digitized administrative functions at the back end including, but not restricted to, financial and pay systems, HR records and procedures; and record and document management systems.

2. Online services delivered directly to the client (including transactional services using authentication).

3. Online information management.

This is a linear model of change. The second paper highlights two other possible alternative scenarios moving towards more radical models of change. Please note that all three models presented in this set of papers are based on government-controlled models of change. In presenting the material in this manner, I have made an assumption that public officials will continue to maintain control of and make key decisions about changes to the public management model. This assumption is not supported by all commentators on e-government, and is open for further discussion.

As with the other papers, these scenarios are for the purpose of stimulating debate and are not presented as definitive models. 


\section{[4] Emerging Trends in Public Management}

From the literature, conference presentations and panel discussions a clear set of trends are emerging in public management, both nationally and internationally. Some of these are trends relating to innovations emerging from the IT sector, and others are emerging from other concerns and issues in public management. The following table is not presented as definitive but an observation of some of the major trends identifiable in current public management discourse.

\begin{tabular}{|l|l|}
\hline \multicolumn{2}{|c|}{ Emerging Trends } \\
structures & $\begin{array}{l}\text { This is a move against the trend to separate } \\
\text { functions that emerged from the } \\
\text { development of NPM. There is a move } \\
\text { towards 'shared services' so that } \\
\text { government agencies can benefit from } \\
\text { economies of scale. The key driver is cost } \\
\text { efficiency. } \\
\text { Some agency groups have been reintegrated } \\
\text { (e.g. Justice/ Social Welfare) }\end{array}$ \\
\hline Citizen-centric services & $\begin{array}{l}\text { Organising services around the needs of the } \\
\text { user, as opposed to the needs of the } \\
\text { organisation. What I observe here in } \\
\text { particular is that the rhetoric of several } \\
\text { years ago of producing a 'front-facing } \\
\text { online web presence' whereby the citizen } \\
\text { could obtain services without having any } \\
\text { interest in whether the services are provided } \\
\text { by local or central government, or by any } \\
\text { particular agency behind the scenes has } \\
\text { largely not been realised. Officials are } \\
\text { coming to realise that they need to do a lot } \\
\text { more work at the back end to integrate } \\
\text { services, policies and technologies, and this } \\
\text { may require both structural and regulatory } \\
\text { change to put into effect. }\end{array}$ \\
\hline Digitisation of paper-based processes & $\begin{array}{l}\text { Largely back-end processes being brought } \\
\text { into digital form to enable faster, and more } \\
\text { efficient management (e.g. financial } \\
\text { processing system; HR; payroll etc). }\end{array}$ \\
\hline Cross-jurisdictional governance & $\begin{array}{l}\text { Governance arrangements are being } \\
\text { developed to leverage advantages for } \\
\text { 'sectors' of public management. Examples } \\
\text { include the Justice Sector Information } \\
\text { Strategy; Geospatial information for } \\
\text { emergency services; Identity Management; } \\
\text { and Coastal Management initiatives. } \\
\text { 'Networking' arrangements are emerging. }\end{array}$ \\
\hline
\end{tabular}




\begin{tabular}{|c|c|}
\hline Standardisation of infrastructure & $\begin{array}{l}\text { NZ has a range of standards governing } \\
\text { public sector infrastructure including } \\
\text { interoperability, development and } \\
\text { management of web-sites, metadata etc. } \\
\text { There remains a lot of work to be done to } \\
\text { allow government online processes to be } \\
\text { seamless. Accenture (2007) identifies } \\
\text { interoperability and common architectural } \\
\text { infrastructures as one of the big challenges } \\
\text { facing governments internationally at this } \\
\text { time. This includes sorting security and } \\
\text { privacy issues. }\end{array}$ \\
\hline Leveraging of innovation & $\begin{array}{l}\text { Organisations are attempting to use existing } \\
\text { technology 'smarter' (and for a broader } \\
\text { range of purposes) rather than investment in } \\
\text { new ground-breaking technologies. Trends } \\
\text { include: } \\
\text { - Leveraging front-end advantages to } \\
\text { other government sectors and non- } \\
\text { government organisations (e.g.. } \\
\text { computers in Police cars trial in } \\
\text { Auckland may be transferable to } \\
\text { Ambulance, Fire and other emergency } \\
\text { service operators). } \\
\text { Emergency Communications } \\
\text { Transformation Programme - cities like } \\
\text { New York have the revenue to invest in } \\
\text { this type of high value integration } \\
\text { programmes. How can NZ leverage off } \\
\text { the outcomes? } \\
\text { Organisations are choosing to 'skip' } \\
\text { innovations (e.g. virtualisation) because } \\
\text { it is not needed. }\end{array}$ \\
\hline Managing for outcomes & $\begin{array}{l}\text { There is a recognition that what Perri } 6 \\
\text { refers to as 'wicked problems' (i.e. crime, } \\
\text { unemployment, housing and education) are } \\
\text { of great concern to the public and need to be } \\
\text { addressed in innovative ways that cross the } \\
\text { boundaries of current structural } \\
\text { accountabilities. One of the major } \\
\text { innovations emerging from this driver is } \\
\text { 'joined up government' initiatives to } \\
\text { identify and achieve common outcomes in a } \\
\text { coordinated manner. }\end{array}$ \\
\hline Safety and security & $\begin{array}{l}\text { International concerns with terrorism, } \\
\text { identity fraud and other forms of safety and } \\
\text { security including border control and transit } \\
\text { issues are driving structural, regulatory and } \\
\text { systemic changes. }\end{array}$ \\
\hline
\end{tabular}




\begin{tabular}{|l|l|}
\hline Climate change & $\begin{array}{l}\text { Officials are looking to identify their } \\
\text { 'carbon footprint' of their organisations and } \\
\text { develop policy, regulatory and behavioural } \\
\text { changes. This includes identifying the } \\
\text { 'techno footprint' of the organisation. }\end{array}$ \\
\hline
\end{tabular}


[5] The Future is Now - A Linear Progression of Public Management: 2009 - 2028

\begin{tabular}{|c|c|}
\hline $\begin{array}{l}\text { Leading discourse: } \\
\text { - 'Managing for Outcomes' } \\
\text { - Network theory and the push for } \\
\text { collaboration, joined-up working } \\
\text { arrangements and joint outcomes } \\
\text { become the predominant drivers. } \\
\text { - Apolitical public service whereby } \\
\text { officials are selected by impersonal } \\
\text { recruitment procedures. }\end{array}$ & $\begin{array}{l}\text { Management model: } \\
\text { - A clearly established hierarchical } \\
\text { system of supervision by higher } \\
\text { offices with clearly articulated } \\
\text { division of labour remains as the } \\
\text { common organisational structure. } \\
\text { - Increased agency and inter-agency } \\
\text { networked working arrangements. } \\
\text { - Monocratic control within the } \\
\text { organisation } \\
\text { (Departmental Head) and the Public } \\
\text { Service (State Services } \\
\text { Commissioner). } \\
\text { - Increasing appearance of inter- } \\
\text { agency governance groups for } \\
\text { particular issues (e.g. climate change/ } \\
\text { foreshore and seabed/ geospatial// } \\
\text { Justice sector management). }\end{array}$ \\
\hline $\begin{array}{l}\text { - Principle of official jurisdictional } \\
\text { areas. } \\
\text { The regular activities of office are } \\
\text { incorporated into job descriptions. } \\
\text { - HR policies and procedures governing } \\
\text { recruitment, promotion, dismissal, } \\
\text { working hours, leave and other aspects } \\
\text { of the working environment increasing } \\
\text { networked so that best practice is } \\
\text { shared and there is increasing } \\
\text { economies of scale. }\end{array}$ & $\begin{array}{l}\text { Relationship management: } \\
\text { - Collaborative working arrangements } \\
\text { based on the interests of 'sectors' } \\
\text { increase with the aim of achieving } \\
\text { common outcomes for the public. } \\
\text { - More inter-agency working } \\
\text { arrangements at a formal and } \\
\text { informal level facilitated by Internet } \\
\text { based collaborative working tools } \\
\text { networked across the public/ state } \\
\text { service. }\end{array}$ \\
\hline
\end{tabular}


- At the most senior level appointments are made on a fixed term contract basis.

- Appointments can be made on a permanent basis or under fixed-term or other contractual arrangements. Flexibility working arrangements are the norm with increasing accommodation of 'remote' office locations and differences in working hours and personal working arrangements.

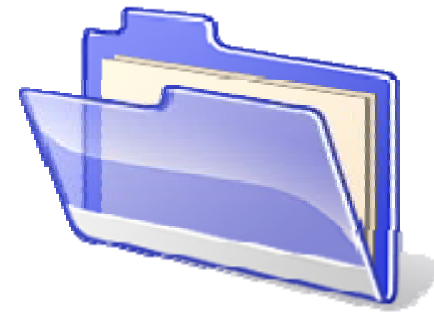

\section{Record management:}

- Official records are held in electronic document (and record) management systems.

- Government held information increasingly available on agency and related government websites. Access can be obtained through 'citizencentric' portals organised around the needs and interests of users.

- Disaster Recovery Backups are commonly held off-site (often in other geographical areas) so that the critical infrastructure of government can be maintained in a national emergency.

- Other official records such and administrative functions are increasingly digitized (e.g.. payroll systems; financial management systems; HR/personnel records etc.) and these are becoming standardised across the state sector.

- Those records pertaining to individuals are becoming networked and transportable across the state sector.

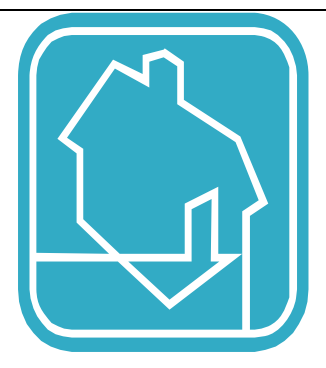

\section{Structure:}

- The principle of single jurisdictional responsibility remains but is configured in clusters of sector based organisations.

- Sector governance groups become structurally based as opposed to dealing with single issues.

Interdepartmental secretariats emerge.

- Policy and operational functions remain split in those cases where this maximises efficiencies.

\section{Public Service Relationships}

\section{Politicians}

Relationship is connected. Some directives and information-based interactions can be

\section{Public}

Relationship is networked. Constituents can contact elected 
made via Internet-based connections.

representatives directly by email and other interactive applications.

Electronic consultation on issues

becomes part of the standard for

developing policy and legislation.

MPs use sophisticated new technologies

including electronic polling and voting on

issues to inform their decision-making. 


\section{[6] Other Possible Future Scenarios: 2009 - 2028}

\section{Introduction}

The previous paper, The Future is Now sets out a picture of modernisation of the NPM system showing how technology could be adopted and used by public officials in a limited and controlled fashion to improve the efficiency (and effectiveness where possible) of existing systems and processes without any significant or radical changes to the fundamental nature of public management in New Zealand. This enables the maximization of technical functionality whilst maintaining existing power structures and the current relationships between component parts of the system - i.e. public, politicians and public officials. It would produce the least disruption to the system but succeed in taking advantage of the significant business process improvements that modern technologies have to offer. It also produces the semblance of transformational change. Under this scenario, the goal of the New Zealand government's E-government Strategy that states "... the operation of government services will be transformed, by 2011 " is likely to be successfully met.

\section{Alternative models of change}

The scenario set out in The Future is Now is one possible way that public officials might use technology to meet their objectives over the next 20 years. Set out below are two other possible options. One is built on the assumption of social determinism. This dictates that public officials will at all times remain in control of their organizational environment and any changes that are effected will occur as a consequence of deliberate decision-making on the part of public sector leaders. Technology will be adopted and used if, and only if, it can be demonstrated to advance the key policy, legal, and regulatory agendas of the day (i.e. improve the ability of public officials to carry out their executive functions to government). In this respect, changes that occur in public management over the next 20 years, while they may be significantly assisted by technological developments and indeed enabled by them, will be driven by changes in different priorities in the government and public service agendas such as managing for outcomes, joined up government, and the push to deliver citizen-centric services. It should be noted, that like the model set out in The Future is Now, this model presupposes that major systemic change will not occur, but that the form of public management may be radically altered. I have labelled this model: NPM - Connected.

The other option I am putting forward is a model based on technological determinism. I have labelled this model IT Strikes Back. It is based on the assumption that as many technologists in the literature would have it, IT systems will increasingly become so sophisticated and complex that they will limit policy maker's discretionary action. That is, that if the computer software doesn't 'allow' a particular transaction to take place, then it can't be done. This implies that there will come a time when the development of policy is controlled by what can be achieved by IT software rather than the agenda of politicians and their policy-makers. Authors such as Prof Patrick Dunleavy and his colleagues (UK) argue that the institutional knowledge and skills required to 'work around' IT limitations no longer exists in public sector organisations; that discretionary judgment is restricted by regulation; that changes to IT systems are costly, complex and time-consuming; and that IT expertise is largely outsourced to private companies forcing government organisations to pre-specify IT services and capabilities thereby reducing the degree of flexibility and adaptability they might have 
(Digital Era Governance, 2006: pp 26 - 27). Like the two models above, this one presupposes that change will be a matter of form only, even if that form is quite radically different from the current NPM model.

\section{NPM - Connected: 2009- 2028}

\begin{tabular}{|c|}
\hline $\begin{array}{l}\text { Leading Discourse } \\
\text { - 'Managing for Outcomes' } \\
\text { - Network theory and the push for collaboration, joined-up working arrangements and } \\
\text { joint outcomes become the predominant drivers. } \\
\text { - Apolitical public service whereby officials are selected by impersonal recruitment } \\
\text { procedures. }\end{array}$ \\
\hline $\begin{array}{l}\text { Management model } \\
\text { - A clearly established hierarchical system of supervision by higher offices with } \\
\text { clearly articulated division of labour remains as the common organisational } \\
\text { structure. } \\
\text { - Increased agency and inter-agency networked working arrangements, including } \\
\text { matrix models, project teams, and virtual teams. } \\
\text { - Monocratic control within the organisation (Departmental Head) and the public } \\
\text { service (State Services Commissioner). } \\
\text { - Increasing appearance of inter-agency governance groups for particular issues (e.g. } \\
\text { climate change/ foreshore and seabed/ geospatial/ Justice sector management). } \\
\text { - Sector based funding arrangements proliferate. }\end{array}$ \\
\hline $\begin{array}{l}\text { Workforce characteristics } \\
\text { - Principles of official jurisdictional area remain in areas of specialisations (e.g. } \\
\text { scientists, historians, legal advisers). Other positions are generalized across sectors. } \\
\text { - HR policies and procedures governing recruitment, promotion, dismissal, working } \\
\text { hours, leave and other aspects of the working environment increasing networked } \\
\text { across agencies so that best practice is shared and there is increasing economies of } \\
\text { scale. } \\
\text { - Job descriptions are increasingly competency based rather than including regular } \\
\text { - Activities of office. } \\
\text { - At the most senior level appointments are made on a fixed term contract basis. } \\
\text { contractual arrangements. Flexibility working arrangements are the norm with } \\
\text { increasing accommodation of 'remote' office locations and differences in working } \\
\text { - hours and personal working arrangements. } \\
\text { - Increasingly expertise is sourced from where it is available rather than restricted to } \\
\text { geographical boundaries with increasing number of flexible working arrangements. }\end{array}$ \\
\hline $\begin{array}{l}\text { Relationship management } \\
\text { - Collaborative working arrangements based on the interests of 'sectors' increase with } \\
\text { the aim of achieving common outcomes for the public. } \\
\text { - More inter-agency working arrangements at a formal and informal level facilitated } \\
\text { by Internet based collaborative working tools networked across the public/ state } \\
\text { service. }\end{array}$ \\
\hline $\begin{array}{l}\text { Record management } \\
\text { - Official records are held in electronic document (and record) management systems. } \\
\text { - Government held information increasingly available on agency and related }\end{array}$ \\
\hline
\end{tabular}


government websites. Access can be obtained through 'citizen-centric' portals organised around the needs and interests of users.

- Disaster Recovery Backups are commonly held off-site (often in other geographical areas) so that the critical infrastructure of government can be maintained in a national emergency.

- Other official records such and administrative functions are increasingly digitized (e.g. payroll systems; financial management systems; HR/personnel records etc.) and these are becoming standardised across the state sector.

- Those records pertaining to individuals are becoming networked and transportable across the state sector.

\section{Structure}

- The principle of single jurisdictional responsibility remains but is configured in clusters of sector based organisations.

- Sector governance groups become structurally based as opposed to dealing with single issues. Interdepartmental secretariats emerge.

- Policy and operational functions remain split in those cases where this maximises efficiencies.

\begin{tabular}{|l|l|}
\hline \multicolumn{2}{|c|}{ Public Service Relationships } \\
\hline Politicians & Public \\
Relationship is connected. Some directives & Relationship is networked. \\
and information-based interactions can be & Constituents can contact elected \\
made via Internet-based communication & representatives directly by email and \\
connections. & other interactive applications. \\
& Electronic consultation on issues \\
& becomes part of the standard for \\
& developing policy and legislation. \\
& MPs use sophisticated new technologies \\
including electronic polling and voting on & issues to inform their decision-making. \\
\hline
\end{tabular}




\begin{tabular}{|c|}
\hline $\begin{array}{l}\text { Leading Discourse } \\
\text { - 'Managing for Outcomes' } \\
\text { - Cost efficiency through the adoptions of modern technologies } \\
\text { - Apolitical Public Service whereby officials are selected by impersonal recruitment } \\
\text { procedures. }\end{array}$ \\
\hline $\begin{array}{l}\text { Management model } \\
\text { - A clearly established hierarchical system of supervision by higher offices with } \\
\text { clearly articulated division of labour remains as the common organisational } \\
\text { structure. } \\
\text { - Increased agency and inter-agency networked working arrangements. } \\
\text { - Monocratic control within the organization (Departmental Head) and the Public } \\
\text { Service (State Services Commissioner). } \\
\text { - Some management duties (e.g. performance management/ output monitoring) } \\
\text { become digitised through a suite of IT products designed for monitoring and } \\
\text { collating statistical information on staff activities. }\end{array}$ \\
\hline $\begin{array}{l}\text { Workforce characteristics } \\
\text { - Principles of official jurisdictional areas remain. The regular activities of office are } \\
\text { incorporated into job descriptions. They become more prescriptive and regulated } \\
\text { especially at the operational level. } \\
\text { - HR policies and procedures governing recruitment, promotion, dismissal, working } \\
\text { hours, leave and other aspects of the working environment increasing networked so } \\
\text { that best practice is shared and there is increasing economies of scale. They become } \\
\text { more generalised and less flexible. } \\
\text { - At the most senior level appointments are made on a fixed term contract basis. } \\
\text { - Appointments can be made on a permanent basis or under fixed-term or other } \\
\text { contractual arrangements. }\end{array}$ \\
\hline $\begin{array}{l}\text { Relationship management } \\
\text { - Collaborative working arrangements based on the interests of 'sectors' increase with } \\
\text { the aim of achieving common outcomes for the public. } \\
\text { - More inter-agency working arrangements at a formal and informal level facilitated } \\
\text { by Internet based collaborative working tools networked across the public/ state } \\
\text { service. } \\
\text { - Increased use of technology to facilitate communication e.g. video conferencing; } \\
\text { real-time computer assisted voice technology (e.g. SKYPE). }\end{array}$ \\
\hline $\begin{array}{l}\text { Record management } \\
\text { - Official records are held in electronic document (and record) management systems. } \\
\text { - Government held information increasingly available on agency and related } \\
\text { government websites. Access can be obtained through 'citizen-centric' portals } \\
\text { organised around the needs and interests of users. } \\
\text { - Disaster Recovery Backups are commonly held off-site (often in other geographical } \\
\text { areas) so that the critical infrastructure of government can be maintained in a national } \\
\text { emergency. } \\
\text { - Other official records such and administrative functions are increasingly digitized } \\
\text { (e.g. payroll systems; financial management systems; HR/personnel records etc.) and } \\
\text { these are becoming standardised across the state sector. } \\
\text { - Public sector databases of archival records based on projects and subjects held in }\end{array}$ \\
\hline
\end{tabular}




\begin{tabular}{|l|}
\hline centralised repositories rather than individual departmental records. \\
\hline - Ttructure \\
- Policy and operational functions remain split in those cases where this maximises \\
efficiencies. \\
\hline
\end{tabular}

\begin{tabular}{|c|c|}
\hline Public Service Relationships & \\
\hline $\begin{array}{l}\text { Politicians } \\
\text { Relationship is connected. Some directives } \\
\text { and information-based interactions can be } \\
\text { made via Internet-based communication } \\
\text { connections. }\end{array}$ & $\begin{array}{l}\text { Public } \\
\text { Relationship is networked. } \\
\text { Constituents can contact elected } \\
\text { representatives directly by email and } \\
\text { other interactive applications. } \\
\text { Electronic consultation on issues is } \\
\text { restricted to areas where change is seen } \\
\text { to be low cost. } \\
\text { E-democracy technology is not routinely } \\
\text { used in decision-making. Public } \\
\text { expectations have to be carefully managed. }\end{array}$ \\
\hline
\end{tabular}

\section{Conclusion}

The models posited above are a starting point for considering different aspects of change across a limited number of pre-selected criteria. One of the most striking features of them is that they are similar in many respects, indicating that change is likely to be subtle in nature and more discernible over time, rather than as a consequence of radical, revolutionary organisational (or political) change processes in the immediate future. As Professor Jane Fountain (USA) suggests in her exposition on the 'virtual state' there are pockets of new forms of management apparent within the existing system (2001: pg164).

I have suggested that these models in themselves do not represent any radical diversion from the original Weberian ideal typology of bureaucracy. One of the many questions that remains for me is whether or not a radical departure from the bureaucratic model is actually possible with respect to public management, or whether the nature of public administration is such that the structure and control that is afforded officials by the bureaucratic model is required to ensure durability, consistency, and credibility over time. In addition, I wonder if this actually matters, as it is the form of the bureaucratic model that significantly alters over time and it is this that moves the axis of power between the public, the elected politicians and public officials.

These considerations, amongst others, will be explored within the focus group meetings. 


\section{Appendix 3: Focus Group Session Template}

\section{Format for Focus Group Meetings: 12 - 15 November 2007}

\begin{tabular}{|c|c|c|}
\hline \multicolumn{3}{|c|}{ Focus Group Meetings } \\
\hline \multicolumn{3}{|c|}{ Session One: Context Setting } \\
\hline Time & Agenda & Content \\
\hline \multirow[t]{2}{*}{$\begin{array}{l}10 \text { mins } \\
9-9: 10 \\
2: 30-2: 40\end{array}$} & Welcome & $\begin{array}{l}\text { Thanks for their time/contribution. } \\
\text { Explain format of focus group and how time } \\
\text { will be spent. }\end{array}$ \\
\hline & Research Purpose & $\begin{array}{l}\text { Key questions and focus of research. } \\
\text { Explain methodology being applied - } \\
\text { qualitative/focus groups as one of two streams } \\
\text { of work/key is the thinking of senior decision- } \\
\text { makers/interest in how change takes place } \\
\text { over time. } \\
\text { Distribute/explain/sign/collect consent forms. }\end{array}$ \\
\hline \multicolumn{3}{|c|}{ Session Two: Introduction } \\
\hline $\begin{array}{l}20 \mathrm{mins} \\
9: 10-9: 30 \mathrm{am} \\
2: 40-3 \mathrm{pm}\end{array}$ & Ice-breaker & $\begin{array}{l}\text { Purpose: it is very important that people share } \\
\text { their ideas as freely as possible. To ensure } \\
\text { there is a level of comfort / base-line common } \\
\text { ground in the group - } \\
\text { Groups of } 3-5: 10 \text { mins to introduce } \\
\text { yourselves and discuss the following } \\
\text { questions: } \\
\text { How have emerging technologies affected } \\
\text { your personal/professional life over the past } \\
5-10 \text { years (changed your behaviour)? } \\
\text { What issues/concerns/questions do you have } \\
\text { about new technologies? } \\
\text { General report back. }\end{array}$ \\
\hline \multicolumn{3}{|c|}{$\begin{array}{l}\text { Session Three: Presentation on Research [Based on background papers } \\
\text { distributed] }\end{array}$} \\
\hline $\begin{array}{l}30 \text { mins } \\
9: 30-10: 00 \mathrm{am} \\
3-3: 30\end{array}$ & $\begin{array}{l}\text { Public Management } \\
\text { Scenarios }\end{array}$ & $\begin{array}{l}\text { 1] Weber's typology of bureaucracy } \\
\text { 2] Alternative scenarios: } \\
\text { - Linear progression - Weber - NPM - } \\
\text { NPM++ [Technology used largely for } \\
\text { service delivery and information } \\
\text { management] } \\
\text { - 'NPM - Connected' - social determinism } \\
\text { - 'IT Strikes Back' - technical determinism } \\
\text { - ' 'Kiwi PM 3.0'? 'Post-Westminster'? } \\
\text { 'Networked PM'? [Agile? - what might this } \\
\text { look like?] }\end{array}$ \\
\hline \multicolumn{3}{|c|}{ Straw Poll: Intuitively - who backs which model at this point in time? } \\
\hline \multicolumn{3}{|c|}{ Session Four: Emerging themes from literature/conferences/ research } \\
\hline $\begin{array}{l}30 \text { mins } \\
10-10: 30 a m\end{array}$ & Themes presentation & $\begin{array}{l}\text { - Reintegration } \\
\text { - Citizen-centric services } \\
\text { - Rationalisation of assets }\end{array}$ \\
\hline
\end{tabular}




\begin{tabular}{|c|c|c|}
\hline \multirow[t]{2}{*}{$3: 30-4 \mathrm{pm}$} & & $\begin{array}{l}\text { - Cross-sector governance } \\
\text { - Compatibility of infrastructure } \\
\text { - Leveraging of innovation. } \\
\text { - Managing for outcomes } \\
\text { - Joined-up government } \\
\text { - Global issues - terrorism/ climate change. }\end{array}$ \\
\hline & General discussion & $\begin{array}{l}\text { Are these the things that we collectively see } \\
\text { as the key issues over the next } 3-5 \text { years? } \\
\text { What about further out - can we anticipate } \\
\text { this? }\end{array}$ \\
\hline \multicolumn{3}{|c|}{$\begin{array}{l}\text { Break: (15 mins) Chance to mingle/eat/drink/refresh/talk about issues. } \\
10: 30-10: 45 \mathrm{am} \quad 4-4: 15 \mathrm{pm}\end{array}$} \\
\hline \multicolumn{3}{|c|}{ Session Five: Focus on Change } \\
\hline $\begin{array}{l}30 \text { mins } \\
10: 45- \\
11: 15 \mathrm{am} \\
4: 15-4: 45 \mathrm{pm}\end{array}$ & Small group exercise & $\begin{array}{l}\text { In groups of } 3-5 \text { focus on the issues raised in } \\
\text { previous session and discuss: } \\
\text { How will these issues be addressed? } \\
\text { By whom? } \\
\text { What changes are we likely to see in: } \\
\text { - Governance arrangements } \\
\text { - Organisational arrangements } \\
\text { (structure/management) } \\
\text { - Policy/law-making processes } \\
\text { - Public/political relationships? } \\
\text { How will change be facilitated by } \\
\text { technology? }\end{array}$ \\
\hline \multicolumn{3}{|c|}{ Session Six: What model of public management will emerge? } \\
\hline $\begin{array}{l}50 \operatorname{mins} \\
11: 15- \\
12: 05 \mathrm{pm} \\
4: 45-5: 35 \mathrm{pm} \\
\end{array}$ & $\begin{array}{l}\text { Feedback/general } \\
\text { discussion }\end{array}$ & $\begin{array}{l}\text { Use feedback from small groups to have a } \\
\text { general discussion. } \\
\text { Map the emerging feedback against the } \\
\text { models posited in session three. }\end{array}$ \\
\hline $\begin{array}{l}15 \mathrm{mins} \\
12: 05- \\
12: 20 \mathrm{pm} \\
5: 35-5: 50 \mathrm{pm}\end{array}$ & Conclusions & $\begin{array}{l}\text { Drawing it all together. } \\
\text { What are the key messages? } \\
\text { Do we have any kind of consensus (this is not } \\
\text { necessary) }\end{array}$ \\
\hline \multicolumn{3}{|c|}{$\begin{array}{l}\text { Straw poll: Following the discussion that has taken place, who backs which } \\
\text { model? Is there any change to the earlier poll? }\end{array}$} \\
\hline \multicolumn{3}{|c|}{ Session Seven: Closing } \\
\hline $\begin{array}{l}10 \text { mins } \\
12: 20- \\
12: 30 \mathrm{pm} \\
5: 50-6\end{array}$ & Closure of session & $\begin{array}{l}\text { Plans for presentation of findings from all } \\
\text { four workshops in one-off seminar - Feb } \\
2008 \text {. } \\
\text { Check for any other requests/ preferences. } \\
\text { Thank participants for time. }\end{array}$ \\
\hline
\end{tabular}




\section{BIBLIOGRAPHY}

Accenture (2003) Rhetoric versus Reality - Closing the Gap, (www.accenture.com) [May].

Accenture (2004) eGovernment Leadership: High Performance, Maximum Value, Government Executive Series (www.accenture.com).

Accenture (2007a) Leadership in Customer Service: Delivering on the Promise, Government Executive Series (www.accenture.com).

Accenture (2007b) Leadership in Customer Service: New Expectations, New Experiences, Government Executive Series (www.accenture.com).

Accenture (2007c) The 2007 E-readiness Rankings: Raising the Bar, A White Paper from the Economist Intelligence Unit. Written in co-operation with the IBM Institute for Business Value.

Adamali Aref, Coffey, John Oliver \& Safdar, Zaid (2006) 'Trends in National EStrategies: A Review of 40 Countries' in World Bank, Information and Communications for Developments in 2006: Global Trends and Policies, World Bank Publications, Chapter 5, pp $87-124$.

Aldrich Duncan, Bertot, John Carlos \& McClure, Charles R. (2002) 'E-government: initiatives, developments and issues' in Government Information Quarterly, Vol 19, Issue 4, pp $349-355$.

Andersen, K.V. (2006) 'e-Government: Five Key Challenges for Management' in The Electronic Journal of E-Government, Vol 4, Issue 1, pp 1-8 (www.ejeg.com).

Andersen, K.V \& Henriksen, H.Z (2005) 'The First Leg of E-Government Research: Domains and Application Areas 1998 - 2003' in International Journal of Electronic Government Research, Vol 1 (4), Oct - Dec., pp 26 - 44.

Ashworth, R., Boyne, G. \& Delbridge, R. (2007) 'Escape from the Iron Cage? Organisational Change and Isomorphic Pressure in the Public Sector' in Journal of Public Administration, Research and Theory Advance Access, (published online Dec $21^{\text {st }}$.

Australia \& New Zealand School of Government (ANZSOG) (2006) 'ANZSOG Case Program: LINZ and the Development of Landonline’ 2006-48SSC.1.

Australian Government National Office for the Information Economy (NOIE) (2003) E-government Strategies and Implementation, (www.noie.gov.au).

Australian Government National Office for the Information Economy (NOIE) (2003) E-government Benefits Study, April (www.noie.gov.au). 
Australian Government National Office for the Information Economy (NOIE), (2006) 2006 e-Government Strategy, Responsive Government: A New Service Agenda, (www.agimo.gov.au).

Bannister, Frank (2007) 'The curse of the benchmark: an assessment of the validity and value of e-government comparisons' in International Review of Administrative Sciences, Sage Publications, Vol 73 (2), pp $171-188$.

Bell, Allan; Crothers, Charles; Goodwin, Ian; Kripalani, Karishma; Sherman, Kevin \& Smith, Philippa (2008) The Internet in New Zealand 2007 Final Report, World Internet Project New Zealand, Institute of Culture, Discourse and Communication, Auckland University of Technology, New Zealand (www.wipnz.aut.ac.nz).

Bellamy, C (1998) 'ICTs and Governance: Beyond Policy Networks? The Case of the Criminal Justice System' in Snellen, I. Th. M \& van de Donk, W.B.H.J. (eds) Public Administration in an Information Age: A Handbook, IOS Press, Netherlands, pp 293 - 306.

Bellamy, C \& Taylor, J (1994) 'Introduction: Exploiting IT in Public Administration: Towards the Information Polity’ in Public Administration, 72 (Spring), pp 1- 12.

Bellamy, C \& Taylor, J. A. (1998) Governing in the Information Age, Buckingham: Open University Press.

Beniger, J.R. (1986) The control revolution: technological and economic origins of the information society, Cambridge, Mass.

Bentley, Tom \& Wilsdon, James (2003) The Adaptive State: Strategies for personalising the public realm, Demos.

Berger, P \& Luckman, T (1966) The Social Construction of Reality: A Treatise in the Sociology of Knowledge, Garden City, New York. Anchor Books.

Bhatnagar, Subhash (2004) E-government: From Vision to Implementation: a Practical Guide with Case Studies, Sage.

Blackburn, Simon (1996) Oxford Dictionary of Philosophy, Oxford University Press.

Blakemore, Michael (2006) Think Paper 4: eGovernment strategy across Europe - a bricolage responding to societal challenges, Paper prepared for the eGovernment Unit, DG Information Society and Media, European Commission, Version 3.0, Ecotec Research \& Consulting.

Borins Sandford, Kernaghan Kenneth, Brown David, Bontis Nick, Perri 6, Thompson Fred (2007) Digital State at the Leading Edge, The Institute of Public Management of Canada, University of Toronto Press.

Boston, J \& Eichbaum, C (2005) 'State sector reform and renewal in New Zealand: lessons for governance' Paper presented at Repositioning of Public Governance Global Experiences and Challenges Conference, Taipei, 18 - 19 November. 
Boston, J., Martin, J., Pallot, J and Walsh, P (1996) Public Management: The New Zealand Model, Oxford University Press.

Bouckaert, Geert (2008) 'Changing Strategies in Public Sector Reform: New Zealand in an International Context' Paper presented at the After the Reforms Conference, Wellington, New Zealand, (Feb).

Bourdieu, Pierre (1977) Outline of a Theory of Practice Cambridge: Cambridge University Press.

Bozeman, B (2002) 'Public Value Failure: When Efficient Markets May Not Work' in Public Administration Review, Vol 62, No 2, (March - April), pp145 - 161.

Bozzelli, Teresa (2007) 'Government Leadership Around the World': A paper presented at the ' 2 nd Annual Government Insights' Conference, $16-17$ August, Wellington.

Brandsen, T \& Kim, S (2008) 'The Politics of Constructing and Implementing New Public Management Reforms: A Comparison of the Netherlands and South Korea' Paper presented at the Twelfth Annual Conference of the International Research Society for Public Management (IRSPM XII) 'Contemporary Issues in Public Management' Brisbane, Australia, $26-28^{\text {th }}$ March.

Canada Country Report (2003) Building Capacity to Accelerate Service Transformation and e-Government, September.

Canadian Internet Project (2005) Canada Online! A comparative analysis of Internet users and non-users in Canada and the world: Behaviour, attitudes and trends 2004, (www.cipic.ca).

Carnoy, Martin (1989) The New Information Technology: International Diffusion and Its Impacts on Employment and Skills. A Review of the Literature, Washington D.C., World Bank.

Castells, M. (1996) The Information Age: Economy, Society and Culture: Volume 1 The Rise of the Network Society, Blackwell Publishers Inc., USA.

Centeno, C., van Bavel, R \& Burgelman, J.C. (2005) 'A Prospective View of eGovernment in the European Union' in The Electronic Journal of E-Government, Vol 3, Issue 2, pp 59 - 66 (www.ejeg.com).

Central Intelligence Agency (2008) The World Factbook, (www.cia.gov).

Centre for the Digital Future (2008) 2008 Digital Future Report: Annual Internet Survey, (www.worldinternetproject.net).

Chadwick, Andrew (2006) Internet Politics: States, Citizens, and New Communication Technologies, Oxford University Press, Inc. 
Chapman, J \& Duncan, G (2007) 'Is there now a new 'New Zealand' model?' in Public Management Review, Vol 9, No. 1, March, pp 1-25.

Child, J \& McGrath, R (2001) 'Organisations unfettered: organisational form in an information intensive economy' in The Academy of Management Journal, Vol 44, No. 6, pp $1135-1148$.

Christensen, T \& Laegreid, P (eds) (2007) Transcending New Public Management: The Transformation of Public Sector Reforms, Ashgate Publishing Ltd., England and USA.

Christensen, T., Laegried, P., Roness, P.G \& Rovik, K.A. (2007) Organisation Theory and the Public Sector: Instrument, culture and myth, Routledge Taylor \& Francis Group.

Christensen, T., Lie, A. \& Laegried, P (2007) 'Still Fragmented Government or Reassertion of the Centre?' in Christensen \& Laegreid, Transcending New Public Management: The Transformation of Public Sector Reforms, Ashgate Publishing Ltd., England and USA, pp $17-41$.

Cisco Systems Inc. (2004) The Connected Republic, (Preliminary Workshop Draft), Cisco Systems, Corporate Headquarters, San Jose, USA., April (www.cisco.com).

Clegg, S.R. \& Courpasson, D (2004) 'Political Hybrids: Tocquevillean views on project organisations' in Journal of Management Studies, Vol 41, No.4, pp 525 547.

Collins English Dictionary \& Thesaurus (1993), Harper Collins Publisher.

Commission for the Reform of the State (1998) Preparing France's entry into the information society, (www.premier-ministre.gouv.fr).

Crossing Boundaries Canada 2020 Working Group (2007) Progressive Governance for Canadians: What You Need to Know, Crossing Boundaries National Council, March.

Crown Entities Act, (2004), [(New Zealand) www.legislation.govt.nz].

Danziger, J.N. (1998) 'Managing Public Administration Personnel in the Era of Information and Computer Technologies' in Snellen, I. Th. M \& van de Donk, W.B.H.J. (eds) Public Administration in an Information Age: A Handbook, IOS Press, Netherlands, pp 461 - 472.

Department of the Premier and Cabinet, (2003) Western Australian Government EGovernment Information Gathering Summary Report, Government of Western Australia, Office of E-Government, October.

DiMaggio, P.J. (1988) 'Interest and agency in institutional theory' in Zucker, Linda G (ed) Institutional Patterns and Organisations: Culture and Environment, Cambridge MA: Ballinger, pp 3 -21. 
DiMaggio, P.J \& Powell, W.W. (1983) 'The Iron Cage Revisited: Institutional isomorphism and collective rationality in organisational fields' in American Sociological Review, 48, pp 147 - 160.

DiMaggio, P \& Powell, W (1991) The new institutionalism in organisational analysis, Chicago: University of Chicago.

Dobbin, F. R., Sutton, J.R., Meyer, J.W. \& Scott, W.R. (1993) 'Equal opportunity law and the construction of internal labour markets' in American Journal of Sociology, 99: pp $396-427$.

Doczi, M (2007) 'Tuning into Our Times' A presentation to the Futures Practitioners Forum, State Services Commission, New Zealand, 3 May.

Driving Government Performance: The Development Goals at Work Conference, 19 Sept, 2007, Wellington.

Dunleavy, P., Margetts, H., Bastow, S., and Tinkler, J. (2006) Digital Era Governance: IT Corporations, The State and E-Government, Oxford University Press.

Dutton, William H. (ed) (1996) Information and Communication Technologies: Visions and Realities, Oxford University Press.

Dutton, W.H. \& Helsper, E (2007) Oxford Internet Survey 2007 Report: The Internet in Britain, Oxford Internet Institute, (www.oii.ox.ac.uk).

Economist Intelligence Unit (2007) The 2007 e-readiness rankings: Raising the Bar, IBM Institute for Business Value.

Edelman, Lauren R. (1992) 'Legal ambiguity and symbolic structures: organisation mediation of civil rights' in American Journal of Sociology, 95: pp 1401 - 1440.

Eggers, W (2005) Government 2.0: Using Technology to Improve Education, Cut Red Tape, Reduce Gridlock, and Enhance Democracy, Rowman and Littlefield Publishers Inc.

Ellis, A (2004) 'Using the New Institutional Economics in e-Government to deliver transformational change' in The Electronic Journal of E-Government, Vol 2, Issue 2, pp $126-138$ (www.ejeg.com).

Eppel, E., Gill, D., Lips, M \& Ryan, B (2008) Better Connected Services for Kiwis: A Discussion Document for Managers and Front-Line Staff on Better Joining Up the Horizontal and the Vertical, Institute of Policy Studies, School of Government, Victoria University of Wellington.

Erin Research Inc. (2003) Citizens First 3, The Institute for Citizen Centred Service $\&$ The Institute of Public Administration of Canada, (January). 
Ewing, Scott, Thomas, Julian \& Schiessl, Julianne (2008) CCi Digital Futures Report: The Internet in Australia, ARC Centre of Excellence for Creative Industries and Innovation, Institute for Social Research, Swinburne University of Technology (www.cci.edu.au).

Finger, M \& Pecoud, G (2003) 'From e-Government to e-Governance? Towards a Model of e-Governance' in The Electronic Journal of E-Government, Vol 1, Issue 1, pp 1-10 (www.ejeg.com).

Fountain, J.E. \& Atkinson, R.D. (1998) Innovation, Social Capital, and the New Economy: New Federal Policies to Support Collaborative Research, Policy brief to Democratic Leadership Council (www.dlc.org).

Fountain, J (2001) Building the Virtual State: Information technology and institutional change, Brookings Institution Press.

Fountain, J (2002) Information, institutions and governance, Cambridge: Harvard University.

Frissen, P.H.A. (1994) 'The Virtual Reality of Informatization in Public Administration' in Informatization and the Public Sector, Vol 3.

Frissen, P.H.A. (1998) 'Public Administration in Cyberspace' in Snellen, I. Th. M \& van de Donk, W.B.H.J. (1998) Public Administration in an Information Age: A Handbook, IOS Press, Netherlands, pp 33 - 46.

Frumkin, P \& Galaskiewicz, J. (2004) 'Institutional Isomorphism and Public Sector Organisations' in Journal of Public Administration, Research and Theory' Vol 14, No. 3, pp $283-307$.

Gadamer, Hans-Georg (1960) Truth and Method, Revised edition, Translated by J. Weinsheimer \& G.G. Marshall, New York: Crossroads [1991].

Gauld, R (2006) 'E-government: What is it, and will it transform government?' in Policy Quarterly, Vol 2 (2), pp 37 - 43.

Gauld, R \& Goldfinch, S. (2006) Dangerous Enthusiasms: E-government, Computer Failure and Information System Development, Otago University Press.

Giddens, A (1984) The Constitution of Society, University of California Press.

Giddens, A (1990) The Consequences of Modernity, Cambridge: Polity Press.

Gil-Garcia, J. Ramon \& Martinez-Moyano, Ignacio J (2007) 'Understanding the Evolution of E-Government: The influence of systems of rules on public sector dynamics' in Government Information Quarterly, Vol 24, Issue 2, April, pp 266 290.

Gould, Stephen J. (1980) The Panda's Thumb: More Reflections on Natural History, New York: W.W. Norton. 
Gouscos Dimitris, Mentzas Gregory, and Georgiadis Panagiotis (2001) Planning and Implementing e-Government Service Delivery: Achievements and Learnings from On-Line Taxation in Greece Presented at the Workshop on e-Government at the $8^{\text {th }}$ Panhellenic Conference on Informatics, Nicosia, Cyprus, November 8-10.

Grant, John (2004) 'The Australian Experience: priorities and possibilities for connected government' in Kaczorowski, Willi (ed) Connected Government, Premium Publishing, pp 12-23.

Greater London Authority (2002) Implementing Electronic Government Statement 2002/3, October.

Gregory, R (2006) 'Theoretical Faith and Practical Works: De-Autonomizing and Joining-Up in the New Zealand State Sector' in Christensen, T \& Laegreid, P (eds) Autonomy and Regulation: Coping with Agencies in the Modern State, London: Edward Elgar, pp 137 - 161.

Gregory, Robert (2007) 'New Public Management and the Ghost of Max Weber: Exorcized or Still Haunting?’ in Christensen, T \& Laegreid, P (eds) Transcending New Public Management: The Transformation of Public Sector Reforms, Ashgate Publishing Ltd., England and USA, pp 221 - 243.

Grimmer, K (1998) 'Public Administration Organisations as Institutions and their Transformation due to Information Technology' in Snellen, I. Th. M \& van de Donk, W.B.H.J. (eds) Public Administration in an Information Age: A Handbook, IOS Press, Netherlands, pp 359 - 382.

Grimsley, M \& Meehan, A (2008) 'Attaining Social Values from Electronic Government' in The Electronic Journal of E-Government, Vol 6, Issue 1, pp 31-42, (www.ejeg.com).

Gronlund, Ake (2005) 'State of the Art in E-Government Research: Surveying Conference Publications' in International Journal of Electronic Government Research, Vol 1 (4), Oct - Dec., pp 1 - 25.

Halligan, John (2007) 'Reform Design and Performance in Australia and New Zealand' in Christensen, T \& Laegreid, P (eds) Transcending New Public Management: The Transformation of Public Sector Reforms, Ashgate Publishing Ltd., England and USA, pp 43 - 63.

Heckscher, C (1998) 'If post-bureaucratic organisation happened, would it be good?' Paper presented at the Academy of Management Conference, San Diego, CA, 8 - 12 August.

Heckscher, C \& Donnellon, A (eds) (1994) The Post-Bureaucratic Organisation: New Perspectives on Organisational Change, Sage, 1000 Oaks, California.

Hedlund, G (1994) 'A model of knowledge management and the N-form corporation' in Strategic Management Journal, Vol 15, pp 454 - 466. 
Heeks, Richard (2005) Implementing and Managing E-Government: An International Text, Sage Publishers.

Heintzman Ralph (2001) Towards Citizen-Centred Service: The Government of Canada's Service Improvement Strategy, Canadian Government Executive, Issue 4 pp $2-6$.

Helsper, E (2008) Researching Trends in Internet Use, Information Systems Research Forum, London School of Economics.

Hernon Peter, Cullen, Rowena \& Relyea, Harold C. (eds) (2006) Comparative Perspectives on E-government: Serving Today and Building for Tomorrow, The Scarecrow Press, Inc.

Hood, C (1989) 'Public Administration and Public Policy: Intellectual Challenges for the 1990s' in Australian Journal of Public Administration, 64: pp 16 - 24.

Hood, C (1991) 'A public management for all seasons?' in Public Administration, Vol 69, No. 1, pp $3-19$.

Hood, C (1998) The Art of the State: Culture, Rhetoric and Public Management, Clarendon Press, Oxford.

Hopfl, H. M., (2006) 'Post-Bureaucracy and Weber's "Modern” Bureaucracy' in Journal of Organisational Change Management, Vol 19, No 1, pp 8-21.

Hughes, Owen E. (2003) Public Management and Administration: An Introduction, $3^{\text {rd }}$ ed., Bassingstoke, UK: Palgrave.

Hume, David (2006) 'When 'E' is for Elected: Technology, Parliamentarians and Local Councillors'. Unpublished research carried out on behalf of the State Services Commission, New Zealand.

Institute of Public Administration of Canada (2003) Citzens First 3, (www.iccsisac.org).

Irish Internet Association, (2002) Ireland's eGovernment Approach, June (www.newperspectives.iia.ie).

i2010 - Strategy for an innovative and inclusive European Information Society, (2008) April (www.ec.europa.eu).

Jackson, Peter M (2001) 'Public Sector Added Value: Can Bureaucracy Deliver?' in Public Administration, Vol 79, Issue 1, pp 5 - 28.

Jacobsen, Katrina (2007) Achieving 100\% Uptake of E-Transaction, Presentation to MMPM/PADM: E-Government in New Zealand, School of Government, Victoria University of Wellington, October. 
Jeong, Kuk-Hwan (2006) E-Government, The Road to Innovation: Principles and Experiences in Korea, Gil-Job-E Media.

Josserand, E (2004) The Network Organisation: The Experience of Leading French Multinationals, Edward Elgar, Cheltenham.

Josserand, E., Teo, S \& Clegg, S (2006) 'From bureaucratic to post-bureaucratic: the difficulties of transition' in Journal of Change Management, Vol 19 (1), pp 54 -64.

Jutla, Dawn, Feindel, Steven and Bodorik, Peter (2004) 'KM Infrastructure and Electronic Services with Innovation Diffusion Characteristics for Community Economic Development' in Electronic Journal of Knowledge Management, Vol 1, Issue 2, Paper 8 (Prepared for the $5^{\text {th }}$ European Conference on Knowledge Management, 9 - 10 September), (www.ejkm.com).

Kaczorowski, Willi (ed) (2004) Connected Government, Premium Publishing.

Kamarck, E.C. (2002) 'Applying twenty-first century government to the challenge of homeland security' in The Forum, Vol 1, Issue 2, Article 5.

Kamarck, E.C. (2003) 'Public Servants for the Twenty-first Century' in Donahue, J.D \& Nye, J.S. (eds) For the People: Can We Fix the Public Service, Brookings Institute, Washington, D.C., pp $134-151$.

Kamarck, E.C. \& Nye, J.S. (eds) (2002) Governace.com: Democracy in the Information Age, Brooking Institution Press.

Kelly, Gavin \& Muers, Stephen (2005) Creating Public Value: An analytical framework for public service reform, Strategy Unit, Cabinet Office, UK.

Keppel, G (1992) Design and analysis: a researchers handbook, Englewood Cliffs, N.J:Prentice-Hall, $3^{\text {rd }}$ edition.

Kettl, D (2000) The Global Public Management Revolution, Brookings Institution Press, Washington, D.C.

King J.L. \& Kraemer, K.L (1998) 'Information Technology in the Establishment and Maintenance of Civil Society’ in Snellen, I. Th. M \& van de Donk, W.B.H.J. (eds) Public Administration in an Information Age: A Handbook, IOS Press, Netherlands, pp 509 - 522.

Kjaer, A.M. (2004) Governance, Cambridge: Polity.

Korteland, E \& Bekkers, V (2008) 'The Diffusion of Electronic Service Delivery Innovations in Dutch E-policing: The Case of Digital Warning Systems' in Public Management Review, Vol 10, No. 1, January pp 71- 88.

Kraemer, K \& King, J.L. (1986) 'Computing and Public Organisations' in Public Administration Review, 46 (Special). 
Kraemer, K \& King, J.L. (2006) 'Information Technology and Administrative Reform: Will E-Government be Different' in International Journal of Electronic Government Research, 2(1) January - March, pp $1-20$.

Kranzberg, M (1985) 'The information age: evolution or revolution' in Guile, Bruce (ed) Information Technologies and Social Transformation, Washington, D.C: National Academy of Engineering.

Kumar, V., Mukerji, B., Butt, I \& Persaud, A (2007) 'Factors for Successful eGovernment Adoption: a Conceptual Framework' in The Electronic Journal of EGovernment, Vol 5, Issue 1, pp 63-76 (www.ejeg.com).

Land Information New Zealand, Statement of Intent 2007/2008, July 2007.

Layne, Karen \& Lee, Jungwoo (2001) 'Developing Fully Functional E-government: A Four-Stage Model' in Government Information Quarterly, Vol 18, Issue 2, Summer, pp $122-136$.

Lee, Betty K.M. \& Zhu, Jonathan J.H. (2002) 'Internet Use and Sociability in Mainland China and Hong Kong' in IT \& Society, Vol 1, Issue 1, Summer, pp 219 237.

Lips, A.M.B. (1998) 'Reorganizing Public Service Delivery in an Information Age' in Snellen, I. Th. M \& van de Donk, W.B.H.J. (eds) Public Administration in an Information Age: A Handbook, IOS Press, Netherlands, pp 325 - 340.

Lips, Miriam (2007) 'E-government under construction: Challenging traditional conceptions of citizenship' in Nixon, P.G \& Koutrakou, V.N (eds) E-Government in Europe: Re-booting the state, Routledge.

Local Government Act, 2002 (www.legislation.govt.nz).

Lynn (Jr), Laurence, E. (2006) Public Management: Old and New, Routledge.

March, James G \& Olsen, Johan P (1989) Rediscovering Institutions: The Organisational Basis of Politics, The Free Press, Collier Macmillan Publishers.

Margetts, H (1998) 'Computerising the Tools of Government?' in Snellen, I. Th. M \& van de Donk, W.B.H.J. (eds) Public Administration in an Information Age: A Handbook, IOS Press, Netherlands, pp 441 - 460.

Marshall, Gordon (1998) A Dictionary of Sociology, Oxford University Press, $2^{\text {nd }}$ edition.

Martin, B \& Bryne, T (2003) 'Implementing e-Gov: widening the lens' in The Electronic Journal of E-Government, Vol 1, Issue 1, pp 11-22 (www.ejeg.com).

Martin, J.R. (2006) Spirit of Service: A History of the Institute of Public Administration in New Zealand, Institute of Public Administration New Zealand. 
McLaughlin, K., Osborne, S.P \& Ferlie, E (eds) (2002) New Public Management: Current Trends and Future Prospects, Routledge.

McSweeney, Brendan 'Are we living in a post-bureaucratic epoch?' in Journal of Change Management, Vol 19, No.1, pp 22-37.

Meijer, A (2007) 'Why don't they listen to us? Reasserting the role of ICT in Public Administration' in Information Polity: The International Journal of Government and Democracy in the Information Age, Vol 12, No. 4, pp 233 - 242.

Michels, A \& Meijer, A (2008) 'Safeguarding Public Accountability in Horizontal Government' in Public Management Review, Vol 10, No. 2, March, pp 165 - 174.

Miles, Ian (1996) 'The Information Society: Competing Perspectives on the Social and Economic Implications of Information and Communication Technologies' in Dutton, William H. (ed) Information and Communication Technologies: Visions and Realities, Oxford University Press, pp 37 - 52.

Millar, Laurence (2004) 'Connected Government: the New Zealand Story' in Kaczorowski, Willi, Connected Government, Premium Publishing, pp 24 - 41.

Millar, Laurence (2004) 'Networking Government: e-government in New Zealand', E-government programme website: Resources, History of the Programme, Dec (www.e.govt.nz).

Millard, Jeremy and Iversen, Jonas Svava (2004) Reorganisation of Government Back Offices for Better Electronic Public Services - European Good Practices (Back-office reorganization), Final Report to the European Commission, Danish Technological Institute, January.

Ministry of Government \& Consumer Services, Canada (2006) (www.gov.on.ca).

Ministry of Justice (2006) Justice Information Strategy 01 July 2006 - 30 June 2011, New Zealand.

Mittman, B.S. (2001) Qualitative Methods and Rigorous Management Research: (How) Are They Compatible? White paper prepared for the Department of Veteran Affairs Management Research in VA Workshop, sponsored by the HSR\&D Management Decision and Research Centre, Nov 19-20.

Moon, M. Jae (2002) 'The Evolution of E-government among Municipalities: Rhetoric or Reality?' in Public Administration Review, Vol 62, Issue 4, July/August pp $424-433$.

Moore, Mark (1995) Creating Public Value: Strategic Management in Government, Harvard University Press, USA.

Moore, M \& Hartley, J (2008) 'Innovations in Governance' in Public Management Review, Vol 10, No. 1, January, pp $3-20$. 
Morgan, David, L. (1996) 'Focus Groups' in Annual Review of Sociology, Vol 22, pp $129-152$.

Morgan, David, L. (1997) Focus Groups as Qualitative Research, Sage.

Mulgan, Richard (1994) Politics in New Zealand, Auckland University Press, $3^{\text {rd }}$ edition.

Myers, Michael D (1997) 'Qualitative Research in Information Systems' in MIS Quarterly, (21:2), June, www.misq.org/discovery/MISQ_isworld/. MISQ Discovery: updated version. (Last updated: Jan 4, 2008).

Nielsen, Klaus (2002) Institutional Theory and Social Reality, Research Papers, Network Institutional Theory, Research Paper \# 8/02, Department of Social Sciences, Roskilde University.

Nixon, P.G \& Koutrakou, V.N (eds) (2007) E-Government in Europe: Re-booting the State, Routledge.

Norman, Richard (2003) Obedient Servants? Management Freedoms and Accountabilities in the New Zealand Public Sector, Victoria University Press.

Norman, Richard (2007) De-fragmenting e-government in New Zealand, ANZSOG Case Program.

Norris, D.F \& Lloyd, B.A. (2006) 'The Scholarly Literature on E-Government: Characterising a Nascent Field' in International Journal of Electronic Government Research, Vol 2 (4), Oct - Dec., pp 40 - 56.

OECD (2000) Government of the Future, OECD Publishing.

OECD (2001) Citizens as Partners: Information, Consultation and Public Participation in Policy Making, OECD Publishing.

OECD (2002) E-Government Project: Key Issues and Findings, Public Governance and Territorial Development Directorate, Public Management Committee, October.

OECD (2003a) e-Government Studies: The E-Government Imperative, OECD Publishing.

OECD (2003b) Promise and Problems of e-Democracy: Challenges of Online Citizen Engagement, OECD Publishing.

OECD (2004a) Country Paper - New Zealand, $3^{\text {rd }}$ OECD Symposium on EGovernment 15-16 March, Cancun, Mexico.

OECD (2004b) Request for Country Information, 3rd OECD Symposium on EGovernment 15-16 March, Cancun, Mexico. 
OECD (2005) e-Government Studies: e-Government for Better Government, OECD Publishing.

OECD (2008) World e-Parliament Report 2008, OECD Publishing, March.

Office of the E-Envoy (2003) Channels Framework: Delivering government services in the new economy, Cabinet Office.

Olsen, J.P. (2006) 'Maybe it's time to rediscover bureaucracy' in Journal of Public Administration Research and Theory, Vol 16 (1), pp $1-24$.

O’Neill, R., Beatie, S \& Ombler, F. (2000) S.E.E. Workspace: Phase 1 Investigation, Oct, (www.e.govt.nz).

O’Neill, R., Beatie, S \& Ombler, F. (2000) S.E.E. Workspace: Phase 2 Identification of High Level User Needs: Focus Group Report, Dec, (www.e.govt.nz).

O’Neill, R., Beatie, S \& Ombler, F. (2001) S.E.E. Workspace: Phase 3 - An Electronic Shared Workspace Model, April, (www.e.govt.nz).

O’Neill, R. (2001) GOVIS 2001: Shared Policy Workspace, Presentation at GOVIS conference, Wellington, New Zealand, May (www.e.govt.nz).

O’Neill, R. (2007) 'Report to State Services Commission on PSI User's Survey: April/May 2007' Unpublished report commissioned by ICT Branch, SSC, New Zealand [July].

O’Neill, R (2008) “'Report to State Services Commission on PSI User's Survey: May 2008' Unpublished report commissioned by ICT Branch, SSC, New Zealand [June].

Osborne, David \& Plastrik, Peter (1997) Banishing Bureaucracy: The Five Strategies for Reinventing Government, Reading, Mass: Addison Wesley Publishing Co.

Osborne, David \& Plastrik, Peter (2000) The Reinventor's Fieldbook: Tools for Transforming Your Government, Jossey-Bass, A Wiley Co., San Francisco.

Patton, M.Q. (2002) Qualitative Research and Evaluation Methods, Sage (3 ${ }^{\text {rd }}$ edition).

Perri 6, (1997) Holistic Government, Demos.

Perri 6, (2004) E-governance: Styles of Political Judgment in the Information Age Polity, Basingstoke, Palgrave: Macmillan.

Perri 6, Leat, D., Seltzer, K \& Stoker, G (2002) Towards Holistic Governance: The New Agenda in Government Reform, Basingstoke, Palgrave: Macmillan. 
Peters, B. Guy (1992) 'Public Policy and Public Bureaucracy' in Ashford, D.G (ed) History and Context in Comparative Public Policy, Pittsburgh, PA: University of Pittsburgh, pp 283 - 316.

Peters, B. Guy (2000) Institutional Theory: Problems and Prospects, Political Science Series, Institute for Advanced Studies, University of Pittsburgh.

Phase 5 Consultation Group Inc (2005) Citizens First 4, The Institute of Citizencentered Services and the Institute of Public Administration, Canada (November).

Pierre, J \& Peters, B. Guy (2000) Governance, Politics and the State, New York: St Martin's Press.

Pollitt, C (1993) Managerialism and the Public Services, $2^{\text {nd }}$ ed., Oxford: Blackwell.

Pollitt, C (2002) 'The New Public Management in international perspective: an analysis of impacts and effects' in McLaughlin, K., Osborne, S.P \& Ferlie, E (eds) New Public Management: Current Trends and Future Prospects, Routledge, pp 274 292.

Pollitt, C. \& Bouckaert, G. (2004) Public Management Reform: A Comparative Analysis, Oxford University Press $\left[2^{\text {nd }}\right.$ ed $]$.

Public Finance Act, 1989 (www.legislation.govt.nz).

Public Finance Amendment Act, 2004 (www.legislation.govt.nz).

Raab, C (2007) 'The EGPA Study Group at 20: Reflections backwards, forwards, and sideways' in Information Polity: The International Journal of Government and Democracy in the Information Age, Vol 12, No. 4, pp 219 - 226.

Raab, C., Bellamy, C., Taylor, J., Dutton, W.H and Peltu, M (1996) 'The Information Polity: Electronic Democracy, Privacy, and Surveillance' in Dutton, W (ed) Information and Communication Technologies: Visions and Realities, Oxford University Press, pp $283-299$.

Rapoport, R.N. (1970) 'Three Dilemmas in Action Research' in Human Relations, (23:6), pp $499-513$

Reeder, Franklin S. (1998) Information Technology as an Instrument of Public Management Reform: A Study of Five OECD Countries, Public Management Service, Public Management Committee, OECD, (PUMA (98) 14 Unclassified).

Reddick, Christopher G. (2005) 'Citizen Interaction with E-government: From the Streets to Servers?' in Government Information Quarterly, Vol 22, Issue 1, pp 38-57.

Report: The Role of Information in the Emerging Global e-government, egovernance and e-democracies Environments, (www.developmentgateway.org) 2003. 
Rhodes, R.A.W. (1997) Understanding Governance: Policy Networks, Governance, Reflexivity and Accountability, Philadelphia PA: Open University Press.

Rhodes, R.A.W (2007) Understanding Governance: Ten Years On, Sage Publications, Organisation Studies 2007: 28, 1234.

Robillard, Lucienne, (2003) When e-Government Becomes Simply Government: Making the Case for Radical Incrementalism in Public Sector Governance, Crossing Boundaries Conference, Ottawa, May 8.

Roness, Paul G (2007) 'Types of State Organisations: Arguments, Doctrines and Changes Beyond New Public Management' in Christensen, T \& Laegreid, P (eds) Transcending New Public Management: The Transformation of Public Sector Reforms, Ashgate Publishing Ltd., England and USA, pp 65 - 88.

Ryan, B (2004) Learning Managing for Outcomes: Developments in managing for outcomes: A Queensland case study, A Research Report for the Institute of Public Administration Australia, Queensland Division.

Ryan, B (2006) 'Beyond Westminister: Thinking the Aotearoa/ New Zealand Way of Governing' in Policy Quarterly, Vol 2, No. 3, pp $40-47$.

Ryan, B (2008) 'Constitutional Adaptation in Practice: Emerging Realities in $21^{\text {st }}$ Century Governing in Aotearoa/ New Zealand' Paper presented to the Symposium: After the Reforms: Where are we? Where are we going? School of Government, Victoria University of Wellington and the Institute of Public Administration of New Zealand, Wellington, New Zealand, 28 - 29 Feb.

Selznick, P (1948) 'Foundations of the Theory of Organisations' in American Sociological Review, 13, pp 25 - 35.

Schick, Allen (1996) The Spirit of Reform: Managing the New Zealand State sector in a Time of Change, Report prepared for the State Services Commission and the Treasury, New Zealand.

Schick, Allen (2001) Reflection on the New Zealand Model, Paper based on a guest lecture presented at the New Zealand Treasury, August, (www.treasury.govt.nz).

Schutz, Alfred (1932) The Phenomenology of the Social World, Translated by G. Walsh \& F.Lehnert, Evanston: Northwestern University Press [1967].

Scott Campbell, D. (2000) Ontario's Approach to E-Government, Workshop 2000: Access and Privacy in the Digital World, September 21, (www.gov.on.ca).

Scott, Graham (2001) Public Sector Management in New Zealand: Lessons and Challenges, Centre for Law \& Economics, ANU.

Scott, Graham (2008) 'After the Reforms: some questions about the state of the State in New Zealand' Paper presented to the Symposium: After the Reforms: Where are we? Where are we going? School of Government, Victoria University of Wellington 
and the Institute of Public Administration of New Zealand, Wellington, New Zealand, 28 - 29 Feb.

Scott, W. R. (1987) 'The Adolescence of Institutional Theory' in Administrative Science Quarterly, 32 (4), pp 493 - 511.

Scott, W. R. (2001) Institutions and Organisations, Thousand Oaks, C.A. Sage, $2^{\text {nd }}$ ed [1995].

Scott, W.R. (2003) Organisations: Rational, Natural and Open Systems, Upper Saddle River, NJ: Prentice-Hall, $5^{\text {th }}$ ed.

Scott, W. R. (2004) 'Institutional Theory: Contributing to a Theoretical Research Programme' in Smith, K.G. \& Hitt, M.A. (eds) Great Minds in Management: The Process of Theory Development, Oxford UK: Oxford University Press.

Scott, W. R \& Meyer, J.W. (1983) 'The organisation of societal sectors' in Meyer, J \& Scott, W. R. Organisational Environments: Ritual and Rationality, Beverley Hills, CA: Sage, pp $129-153$.

Scott, W. R \& Meyer, J.W. (1994) Institutional Environments and Organisations: Structural Complexity and Individualism, Thousand Oaks, CA: Sage.

Seely Brown, J \& Duguid, P (2000) The Social Life of Information, Harvard Business School Press.

Shaw, R \& Eichbaum, C. (2005) Public Policy in New Zealand: Institutions, processes and outcomes, Pearson Education New Zealand.

Silverstone, R. (1996) 'Future Imperfect: Information and Communication Technologies in Everyday Life' in Dutton, William H. (ed) Information and Communication Technologies: Visions and Realities, Oxford University Press, pp $217-231$.

Sim, S \& Van Loon, B (2004) Introducing Critical Theory, Icon Books Ltd.

Simmel, Georg (1907) On Individuality and Social Forms: Selected Writings, Translated by Donald N Levine, University of Chicago Press, 1971.

Smahel, D \& Machovcova, K (2006) 'Internet Use in the Czech Republic: Gender and Age Differences' in Sudweeks, F., Hanchover, H \& Ess (eds) Cultural Attitudes Towards Technology and Communication, Murdoch University.

Snellen, I (2007) 'Is "Informatisation" after 20 years still a "corpus alienum" in Public Administration?' in Information Polity: The International Journal of Government and Democracy in the Information Age, Vol 12, No. 4, pp $201-206$.

Snellen, I. Th. M \& van de Donk, W.B.H.J. (eds) (1998) Public Administration in an Information Age: A Handbook, IOS Press, Netherlands. 
State Sector Act, 1988 [(New Zealand) www.legislation.govt.nz].

State Services Commission (1998) Assessment of the State of the New Zealand Public Service, Occasional Paper, No. 1.

State Services Commission (2002) 'Review of the Centre'(www.ssc.govt.nz).

State Services Commission (2003) 'Strategy Update - June 2003’ (www.e.govt.nz).

State Services Commission (2005a) 'Managing for Outcomes' (www.ssc.govt.nz).

State Services Commission, (2005b) 'The Digital Strategy: Creating Our Digital Future' [May], (www.digitalstrategy.govt.nz).

State Services Commission (2006a) PSI Online User's Survey, Summer Survey Series, Nov [Internal document provided on request to the researcher].

State Services Commission (2006b) 'E-government Strategy’ [Dec], (www.e.govt.nz).

State Services Commission (2006c) 'State Sector Development Goals' (www.ssc.govt.nz).

State Services Commission (2007) 'Standards of Integrity and Conduct' (www.ssc.govt.nz).

State Services Commission (2008) Public Satisfaction with Service Quality 2007: The Kiwis Count Survey, April.

Steane, P (2008) 'Public Management Reforms in Australia and New Zealand' in Public Management Review, Vol 10, Issue 4, pp 453 - 465.

Stewart, J (2008) Public Service Independence and Responsiveness: Striking a Balance, Occasional Paper 2/2008, Policy Paper \# 8, The Academy of the Social Sciences in Australia, Canberra.

Tapscott, D (2007) Gov 2.0: Wikinomics, Government and Democracy, New Paradigm Learning Corporation (Nov).

Taylor, J (1992) 'Information Networking in Government' in International Review of Administrative Sciences’ (69), pp 375 - 389.

Taylor, J (1998) 'Informatization as X-Ray: What is Public Administration for the Information Age?' in Snellen, I. Th. M \& van de Donk, W.B.H.J. (eds) Public Administration in an Information Age: A Handbook, IOS Press, Netherlands, pp 21 32.

Taylor, J (2007) 'Rediscovering the grand narratives of the information polity: Reflections on the achievement and potential of the EGPA Study Group on ICT in 
Public Administration' in Information Polity: The International Journal of

Government and Democracy in the Information Age, Vol 12, No. 4, pp 213 - 218.

Taylor, J., Bellamy, C., Raab, C., Dutton, W \& Peltu, M. (1996) 'Innovation in Public Service Delivery' in Dutton, William H. (ed), Information and Communication Technologies: Visions and Realities, Oxford University Press, pp $165-282$.

Taylor, J.A. \& Lips, A.M.B. (2004) Theory and Practice in Public Administration and e-Government: Searching for Analytical Depth in an Information Polity, Paper prepared for the Study Group on ICTs in Public Administration, European Group of Public Administration Conference, Ljubljana (Sept).

Thompson, Fred (2008) 'The Three Faces of Public Management' in International Public Management Review, Vol 9, Issue 1, pp 1 - 17, (www.ipmr.net).

Thompson, F \& Jones, L.R. (2008) 'Reaping the Advantages of Information and Modern Technology: Moving from Bureaucracy to Hyperarchy and Netcentricity' in International Public Management Review, Vol 9, Issue 2, pp 142 - 186.

United Nations (2008) The UN e-government survey 2008: From e-Government to Connected Governance (http://upan1.un.org).

United States General Accounting Office (1990) Prospective Evaluation Methods: The Prospective Evaluation Synthesis, November.

Van de Donk, W.B.H.J. (1998) 'Beyond Incrementalism?' in Snellen, I. Th. M \& van de Donk, W.B.H.J. (eds) Public Administration in an Information Age: A Handbook, IOS Press, Netherlands, pp 381 - 404.

Van de Donk, Wim B.H.J \& Snellen Ignace, Th.M. (1998) 'Towards a Theory of Public Administration in an Information Age' in Snellen, I. Th. M \& van de Donk, W.B.H.J. (eds) Public Administration in an Information Age: A Handbook, IOS Press, Netherlands pp 3 - 19.

Wagenaar, H (2000) Government Institutions: Effects, Changes and Normative Foundations, Springer.

Walters, Neil (2008) 'Background on the New Zealand Public Sector' in Report on the Efficiency and Effectiveness of the Office of the Controller and Auditor-General of New Zealand by an International Peer Review Team, March, (Attachment 5).

Ward, Stephen, Lusoli, Wainer \& Gibson, Rachel (2007) 'Australian MPs and the Internet: Avoiding the Digital Age?' in The Australian Journal of Public Administration, Vol 66, pp $210-222$.

Wassink, G \& Kordelaar, P (1998) 'Let's Digitize, Let's Make Things Better?' in Snellen, I. Th. M \& Van de Donk, W.B.H.J. (eds) Public Administration in an Information Age: A Handbook, IOS Press, Netherlands, pp 425 - 440. 
Weber, Max (1922) Economy and Society: An Outline of Interpretive Sociology, English translation, 1968, Bedminster Press Inc., N.Y.

Weick, Karl (1995) Sensemaking in Organisations, Thousand Oaks CA: Sage.

West, Darrell M. (2000) Assessing E-Government: The Internet, Democracy and Service Delivery by State and Federal Governments, September, Taubman Centre for Public Policy, Brown University, Providence.

West, Darrell M. (2007a) Global E-Government Full Report 2007, Taubman Centre for Public Policy, Brown University, Providence, (www.InsidePolitics.org).

West, Darrell M., (2007b) State and Federal E-Government in the US, 2007, Taubman Centre for Public Policy, Brown University, Providence.

Whitcombe, J (2008) Policy, Service Delivery and Institutional Design: The Case of New Zealand's Social Sector Government Agencies, 1984 - 2007, A thesis submitted to the Victoria University of Wellington in fulfilment of the requirements of the Degree of Doctor of Philosophy in Public Policy.

Williams, R \& Edge, D. (1996) 'The Social Shaping of Technology' in Dutton, William H. (ed) Information and Communication Technologies: Visions and Realities, Oxford University Press, pp 53 - 67.

Windley, Phillip J. (2002) eGovernment Maturity, Office of the Governor, State of Utah.

World Bank (2006) Information and Communications for Development 2006: Global Trends and Policies, World Bank Publications.

World Internet Institute (2008) The Internet in Sweden: 2007, (www.worldinternetproject.net).

Yin, Robert K (2003) Case Study Research: Design and Methods, $3^{\text {rd }}$ edition, Applied Social Science Methods Series, Vol 5, Sage Publications Inc.

Zhu, Jonathan J.H. \& He, Zhou (2002) 'Diffusion, Use and Impact of the Internet in Hong Kong: A Chain Process Model' in Journal of Computer Mediated Communication, Vol 7(2), January.

Zucker, L.G (1987) 'Institutional Theories of Organisation' Annual Reviews of Sociology, Vol 13, pp $443-463$.

Zuurmond, A (1994) 'From Bureaucracy to Infocracy: A Tale of Two Cities' in Informationization and the Public Sector, Vol 3, pp 189 - 204.

Zuurmond, A (1998) 'From Bureaucracy to Infocracy: Are Democratic Institutions Lagging Behind?' in Snellen, I. Th. M \& van de Donk, W.B.H.J. (eds) Public Administration in an Information Age: A Handbook, IOS Press, Netherlands pp 259 $-272$. 
Zuurmond, A. \& Snellen, I.Th.M. (1997) 'From Bureaucracy to Infocracy: Towards Management Through Information Architectures' in Taylor et al (eds) Beyond BPR in Public Administration: Transformation in an Information Age, Amsterdam: IOS Press, pp $205-224$.

Selected National E-Government Websites

www.cabinetoffice.gov.uk

www.canada.gc.ca

www.e.govt.nz

www.ec.europa.eu

www.finance.gov.au

www.irlgov.ie

www.gov.mt

www.premier-ministre.gouv.fr

www.whitehouse.gov

Other website resources

www.accenture.com

www.cisco.com

www.gartner.com

www.gen-i.co.nz

Www.ibm.com

www.it.gen.nz

www.justice.govt.nz/jsis/index.html

www.kiwiblog.co.nz

www.kiwiblog.co.nz/must read blogs

www.linz.govt.nz

www.legislation.govt.nz

www.psi.govt.nz

www.nzfamilies.org.nz

www.thecouch.org.nz

www.stuff.co.nz/blogs/politics

www.ssc.govt.nz

www.worldinternetproject.net 